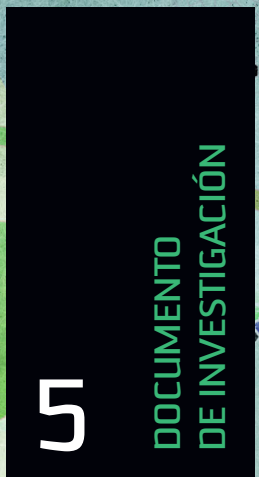

\title{
Ensayos de investigación sobre contabilidad: análisis y propuestas
}

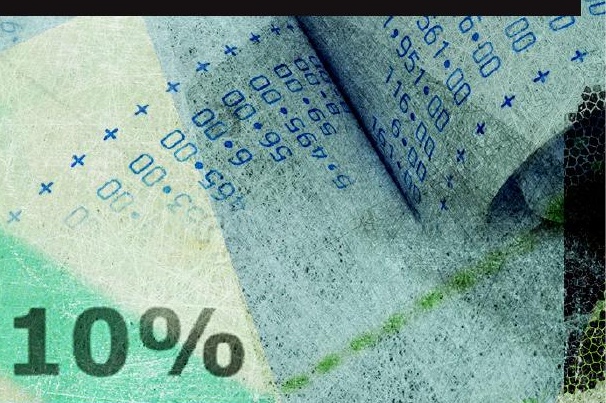

\section{$15 \%$}

Kerlyn Ávalos

Camila Bellido

David Carranza Carmen Carrillo Cecilia Figueroa Alejandro Gonzales Marlene Ke Jun Carolina Li Claudia Luyo Juan José Melgar Mary Takehara Alonso Ulloa Arturo Yamagoshi Jaime Yépez

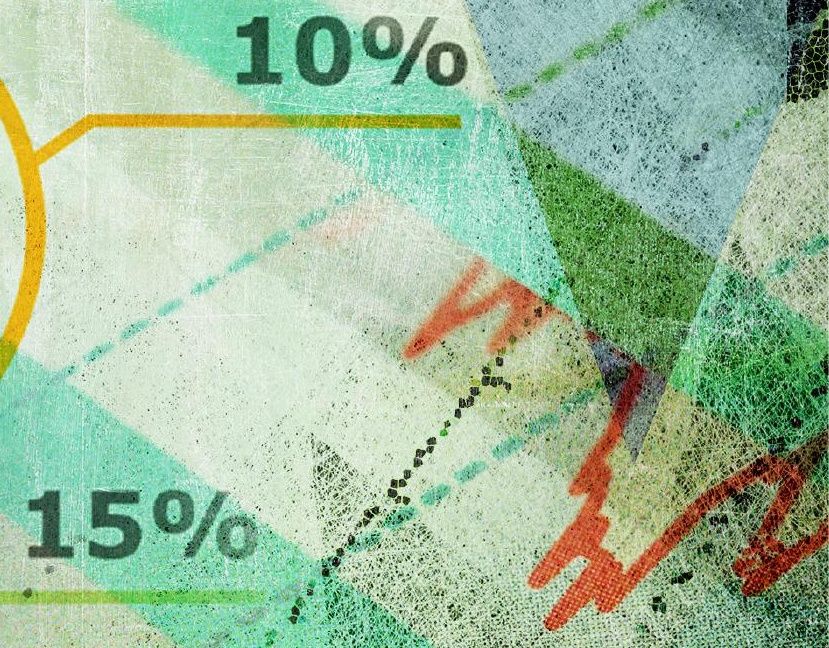

Pedro P. Franco - Santiago M. Collas (editores) ies9. 



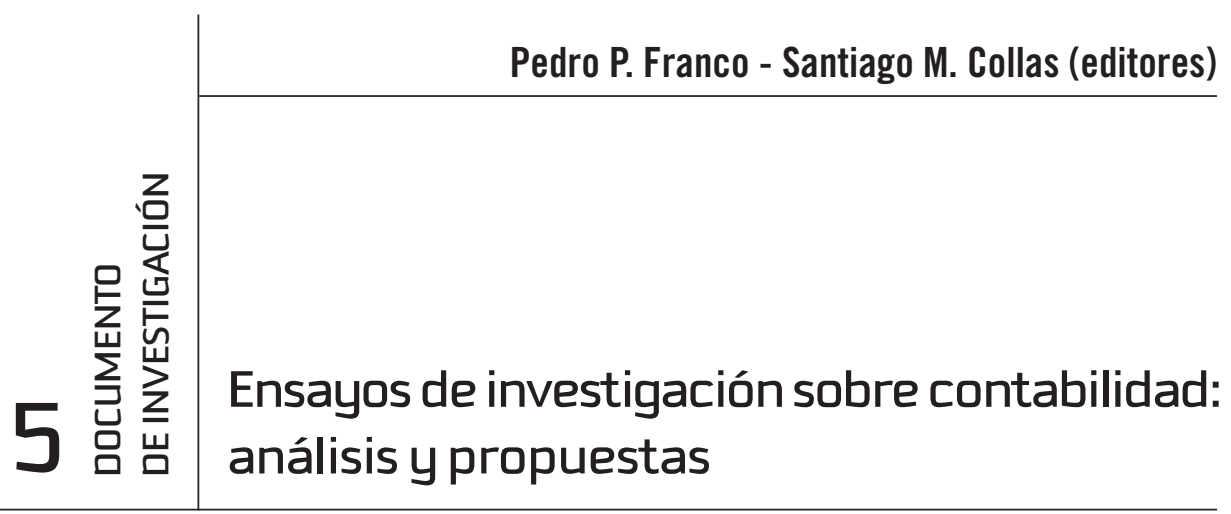

Kerlyn Ávalos

Camila Bellido

David Carranza

Carmen Carrillo

Cecilia Figueroa

Alejandro Gonzales

Marlene Ke Jun

Carolina Li

Claudia Luyo

Juan José Melgar

Mary Takehara

Alonso Ulloa

Arturo Yamagoshi

Jaime Yépez 
(C) Universidad del Pacífico

Avenida Salaverry 2020

Lima 11, Perú

www.up.edu.pe

Ensayos de investigación sobre contabilidad:

análisis y propuestas

Pedro P. Franco - Santiago M. Collas (editores)

$1^{\text {a }}$ edición versión e-book: enero 2016

Diseño gráfico: Ícono Comunicadores

ISBN: 978-9972-57-350-7

doi: http://dx.doi.org/10.21678/978-9972-57-350-7

\section{BUP}

Ensayos de investigación sobre contabilidad : análisis y propuestas / Pedro P. Franco, Santiago M. Collas (editores). -- 1a edición, versión e-book. -- Lima : Universidad del Pacífico, 2016.

241 p. -- (Documento de investigación ; 5)

1. Contabilidad -- Investigación -- Ensayos, conferencias, etc.

2. Estados financieros -- Ensayos, conferencias, etc.

3. Contabilidad -- Normas -- Ensayos conferencias, etc.

I. Franco Concha, Pedro, editor.

II. Collas, Santiago M., editor.

III. Universidad del Pacífico (Lima)

657.072 (SCDD)

Miembro de la Asociación Peruana de Editoriales Universitarias y de Escuelas Superiores (Apesu) y miembro de la Asociación de Editoriales Universitarias de América Latina y el Caribe (Eulac).

La Universidad del Pacífico no se solidariza necesariamente con el contenido de los trabajos que publica. Prohibida la reproducción total o parcial de este texto por cualquier medio sin permiso de la Universidad del Pacífico.

Derechos reservados conforme a Ley. 


\section{Comité Evaluador}

\section{CHRISTIAN DE LA TORRE - Socio}

\section{Assurance}

- Contador Público Colegiado Certificado de la Universidad de Lima

- Actualmente cursa el MBA en la Universidad del Pacífico

- Ha sido docente de la Pontificia Universidad Católica del Perú y de la Universidad Peruana de Ciencias Aplicadas (UPC)

- Expositor del Programa de Capacitación Empresarial de la Firma

\section{JOSÉ TAFUR - Socio}

\section{Assurance}

- Contador Público Colegiado de la Pontificia Universidad Católica del Perú

- Certificación y Diplomado en Normas Internacionales de Información Financiera (NIIF) otorgado por Association of Chartered Certified Accountants (ACCA)

- $\quad$ MBA de la Universidad del Pacífico y ESADE Business School

- Diplomado Internacional de Valorización de Empresas de ESAN

- Expositor del Programa de Capacitación Empresarial de PwC

- Docente de la Universidad del Pacífico

\section{MÓNICA BYRNE - Gerente Senior}

Tax \& Legal Services

- Abogada Colegiada, egresada de la Pontificia Universidad Católica del Perú

- Master (Msc) en Política Tributaria de la Universidad de Bath (Gran Bretaña)

- Visiting Scholar del Programa Internacional de Tributación (ITP) de la Universidad de Harvard 



\section{Índice}

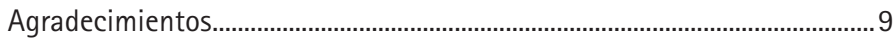

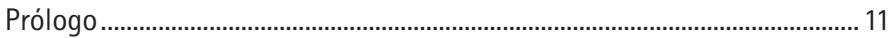

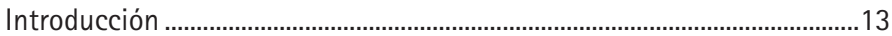

1. El impacto en los estados financieros de la determinación y la variación del nivel de las reservas petroleras en las empresas de hidrocarburos en el Perú

Carolina Li, Claudia Luyo y Juan José Melgar.

2. La aplicación de las normas contables y tributarias en los sectores construcción e inmobiliario para la correcta determinación del impuesto general a las ventas y del impuesto a la renta Carmen Carrillo, Cecilia Figueroa y Mary Takehara

3. Principales diferencias en el tratamiento contable en el sector minero Camila Bellido, Alonso Ulloa y Arturo Yamagoshi.

4. Investigación sobre los métodos de costeo de huevos comerciales y la valorización del activo biológico Kerlyn Ávalos y Jaime Yépez.

5. Método de costeo de ganado vacuno para las empresas ganaderas peruanas David Carranza, Alejandro Gonzales y Marlene Ke Jun 161 
Anexos.

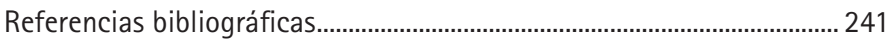




\section{Agradecimiento}

A todos los alumnos de la carrera de Contabilidad, por creer en el sueño de poder hacer investigación en contabilidad; $y$ al equipo de trabajo, por hacer posible que cumpliéramos con todas las entregas del material. 



\section{Prólogo}

Todo esfuerzo editorial es loable, y más aún si comprende un selecto grupo de trabajos de investigación sobre temas vinculados a la contabilidad, las finanzas y la tributación. Ello es aún más importante cuando los responsables de la investigación son un grupo de estudiantes de los últimos años del Programa de Contabilidad de esta casa de estudios.

El aspecto más destacable es la contribución que esta labor conlleva para la formación investigadora de los alumnos y que, sin duda, constituirá un sello para diferenciarlos en el mercado laboral en el cual se deberán iniciar.

La Universidad del Pacífico se pone así a la vanguardia de la formación académica, usando un modelo que interactúa con la realidad empresarial y permite a los alumnos conocer temas específicos y especializados. Una característica importante de estos trabajos de investigación es que han sido seleccionados de un grupo mayor. El presente libro comprende cinco trabajos sobre diferentes materias, que representan el esfuerzo de más de 15 alumnos de la carrera de Contabilidad y la participación, como revisores finales, de un selecto y experimentado conjunto de profesionales de PwC, para asegurar la calidad de estas investigaciones. A ellos, mi agradecimiento por el esfuerzo desplegado y la labor de refrendar con su significativa experiencia la validez y el contenido de los trabajos de investigación.

No puedo dejar de referirme al vínculo que mantengo con esta casa de estudios. Todos quienes me conocen saben que he dedicado, y dedico, una parte importante de mi tiempo a la labor educativa. Somos el resultado de una conjunción de circunstancias que nos han puesto como líderes en el mundo 
de los negocios, y qué mejor que poder contribuir de esta humilde manera con mi querida y recordada universidad.

Finalmente, debo mencionar que esta publicación y colaboración con la Universidad del Pacífico se lleva a cabo como parte de la celebración de los 90 años de permanencia en el país de PwC, a la cual me enorgullece representar.

Es importante mencionar que nuestra constante preocupación por acompañar al país en la creación de valor de sus organizaciones empresariales pasa, sin duda, por la necesidad de contar con graduados universitarios de diferentes especialidades y que se incorporen a nuestra firma con la confianza de desarrollar sus mejores aptitudes en una institución que conoce su pasado, vive intensamente la celebración del presente y se proyecta al futuro con optimismo y seguridad.

Esteban Chong

Socio principal

$\mathrm{PwC}$ 


\section{Introducción}

Con frecuencia, se puede advertir que la contabilidad es definida desde un punto de vista operativo, destacando su uso fundamentalmente instrumental y rezagando, e incluso ensombreciendo, otras características que se ubican en el plano de la ciencia. Como consecuencia de ello, tanto la contabilidad como disciplinas asociadas a ella, como las finanzas y la tributación, sufren un menoscabo en su percepción o en la visión con que son abordadas para su desarrollo en términos de asignaturas como parte de una carrera profesional, o cuando se elaboran textos que se orientan básicamente a la enseñanza de la técnica.

Sea que se conciba la contabilidad como un sistema, o como un medio o un proceso, se subraya principalmente su valor como herramienta cuando se asegura que con ella se obtiene información estructurada para que los usuarios de la misma decidan aquello que afectará su situación. Así, se puede citar lo mencionado por Horngren et al. (2010), quienes la enfocan como un sistema de información cuya utilidad radica en la medición de las actividades de una empresa, de modo tal que los datos que se recogen de la realidad se traducen en informes que contienen resultados que son usados por quienes toman decisiones. De modo similar, Stickney et al. (2012) identifican la contabilidad como un proceso que se orienta a la recolección, la anotación y la presentación de información resumida de índole económico-financiera a quienes toman las decisiones. Warren et al. (2010) no se apartan de esta focalización al destacarla como una herramienta con la que los administradores obtienen información en forma de reportes que aplican como usuarios para la gestión de sus operaciones.

Sin negar de ninguna manera la utilidad instrumental de estas disciplinas como herramientas de gestión, tenemos la sólida intención de fortalecer sus atributos 
como ciencias en la medida en que, con adecuación a su práctica concreta, se visualicen las enormes posibilidades que estas ofrecen en la búsqueda y generación de nuevos conocimientos o nuevas perspectivas o ideas respecto de los conocimientos puestos a disposición de la comunidad anteriormente.

Ya en Contabilidad, finanzas y tributación: reflexiones académicas, publicado en 2005, destacamos la indispensabilidad del proceso de investigación como motor para la generación de conocimiento, que incluye tanto al existente con distintas perspectivas o un mayor alcance, como al nuevo por desarrollar desde la base más incipiente. Por ello, el enfoque científico resulta fundamental para que la investigación evidencie sus resultados a toda una comunidad que se nutre de ellos, y que sean sometidos y expuestos para su discusión, su mejoramiento y su ampliación, entre otras acciones que se deriven de la actividad científica. Este aspecto, entre otros, diferencia a la investigación de la consultoría, pues esta última es básicamente de uso particular aun cuando una entidad u organismo público ordene su realización, ya que la solicita en su rol de cliente que requiere una solución a sus problemas específicos y no como promotor de nuevo conocimiento con valor y alcance universales. Así, la consultoría puede ser definida como la actividad del consultor, y este, como la persona experta que asesora profesionalmente sobre una materia (DRAE 2001). Por su parte, William A. Cohen (2003) destaca la consultoría como una actividad a través de la cual un especialista en determinada área ofrece consejos u otros servicios de naturaleza profesional o semiprofesional a un cliente a cambio de honorarios, sobre la base de capacidades acreditadas que avalan su experiencia para ayudar con una tarea específica que un individuo o una compañía necesitan ejecutar, razón por la cual el acceso al resultado de la consultoría está restringido al consultante o cliente, quien la patrocina o financia.

Por supuesto, como en casi todo y en relación con unos y otros aspectos, se pueden también advertir similitudes entre investigación y consultoría, que en muchas ocasiones originan una confusión tal que la línea divisoria entre una y otra se difumina debido a prácticas circunstanciales o políticas que tergiversan el objeto y objetivo de estas. Sin embargo, existen aspectos sustanciales que marcan límites intransgredibles. A decir de Eco (1986), y en concordancia con lo manifestado líneas arriba, la investigación científica plantea, entre otros requisitos, orientarse a un objeto definido y reconocible de una manera que permita que los demás también lo reconozcan, y sobre el que tiene que revelar puntos que no han sido aún revelados o bien revisar con otra óptica lo que 
ya ha sido anteriormente manifestado. Del mismo lado, Day (1996) destaca algunos atributos contenidos en la definición de un artículo científico que el Council of Biology Editors realizara en 1998, entre los cuales se encuentran la necesidad de revelar nuevos datos, la posibilidad de que la comunidad pueda evaluar las observaciones, repetir los experimentos y evaluar los procesos intelectuales aplicados, entre otros. Es, pues, la divulgación de nuevos conocimientos o de nuevas perspectivas u ópticas lo que ofrece la investigación a toda una colectividad como resultado propio de su actividad.

Por todo lo anotado, hemos realizado esfuerzos por que la contabilidad, las finanzas y la tributación sean visualizadas desde su dimensión científica, para lo cual nos hemos encaminado en una ruta que permita diferenciar la investigación de la consultoría en las labores desarrolladas en las clases, más aún cuando la investigación no se promueve con la misma intensidad en las diversas carreras que ofrece la Universidad. Así, en clases referidas a la asignatura de proyecto contable, hemos llevado a cabo asesorías metodológicas a través de las cuales los alumnos cobran conciencia del proceso de investigación y de consultoría y de los fines y alcances de cada una de estas labores.

El tomo del título que en esta oportunidad presentamos constituye, pues, el resultado de un largo proceso de enseñanza y aprendizaje en el que, desde hace más de una década, los alumnos del curso de proyecto contable de la carrera de Contabilidad de la Universidad del Pacífico han desarrollado, bajo asesoría y supervisión estricta del docente investigador, trabajos de investigación que han ido evolucionando notablemente en calidad de contenido.

Hace casi diez años, publicamos el texto Contabilidad, finanzas y tributación: reflexiones académicas. Desde entonces y hasta ahora, hemos logrado desarrollar una metodología de trabajo cada vez más cuidadosa en cuanto al proceso mismo de investigación, que empieza con la identificación del área de conocimiento relacionada con la contabilidad, las finanzas o la tributación, y de un problema a partir del cual se puedan plantear los objetivos de la investigación, la hipótesis y las variables correspondientes. Esto, aparentemente obvio y simple, se convirtió en el principal reto de nuestra labor académica. El principal obstáculo para ello fue la confusión entre la investigación y la consultoría, asunto que ya abordamos en párrafos anteriores. A partir de esto, se plantea el método de investigación, el plan de trabajo y el desarrollo en sí de la investigación, que termina con la aceptación o el rechazo de la hipótesis, 
las conclusiones y, finalmente, con las recomendaciones y la propuesta de investigaciones futuras.

Lamentablemente, el número de contadores que egresan de la Universidad del Pacífico no permite generar un volumen de trabajos de investigación que sostenga una publicación periódica regular. Sin embargo, la calidad de los contenidos logrados y avalados por expertos profesionales de la firma PricewaterhouseCoopers, guardando especial cuidado y respeto de los elementos de investigación señalados, y en permanente coordinación con el docente investigador del curso mencionado, evidencia el valor del esfuerzo realizado con el propósito de que los procesos desarrollados en los trabajos de investigación sean rigurosos y confiables.

El proceso que desarrollamos en clase, coincidiendo con lo que mencionamos antes, se inicia con la identificación del área de conocimiento e incluye el planteamiento de la propuesta de investigación y trabajo de campo, cuya primera etapa se orienta a la revisión del material bibliográfico y continúa con el levantamiento de información de las fuentes primarias. El resultado de esta etapa se evalúa, procesa, resume y analiza. Luego, se determina si la información es suficiente o si se requiere de mayor información. Concluida esta fase, se prosigue con el análisis de la información y el diseño de los borradores, que se revisan, observan y ajustan, y que posteriormente se integran al conjunto de la investigación. Este resultado es revisado por el docente investigador que dirige la asignatura, quien ofrece sugerencias y recomendaciones que pueden ser incorporadas para, finalmente, lograr la versión final que es defendida ante un jurado formado por profesionales expertos en los temas desarrollados en los trabajos de investigación.

La parte final de todo este proceso consiste en la selección de los trabajos de investigación con potencial para ser publicados. El editor del texto es el responsable de la selección de trabajos. En este sentido, y producto de un estudio minucioso de cada trabajo de investigación en cuanto a su selección, que ha incluido desde la evaluación de la calidad de la investigación traducida o manifestada a través de diversos parámetros metodológicos, hasta la incorporación de expertos, seleccionados según su área específica de dominio e integrados según su visión consultora a la idea de investigación científica, hemos logrado obtener un conjunto de documentos de investigación de alta calidad para su publicación. En esta ocasión, aceptamos la generosa colabo- 
ración de la firma PricewaterhouseCoopers, que ofreció la participación de un grupo de destacados expertos en los temas planteados para que realizaran la revisión y recomendación para su publicación, quienes fueron elegidos por la mencionada firma en coordinación con el editor del título. El profesor Santiago Collas realizó las coordinaciones internas para la selección de los revisores y las gestiones correspondientes para asegurar el cumplimiento de los plazos. Las observaciones realizadas por los revisores se levantaron con la supervisión del editor del libro, logrando así, finalmente, la aprobación final del revisor para la publicación de los trabajos de investigación.

El libro cuenta con una estructura medular compuesta por cinco capítulos, dentro de los cuales se exponen las investigaciones seleccionadas, que fueron desarrolladas durante el año 2014. El primero trata del «Impacto en los estados financieros de la determinación y la variación del nivel de las reservas petroleras en las empresas de hidrocarburos en el Perú», y su objetivo es indagar acerca de la metodología contable utilizada por las empresas petroleras peruanas para registrar los cambios de algunas operaciones contables específicas del sector de hidrocarburos y respecto de las cuales no se cuenta con una normativa especializada contable que proponga parámetros claros para el registro de dichas transacciones. En el segundo capítulo, se aborda «La aplicación de las normas contables y tributarias en los sectores construcción e inmobiliario para la correcta determinación del impuesto general a las ventas y del impuesto a la renta", cuyo objetivo es el desarrollo un compendio de normas contables y tributarias que permitan a las personas interesadas en los sectores construcción e inmobiliario contar con el marco conceptual y normativo adecuado para registrar sus operaciones y determinar en forma adecuada la base imponible para el cálculo del impuesto general a la ventas y del impuesto a la renta, con el propósito de optimizar los beneficios del proyecto emprendido. El tercer capítulo se ocupa de las "Principales diferencias en el tratamiento contable en el sector minero", investigación cuyo objetivo es proponer un tratamiento contable homogéneo de aquellas operaciones específicas del sector minero que aún presentan vacíos normativos contables para su respectivo registro. Por su parte, el cuarto capítulo ofrece una «Investigación sobre los métodos de costeo de huevos comerciales y la valorización del activo biológico», la cual se plantea como objetivos proponer un modelo de costeo para huevos comestibles aplicable a las empresas avícolas en el Perú dentro del marco de las normas internacionales de contabilidad y valorizar el activo biológico. Finalmente, el quinto capítulo nos brinda el estudio de un «Método de costeo 
de ganado vacuno para las empresas ganaderas peruanas", cuyo objetivo es ofrecer la propuesta de modelo de costeo del ganado vacuno a partir de los modelos de Llenque (Universidad del Callao) y Fongal (Fondo Nacional de Ganadería Lechera).

Como se evidencia, el resultado final de esta labor intelectual es un conjunto de trabajos de investigación que han sido desarrollados y seleccionados con la mayor rigurosidad académica de parte de los autores y del editor, y con el sólido apoyo del profesor Santiago Collas, sin cuya participación y estrecha coordinación con los revisores no habría sido posible lograr la alta calidad alcanzada por estos.

Ofrecemos una mención especial de agradecimiento al profesor Edgar Alva, por sus permanentes recomendaciones y consejos en las diferentes etapas del proceso de elaboración del presente texto. Su enfoque de investigación nos permitió elevar la calidad de este documento que presentamos como aporte a la comunidad contable y a la comunidad científica en general, a cuyos juicios y observaciones nos entregamos constantemente. 


\title{
1. El impacto en los estados financieros de la determinación y la variación del nivel de las reservas petroleras en las empresas de hidrocarburos en el Perú
}

\author{
Carolina Li \\ Claudia Luyo \\ Juan José Melgar
}

\section{Resumen}

El presente trabajo de investigación ha sido elaborado con el objetivo de indagar acerca de la metodología contable utilizada por las empresas petroleras peruanas para registrar los cambios de algunas operaciones contables especificas del sector hidrocarburos, las cuales no cuentan con una normativa especializada contable que proponga parámetros claros para el registro de dichas transacciones.

Se busca abarcar el entendimiento y la comparación de los registros contables correspondientes a las siguientes operaciones entre empresas que operan en el sector hidrocarburos: provisión por taponamiento de pozos; ajuste de depreciación relacionado con los cambios en el nivel de reservas petroleras; y activación de trabajos de perforación en los pozos petroleros.

Por otra parte, con el propósito de poder documentar una investigación válida y contar con información veraz, se realizaron entrevistas con expertos del sector, firmas auditoras y gerentes auditores encargados de empresas del sector analizado.

Asimismo, se optó por comparar las políticas y metodología contable de las siguientes empresas elegidas del sector hidrocarburos: Maple Gas Corporation S. R. L., Petrolera Monterrico S. A., Savia Perú S. A. y Olympic Perú Inc. Cabe resaltar que en las entrevistas mencionadas se pudo obtener información relevante proveniente de las notas de los estados financieros de dichas empresas y el entendimiento de la metodología contable utilizada en cada empresa.

Por último, sobre la información obtenida y la revisión del marco normativo aplicable a cada una de las operaciones contables analizadas, se presentan conclusiones acerca del tratamiento contable sobre la base de las empresas entrevistadas. 


\section{Introducción}

Los hidrocarburos son recursos no renovables que tienen gran importancia en la economía mundial. El término hidrocarburos comprende a todo compuesto orgánico, gaseoso, líquido o sólido que consiste principalmente de hidrógeno o carbono, según se menciona en el Texto Único Ordenado de la Ley N. ${ }^{\circ}$ 26221 - Ley Orgánica de Hidrocarburos.

Actualmente existe una tendencia al crecimiento de la demanda mundial de combustibles líquidos, entre ellos el petróleo; por ejemplo, para 2011 se obtuvo una demanda de 88,3 MM de barriles diarios, y para 2012 este indicador aumentó a 89,2 $\mathrm{MM}^{1}$.

Este panorama favorable se puede ver afectado por el hecho de que, por condiciones naturales, las reservas de petróleo en el mundo cada vez son más escasas y reducidas, lo que trae como consecuencia volatilidades en el precio del barril de petróleo con tendencia al alza, debido a una demanda con cada vez menos posibilidades de ser abastecida. Por ejemplo, citamos el siguiente artículo del diario El Mundo de Venezuela: «El precio promedio del petróleo en la última década ha sido tres veces mayor que el promedio que prevaleció a lo largo del siglo pasado. El primer factor que explica esta alza ha sido el cambio en el patrón mundial de consumo»².

Para el corto plazo, se espera un crecimiento más lento en la demanda de este bien por la crisis mundial que se atraviesa; asimismo, según Reuters, el mundo tendrá un exceso de oferta de productos refinados por aumento de la industria en Asia y el Medio Oriente. Sin embargo, para finales de este año se pronostica que el consumo mensual mundial mejore: este aumentará en $785.000^{3}$ bpd este año.

La producción de petróleo e hidrocarburos representa un porcentaje significativo en el crecimiento de la economía del país, lo que ha traído como resultado inversiones significativas en este sector por parte de las empresas existentes y de nuevas empresas.

1. <http://www.repsol.com/imagenes/pe_es/EIEntorno_tcm18-644024.pdf>.

2. <http://www.elmundo.com.ve/firmas/ramon-espinasa/razones-del-aumento-del-precio-del-petroleo. aspx\#ixzz2VIEkNohC>.

3. <http://gestion.pe/economia/se-avecina-exceso-oferta-combustibles-mayor-actividad-refinera-2068436>. 
Para marzo de 2013, en el ámbito nacional, existen $77^{4}$ contratos en el sector, de los cuales 56 son de exploración y 21 pertenecen a explotación.

Este tipo de compañias cuentan con diversos tipos de actividades y operaciones no convencionales propias del sector, las cuales tienen poca similitud y relación con las de los demás sectores. Asimismo, muchas de ellas presentan un alto grado de complejidad tanto de cálculo como de valorización y tratamiento contable.

Actualmente, la normativa contable no ha desarrollado reglas de contabilidad que hayan establecido parámetros específicos en este sector, que abarquen temas de las distintas actividades y procesos que afectan a los estados financieros.

Tampoco existe una estandarización en el tratamiento contable dentro de las distintas empresas que se desarrollan en el mercado. Esta carencia de información trae como consecuencia que las empresas utilicen su propio criterio para realizar ciertas etapas dentro del proceso contable, y este, al no ser realizado de manera uniforme, impide elaborar informes contables y financieros exactamente comparables entre sí.

\section{Planteamiento del problema}

\section{Área de la investigación}

Contabilidad.

\section{Problema}

«La falta de directrices específicas para la valorización y el registro contable de las reservas petroleras".

Las compañias extractoras de petróleo, al estar reguladas por entidades, tienen que cumplir con diversas obligaciones y parámetros, los cuales deben estar reflejados en los estados financieros para presentar la situación real de la empresa.

Para poder empezar a operar, las empresas del este sector están obligadas a contar con un contrato de concesión, la cual es otorgada por el Estado. En dicho contrato, se especifican las zonas permitidas para la extracción de los

4. <http://www.perupetro.net.pe/wps/wcm/connect/f8236b804f86931a8bf9ffd3871f59b6/2013-03+ Informe+Mensual+de+Actividades. $p d f ? M O D=A J P E R E S E t /$ mod $=-37726885>$. 
hidrocarburos, así como los pozos asignados a cada compañía y la cantidad de años por los que la empresa está autorizada para extraer este recurso natural. Dicho acuerdo presenta, en todos los casos, una cláusula que señala que las empresas extractoras están obligadas a entregar al Estado peruano las instalaciones localizadas en el área de los contratos de licencia, por lo que existe una obligación asociada a dichas entregas, correspondiente al taponamiento de los pozos que no tengan reservas a esa fecha.

Esta obligación y dicha cantidad de pozos deben estar reflejadas en los estados financieros de las empresas, como una provisión dentro del pasivo o como un activo fijo dentro del activo de la empresa. Para el caso de estos registros contables, se tiene como normativa contable la NIC 16 Propiedades, Planta y Equipo; la NIC 37 Provisiones, Pasivos Contingentes y Activos Contingentes; y la CINIIF 1 Cambios en Pasivos Existentes por Retiro del Servicio, Restauración y Similares, como fuentes principales de información para el registro de dichos conceptos.

Los registros antes mencionados deben ser efectuados sobre la base del estudio técnico con el cual la compañía determina el nivel de las reservas petroleras en un período determinado. Este estudio técnico debe ser preparado por expertos sobre la base de los lineamientos establecidos por el Comité de Reservas de Petróleo y Gas de la Sociedad de Ingenieros de Petróleo de los Estados Unidos de América, revisados y coauspiciados por el Consejo Mundial del Petróleo, la Asociación Americana de Geólogos de Petróleo y la Sociedad de Ingenieros Evaluadores de Petróleo.

Luego de la determinación de las reservas petroleras, se tienen que actualizar los montos de la compañía al final de cada período o cuando esta lo considere necesario. Dicho nivel de reservas, el cual es determinado por el informe técnico mencionado, tiene como consecuencias adicionales el ajuste en la depreciación del año relacionada con los pozos activados, y la decisión de optar por la activación o por el registro del importe de los gastos incurridos por la empresa extractora en los trabajos de perforación realizados en los pozos de petróleo existentes.

Cabe mencionar que el proceso de estimación de las cantidades de reservas es complejo, y requiere decisiones subjetivas en la evaluación de todos los datos geológicos, geofísicos, de ingeniería y económicos disponibles. Asimismo, los datos pueden variar sustancialmente a lo largo del tiempo como resultado de numerosos factores, por ejemplo: la evolución de la producción histórica y la 
continua reevaluación de la viabilidad de la producción bajo diversas condiciones económicas.

Un factor importante por considerar para el presente trabajo es que los cambios en la cantidad de las reservas podrían originar cambios en los gastos de depreciación y amortización, tanto en el periodo actual como en los períodos siguientes a la revisión. Asimismo, podrían originar un deterioro o un aumento de los valores en libros de los rubros propiedad, planta y equipo, y activos intangibles. Estas dos consecuencias formarán de la investigación realizada, para la cual nos basaremos en la NIC 16 Propiedades, Planta y Equipo como principal norma contable.

Cabe resaltar que los cálculos y la metodología de registro contable utilizados por cada empresa pueden diferir en ciertos aspectos, considerando la falta de normas o manuales específicos que indiquen a las compañías petroleras cómo registrar la provisión relacionada con el taponamiento de los pozos o cómo decidir si se activan o se envían a resultados los trabajos orientados a brindar mejoras al pozo. Dicha falta de teoría es considerada como un vacío en el tratamiento contable actual, el cual limita la comparabilidad de los estados financieros entre las empresas que pertenecen al sector hidrocarburos. Esto es considerado como una desventaja importante pues no permite tener la seguridad de contar con estados financieros comparables en todo momento, sobre todo en esta época, en la cual hay una tendencia cada vez más fuerte a la homogenización de parámetros contables y financieros en el mundo.

\section{Objetivos}

\section{Objetivo general}

Identificar las diferencias en los criterios utilizados para el tratamiento contable de los registros más relevantes identificados; asimismo, desarrollar una propuesta de estandarización que permita un mejor procesamiento de información y así poder tener mayor seguridad en la comparabilidad de registros entre los estados financieros de las empresas petroleras en el Perú.

\section{Objetivos específicos}

- Analizar el marco teórico aplicable al tema en investigación y determinar la existencia de información suficiente para lograr una presentación de estados financieros comparables. 
- Identificar las principales incidencias contables en las empresas petroleras analizadas.

- Identificar las diferencias de registro de las incidencias contables más relevantes identificadas y analizadas.

\section{Hipótesis}

La normativa actual no presenta la información suficiente para determinar parámetros establecidos que permitan calcular y registrar la determinación y variación del nivel de las reservas petroleras, lo que da cierto nivel de libertad a utilizar diferentes criterios e interpretaciones en la presentación de los estados financieros.

\section{Hipótesis específicas}

- Existen diferentes criterios para el tratamiento contable de ciertas operaciones dentro de las empresas del sector.

- La influencia del cálculo y el tratamiento contable de las reservas petroleras tiene alta importancia en los estados financieros.

- No existe normativa suficiente que brinde parámetros para los registros y el cálculo de las reservas petroleras, por lo que existe gran influencia del criterio de cada empresa del sector.

- La propuesta de estandarización en el registro y tratamiento de las cuentas analizadas reducirá el riesgo de una posible manipulación de los estados financieros en compañías del sector hidrocarburos.

- De aplicarse la propuesta, se podrán presentar estados financieros comparables entre empresas del sector, con criterios homogéneos.

\section{Fuentes de información}

\section{Fuentes primarias}

En el primer punto del presente trabajo, se realizaron entrevistas a auditores de las empresas seleccionadas de hidrocarburos y auditores relacionados con 
el sector. Sobre la base de dichas entrevistas, se logró el entendimiento de los procesos relacionados con las transacciones analizadas, además de entender la importancia y los efectos que tiene cada tratamiento contable relacionado con las variables involucradas.

Asimismo, estas entrevistas permitieron obtener mayor información acerca del entendimiento y alcance del tratamiento de las reservas petroleras y su relación con la parte técnica de las operaciones de las empresas petroleras.

\section{Fuentes secundarias}

En lo que respecta a las fuentes secundarias, se realizó un análisis de la teoría contable relacionada con los temas de la presente investigación, además de toda la normatividad regulatoria y aspectos legales que estén relacionados con el sector. Asimismo, se obtuvieron datos de informes auditados de las empresas de hidrocarburos analizadas, con el propósito de contar con un mejor entendimiento de sus operaciones y del tratamiento contable aplicado por cada una.

\section{Metodología}

A continuación, se describe el método utilizado para el desarrollo de la presente investigación, con el propósito de cumplir con los objetivos planteados y poder validar las hipótesis.

\section{Enfoque}

La investigación busca generar una propuesta que permita estandarizar las prácticas contables de las empresas del sector hidrocarburos, la cual se centre en las incidencias contables identificadas y analizadas. Se espera que esta propuesta se convierta en una herramienta útil para su aplicación por las empresas como parte de su política contable. Cabe resaltar que el cálculo de las reservas está ligado a estudios de técnicos profesionales, por ello, para efectos de esta investigación, se tratarán exclusivamente temas relacionados con el tratamiento contable y con el correcto registro de estas valorizaciones.

Esta propuesta se elaborará a partir de la información recopilada en las fuentes primarias y secundarias, y luego de realizar el análisis del marco contable actual existente en el sector. 


\section{Etapas de la investigación}

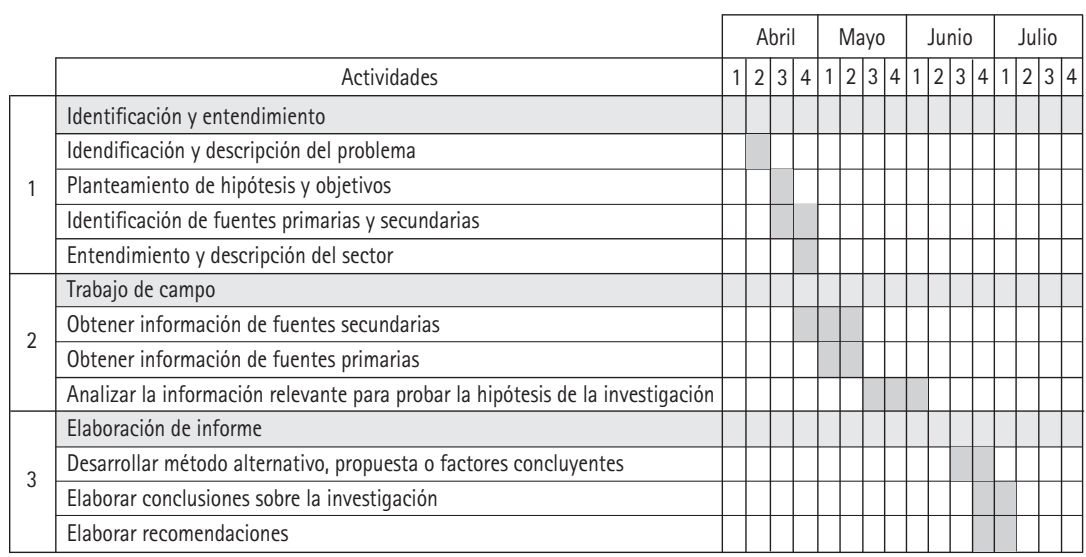

\section{Etapas de identificación y entendimiento}

- Identificación y descripción del problema

- Objetivos e hipótesis

2

- Identificación de fuentes primarias y secundarias (marco teórico)

- Entendimiento y descripción del sector

4

Trabajo de campo y elaboración de informe

- Entrevista a auditores

- Análisis del marco teórico

- Entrevistas a expertos en el sector

3

- Elaboración de propuesta

4

- Conclusiones y recomendaciones

5 


\section{Descripción del sector hidrocarburos}

El sector hidrocarburos es una de las actividades económicas que mayor importancia han ganado en los últimos años, como consecuencia del descubrimiento de Camisea en la década de 1990. Para el caso de los hidrocarburos líquidos, existen diversas empresas que cuentan con concesiones para extraer petróleo en distintas zonas del país. Sin embargo, la producción local es insuficiente para atender la demanda interna, por lo que se realizan importaciones para abastecer la totalidad de la demanda ${ }^{5}$.

El sector hidrocarburos se caracteriza por requerir grandes niveles de inversión para la etapa de explotación y desarrollo de los yacimientos, ya sean de gas natural o de hidrocarburos líquidos, debido a los altos costos de capital, investigación y desarrollo, infraestructura y tecnología requeridos para el desarrollo de las operaciones. El sector cuenta con un ente regulador llamado Osinergmin, y, específicamente para el caso de los hidrocarburos líquidos, existe una regulación especial de precios denominada "Banda de precios de los combustibles»" .

Entre los hidrocarburos más importantes que el Perú produce están el gas natural y el petróleo.

Cabe resaltar que el gas natural se ha convertido en los últimos años en una importante fuente de energía para la economía mundial debido a que presenta una competitividad importante frente a otros combustibles, ya que posee propiedades menos contaminantes y se comercializa a un precio de mercado inferior al de cualquier otro combustible fósil. Por otro lado, el petróleo, conocido también como crudo, es un compuesto químico en el que se encuentran tanto partes sólidas y líquidas, como gaseosas. El petróleo es un recurso natural considerado como no renovable y es la materia prima que aporta el mayor porcentaje del total de la energía que se consume en el mundo, razón por la cual existe una alta dependencia de él; sin embargo, la inestabilidad del mercado y las fluctuaciones en el precio han llevado a la búsqueda de otros tipos de fuentes de energía que actúen como sustitutos del petróleo.

En el proceso de estimación de reservas se requiere del conocimiento de profesionales geólogos, ingenieros de petróleo y especialistas, quienes determinan

5. <http://www.aai.com.pe>. Informe del sector hidrocarburos.

6. ídem. 
las reservas probadas como estimaciones, más que como medidas de cantidades precisas $^{7}$.

Con respecto a las condiciones económicas, el nivel de reservas depende del precio actual y futuro del petróleo crudo. El precio promedio anual de petróleo crudo para 2012 fue de 94,05 US $\$ / \mathrm{Bl}^{8}$. Sin embargo, existió mucha volatilidad y especulación durante 2012, debido a la coyuntura internacional, las perspectivas económicas mundiales, los cortes de producción y otros aspectos geopolíticos que aumentaron la especulación ${ }^{9}$.

En 2012, en el Perú se han perforado 207 pozos (9 pozos exploratorios, 2 pozos confirmatorios y 196 pozos de desarrollo), de los cuales el 86\% se han perforado en el Noroeste - Costa. La cantidad de pozos perforados en 2012 fue menor que la del año anterior (con 242 pozos). La producción promedio para 2012 fue de 66.655 barriles por día ${ }^{10}$. (Ver anexo 1 ).

\section{Proceso de la actividad extractiva}

\section{- Etapa de exploración ${ }^{11}$}

Esta actividad es el primer paso del proceso de producción de hidrocarburos. Consiste en un estudio previo del subsuelo con el propósito de asegurar que existan reservas suficientes que ameriten una futura extracción. Una vez comprobada la existencia de dichas reservas, se da paso al proceso de perforación de pozos en las zonas geográficas, previo estudio de suelos. Esta primera etapa es considerada una de las más riesgosas, porque no se tiene un cien por ciento de seguridad de la existencia de las reservas.

\section{- Etapa de explotación ${ }^{12}$}

Este segundo paso consiste en la explotación del petróleo y/o gas natural de los pozos previamente perforados, los cuales deben encontrarse dentro de la zona

7. Energy Information Administration. Annual Survey of Domestic Oil and Gas Reserves. Survey Year 2012. 8. <http://www.minem.gob.pe/minem/archivos/file/hidrocarburos/publicaciones/R_E_\%20Libro\%20de\%20 Reservas\%2031_12_2012.pdf>.

9. Ídem.

10. Ídem.

11. <http://www.scotiabank.com.pe/i_financiera/pdf/sectorial/20020206_sec_es_hidrocarburos.pdf>.

12. Ídem. 
asignada por el Estado en el contrato de licencia correspondiente. Asimismo, se realizan todas las actividades de extracción, siguiendo los parámetros del cuidado del medio ambiente y de la salud y seguridad de los trabajadores. En esta etapa se realiza la separación del crudo, el gas y otros elementos que normalmente se encuentran presentes en la extracción.

\section{- Transporte $^{13}$}

En el caso del petróleo, una vez que ha sido separado y almacenado, es transportado a refinerías por medio de oleoductos. En el caso del gas natural, este es transportado por medio de tuberías denominadas gasoductos.

\section{- Refinación ${ }^{14}$}

Esta actividad consiste en la refinación del petróleo, la cual separa el petróleo de los diversos componentes con los que fue extraído anteriormente. Luego de este proceso, el petróleo es utilizado para producir los combustibles derivados ${ }^{15}$ : diésel, gasolina, querosene, GLP, etc.

\section{- Cierre y abandono de pozos ${ }^{16}$}

Esta es la última etapa del ciclo de las empresas del sector hidrocarburos. Esta etapa deberá realizarse de acuerdo a los lineamientos de la Ley de Exploración y Explotación de Hidrocarburos ${ }^{17}$. Además, esta actividad es regulada por Perupetro $^{18}$ y Osinergmin ${ }^{19}$. Esta etapa consiste en el retiro de la empresa de los pozos petroleros en los que se encontraba extrayendo materia prima. Al retirarse, la empresa deberá devolver al Estado todos los pozos, campos, ductos, construcciones y otras instalaciones localizados en el área designada. Los pozos que carezcan de reservas deberán ser entregados debidamente tapados. (Ver anexo 2).

\footnotetext{
13. Ídem.

14. Ídem.

15. $<$ http://www.info-petroleo.com/productos.html>.

16. Ídem.

17. <http://www2.osinerg.gob.pe/MarcoLegal/pdf/LEYOH-\%2026221.pdf>.

18. <http://www.perupetro.com.pe/>.

19. <http://6iserver.osinerg.gob.pe/newweb/pages/Publico/1.htm>.
} 


\section{Incidencias contables particulares en la actividad petrolera}

Sobre la base de nuestra indagación y entendimiento de las operaciones de las empresas del sector hidrocarburos, hemos identificado las siguientes particularidades, las cuales tienen como consecuencia registros contables y proyecciones financieras aplicables únicamente a dichas empresas:

\section{- Pago de regalías}

De acuerdo con lo indicado en la Ley N. ${ }^{0} 26221$ - Ley Orgánica de Hidrocarburos, y el Reglamento de Regalía y Distribución aprobado por Decreto Supremo N. ${ }^{\circ}$ 049-93-EM, las empresas del sector deberán pagar regalías en efectivo, aplicando un porcentaje a la valorización de la producción de los hidrocarburos fiscalizados. Esto representa una obligación existente para las empresas del sector hidrocarburos.

\section{- Fondo de estabilización de precios}

La empresas del sector hidrocarburos están sujetas a un fondo de estabilización de precios establecido por el Gobierno peruano (Ministerio de Energía y Minas) con el objetivo mitigar la alta volatilidad de los precios internacionales del petróleo para beneficiar a los clientes finales. Dicho fondo trabaja a través de contribuciones y compensaciones recolectadas y/o entregadas a las empresas vendedoras de los combustibles afectos. Cuando el índice de precios está por encima de cierto límite, dichas empresas reciben un pago; y, por el contrario, cuando el índice de precios se encuentre por debajo de cierto nivel, los participantes del fondo (empresas petroleras) deben efectuar una contribución a este. La existencia de dicho fondo puede representar tanto una obligación como un beneficio para las empresas petroleras.

\section{- Costos previos a la explotación}

Las empresas petroleras incurren en una gran cantidad de gastos y costos previos a la explotación de los recursos, básicamente en la etapa de exploración, la cual tiene como objetivo definir la existencia de reservas petroleras. Estos costos representan una parte importante de la inversión realizada por las empresas del sector, y el tratamiento contable que se les otorgue afecta los estados financieros. 


\section{- Taponamiento de pozos}

No existe obligación por el retiro de las instalaciones de producción al final del período de licencia, excepto por el taponamiento de los pozos que no tengan reservas a esa fecha. Dicha obligación debe verse reflejada en los estados financieros de la empresa.

\section{- Depreciación y amortización de activos petroleros}

Las empresas del sector deben seleccionar el método más adecuado para depreciar y/o amortizar sus activos petroleros. Dicho registro se ve afectado por las políticas contables seleccionadas por la empresa, pues estas van a influir en el nivel de costos capitalizados como activos fijos y en el nivel de reservas que la compañía considere para el cálculo de depreciación.

Luego de la información obtenida de las entrevistas realizadas a profesionales auditores en el sector de firmas reconocidas ${ }^{20} \mathrm{y}$ del análisis de los informes de los estados financieros de las compañias analizadas, se ha decidido que la presente investigación se enfocará en tres incidencias en el tratamiento contable en las empresas. Estos tres registros han sido elegidos por su importancia en los estados financieros; asimismo, por contar con una mayor vulnerabilidad para el uso de criterios y políticas internas de cada empresa.

Los tratamientos por analizar son los siguientes:

\section{Tratamiento de costos previos a la explotación}

La exploración y evaluación de un pozo petrolero consiste de tres etapas: la evaluación del potencial petrolero, la incorporación de reservas y la delimitación de yacimientos. Durante la evaluación del potencial petrolero, se identifican, mapean y jerarquizan las áreas donde existan mayores probabilidades de encontrar hidrocarburos en el subsuelo; para ello, es necesario realizar estudios de geología y otros, con el propósito de comprobar el potencial del área por explotar. El siguiente paso es la incorporación de reservas, la cual tiene el objetivo de descubrir reservas de hidrocarburos a partir de la identificación, jerarquización y perforación de oportunidades exploratorias detectadas por

20. Ariel García (gerente senior de la empresa E\&Y) / José Tafur (gerente senior de la empresa PwC). 
los especialistas geocientíficos. La tercera y última etapa de la exploración es la delimitación de yacimientos, sobre la cual se da certeza de volúmenes de reservas descubiertas mediante un análisis de la geometría y las propiedades de los yacimientos; es decir, permite calcular con mayor grado de confianza el desarrollo y las futuras explotaciones ${ }^{21}$. Estas etapas conllevan elevados gastos de personal para el trabajo geológico, depreciaciones, mantenimiento y costos de reparación de equipos, entre otros.

Cabe mencionar que las empresas del sector incurren en estos gastos una gran cantidad de veces a lo largo de su período de operación. Como resultado de la tercera etapa mencionada, generalmente se emite un informe técnico de reservas, en el cual se indica el nivel estimado de reservas petroleras a la fecha. Este informe suele ser emitido una vez al año como mínimo.

El tratamiento contable de los costos previos a la explotación puede realizarse de tres maneras:

- Activar todos los costos de exploración y evaluación.

- Registrar en la cuenta adecuada en el estado de pérdidas y ganancias la totalidad de los costos de explotación y evaluación en el período correcto.

- Registrar en la cuenta adecuada en el estado de pérdidas y ganancias la totalidad de los costos de exploración incurridos hasta que exista seguridad de la obtención de recursos de hidrocarburos explotables. A partir de esa etapa, se empezarían a capitalizar los costos o activarlos.

\section{Provisiones por taponamiento de pozos}

Las compañías petroleras están expuestas a obligaciones legales, contractuales y/o constructivas para cumplir con los costos de retiro de servicios y desmantelamiento de los activos al final de su vida productiva, en adición a la restauración del lugar donde se encontraban esos activos. Estos costos probablemente sean un aspecto significativo de gastos para la mayor parte de las compañias petroleras. Las actividades específicas de retiro de servicios pueden incluir el taponamiento y abandono de pozos; el desmantelamiento de cabezales de

21. <http://www.industriapetroleramexicana.com/2012/03/la-exploracion-petrolera-en-mexico/>. 
pozos, y de actividades de producción y transporte; y la restauración física de un área de actividad a su condición original o a una mejor que la original ${ }^{22}$.

Las empresas de hidrocarburos deben reconocer una provisión contable por las obligaciones asociadas con el abandono de pozos. Para el registro de dicha provisión, se requiere de supuestos y estimados en relación con las tasas de descuento y el costo esperado para tapar los pozos.

La presente investigación tiene como objetivo indagar acerca del criterio de estimación utilizado por cada una de las compañías analizadas, con el propósito de identificar posibles diferencias que permitan proponer un método uniforme de registro.

\section{Metodología de depreciación utilizada para los pozos petroleros y activos intangibles} relacionados con los costos y gastos de exploración

Tal como se mencionó en el informe, las compañias del sector hidrocarburos pueden incluir los pozos petroleros y todos los gastos relacionados con la exploración y explotación como parte de sus activos fijos y activos intangibles.

Dichos activos deben ser depreciados y/o amortizados, según sea el caso, sobre la base de las reservas probadas. Los cambios en la cantidad de las reservas, incluyendo cambios como resultado de los supuestos en el precio, podrían originar cambios en los gastos de depreciación y amortización en los períodos siguientes a la revisión, y podrían originar un deterioro de los valores en libros de propiedad, planta y equipo, y activos intangibles.

La presente investigación tiene como uno de sus objetivos el entendimiento de la metodología utilizada por cada una de las empresas analizadas para registrar la depreciación de los pozos y los costos relacionados con la exploración. A la vez, se realizó una indagación acerca del tratamiento contable, el cual registra el ajuste de depreciación correspondiente al cambio en el nivel de reservas, con el propósito de identificar posibles diferencias y proponer un método uniforme.

22. <http://www.kpmg.com/CL/es/IssuesAndInsights/ArticlesPublications/Documents/2008-10-kpmgaudit-niif-petroleo-gas.pdf>. 


\section{Normativa contable aceptada internacionalmente}

A continuación, se presenta el marco teórico utilizado como fuente primaria para el análisis de los registros contables relacionados con el sector hidrocarburos. Dicho marco teórico incluye tanto normas contables como normas que regulan el sector hidrocarburos utilizadas nacional e internacionalmente.

\section{Tratamiento de costos previos a la explotación}

A continuación, se presentan las implicancias de las normas analizadas en lo que concierne al tratamiento de los costos y gastos incurridos previos a la explotación petrolera.

\section{NIIF 6 Exploración y evaluación de recursos minerales}

El objetivo de esta NIIF es especificar la información financiera relativa a la exploración y la evaluación de recursos minerales. Esta norma se aplica para desembolsos relacionados con la exploración y evaluación en los que incurra la empresa.

Esta norma describe la forma de valorización de activos para la exploración y evaluación, la cual menciona que la valorización de estos activos será al costo.

Los componentes del costo de los activos para la exploración y evaluación serán identificados de acuerdo a la política establecida por la entidad, la cual debe ser aplicada uniformemente; asimismo, la entidad deberá considerar el grado en que los desembolsos están asociados en el descubrimiento de los recursos minerales. Por otro lado, de acuerdo a la NIC 37, la entidad deberá reconocer cualquier obligación en que se incurra por el desmantelamiento y restauración luego de las actividades de exploración y evaluación de recursos minerales. La valorización posterior al reconocimiento estará regida por las normas NIC 16 y NIC 38.

Por otra parte, ante cambios en las políticas que rigen a los componentes del costo en la etapa de exploración y evaluación, se deberá aplicar la NIC 8; cabe mencionar que estos cambios serán aceptados solo si brindan a los estados financieros una mayor razonabilidad y fiabilidad. 
La NIIF 6 detalla los criterios para la clasificación de activos para la exploración y evaluación. Esta clasificación se divide en dos tipos: intangibles (derechos de perforación) y materiales (vehículos y torres de perforación). Asimismo, indica que un activo material podrá ser parte de un activo intangible solo si se consume para desarrollar este último, mas no si es solo usado para este fin.

En cuanto al deterioro del valor, la NIIF 6 menciona que uno o más de los siguientes hechos y circunstancias indican que la entidad debería comprobar el deterioro del valor de los activos para exploración y evaluación; estos deterioros deberán ser tratados de acuerdo a la NIC 36.

- El período de tiempo durante el cual la entidad tiene el derecho a explorar en un área específica ha expirado durante el ejercicio, o lo hará en un futuro cercano, y no se espera que sea renovado.

- $\quad$ No se han presupuestado ni planeado desembolsos significativos para la exploración y evaluación posterior de los recursos minerales en esa área específica.

- La exploración y evaluación de recursos minerales en un área específica no ha conducido a descubrir cantidades comercialmente viables de recursos minerales, y la entidad ha decidido interrumpir dichas actividades en dicha área.

- Existen datos suficientes para indicar que, aunque es probable que se produzca un desarrollo en un área determinada, resulta improbable que el importe en libros del activo para exploración y evaluación pueda ser recuperado por completo a través del desarrollo con éxito o a través de su venta.

Si bien es cierto que la NIIF 6 fue creada específicamente para la exploración y evaluación en el sector minero, esta puede ser utilizada o servir como parámetro para el tratamiento contable de las empresas pertenecientes al sector hidrocarburos, ya que sus etapas y actividades tienen procedimientos similares a las del sector minero.

NIC 36 Deterioro del valor de los activos

La NIC 36 establece los procedimientos que una empresa debe seguir para asegurar que sus activos no se encuentran sobrevalorados con respecto al 
valor que se espera recuperar de los mismos, bien a través de su uso o de su venta.

El aspecto más destacado de esta NIC 36 es el análisis del deterioro al cierre de cada período contable. Se tiene que analizar al final de cada período contable el deterioro de todos los activos, si existen indicios de que estos últimos puedan haber sufrido una pérdida de valor. Esto quiere decir que si se produjeran cambios en las circunstancias entre la fecha del último análisis de deterioro y la fecha concreta de cierre contable, será necesario efectuar más de un análisis de deterioro cada año. Se debe procurar realizar los análisis en las mismas fechas todos los años.

El análisis de deterioro es necesario cuando existen indicios de que el activo refleja un deterioro mayor o menor que el registrado. Asimismo, este análisis se da si el activo en cuestión o la unidad generadora de efectivo incluyen un activo intangible de vida útil indefınida o que aún no está en disposición de ser utilizado.

Por otra parte, se analiza cada año el potencial deterioro de sus activos en un momento intermedio de este período. No obstante, en tiempos de incertidumbre económica y gran volatilidad, podría ser necesario repetir los análisis de deterioro al cierre del ejercicio si se produjeran indicios adicionales de deterioro con posterioridad al momento del análisis anual. Cabe resaltar que un análisis completo del deterioro con base en proyecciones del negocio, debidamente aprobadas por la dirección, es un proceso costoso si los datos no están disponibles. Por esta razón, muchas empresas consideran suficiente limitar los análisis del deterioro al cierre del ejercicio con actualizaciones anuales. Si el valor contable fuera mayor que su importe recuperable, el activo se encontraría deteriorado y se exige que la entidad reconozca una pérdida por deterioro del valor de ese activo en su estado de resultados.

NIC 8 Políticas contables, cambios en las estimaciones contables y errores

Esta norma señala que la entidad debe seleccionar y aplicar uniformemente sus políticas contables para transacciones, otros eventos y condiciones que sean similares, a menos que una NIIF exija o permita específicamente establecer categorias de partidas para las cuales podrian ser apropiadas diferentes políticas. Es importante mencionar que estas políticas no necesitan ser aplicadas cuando 
el efecto de su utilización no sea significativo. Sin embargo, no es adecuado dejar de aplicarlas.

La NIC 8 señala que en ausencia de una NIIF que sea aplicable específicamente a una transacción o a otros hechos o condiciones, la gerencia deberá usar su juicio en el desarrollo y aplicación de una política contable, con el propósito de suministrar información que sea:

(a) relevante para las necesidades de toma de decisiones económicas de los usuarios; y

(b) fiable, en el sentido de que los estados financieros presenten de forma fidedigna la situación financiera; reflejen la esencia económica de las transacciones, otros eventos y condiciones, y no simplemente su forma legal; sean neutrales y prudentes, y estén completos en todos sus extremos significativos.

Estas políticas deberán ser aplicables en relación con las normas debido a que los usuarios de los estados financieros tienen la necesidad de poder comparar los estados financieros de una entidad a lo largo del tiempo, con el propósito de identificar tendencias en su situación financiera, rendimiento financiero y flujos de efectivo.

\section{NIC 38 Activos intangibles}

Esta norma tiene como objetivo describir el tratamiento contable de los activos intangibles que no estén descritos específicamente en otra norma. Asimismo, detalla el tratamiento contable de la valorización de estos activos intangibles y la forma de revelación en los estados financieros. El alcance de esta norma se aplica para todas las empresas al contabilizar los activos intangibles, excepto en los siguientes casos:

- Activos intangibles que estén tratados en otras normas.

- Activos financieros, definidos en la NIC 39 Instrumentos financieros: reconocimiento y valoración.

- El reconocimiento y valoración de activos para exploración y evaluación (véase la NIIF 6 Exploración y evaluación de recursos minerales). 
- Desembolsos relacionados con el desarrollo y extracción de minerales, petróleo, gas natural y recursos no renovables similares.

Para fines de este trabajo de investigación, esta norma internacional de contabilidad (NIC 38) no aplica como marco teórico ni como normativa contable para el tratamiento contable del sector hidrocarburos.

\section{FAS 19: Financial Accounting and Reporting by Oil and Gas Producing Companies}

El objetivo de la FAS 19 es definir criterios de tratamiento para las actividades relacionadas con la producción de petróleo y gas. No hace referencia a otras actividades relacionadas con el sector como el transporte, la refinación o la comercialización del recurso natural.

Esta norma describe que las empresas pertenecientes al sector hidrocarburos poseen activos especiales, los cuales deben ser capitalizados cuando se incurre en ellos.

Entre los costos admitidos como capitalizables están:

- Propiedades: incluye tanto las reservas no probadas como las probadas.

- Pozos y equipamientos e instalaciones relacionadas.

- Equipamientos e instalaciones de soporte utilizados en actividades de producción de petróleo y gas.

- Pozos, equipamientos e instalaciones incompletos.

Para los costos considerados como no capitalizables están:

- Gastos geológicos y geofísicos.

- Costo de retener propiedades no desarrolladas.

- Costo de perforar pozos exploratorios y pozos de prueba estratigráficos exploratorios que no han encontrado reservas probadas.

Los costos de adquisición de propiedades (intereses minerales en propiedades) no probadas deben ser capitalizados como "Propiedades no probadas». Estas 
propiedades deben tener un análisis periódico con el propósito de determinar su viabilidad de extracciones futuras. En caso se encuentren reservas probadas que sean atribuidas a propiedades, los costos de adquisición de estas deben ser reclasificados como «Propiedades probadas» para su posterior amortización.

Los costos de perforación y equipamiento de pozos exploratorios y de perforación de pozos estratigráficos exploratorios deben ser capitalizados si el pozo encuentra reservas probadas; los costos deben pasar a ser parte de pozos, equipamientos e instalaciones relacionados con la empresa (aunque no sea completado como pozo productor). Por otra parte, en caso de no encontrar reservas probadas, los costos deben ser reclasificados a gastos.

Los costos en la etapa de desarrollo deben ser capitalizados, independientemente del éxito de los pozos. Estos costos pueden ser costos de perforación y construcción de los equipamientos e instalaciones, y deben ser incluidos en los costos de los pozos, equipamientos e instalaciones incompletos hasta el final de la perforación o hasta que la construcción esté completa.

\section{Provisiones por taponamiento de pozos}

La provisión por taponamiento de pozos no cuenta con una norma contable específica para su registro; sin embargo, ya existe normativa que regula y determina el tratamiento en aspectos técnicos y tributarios.

A continuación, se presentan las normas analizadas en lo que concierne al tratamiento de la provisión por taponamiento de pozos:

NIC 37 Provisiones, activos y pasivos contingentes

Esta norma señala que las provisiones pueden distinguirse de otros pasivos, tales como los acreedores comerciales y otras obligaciones acumuladas (o devengadas) que son objeto de estimación. Esto se debe a la existencia de incertidumbre acerca del momento del vencimiento o de la cuantía de los desembolsos futuros necesarios para proceder a su cancelación.

La NIC 37 destaca las condiciones fundamentales que debe cumplir una provisión para ser reconocida como tal:

- una entidad tiene una obligación presente (ya sea legal o implícita) como resultado de un suceso pasado; 
- es probable que la entidad tenga que desprenderse de recursos, que incorporen beneficios económicos para cancelar tal obligación; y

- puede hacerse una estimación fiable del importe de la obligación.

Esta norma también da un alcance sobre cómo tener una mejor estimación de las provisiones.

Las provisiones deben ser objeto de revisión al final de cada período sobre el que se informa, y ajustadas consiguientemente (mediante una tasa de descuento corriente de mercado) para reflejar en cada momento la mejor estimación disponible. En el caso de que no sea ya probable la salida de recursos que incorporen beneficios económicos, para la cancelación de la obligación correspondiente, se procederá a liquidar o revertir la provisión.

CINIIF 1 Cambios en pasivos existentes por retiro del servicio, restauración y similares

Muchas entidades tienen la obligación de desmantelar, retirar y restaurar elementos de sus propiedades, planta y equipo.

En esta interpretación, dichas obligaciones se denominan "pasivos por retiro del servicio, restauración y similares». Esta norma se aplica ante cambios en la medición de cualquier pasivo existente por retiro de servicio o restauración.

Esta CINIIF detalla cómo se debe realizar el tratamiento contable en las siguientes situaciones:

- Modificación de salida estimada de recursos que incorporan beneficios económicos.

- Cambio en la tasa de descuento.

- Algún incremento que refleje el paso del tiempo

La contabilización de estos pasivos variará dependiendo de la forma de la medición del activo.

- Activo valorizado por el método del costo

Los cambios en el pasivo aumentarán o disminuirán del costo del activo correspondiente. Cabe mencionar que la disminución del activo no deberá ser 
mayor que el valor en libros que este tenga; en caso sea mayor, se reconocerá la pérdida en el estado de resultados.

\section{- Activo valorizado por el método de revaluación}

Ante una disminución en el pasivo, se reconocerá en otro resultado integral e incrementará el superávit en el patrimonio. En caso contrario, ante un aumento en el pasivo, se reconocerá en resultados, excepto que sea reconocido en otro resultado integral, luego de disminuir en el patrimonio. Asimismo, en caso la disminución del pasivo sea mayor que el valor en libro del activo, la diferencia será reconocida en resultados.

\section{NIIF 13 Medición del valor razonable}

Se define como valor razonable «el precio que sería recibido por vender un activo o pagado por transferir un pasivo en una transacción ordenada entre participantes de mercado en la fecha de la medición».

FAS 143 Accounting for Asset Retirement Obligations (ARO)

Esta norma señala que, a partir del reconocimiento inicial de un pasivo por la obligación de retiro de activos, la entidad tiene que capitalizar un costo de retiro de activos, aumentando el valor en libros del activo de larga vida relacionado con la misma cantidad que el pasivo.

Una entidad debe asignar ese costo de retiro de activos al gasto mediante un método sistemático y racional durante su vida útil. La aplicación de un método de distribución sistemática y racional no se opone a que una entidad capitalice una cantidad de costos de retiro de activos, junto con la asignación de una cantidad igual a resultados en el mismo período contable.

La entidad debe medir los cambios en el pasivo por una obligación de retiro de activos según el paso del tiempo, mediante la aplicación de un método de interés de la asignación de la cantidad de la deuda a principios de la época. La tasa de interés utilizada para medir este cambio debe ser la tasa ajustada por riesgo de crédito gratuito que existía cuando el pasivo, o parte de este, se valoró inicialmente. 
Esa cantidad (cambio en el monto del pasivo) se reconocerá como un incremento en el valor en libros del pasivo y como un gasto en el estado de resultados.

\section{Métodos de depreciación utilizados}

Para la contabilización de la depreciación y amortización de los activos correspondientes a pozos petroleros y costos de exploración, se analizaron las siguientes normas contables:

\section{NIC 16 Propiedades, planta y equipo}

Esta norma tiene como objetivo describir el tratamiento contable de inmovilizado material para que los usuarios de los EE. FF. puedan conocer la inversión y los cambios que la entidad ha realizado. Asimismo, esta norma tiene como finalidad atacar los problemas que se derivan del reconocimiento del efecto contable.

La norma también hace mención a las formas de valorar el activo luego de su reconocimiento:

- Modelo del costo: se contabilizará de acuerdo al valor de adquisición menos la amortización acumulada y las pérdidas por deterioro.

- Modelo de revalorización: se contabilizará al valor razonable menos la amortización acumulada y el importe acumulado de pérdidas.

- La amortización y la vida útil de las partes de un activo en conjunto pueden ser calculadas de manera separada si es que se les puede identificar de manera fácil y son significativas.

\section{FAS 19 Financial Accounting and Reporting by Oil and Gas Producing Companies}

Los costos capitalizados de los pozos exploratorios que han encontrado reservas probadas y los costos de desarrollo capitalizados se depreciarán por el método de unidades de producción, de manera que a cada unidad producida se le asigna una parte proporcional de los gastos no depreciados.

Bajo dicho método, la depreciación puede ser calculada sobre una base propiedad-por-propiedad o sobre la base de cierto grado de agregación razonable de propiedades con una característica estructural común o condición geológica 
estratigráfica, tal como un depósito o campo. El costo unitario se calculará sobre la base del total de unidades estimadas de reservas probadas desarrolladas, y no sobre la base de todas las reservas probadas, que es la base para la depreciación de los costos de adquisición de propiedades probadas. Si se incurre en costos de desarrollo significativos en relación con un grupo previsto de pozos de desarrollo antes de que todos los pozos planificados sean perforados, será necesario excluir una parte de estos costos de desarrollo en la determinación de la tasa de depreciación hasta que se perforen los pozos de desarrollo adicionales. Del mismo modo, será necesario excluir, en el cálculo de la tasa de depreciación, las reservas probadas desarrolladas que se producen solo después de incurrir en costos adicionales de desarrollo importantes, como los sistemas de recuperación mejorada. Asimismo, los coeficientes de amortización deben ser recalculados cuando existan revisiones o al menos una vez al año, y registrados como cambios en las estimaciones.

\section{Normas especializadas en el sector hidrocarburos}

Se ha analizado la siguiente normativa especializada en el sector hidrocarburos.

- Decreto Supremo N. ${ }^{\circ}$ 084-98-EF - Reglamento del Decreto Legislativo N. ${ }^{\circ}$ 818, que estableció normas aplicables a empresas que suscriban contratos con el Estado para exploración, desarrollo y/o explotación de recursos naturales.

- Decreto Supremo N. ${ }^{\circ}$ 032-2004-EM - Reglamento de las Actividades de Exploración y Explotación de Hidrocarburos.

- Decreto Supremo N. ${ }^{\circ}$ 084-98-EF - Reglamento del Decreto Legislativo N. ${ }^{\circ}$ 818, que estableció normas aplicables a empresas que suscriban contratos con el Estado para exploración, desarrollo y/o explotación de recursos naturales.

- Decreto Supremo N. ${ }^{0}$ 042-2005-EM - Texto Único Ordenado de la Ley Orgánica de Hidrocarburos.

Estas normas mencionadas son las que regulan al sector hidrocarburos, y tratan diferentes aspectos, como métodos y parámetros que se tienen que cumplir para realizar todo el proceso en el sector. Sin embargo, no brindan mayor información en especificaciones de carácter contable para las empresas del sector, lo 
cual deja un vacío normativo muy amplio, sujeto a distintas interpretaciones, en el tratamiento contable de las empresas de hidrocarburos.

La Ley Orgánica de Hidrocarburos trata temas generales de regulación del sector en el territorio nacional. Define la palabra hidrocarburos como todo compuesto orgánico, gaseoso, líquido o sólido, que consiste principalmente de carbono e hidrógeno. Se indica que el Ministerio de Energía y Minas y Osinergmin son las entidades reguladoras encargadas de velar por el cumplimiento de la ley; que Osinerg es el organismo encargado de fiscalizar los aspectos legales y técnicos de las actividades de hidrocarburos; y que Perupetro S. A. es la empresa estatal del derecho privado del sector energía y minas.

El Estado otorga a Perupetro S. A. el derecho de propiedad sobre los hidrocarburos extraídos para el efecto de que pueda celebrar contratos de exploración y explotación o de explotación de estos.

Los contratos pueden ser de dos tipos principalmente:

a) Contrato de licencia: donde el contratista obtiene la autorización de explorar y explotar o explotar hidrocarburos en el área de contrato, en mérito del cual Perupetro S. A. transfiere el derecho de propiedad de los hidrocarburos extraídos al contratista, quien debe pagar una regalía al Estado.

b) Contrato de servicios: donde el contratista ejercita el derecho de llevar a cabo actividades de exploración y explotación o explotación de hidrocarburos en el área de contrato, recibiendo el contratista una retribución en función de la producción fiscalizada de hidrocarburos.

c) Otras modalidades de contratación autorizadas por el Ministerio de Energía y Minas.

Según el artículo 22. de la Ley Orgánica de Hidrocarburos, los contratos contemplarán dos fases: la de exploración y la de explotación.

a) Para la fase de exploración, se otorgan hasta 7 (siete) años contados a partir de la fecha efectiva establecida en cada contrato. En caso excepcionales, se podrá autorizar una extensión del plazo de la fase de exploración hasta en 3 (tres) años, siempre que el contratista haya cumplido estrictamente el programa mínimo garantizado previsto en el contrato y además se comprometa a la ejecución de un programa de trabajo adicional que justifique la 
extensión del plazo y que esté garantizado con una fianza, a satisfacción del contratante.

b) Para la fase de explotación:

1) Tratándose de petróleo crudo, hasta completar treinta (30) años, contados desde la fecha efectiva del contrato.

2) Tratándose de gas natural no asociado y de gas natural no asociado y condensados, hasta completar cuarenta (40) años, contados a partir de la fecha efectiva del contrato. El plazo del contrato podrá extenderse para incluir los períodos de retención que se acuerden. La suma de los períodos de retención no podrá ser mayor de diez (10) años.

Además, en el artículo $390^{\circ}$ se menciona que el contratista tendrá la libre disponibilidad de los hidrocarburos y podrá exportarlos libre de todo tributo, incluyendo aquellos que requieren mención expresa. Los contratistas estarán sujetos al régimen tributario común del impuesto a la renta.

Dada la normativa actual, se percibe que su alcance es limitado; en este sentido, no se ha podido encontrar un detalle de especificaciones o parámetros que permitan a las empresas de hidrocarburos calcular sus provisiones de reservas de la manera más acertada, explícita y regulada, además de especificaciones que permitan registrar de manera correcta los costos implicados en el taponamiento de pozos.

Asimismo, el Reglamento de las Actividades de Exploración y Explotación de Hidrocarburos describe todas las normas y los lineamientos por seguir en los temas de seguridad, salud y ambiente, que deben cumplir las empresas para su adecuada gestión.

Por otra parte, el documento menciona en el título III, referido a las actividades de explotación, que son consideradas como tales estudios geográficos, estudios geológicos, perforación y compleción de pozos y pruebas de producción.

Además, describe las actividades del uso de explosivos y la perforación de pozos, las cuales deben realizarse de acuerdo a las medidas de seguridad establecidas y bajo supervisión de las entidades reguladoras. Es importante mencionar los siguientes puntos para un mejor entendimiento del tema de hidrocarburos en el tema de abandono del pozo: 
Artículo 193.: El abandono del pozo tendrá que ser aprobado por Perupetro.

Artículo $194 .^{\circ}$ : Tapones de abandono - El pozo debe abandonarse con tapones de cemento o mecánicos, aislando las zonas en las que no se haya puesto revestimiento o donde pudieran existir fluidos.

Artículo $193 .^{\circ}$ : Tapones adicionales - El pozo puede requerir tapones adicionales para cubrir o contener un horizonte productivo o para separar algún estrato de agua.

Artículo 196. ${ }^{\circ}$ : Taponamiento de hueco abierto bajo el revestimiento - Donde exista hueco abierto bajo el revestimiento más profundo se debe colocar un tapón de cemento.

Artículo 200.: Tapones en caso de abandono permanente - Se colocará un tapón de cemento desde los 200 metros de profundidad hasta la superficie.

Artículo 207. ${ }^{\circ}$ : Listado de clasificación de pozos - El contratista deberá brindar información a Perupetro, con copia a Osinerg, sobre el listado de los pozos inactivos (cerrados, abandonados temporalmente, abandonados permanentemente).

Por último, es importante mencionar los lineamientos por seguir en las actividades de producción y medición de hidrocarburos fiscalizados descritas por el documento. Para el caso de las actividades de producción, se mencionan los siguientes artículos relevantes:

Artículo 250.: Registro de producción por pozo - El contratista llevará por cada pozo un registro de la producción de los fluidos, así como la indicación de los servicios y eventos realizados durante su vida productiva.

Artículo 258. : Servicio de pozo - Cuando en un pozo sea necesario realizar un trabajo de reparación, rehabilitación o reacondicionamiento, se planeará el trabajo basado en los problemas encontrados.

Asimismo, en cuanto a la medición de hidrocarburos fiscalizados, se destacan los siguientes artículos:

Artículo 278. ${ }^{\circ}$ : Petróleo fiscalizado - La medición y fiscalización de los hidrocarburos provenientes del área de contrato deberá efectuarse en la frecuencia 
acordada en los puntos de fiscalización de la producción establecidos en el contrato, mediante aforo o medición automática. Los hidrocarburos fiscalizados medidos se registrarán en las boletas respectivas.

Artículo 286. ${ }^{\circ}$ : Aplicación de normas - Los procedimientos para aforo, muestreo, medición y fiscalización y control de calidad de hidrocarburos se regirán de acuerdo a las normas API, ASTM y AGA correspondientes.

Cabe resaltar que los lineamientos descritos en esta norma no hacen referencia a los cálculos de medición de reservas de petróleo, ni a temas de tratamientos contables, como, por ejemplo, ajustes ante variaciones de depreciación de pozos y provisiones de estos.

\section{Análisis de los tratamientos contables}

En el siguiente punto de la presente investigación, se presentan las diferencias encontradas de las incidencias contables antes descritas. Para poder realizar esta comparación, se realizaron entrevistas y análisis a las siguientes empresas: Maple Gas Corporation S. R. L., Petrolera Monterrico S. A., Savia Perú S. A. y Olympic Perú Inc.

\section{Tratamiento de costos previos a la explotación}

Para analizar los tratamientos contables para el registro de los costos previos a la explotación, es importante tener en cuenta las etapas en el proceso de extracción de combustibles.

Hemos identificado dos métodos de registro, adoptados como políticas contables por las empresas analizadas. A continuación, se describirán los métodos encontrados, los cuales son aceptados por las Normas Internacionales de Información Financiera (NIIF):

\section{- Método de costeo total}

Dentro del método del costeo total, las empresas Maple Gas Corporation S. R. L. y Petrolera Monterrico S. A. capitalizan todos los costos incurridos en la exploración y el desarrollo de los hidrocarburos. A continuación, se presenta una descripción del método mencionado. 
Dentro de este método, la empresa considera el total del área geográfica designada para la extracción como una única unidad de producción (centro de costo). En esta unidad de producción, se encuentran diversas cantidades de pozos mediante los cuales la empresa obtiene el combustible luego del proceso de extracción.

Cabe mencionar que, con este método, todos los costos de exploración son capitalizados, independientemente de si estén asociados al descubrimiento de un mayor nivel de reservas en un pozo específico, pues se asume que el costo incurrido en explorar esa zona igualmente tiene una contribución en el descubrimiento de reservas en una zona o en algún pozo aledaño.

Otro aspecto importante de este método es que la empresa considera como parte del activo el nivel total de reservas probadas, el cual incluye las reservas desarrolladas y no desarrolladas. Se entiende como reservas desarrolladas a las que poseen nivel de recursos existentes dentro de la zona geográfica en la cual la empresa tiene derecho de extracción; asimismo, aquellas de las que se tiene la posibilidad de extraer el recurso con la inversión ya realizada. Las reservas no desarrolladas también corresponden al nivel de recursos existentes, pero sobre los cuales la empresa necesita realizar una inversión mayor para poder extraerlos.

En cuanto a la inversión realizada en los estudios de geología y geofísica, que son los costos más importantes en la etapa de exploración, estos sí son capitalizados en este método.

\section{- Método de esfuerzos exitosos}

A diferencia del método de costeo total, Savia Perú S. A. y Olympic Perú Inc. utilizan el método de esfuerzos exitosos, donde capitalizan únicamente los costos de exploración en los cuales se haya obtenido un resultado positivo en el descubrimiento de un mayor nivel de reservas. Se requiere una relación de causa-efecto entre los costos en que se ha incurrido y el descubrimiento de reservas específicas. Por el contrario, si se incurre en un costo sin un beneficio futuro identificable, se carga a gastos en el estado de resultados.

El método de esfuerzos exitosos considera a la propiedad, proyecto o lote como centro de costo. Esto quiere decir que, a diferencia del método de costeo total, en este método la empresa divide el total del área geográfica designada para la 
extracción en diversas zonas de producción, sobre las cuales se evalúa el éxito o el fracaso de un trabajo de exploración por separado.

Cabe resaltar que, dentro de este método, se considera como parte del activo únicamente el nivel de reservadas probadas y desarrolladas. Asimismo, los gastos de exploración no son capitalizados como parte del activo.

Por otra parte, toda renovación y mejora significativa se capitaliza únicamente cuando es probable que se produzcan beneficios económicos futuros que excedan el rendimiento estándar originalmente evaluado para el activo. En consecuencia, los desembolsos posteriores son capitalizados solo cuando estos generen beneficios económicos relacionados con el desarrollo de bienes o reemplacen parte del desarrollo actual. En caso contrario, dichos desembolsos se registran como gasto.

Otra diferencia identificada sobre la base de la revisión de las empresas mencionadas es que Olympic Perú Inc. valoriza sus activos petroleros a valor razonable, a diferencia del resto de las compañías, que efectúan esta valorización al costo.

\section{- Concordancias entre los métodos: costeo total y esfuerzos exitosos}

Se ha identificado que es una práctica común de las empresas analizadas, el realizar una evaluación de desvalorización al 31 de diciembre de cada año sobre los activos intangibles aún no utilizados en la producción. Para el resto de activos no financieros, dicha evaluación es realizada cuando existen indicios de que su valor en libros no puede ser recuperado. Asimismo, cuando el importe en libros de un activo o de una unidad generadora de efectivo excede su importe recuperable, el activo se considera deteriorado y su valor se reduce a su importe recuperable.

Por otra parte, en ambos métodos, todos los costos de producción son cargados a resultados del período corriente a medida que el petróleo y el gas se van vendiendo.

\section{Provisiones por taponamiento de pozos}

Para la determinación del importe de la provisión, las empresas necesitan definir supuestos y estimados en relación con las tasas de descuento y el costo 
esperado para el taponamiento de pozos. Por lo general, el costo de retiro de activos es estimado por un proveedor técnico especializado, el cual calcula el valor presente utilizando flujos de caja estimados.

Se reconoce una partida de activo fijo por un monto equivalente a la provisión, la cual es posteriormente depreciada como parte de los costos de capital de la instalación o del equipo.

Los costos futuros estimados de retiro se revisan anualmente y se ajustan según corresponda, incrementando o reduciendo el monto registrado como provisión en el pasivo directamente contra el resultado de la empresa del período correspondiente. Dichos costos pueden variar por diversos factores, entre los cuales se encuentran los cambios en los costos futuros estimados o en la tasa de descuento utilizada por la empresa.

La tasa de descuento utilizada por las empresas analizadas es usualmente la tasa libre de riesgo del mercado en el cual se opera. También se puede utilizar la tasa libre de riesgo del Tesoro estadounidense, a la cual se le debe sumar el efecto de la tasa de riesgo país correspondiente.

Dentro de la provisión por taponamiento de pozos, las empresas analizadas realizan el registro bajo la misma metodología, tanto para los registros iniciales como para los ajustes correspondientes a la actualización de la provisión.

Se ha identificado que la principal diferencia en el monto provisionado puede ser originada por la elección del método de registro de costos previos a la explotación utilizado por cada empresa. Esto se debe a que si la empresa utiliza el método del costeo total, el cual considera como total de reservas tanto las desarrolladas como las no desarrolladas, los flujos estimados de esta considerarán un horizonte de tiempo mayor en comparación con la empresa que utilice el método de costeo de esfuerzos exitosos, ya que en este caso solo se considera el nivel de reservas desarrolladas.

\section{Métodos de depreciación y amortización utilizados}

En cuanto a la depreciación y amortización, se ha identificado que las empresas analizadas utilizan el método de unidades de producción para el cálculo de 
la depreciación y amortización de sus pozos y activos intangibles, basado en reservas probadas.

Es importante tener en consideración que los cambios en la cantidad de las reservas podrían tener como consecuencia cambios en los gastos de depreciación y amortización, tanto en el período de ocurrencia de dichos cambios, como en los períodos siguientes. Asimismo, podrían originar un deterioro de los valores en libros en los rubros de activo fijo y activos intangibles. Cada año se realiza el ajuste de amortización con el resultado de los niveles de reservas, sobre la base de la producción del año como una proporción de las reservas al inicio del período de amortización.

Se ha podido identificar que, al igual que en el punto anterior, la principal diferencia en el registro de la depreciación y amortización en las empresas analizadas es generada como consecuencia del método de costeo que adopte dicha empresa como política contable. En caso se utilice el método de esfuerzos exitosos, la empresa debe calcular la proporción de la producción del año sobre la base de las reservas probadas y desarrolladas. Posteriormente, dicho cálculo es utilizado como un factor, el cual es aplicado al valor en libros de las reservas petroleras actuales, con el objetivo de poder determinar el nivel de reservas iniciales de manera retrospectiva y así actualizar el importe de depreciación de los pozos y activos petroleros.

Del lado contrario, si la empresa utiliza el método del costeo total, el cálculo del factor mencionado anteriormente puede ser equivalente a la proporción de la producción sobre el nivel de reservas probadas, tanto desarrolladas como no desarrolladas. En este caso, este factor debe ser aplicado al valor en libros, más el monto estimado de inversión que requerirán las reservas no desarrolladas para poder ser extraídas.

Cabe mencionar que las empresas que utilicen el método de costeo total pueden elegir si aplicar o no la forma de cálculo para determinar la depreciación y/o amortización descrita en el párrafo anterior, debido a que también cuentan con la opción de utilizar exactamente el mismo método que el usado por las organizaciones que aplican el método de esfuerzos exitosos, es decir, no considerar el nivel de reservas no desarrolladas ni el monto estimado de inversión para extraer dichas reservas, como es el caso de la empresa Petrolera Monterrico S. A. 


\section{Planteamiento de propuestas}

Sobre la base de la información desarrollada en los puntos anteriores, se describen las principales diferencias identificadas en las operaciones contables analizadas. Asimismo, se presentan las propuestas para contar con un tratamiento contable uniforme.

\section{Costos previos a la explotación}

\section{Diferencias halladas}

Se ha identificado que la principal diferencia en el tratamiento de los costos previos de explotación es la elección entre el método de costeo total y el método de esfuerzos exitosos. Esta elección del tipo de costeo genera una diferencia en el nivel de activos petroleros considerados por la empresa, lo cual impide que exista una perfecta comparabilidad entre los estados financieros de las empresas que apliquen diferentes políticas contables.

Asimismo, las empresas analizadas registran dichos costos al valor razonable, lo cual es aceptado por las normas internacionales de información financiera (NIIF 13), pero difiere de la práctica común de las empresas del sector, las cuales registran sus activos petroleros al costo.

\section{Propuesta planteada}

Se propone que las empresas del sector hidrocarburos deberían optar por la aplicación del método de esfuerzos exitosos para el registro de sus activos petroleros. Con este método, las compañías del sector analizado deberían registrar los costos de exploración como gastos, hasta el momento en el cual exista la certeza de la existencia de reservas probadas y desarrolladas, descubiertas como consecuencia de lo invertido en exploración.

Se considera este registro como el más apropiado y conservador, debido a que se tendría la seguridad de la existencia de beneficios económicos futuros relacionados con el gasto efectuado para que este sea capitalizable y forme parte del activo. Esta es una condición mencionada en la NIC 38 para la capitalización de un activo intangible. 
Finalmente, la FAS 19 recomienda que los costos de exploración destinados a determinar la existencia o no de reservas naturales, sean reconocidos como resultados, asumiendo que no haya probabilidad de su contribución en los ingresos, lo cual es consistente con la propuesta planteada.

Por último, se propone que los activos petroleros sean registrados al costo, según lo recomendado por la NIIF 6.

\section{Provisión de taponamiento de pozos}

\section{Diferencias halladas}

Se considera que la principal diferencia se origina en los supuestos utilizados por la empresa en el momento de registrar la actualización del modo de la provisión, pues dicho registro debe ser realizado sobre la base del valor presente de los flujos de caja estimados, descontados a una tasa de descuento específica.

La base contable que siguen las empresas para registrar los costos de abandono y de restauración del medio ambiente está dada por la NIC 16 Propiedades, planta y equipo, y la NIC 37 Pasivos contingentes y activos contingentes, por lo que es de suma importancia que todas las compañias consideren la provisión inicial como parte del activo de la empresa y que actualicen la provisión correspondiente al final de cada período, según lo requerido por las normas contables mencionadas.

Asimismo, otra diferencia importante se origina, al igual que en el punto anterior, por la elección del método de registro de los costos de exploración, la cual genera una diferencia importante en el momento del registro y la actualización de la provisión.

\section{Propuesta planteada}

Debido a lo mencionado en el punto anterior, se considera importante que todas las compañías del sector utilicen la misma tasa de descuento, la cual debería ser la tasa libre de riesgo, ya sea la del Tesoro estadounidense, si la empresa tiene como moneda funcional el dólar; o la tasa de los bonos soberanos que emite el Estado peruano, si la empresa presenta sus estados financieros en nuevos soles. 
Estos parámetros son utilizados por la totalidad de las empresas analizadas, pero no es una obligación por parte de ellas, lo cual podría dejar un espacio abierto a la utilización de otro tipo de tasa de descuento.

Asimismo, los flujos de caja estimados deberían ser calculados por todas las compañías del sector sobre la base de las reservas probadas y desarrolladas, bajo el supuesto de que la empresa esté aplicando el método de esfuerzos exitosos.

\section{Métodos de depreciación y amortización}

\section{Diferencias halladas}

En lo referente al cálculo de la depreciación y/o amortización de los activos petroleros, la principal diferencia identificada es originada por la elección de la metodología contable de costeo que utilizan las empresas del sector.

En caso la empresa utilice el método del costeo total, la depreciación será registrada a un único centro de costo y la fórmula de la depreciación/amortización de los costos de adquisición de propiedades y de los costos de exploración y desarrollo es calculada de la siguiente manera:

$$
\begin{gathered}
\text { [Valor residual + Costos futuros de desarrollo + Costos de abandono] } \\
\text { X Producción }
\end{gathered}
$$

Reservas probadas al inicio del período

Este método incluye la totalidad de las reservas probadas y los costos futuros de desarrollo.

Por otro lado, si la política contable de la compañía implica utilizar el método de esfuerzos exitosos, la depreciación será dividida entre los centros de costos correspondientes a cada proyecto, pozo petrolero, etc.; y la fórmula de cálculo para la depreciación de los pozos petroleros será la siguiente:

[Valor residual + Costos de abandono] x Producción

Reservas probadas y desarrolladas al inicio del período 
Cabe mencionar que las empresas que utilicen el método de costeo total pueden optar por utilizar cualquiera de las dos fórmulas presentadas para la actualización del monto de depreciación sobre la base de los cambios en los niveles de reservas.

\section{Propuesta planteada}

Se propone que la depreciación y/o amortización de los activos petroleros debe ser calculada sobre la base de la cantidad de reservas consideradas como parte del activo de la empresa. Es decir, si la empresa, dentro del método de costeo total, efectúa la capitalización de la totalidad de reservas probadas, el cálculo del factor de ajuste de depreciación debería considerar el mismo nivel de reservas.

$\mathrm{Al}$ igual que en el punto anterior, la propuesta inicial de adoptar el método de esfuerzos exitosos para el registro de los costos de exploración, debería tener como consecuencia que todas las compañias del sector utilicen el nivel de reservas probadas y desarrolladas para la actualización de la depreciación y/o amortización de los activos petroleros.

\section{Conclusiones}

- A partir del análisis previo, se ha identificado que no existe ninguna norma contable especializada y exclusiva que regule el tratamiento contable de las empresas del sector hidrocarburos. Los decretos supremos desarrollados para este sector no describen procedimientos ni normas contables, sino más bien detallan procedimientos y parámetros por seguir para las diferentes actividades involucradas, como temas de medio ambiente, salud y uso de maquinaria, entre otros.

- Existe evidencia de que el tratamiento contable en este tipo de empresas en el Perú está basado en las políticas contables establecidas internamente por cada empresa y/o normas contables generales; esto puede traer como consecuencia que existan diferencias en la contabilidad y, por ende, en los estados financieros de estas empresas; y que esto perjudique los resultados en situación de comparabilidad de la competencia. 
- La falta de normativa contable del sector analizado permite que las empresas utilicen su propio criterio para el registro de algunas transacciones. Esto hace que disminuya la confianza y la seguridad de inversionistas externos en el momento de tomar una decisión de inversión en el sector petrolero.

- Existe una tendencia mundial que busca adaptar las normas contables, con el objetivo de presentar información financiera comparable y estandarizada en todo el mundo. Luego de realizar la investigación, se puede apreciar que existen diferencias en los parámetros utilizados por las empresas del sector hidrocarburos. Si bien en el presente trabajo se han encontrado diferencias específicas entre los registros contables de las empresas del sector hidrocarburos, la información contable y financiera de las empresas de dicho sector podría ser aún más homogénea con normativa contable especializada. 


\title{
2. La aplicación de las normas contables y tributarias en los sectores construcción e inmobiliario para la correcta determinación del impuesto general a las ventas y del impuesto a la renta
}

\author{
Carmen Carrillo \\ Cecilia Figueroa \\ Mary Takehara
}

\section{Resumen}

Los sectores construcción e inmobiliario han mostrado un gran dinamismo desde mediados de la década pasada; sin embargo, su desarrollo se ha dado sobre bases débiles en materia conceptual y normativa, generando confusión en los empresarios en el momento de determinar sus impuestos.

Por ello, el objetivo de la presente investigación es desarrollar un compendio de las normas contables y tributarias que permita a las personas interesadas en los sectores construcción e inmobiliario, y público en general, contar con un marco conceptual y normativo adecuado para registrar sus operaciones, con el propósito de determinar en forma adecuada la base imponible para el cálculo del impuesto general a la ventas y del impuesto a la renta, y de esta manera optimizar los beneficios de sus proyectos.

La metodología utilizada para el desarrollo de la investigación fue la recolección de información de fuentes primarias y secundarias, para su posterior análisis. Como fuente de información primaria, consideramos las entrevistas realizadas a expertos, ejecutivos y contadores que laboran en empresas de los sectores construcción e inmobiliario, con la finalidad de obtener de primera mano sus experiencias y opiniones respecto a temas contables y tributarios relacionados con los sectores antes mencionados. Como fuente de información secundaria hemos considerado principalmente las Normas Internacionales de Contabilidad 11 y 18 ; la ley y el reglamento del impuesto general a las ventas e impuesto a la renta; e investigaciones existentes sobre los temas materia de la investigación.

Luego de realizado el análisis de la información recopilada, una de nuestras conclusiones fue que las normas contables y tributarias, por sí solas, no son 
suficientes para que las empresas de los sectores construcción e inmobiliario puedan determinar de forma adecuada su impuesto general a las ventas e impuesto a la renta, debido principalmente a que en ellas no existe una buena definición de las actividades que desarrollan las empresas de cada sector, dando lugar a que se genere confusión sobre la metodología que deben aplicar las empresas constructoras e inmobiliarias para la determinación de sus impuestos.

\section{Introducción}

Desde mediados de la década pasada, la industria de la construcción en el Perú ha mostrado un crecimiento sostenido, posicionándose como una de las actividades económicas más importantes y dinámicas de la economía peruana. El desarrollo de esta industria se ha convertido en un indicador del bienestar económico, en la medida en que es el reflejo de las mayores inversiones tanto del sector público como del privado, y del incremento de los ingresos familiares, como consecuencia del crecimiento económico.

Según las estadísticas del Banco Central de Reserva ${ }^{1}$, el sector construcción ha crecido a una tasa promedio de 11\% entre los años 2005 y 2011, logrando un pico de 17,4\% en 2010, pero con caídas a cifras de un dígito en 2009 y 2011, producto de la crisis financiera internacional. La proyección del crecimiento de este sector para el presente año es de 12\%, continuando con tasas de alrededor de $8 \%$ para los siguientes períodos.

Lo interesante del crecimiento del sector construcción es que su dinamismo ha contribuido al crecimiento de otras industrias y sectores con los que tiene una relación directa. Tal es el caso de las industrias del cemento, de acabados, de instalaciones eléctricas, entre otras, que se han visto favorecidas con el boom de la industria de la construcción. Por otro lado, al ser una actividad tan intensiva en mano de obra, ha generado miles de puestos de trabajo, contribuyendo al incremento de los ingresos familiares. Del mismo modo, el sector inmobiliario se ha visto favorecido gracias al crecimiento de los créditos hipotecarios otorgados por las entidades financieras.

El crecimiento de la industria de la construcción en el Perú está caracterizado básicamente por la construcción de viviendas y centros comerciales. En los 
últimos años, la construcción de viviendas ha estado enfocada en la clase media-alta, pero hoy, gracias a la mejora de las condiciones de los créditos hipotecarios con tasas de interés y cuotas asequibles, y a los programas de vivienda sociales desarrollados por el Estado, el foco de las constructoras se encuentra en la clase media-baja y baja, lo cual las obliga al desarrollo de megaproyectos de vivienda para poder sacar provecho a las economías de escala y ofrecer un producto económico.

A pesar de las miles de viviendas que se han construido en los últimos años, aún existe una demanda insatisfecha en el país. Según lo indicado por el Banco de Crédito del Perú al diario Gestión, «se construyen un total de 50 mil viviendas, mientras que cada año se forman 100 mil hogares»². Esto nos indica que la industria de la construcción e inmobiliaria tiene todavía un amplio campo de acción.

En ese sentido, ante sectores tan dinámicos, en los cuales los montos de inversión son considerables y en los que no solo participan grandes empresas sino también personas que al tener un terreno se han visto atraídas a invertir en el rubro, hemos visto necesario el desarrollo de un compendio de las normas contables y tributarias, que permita a las personas interesadas en los sectores construcción e inmobiliario contar con el marco conceptual y normativo adecuado para registrar sus operaciones con el propósito de determinar en forma adecuada la base imponible para el cálculo del impuesto general a la ventas y del impuesto a la renta, y el posterior pago de estos.

\section{Planteamiento del problema}

\section{Área de la investigación}

La presente investigación se centrará en los temas de contabilidad y tributación en los sectores construcción e inmobiliario.

\section{Tema de la investigación}

La aplicación de las normas contables y tributarias en los sectores construcción e inmobiliario para la correcta determinación del impuesto general a las ventas y el impuesto a la renta.

2. <http://gestion.pe/2012/06/02/inmobiliaria/casashow-oferta-80-mercado-inmobiliario-pais-2004144>. 


\section{Problema de la investigación}

Cada sector económico tiene sus propias particularidades, y los de construcción e inmobiliario no son una excepción. Si bien existe una relación muy fuerte entre la actividad de construcción y la inmobiliaria, hay muchos factores que hacen que sean diferentes entre sí.

El problema que la presente investigación busca analizar, en primer lugar, está enfocado en que no hay una buena compresión de lo que implica ser una empresa constructora y una inmobiliaria, lo cual lleva a que se confundan los términos al referirse a un sector o al otro.

Luego, una vez enrumbados en el negocio y en la tarea de cumplir con la obligación de declaración del impuesto general a las ventas y el impuesto a la renta, surge el problema de falta de consenso en lo dispuesto por las normas contables y tributarias para el tratamiento contable-tributario que deben dar las empresas constructoras e inmobiliarias para el cálculo de los impuestos antes mencionados.

De esta manera, ante un panorama de falta de claridad de conceptos y de imprecisiones en las normas, las empresas corren el riesgo de aplicar de manera errada las normas contables y tributarias para efectos de la determinación del impuesto general a las ventas y el impuesto a la renta, y el posterior pago de estos.

\section{Hipótesis}

- Las empresas constructoras e inmobiliarias tienen confusión en el momento de decidir a qué régimen tributario deben acogerse de acuerdo con el giro propio de la empresa, lo que lleva a que en muchos casos el pago del impuesto a la renta se realice de forma incorrecta.

- El desarrollo de normas tributarias no se ha dado con la misma rapidez que el crecimiento mostrado en los sectores construcción e inmobiliario.

- La comunicación y el flujo de información del personal de campo (obra) y del área contable son fundamentales para el correcto registro de las operaciones con el propósito obtener una base adecuada para el cálculo de los impuestos.

- La rentabilidad de un proyecto inmobiliario puede verse afectada en forma negativa por no contar con una estrategia tributaria adecuada. 


\section{Objetivos}

\section{Objetivo general}

Desarrollar un compendio de las normas contables y tributarias que permita a las personas interesadas en los sectores construcción e inmobiliario contar con el marco conceptual y normativo adecuado para registrar sus operaciones, con el propósito de determinar en forma adecuada la base imponible para el cálculo del impuesto general a la ventas y del impuesto a la renta, y de esta manera optimizar los beneficios del proyecto.

\section{Objetivos específicos}

- Identificar el tratamiento contable y tributario aplicable a las empresas del sector construcción.

- Identificar el tratamiento contable y tributario aplicable a las empresas del sector inmobiliario.

- Determinar las discrepancias que existen entre la norma contable y la norma tributaria en los sectores construcción e inmobiliario.

- Comprender la importancia de la planificación tributaria para las empresas constructoras e inmobiliarias.

\section{Alcance}

La presente investigación se desarrollará a lo largo del ciclo académico 2012II (del 20 de agosto al 19 de noviembre) y se enfocará en las empresas de los sectores construcción e inmobiliario con las limitaciones del marco tributario de los impuestos detallados.

\section{Metodología}

En la presente investigación se utilizó información cualitativa y cuantitativa, que permitió generar información específica de los sectores construcción e inmobiliario a partir de una metodología establecida, la cual permitió establecer conclusiones que representan un aporte a las fuentes de información ya existentes para todas aquellas personas que estén interesadas en los temas planteados. 


\section{Fuentes de Información}

\section{Fuentes primarias}

Se consideraron como fuentes de información primaria las entrevistas a expertos, ejecutivos y contadores que laboran en empresas de los sectores construcción e inmobiliario, así como a profesionales dedicados al tema tributario. Con las entrevistas se buscó obtener de primera mano las experiencias de cada uno en los sectores mencionados, lo que permitió identificar los principales problemas tributarios a los que se enfrentan en el desarrollo de proyectos inmobiliarios.

- Entrevista a un consultor y asesor experto en los sectores construcción e inmobiliario.

- Entrevista a ejecutivos de empresas de los sectores construcción e inmobiliario.

- Entrevista a contadores de empresas de los sectores construcción e inmobiliario.

- Entrevista a tributaristas de los sectores construcción e inmobiliario.

\section{Fuentes secundarias}

Las fuentes secundarias se utilizaron como información complementaria y permitieron enriquecer la investigación mediante un análisis más completo y profundo. Los textos considerados fueron los siguientes:

- Norma Internacional de Contabilidad 11.

- Norma Internacional de Contabilidad 18.

- Código Tributario.

- T. U. 0. de la Ley del Impuesto General a las Ventas.

- Reglamento de la Ley del Impuesto General a las Ventas.

- T. U. 0. de la Ley del Impuesto a la Renta.

- Reglamento de la Ley del Impuesto a la Renta.

- Informes presentados por la Sunat.

- Resoluciones del Tribunal Fiscal.

- Tax \&t Legal Report de PwC.

- Otros trabajos de investigación relacionados con los temas de construcción e inmobiliario. 


\section{Análisis de la información}

Una vez consultadas las fuentes primarias y secundarias, se procesaron los datos más relevantes, estableciéndose así un marco conceptual de los sectores construcción e inmobiliario en cuanto al tema tributario (IGV e impuesto a la renta).

\section{Descripción de la actividad económica}

Como se mencionó en el planteamiento del problema, los sectores construcción e inmobiliario están muy relacionados entre sí, lo cual lleva a que se confundan los términos al referirse a un sector o el otro.

Lo cierto es que cada sector cuenta con características propias que dan lugar a tratamientos especiales en materia de la determinación del impuesto general a las ventas y del impuesto a la renta.

En el presente capítulo, se procederá a describir las particularidades de la actividad de construcción e inmobiliaria de forma detallada, de manera que los interesados en estas actividades tengan la base conceptual suficiente para introducirse sin mayor problema al mundo de los tributos.

\section{Actividad de construcción}

La actividad de construcción se encuentra ubicada en las divisiones 41, 42 y 43 de la Clasificación Industrial Internacional Uniforme (CIIU) de todas las actividades económicas de las Naciones Unidas - 4. ${ }^{a}$ Revisión.

Comprende, entre otras actividades, la construcción completa de viviendas, edificios de oficinas, locales de almacenes y otros edificios públicos y de servicios, locales agropecuarios, etc.; y la construcción de obras de ingeniería civil como carreteras, calles, puentes, túneles, líneas de ferrocarril, aeropuertos, puertos y otros proyectos de ordenamiento hídrico, sistemas de riego, redes de alcantarillado, instalaciones industriales, tuberías y líneas de transmisión de energía eléctrica, instalaciones deportivas, etc.

Por lo tanto, una empresa constructora es aquella que se dedica a edificar, fabricar o desarrollar obras públicas o privadas para terceros. Dentro de las obras públicas se encuentran las carreteras, los puentes, los aeropuertos y muchas 
otras. Dentro de las privadas se encuentran las que se dedican a desarrollar edificios, casas y urbanizaciones. En esto hay una diferencia muy leve y son pocas las empresas constructoras que se dedican a una u otra exclusivamente, y abundan las que hacen ambas actividades. Desde esa perspectiva, se puede observar que existen varios tipos de construcciones, pero para efectos de la presente investigación nos centraremos en la construcción de unidades de vivienda.

Luego de conocer qué es una empresa constructora, es importante comprender qué vende una empresa constructora.

Una empresa constructora vende el servicio de ejecución de un proyecto inmobiliario de acuerdo a las especificaciones del cliente para su propio uso o para la venta posterior.

Las empresas constructoras se rigen mediante un contrato de construcción que firman con el cliente y en el cual estarán especificadas todas las características y condiciones que debe tener la obra por ejecutar.

La actividad de construcción se encuentra dentro del marco contable de la Norma Internacional de Contabilidad (NIC) 11, donde se define el contrato de construcción como: «un contrato, específicamente negociado, para la fabricación de un activo o un conjunto de activos, que están íntimamente relacionados entre sí o son interdependientes en términos de su diseño, tecnología y función, o bien en relación con su último destino o utilización».

Mediante el contrato de construcción, el constructor se obliga a ejecutar una obra determinada, y el cliente, a pagarle una retribución; asimismo, se precisan los compromisos, obligaciones y responsabilidades de cada una de las partes.

Las modalidades de contrato más comunes son:

\section{a. Contrato a suma alzada}

En este sistema de contratación, la empresa formula su propuesta económica por un monto fijo integral y no está obligada a presentar el detalle de los precios unitarios de cada una de las partidas del proyecto. Lo que se acuerda entre las partes es que se ejecute una obra a cambio de un monto fijo como retribución y en un plazo establecido. Este tipo de contrato se da cuando las cantidades, magnitudes y calidades de la prestación estén 
totalmente definidas tanto en las especificaciones técnicas de los bienes por contratar, como en los términos de referencia de los servicios, y en los planos y especificaciones técnicas que forman parte del expediente técnico $^{3}$. El cliente pagará un precio fijo y cualquier modificación en el monto, que sea producto, por ejemplo, de variaciones en los precios de los materiales, será por cuenta y costo del constructor. En ese sentido, el constructor asume los riesgos o beneficios producto de factores externos que puedan afectar el monto del contrato.

\section{b. Contrato a precios unitarios}

Si bien los contratos a suma alzada se emplean cuando las cantidades del contrato son conocidas, los contratos a precios unitarios se utilizan cuando la naturaleza de la prestación no permite conocer con exactitud o precisión las cantidades o magnitudes de recursos requeridas. De esta manera, lo que se pacta son los precios unitarios para cada una de las partidas del presupuesto.

\section{c. Contrato de construcción por administración}

En un contrato de construcción por administración, el contratista (constructor) aportará únicamente los servicios de construcción; es decir, su experiencia profesional en la ejecución de la obra. Todo aquello referido a los materiales, mano de obra y demás elementos necesarios para la ejecución de la obra, será por cuenta y costo del comitente (cliente).

En este tipo de contrato, a diferencia de aquellos a suma alzada, los riesgos o beneficios producto de factores externos que puedan afectar el monto del contrato son asumidos por el comitente. El contratista emitirá facturas únicamente por los honorarios producto de los servicios prestados.

Por lo general, los contratos de construcción abarcan más de un ejercicio gravable, dependiendo de la envergadura del proyecto por desarrollar. Esta particularidad será de gran importancia para el reconocimiento de los ingresos y los costos para la posterior determinación del impuesto a la renta y la oportunidad de los pagos a cuenta, como veremos más adelante.

3. <http://www.perucontrata.com.pe>. Pacheco Claros, Iris. "Contratando a suma alzada". 


\section{Actividad Inmobiliaria}

La actividad inmobiliaria se encuentra ubicada en la división 68 de la Clasificación Industrial Internacional Uniforme (CIIU) de todas las actividades económicas de las Naciones Unidas - 4. ${ }^{a}$ Revisión.

Comprende las actividades de arrendadores, agentes y/o corredores en la venta, compra y alquiler de bienes raíces, y en la prestación de otros servicios inmobiliarios como los de tasación inmobiliaria o los de depositarios de plicas inmobiliarias. Estas actividades pueden desarrollarse con bienes propios o arrendados a cambio de una retribución, o a través de un contrato.

El adjetivo "inmobiliario" se refiere a aquello perteneciente o relativo a las cosas inmuebles. Un inmueble, por su parte, es un bien que se encuentra unido a un terreno de modo inseparable, tanto física como jurídicamente.

La Real Academia Española (RAE) define a la empresa inmobiliaria como aquella que se dedica a construir, arrendar, vender y administrar viviendas. Una empresa inmobiliaria puede realizar una o más de las actividades mencionadas. A partir de esta defınición, se infiere que las empresas inmobiliarias venden tanto bienes como servicios en el caso del arriendo y administración de viviendas.

Lo crucial en esta definición es que indica que una empresa inmobiliaria puede "construir». Por ello, la pregunta que surge es: si construye, ¿no es entonces una empresa constructora? Es precisamente este cuestionamiento lo que demuestra que existe confusión para determinar cuál es la actividad que realiza la empresa $\mathrm{y}$, por tanto, qué normas contables y tributarias le corresponde aplicar.

Para dar respuesta al cuestionamiento antes planteado, se debe indicar que, en principio, si la empresa solo construye, efectivamente sería una empresa constructora. Sin embargo, lo importante es entender para qué construye. Las empresas inmobiliarias construyen con el fin último de vender las unidades inmobiliarias. Es decir, el objeto de la transacción con el cliente es un bien inmueble, a diferencia de una empresa constructora, que vende, como ya se ha visto, el servicio de construir.

Para efectos de la presente investigación, nos centraremos en la primera venta de inmuebles por parte de las empresas inmobiliarias. 
Como cualquier empresa que decide desarrollar un proyecto, las empresas inmobiliarias se ven en la necesidad de recurrir a una entidad financiera para solicitar un crédito. Uno de los requisitos de las entidades financieras es que las empresas inmobiliarias cuenten con un porcentaje de las viviendas vendidas antes de efectuar cualquier desembolso del crédito. Pero si las empresas inmobiliarias acuden a las entidades financieras para poder desarrollar el proyecto, ¿cómo es que les piden que tengan un porcentaje de ventas realizadas?

Las entidades financieras tienen un sinnúmero de razones para establecer ese requisito, pero lo cierto es que las empresas inmobiliarias, para poder cumplirlo, se han visto en la necesidad de aplicar un sistema de venta a futuro. Es decir, realizan la venta de las viviendas con base en los planos antes de ser construidas. Como bien indica el C. P. C. Raúl Ramírez, «las empresas inmobiliarias venden sueños», haciendo referencia a que venden un bien que en el momento de la transacción no existe y que será ejecutado en un determinado lapso de tiempo.

Como en cualquier transacción que ejecuten dos partes, en la venta de inmuebles la transacción queda estipulada en un contrato de compraventa. Lo particular en este caso es que se habla de un contrato de compraventa de "bien futuro". Mediante este tipo de contrato, la empresa se obliga a cumplir con la entrega del bien en una fecha determinada.

El hecho de vender hoy un bien que va a existir en el futuro, ha dado lugar a que las autoridades responsables de los temas contables y tributarios promulguen los lineamientos bajo los cuales una empresa inmobiliaria debe registrar sus operaciones con el propósito de determinar el pago de sus impuestos, como veremos en los siguientes acápites.

\section{Reconocimiento de ingresos y costos - base contable y tributaria}

El momento en que los ingresos y costos relacionados con los contratos de construcción deben ser reconocidos resulta ser un tema relevante para las empresas, ya que de ello se va a determinar la base imponible para efectos del impuesto a la renta.

Si bien la norma contable, a través del principio de devengado, establece que los ingresos y los gastos deben reconocerse cuando ocurren, independientemente de si han sido cancelados o no, lo dispuesto por la norma tributaria no 
necesariamente se ajusta a dicho principio. Más aún cuando se sabe que, por lo general, los contratos de construcción abarcan más de un ejercicio gravable, lo cual obliga a que se deban identificar los ingresos y gastos que pertenecen a un determinado ejercicio.

En este capítulo se detalla la metodología establecida, tanto por la norma contable como por la norma tributaria, para el reconocimiento de los ingresos y los costos para efectos de la determinación de la base imponible; y analizaremos las desviaciones o coincidencias que existen entre ellas.

\section{Sector construcción}

Norma contable - NIC 11

Como se mencionó anteriormente, los contratos de construcción se encuentran dentro del marco contable de la Norma Internacional de Contabilidad (NIC) 11. El objetivo de esta norma es establecer criterios para el reconocimiento de los ingresos y los costos asociados a las actividades de construcción, teniendo presente que en estas actividades es usual que las fechas de inicio y término del contrato de construcción correspondan a ejercicios diferentes.

\section{a. Ingresos de un contrato de construcción}

La norma contable establece que los ingresos ordinarios de los contratos de construcción deben comprender tanto el ingreso inicial pactado en el contrato como todos aquellos ingresos producto de cualquier modificación, reclamación o incentivo que se lleve a cabo a lo largo de la ejecución de obra, siempre que pueda ser valorizada en forma confiable según el valor razonable.

En ese sentido, queda claro que a pesar de la existencia de un monto pactado en el contrato, los ingresos pueden verse afectados por ciertas incertidumbres producto de hechos futuros que se irán resolviendo en la medida en que el proyecto se vaya ejecutando.

Algunos ejemplos de hechos que generan variaciones en los ingresos son:

- Modificaciones del proyecto pactadas entre el cliente y el contratista.

- Cambios en los precios de materiales. 
- Penalizaciones por concepto de demoras o incumplimientos por parte del contratista.

- Incentivos otorgados al contratista como bonificación por el desarrollo del proyecto en un tiempo menor que el estimado en el contrato.

\section{b. Costos de un contrato de construcción}

La norma establece que los costos del contrato deben comprender todos aquellos que puedan ser imputados directamente al contrato específico y cualquier otro que se pueda imputar al cliente en la medida en que se encuentre dentro del marco contractual.

Asimismo, establece que los costos del contrato comprenden todos aquellos en los que incurren las empresas constructoras desde la fecha en que se firma el contrato hasta el final de la ejecución de la obra. Sin embargo, existen costos en los que una empresa constructora puede haber incurrido en fechas previas a la firma del contrato. La NIC 11 establece que estos costos deben ser reconocidos como gastos en el período en que se realizan, pero pueden ser incluidos como parte de los costos del contrato en la medida en que puedan ser identificados por separado y valorados con suficiente fiabilidad.

Los costos en los que una empresa constructora incurre para dar cumplimiento a un contrato de construcción pueden clasificarse en:

- Costos que se relacionen directamente con el contrato específico: dentro de los costos directos se consideran la mano de obra que se encuentra en el lugar de la construcción, los materiales usados en la construcción, la depreciación de las maquinarias y los equipos usados para la ejecución del contrato, el costo de transporte de los materiales, costos de diseño y asistencia técnica directamente relacionados con el contrato, costos de rectificación y garantía.

- Costos atribuibles a la actividad de contratación en general: son aquellos costos indirectos de fabricación en los que incurren las empresas constructoras. Algunos de estos costos son los seguros, los costos de diseño y asistencia técnica que no están directamente relacionados con ningún contrato específico, y los gastos generales de fabricación. 
- Costos que no pueden ser atribuibles a la actividad de contratación: son todos aquellos costos que no puedan ser distribuidos a los contratos específicos, como, por ejemplo, los costos de ventas, los costos generales de administración y los costos de investigación y desarrollo que no han sido especificados en el contrato.

\section{c. Método de porcentaje de avance de obra}

La NIC 11 establece que cuando el resultado de un contrato de construcción pueda ser estimado con suficiente fiabilidad, los ingresos ordinarios y los costos asociados deben ser reconocidos como tales en el estado de resultados con referencia al grado de realización del contrato al cierre del período contable.

Al grado de realización del contrato se le denomina «método del porcentaje de realización o avance de obra" y establece que los ingresos ordinarios del contrato deben compararse con los costos asociados a este de acuerdo con el estado de avance en el que se encuentre; de esta manera, se revelará el importe de los ingresos ordinarios, los gastos y los resultados de la parte del contrato ya ejecutada.

\section{Norma tributaria}

En relación con el reconocimiento de los ingresos y los gastos, la norma tributaria establece, en el inciso a) del artículo 57. de la Ley del Impuesto a la Renta, que las rentas de tercera categoría se considerarán producidas en el ejercicio comercial en el que se devenguen. De esta manera, encontramos coincidencia con la norma contable a través del principio de devengado.

Sin embargo, la norma tributaria establece un tratamiento especial para las empresas constructoras, que no necesariamente se alinea al principio de devengado antes mencionado.

Para la determinación del impuesto a la renta, las empresas constructoras en el Perú deben ceñirse a lo estipulado en el artículo 63. ${ }^{\circ}$ del T. U. 0. de la Ley del Impuesto a la Renta (Decreto Legislativo 774). Dicho artículo establece que las empresas constructoras cuyas obras requieran de más de un ejercicio gravable, podrán acogerse a cualquiera de los siguientes tres métodos para determinar la renta correspondiente. 
a. Asignar a cada ejercicio gravable la renta bruta que resulte de aplicar sobre los importes cobrados por cada obra, durante el ejercicio comercial, el porcentaje de ganancia bruta calculado para el total de la respectiva obra.

b. Asignar a cada ejercicio gravable la renta bruta que se establezca deduciendo del importe cobrado y por cobrar por los trabajos ejecutados en cada obra durante el ejercicio comercial, los costos correspondientes a tales trabajos.

c. Diferir los resultados hasta la total terminación de las obras, cuando estas, según contrato, deban ejecutarse dentro de un plazo no mayor de tres (3) años, en cuyo caso los impuestos que correspondan se aplicarán sobre la ganancia así determinada, en el ejercicio comercial en que se concluyan las obras o se reciban oficialmente, cuando este requisito deba recabarse según las disposiciones vigentes sobre la materia. En caso de que la obra se deba terminar o se termine en un plazo mayor de tres (3) años, la utilidad será determinada el tercer año conforme a la liquidación del avance de la obra por el trienio, y a partir del cuarto año siguiendo los métodos a que se refieren los incisos a) y b) de este artículo.

Cabe resaltar que una vez que se ha optado por uno de los tres métodos, este deberá ser empleado en forma uniforme en todas las obras que desarrolle la empresa constructora, no existiendo la posibilidad de aplicar métodos diferentes para cada obra.

Por otro lado, el artículo 36. del Reglamento del Impuesto a la Renta establece qué deben reconocer las empresas constructoras para determinar los pagos a cuenta mensuales del impuesto a la renta de acuerdo al método elegido.

Lo dispuesto en la presente norma está relacionado con el artículo 63. de la Ley de Impuesto a la Renta antes mencionada. En ese sentido, establece lo siguiente:

a. Las empresas que se acojan a los métodos señalados en los incisos a) y c) del artículo $63 .^{\circ}$ de la ley deberán considerar como ingresos netos los importes cobrados en cada mes de acuerdo al avance de obra.

Cabe precisar que para las empresas que opten por la opción de diferimiento de resultados hasta la finalización de obras, es decir el inciso c) del artículo 63. ${ }^{\circ}$ de la Ley del Impuesto a la Renta, esta disposición solo será aplicable para los ingresos netos cobrados en los meses que corresponden al ejercicio 
gravable en que debe culminar la obra o a partir del tercer año, lo que ocurra primero.

b. Las empresas que se acojan al inciso b) del artículo $63 .^{\circ}$ de la ley deberán considerar como ingresos netos del mes no solo los importes cobrados, sino también los importes que tuvieran por cobrar por los trabajos ejecutados durante el mes. En ese sentido, deberán preparar valorizaciones de los trabajos ejecutados en cada mes para determinar la base para el cálculo de los pagos a cuenta mensuales.

c. Las empresas que obtengan ingresos distintos a los provenientes de la ejecución de contratos de construcción a los que se refiere el artículo $63 .^{\circ}$ de la Ley del Impuesto a la Renta, sumarán estos ingresos a aquellos obtenidos por obras para calcular sus pagos a cuenta.

Una vez que las empresas han identificado qué es lo que deben considerar como ingreso neto, deberán determinar el factor que deben aplicar para el cálculo de los pagos a cuenta del impuesto a la renta de acuerdo a lo establecido en el artículo $85 .^{\circ}$ de la Ley del Impuesto a la Renta.

Luego de conocer los métodos considerados por la norma tributaria para el reconocimiento de ingresos y la determinación de la renta bruta, procederemos a analizar cada uno de ellos en relación con lo que establece la norma contable.

De esta manera, encontramos que el método establecido en el inciso a) difiere de los principios contables al reconocer como ingresos solo a aquellos que han sido cobrados contraviniendo lo indicado por el principio de devengado. Algunos autores se refieren a este método como el "método de lo percibido", por el hecho de que solo considera los montos cobrados.

El método del inciso b), en cambio, reconoce como ingresos aquellos que han sido cobrados y los que se encuentren por cobrar al cierre de cada período, y se les deducen los costos, por lo que difiere notablemente de lo establecido por las normas contables. Es por ello que a este método se le conoce como el «método de lo devengado".

Dado que el método del inciso c) considera como ingreso solo a aquellos que han sido cobrados, al igual que el método del inciso a), difiere de lo establecido 
por los principios contables. Además de ello, al permitir el diferimiento de los resultados hasta la terminación de la obra o hasta el tercer año (lo que ocurra primero), se aleja aún más del principio de devengado.

\section{- Modificaciones a la norma}

La cuarta disposición complementaria del Decreto Legislativo 1112 se pronuncia respecto del inciso c) del artículo $63 .^{\circ}$ de la Ley del Impuesto a la Renta estableciendo que "Las empresas de construcción o similares que hubieran adoptado el método establecido en el inciso c) del primer párrafo del artículo $63 .^{\circ}$ de la Ley hasta antes de su derogatoria por el presente decreto legislativo, seguirán aplicando la regulación establecida en dicho inciso respecto de las rentas derivadas de la ejecución de los contratos de obras iniciadas con anterioridad al 1 de enero de 2013, hasta la total terminación de las mismas». Es decir, las empresas constructoras que inicien obras a partir del 1 de enero de 2013 solo podrán acogerse a los métodos indicados en los incisos a) y b) del artículo $63 .^{\circ}$ de la Ley del Impuesto a la Renta.

Esta disposición ha generado que algunas entidades relacionadas con el sector construcción manifiesten su opinión al respecto. Por ejemplo, Capeco sostiene que «los proyectos se encarecerán porque los impuestos se pagarán ahora en un año» ${ }^{4}$. Esta afirmación no es del todo precisa, en el sentido de que el impuesto no se va a pagar en un año sino que, al ya no contar con el método de diferimiento de renta, las empresas tendrán que hacer sus pagos a cuenta mensualmente.

Consultamos con algunos empresarios dedicados a la construcción y todos coincidieron en que esta nueva disposición definitivamente afecta los proyectos que tienen planificado desarrollar a partir de 2013. El hecho de ya no contar con la posibilidad de diferir el pago del impuesto a la renta hasta el tercer año los ha llevado a reevaluar las condiciones financieras de sus proyectos, en la medida en que van a requerir contar con niveles de liquidez suficientes para cubrir los pagos a cuenta correspondientes al impuesto a la renta. Algunos, incluso, están evaluando la posibilidad de adelantar el inicio del proyecto a diciembre de este año con la finalidad de tener la opción de acogerse al beneficio de diferimiento de los pagos a cuenta del impuesto a la renta.

4. Perú.21 (jueves 9 de agosto de 2012). "Aumentan trabas en sector construcción". 
Asimismo, consultamos a algunos expertos y empresarios del sector sobre el método que aplicarán para determinar el impuesto a la renta en los proyectos que inicien a partir del 1 de enero de 2013. La respuesta fue unánime: aplicar el método del inciso a), ya que les va a permitir pagar menos impuestos el primer año, en la medida en que solo será por la parte que ha sido cobrada.

\section{Sector inmobiliario}

Norma contable - NIC 18

La NIC 18 establece el tratamiento contable de los ingresos de actividades ordinarias que surgen de transacciones tales como la venta de bienes, la prestación de servicios y el uso por parte de terceros de activos de la entidad que produzcan intereses, regalias y dividendos.

Para efectos de la presente investigación, pondremos atención a los ingresos provenientes de la venta de bienes cuyo tratamiento se detalla en los párrafos 14 al 19 de la NIC 18.

El párrafo 14 de la NIC 18 establece las condiciones que se deben cumplir para que una transacción sea reconocida como una venta. Los párrafos 15 al 19 contienen una breve explicación de cada una de las condiciones mencionadas en el párrafo 14. Estas condiciones son:

a. La empresa ha transferido al comprador los riesgos y ventajas derivados de la propiedad de los bienes. La transferencia de los riesgos y ventajas comúnmente se dan con la transferencia de la titularidad legal o el traspaso de la posesión al comprador.

b. La empresa no conserva para sí misma ninguna implicación en la gestión corriente de los bienes vendidos ni retiene el control efectivo sobre los mismos. Una de las formas por las que la empresa puede conservar alguna implicación correspondiente a la propiedad, es cuando asume obligaciones derivadas del mal funcionamiento del bien.

c. El importe de los ingresos producto de la venta pueden ser medidos con fiabilidad. Si una empresa conserva solo una parte insignificante de los riegos y las ventajas de la propiedad, la transacción se considera como una venta $y$, por tanto, se procederá a reconocer los ingresos productos de la transacción. Un motivo para conservar una parte de los riesgos es cuando 
existe la posibilidad de que la empresa tenga el compromiso de devolver el dinero en caso el cliente no quede satisfecho. En este caso, la transacción se registra como venta, siempre y cuando la empresa pueda medir de forma fiable las posibles devoluciones futuras.

d. Que sea probable que la empresa reciba los beneficios económicos asociados con la venta. Cuando exista alguna incertidumbre sobre la cobranza de algún saldo ya considerado como ingresos, se procederá a reconocerlo como gasto en lugar de ajustar el importe del ingreso ya reconocido.

e. Los costos incurridos o por incurrir relacionados con la venta pueden ser medidos con fiabilidad. Debe existir correlación de los gastos con los ingresos; es decir, los gastos y los ingresos deben ser reconocidos en forma simultánea. Un ingreso no puede ser reconocido como tal en tanto los gastos correlacionados no puedan ser determinados con fiabilidad.

\section{Norma tributaria}

La Superintendencia Nacional de Administración Tributaria (Sunat), a través de su Informe 085-2009-Sunat/2B0000, ha establecido que para fines de la realización de los pagos a cuenta del impuesto a la renta, los ingresos de las empresas inmobiliarias deben haber cumplido las condiciones establecidas en el párrafo 14 de la NIC 18. Es decir, que los ingresos cumplan con las condiciones para ser reconocidos como venta y, por tanto, sirvan de base para el cálculo de los pagos a cuenta mensuales del impuesto a la renta.

En ese sentido, para efectos de la determinación del impuesto a la renta en el sector inmobiliario, no encontramos diferencia entre lo establecido por la norma contable y lo establecido por la norma tributaria, ya que esta última ha sido clara en precisar que se debe adoptar lo establecido en la NIC 18.

\section{Tratamiento del impuesto general a las ventas}

\section{El impuesto general a las ventas en las empresas constructoras}

De acuerdo a lo establecido en el inciso c) del artículo $1 .^{\circ}$ de la Ley de Impuesto General a las Ventas (IGV), las operaciones relacionadas con los contratos de construcción están gravadas por el IGV. Esto teniendo en cuenta el ámbito de aplicación establecido en el inciso c) del numeral 1 del artículo $2 .^{\circ}$ del Re- 
glamento del Impuesto General a las Ventas, según el cual son los contratos de construcción que se ejecuten en el territorio nacional, cualquiera sea su denominación, sujeto que lo realice, lugar de celebración del contrato o de percepción de los ingresos.

\section{- Nacimiento de la obligación tributaria en la construcción}

En una primera revisión a la Ley del Impuesto General a las Ventas y su reglamento, no identificamos alguna disposición que indique especificamente el nacimiento de la obligación tributaria para las empresas constructoras. Sin embargo, al hacer un análisis del giro de negocio y de la actividad que realizan este tipo de empresas, consideramos que las constructoras, al ser empresas que prestan un servicio, deben ceñirse a lo establecido en el inciso c) del artículo $4 .{ }^{\circ}$ de la Ley del Impuesto General a las Ventas. Este establece que "la obligación tributaria en la prestación de servicios se origina en la fecha en que se emite el comprobante de pago de acuerdo a lo que establezca el reglamento ${ }^{5}$, o en la fecha en que se percibe la retribución, lo que ocurra primero".

\section{- El crédito fiscal en las empresas constructoras}

Para poder abordar este punto fue necesario plantearnos algunas preguntas. ¿Las operaciones que realizan las empresas constructoras están afectas al IGV? ¿Existe alguna proporción de las operaciones que no esté afecta al IGV? ¿Qué venden las constructoras?

Si bien casi todas estas preguntas ya las hemos respondido a lo largo del presente trabajo, consideramos necesario plantearlas para poder entender la lógica del derecho a crédito fiscal con el que cuentan las empresas constructoras.

Dado que las constructoras venden un servicio, sus operaciones están gravadas por el IGV y el 100\% de estas operaciones están afectas al 18\% del IGV, entendemos que al existir la obligación del pago del 18\% del IGV en el momento de la venta, lo lógico es que las empresas constructoras tengan derecho a utilizar el 100\% del IGV proveniente de las compras como crédito fiscal. 
Luego de haber realizado este análisis, para validar nuestra posición, acudimos a la Sunat a través de su central de consultas y realizamos la siguiente consulta: ¿El IGV provenientes de las compras que realizan las empresas constructoras puede ser usado al 100\% como crédito fiscal? Lamentablemente, la respuesta que obtuvimos estaba referida al método de la prorrata, el cual está relacionado con el derecho a crédito fiscal para las empresas inmobiliarias.

Sin embargo, el contacto con la Sunat nos ha permitido comprobar que existe una confusión entre lo que es construcción y lo que es inmobiliario. Por error, se suele denominar "de construcción» muchos aspectos que corresponden al sector inmobiliario, lo que genera confusión en las personas.

\section{El impuesto general a las ventas en las empresas inmobiliarias}

- Ámbito de aplicación y nacimiento de la obligación tributaria en la venta de un bien futuro

La Ley del Impuesto general a las Ventas (IGV) establece en el inciso d) del artículo $1 .^{\circ}$ que la primera venta de inmuebles que realicen las empresas constructoras se encuentra gravada con el IGV.

En este punto es importante precisar que si bien el artículo $1 .^{\circ}$ hace referencia a las empresas constructoras, la norma está dirigida a las empresas inmobiliarias, ya que, como hemos visto anteriormente, las empresas inmobiliarias son aquellas que se dedican a la venta de inmuebles, mientras que las constructoras se limitan netamente a la edificación. Si una empresa constructora pasa los límites de lo que es solo la construcción y decide vender los inmuebles, automáticamente se convierte en una empresa inmobiliaria con construcción propia, y, por tanto, deberá acogerse al tratamiento contable y tributario de una inmobiliaria.

Hecha la aclaración, pasamos a indicar lo que la norma tributaria considera como venta para efectos del nacimiento de la obligación tributaria del IGV.

Hasta el 31 de julio de 2012, el artículo $3 .^{\circ}$ definía el concepto de ventas como "todo acto por el que se transfieren bienes a título oneroso, independientemente de la designación que se dé a los contratos o negociaciones que originen esa transferencia y de las condiciones pactadas entre las partes». Como se puede observar, el mencionado artículo no hace distinción entre la venta de un bien existente o un bien futuro. 
La Superintendencia Nacional de Administración Tributaria (Sunat) se pronunció a través del Informe 104-2007-Sunat/2B0000, precisando que la obligación tributaria en la primera venta de inmuebles nace en la fecha de percepción parcial o total del ingreso tal como se indica en el inciso f) del artículo $4 .^{\circ}$ de la ley del IGV. En este mismo artículo, el inciso a) establece que la obligación tributaria en la venta de inmuebles se origina en la fecha en que se emite el comprobante de pago de acuerdo a lo que establezca el reglamento o en la fecha en que se entregue el bien, lo que ocurra primero.

En ese sentido, al tratarse de una venta futura en la cual el cliente efectúa pagos antes de la entrega del bien, lo primero que ocurre es la emisión del comprobante de pago, originándose en ese momento la obligación tributaria.

Por su parte, el Tribunal Fiscal, en la Resolución 640-5-2001, señalaba que para que nazca la obligación de pago del impuesto general a las ventas es necesario que exista una venta, la cual, tratándose de bienes futuros, recién ocurrirá cuando el bien haya llegado a existir. Esta posición se ampara en el artículo 1534. del Código Civil, que establece que «en la venta de un bien que ambas partes saben que es futuro, el contrato está sujeto a la condición suspensiva de que llegue a tener existencia, es decir, no surte efectos el contrato hasta que se cumpla la condición de existencia del bien".

Como podemos ver, la posición de Sunat y la del Tribunal Fiscal son totalmente opuestas. Entonces, ¿qué posición adoptan las empresas inmobiliarias para la determinación del IGV?

Consultamos con algunos empresarios y contadores especializados en el sector sobre cuál de las dos opciones aplican para determinar el nacimiento de la obligación tributaria del IGV. Todos coincidieron en que aplican lo dispuesto por la Sunat, debido básicamente al temor de una acotación ante una eventual fiscalización por parte de la autoridad tributaria y para evitar todo el proceso engorroso que implicaría un proceso legal para poder impugnar las observaciones que pudiera hacer la Sunat.

Sin embargo, dentro del paquete de modificaciones que se han llevado a cabo este año en las normas tributarias, se han realizado modificaciones a la Ley del Impuesto General a las Ventas para perfeccionar algunos supuestos de nacimiento de la obligación tributaria, la determinación de la base imponible y la aplicación del crédito fiscal, así como para cubrir vacíos legales y supuestos 
de evasión y elusión tributaria, garantizando la neutralidad en las decisiones de los agente económicos.

A partir del 1 de agosto de 2012, en el artículo 3. ${ }^{\circ}$ de la Ley del Impuesto General a las Ventas se ha incluido un párrafo adicional que establece que en todo acto por el que se transfieren bienes a título oneroso están incluidas las operaciones sujetas a la condición suspensiva en las cuales el pago se produce antes de la existencia el bien. De esta manera, la posición del Tribunal Fiscal ha quedado sin efecto.

Si bien con la modificación del artículo $3 .^{\circ}$ ha desaparecido la disyuntiva sobre qué posición seguir para considerar el nacimiento de la obligación del impuesto general a la ventas, queda confirmada la desviación entre lo establecido por la norma contable y la tributaria en el sentido de que, según la NIC 18, el ingreso o la venta debe ser reconocido con la existencia del bien, mientras que de acuerdo con lo establecido por la Sunat, el ingreso en el momento de la percepción del mismo.

La siguiente pregunta que nos planteamos es: ¿cómo afecta a las empresas inmobiliarias lo dispuesto por la Sunat?

Por las consultas realizadas a algunos empresarios, pudimos conocer que la mayoría de las empresas venían aplicando lo dispuesto por la Sunat, por lo cual no encontramos mayor impacto generado por los cambios en la normativa. Sin embargo, hay un aspecto importante sobre el nacimiento de la obligación tributaria del impuesto general a las ventas cuando se trata de contratos de bienes futuros, y es la oportunidad en que se genera el IGV de compras y el de ventas.

Esto se debe a que, como mencionamos en el acápite 3.1.2, las empresas inmobiliarias financian parte inicial de la construcción del proyecto inmobiliario a través de las preventas. De esta manera, y de acuerdo a la disposición de la norma tributaria, se genera IGV de ventas antes de realizar cualquier compra que dé lugar a crédito fiscal, por lo que se tienen que realizar pagos por concepto de IGV.

Si lo analizamos por el lado financiero, en definitiva a las empresas inmobiliarias les conviene optar por lo dispuesto por el Tribunal Fiscal, ya que ello implica no tener que hacer desembolsos por concepto de IGV hasta que el bien llegue a tener existencia. De esta manera, se eliminaría el problema que planteamos inicialmente sobre el descalce en la oportunidad de generación de IGV de ventas y de compras. 


\section{- Base imponible del IGV en la primera venta de inmuebles}

Para poder determinar la base imponible para el cálculo del impuesto general a las ventas en la primera venta de inmuebles, debemos remitirnos a lo establecido en el numeral 9 del artículo 5. ${ }^{\circ}$ de la Ley del Impuesto General a las Ventas. Este establece que para determinar del IGV en la primera venta de inmuebles, se debe excluir del monto total del inmueble aquella parte correspondiente al terreno. Es decir, la base imponible en este caso corresponde al valor de la construcción.

Por un tema de simplicidad, la norma ha establecido que el valor del terreno representa el cincuenta por ciento (50\%) del valor total de la transacción del inmueble.

Si traducimos en una fórmula lo establecido por la norma, tendríamos lo siguiente:

Valor de construcción + Valor de terreno + IGV = Precio de venta

Dado que el valor del terreno representa el 50\% del valor del valor total de la transacción, entonces:

Valor de construcción = Valor de terreno

Si reemplazamos el valor del terreno y el IGV en la fórmula, obtenemos lo siguiente:

V. de construcción + V. de construcción $+0,18$ (V. de construcción) $=$ Precio de venta

Esto quiere decir que el precio de venta es igual a 2,18 veces el valor de la construcción.

Supongamos que tenemos una vivienda cuyo precio de venta es S/. 250.000,00: la base imponible se calcula de la siguiente manera:

2,8(Valor de construcción $)=S / .250 .000,00$

Valor de construcción $=\mathrm{S} / .250 .000,00 / 2,18$

Valor de construcción (base imponible) = S/. 114.678,90 
- El crédito fiscal para las empresas inmobiliarias

En la legislación peruana existen dos condiciones que deben cumplirse para que el IGV de las adquisiciones que realicen las empresas pueda aplicarse como crédito fiscal.

El artículo $18 .^{\circ}$ de la Ley del Impuesto General a las Ventas establece que para que el IGV sea reconocido como crédito fiscal, las adquisiciones que dieron lugar al impuesto deben ser admitidas como gasto para efectos del impuesto a la renta, y, por otro lado, deben ser destinadas a operaciones que estén gravadas por el impuesto general a la ventas. Esta última condición es importante para las empresas inmobiliarias en la medida en que, como hemos mencionado anteriormente, la parte correspondiente al terreno se encuentra exonerada del IGV; por lo tanto, nos encontramos ante el caso de empresas que realizan operaciones gravadas y no gravadas al mismo tiempo.

Al respecto, la Sunat se ha pronunciado a través del Informe 158-2008/Sunat, en el cual establece que «el IGV que grava la venta de bienes o prestación de servicios destinados exclusivamente a la construcción del inmueble podrá deducirse en su integridad como crédito fiscal, en la medida que dichas adquisiciones se contabilicen separadamente de aquéllas destinadas a la venta del terreno. En caso no puedan discriminarse las adquisiciones que han sido destinadas a realizar las operaciones gravadas y no gravadas, deberá utilizarse el procedimiento de la prorrata".

\section{Cuadro comparativo entre el sector construcción y el sector inmobiliario}

Luego de haber abordado los aspectos contables y tributarios correspondientes a los sectores construcción e inmobiliario, hemos realizado un cuadro comparativo con la finalidad de sintetizar los aspectos más relevantes de cada uno.

Este cuadro permitirá al lector identificar si la actividad que realiza se encuentra considerada como actividad de construcción o como actividad inmobiliaria, y qué procedimientos seguir en cada caso para la determinación del impuesto general a las ventas y el impuesto a la renta. 


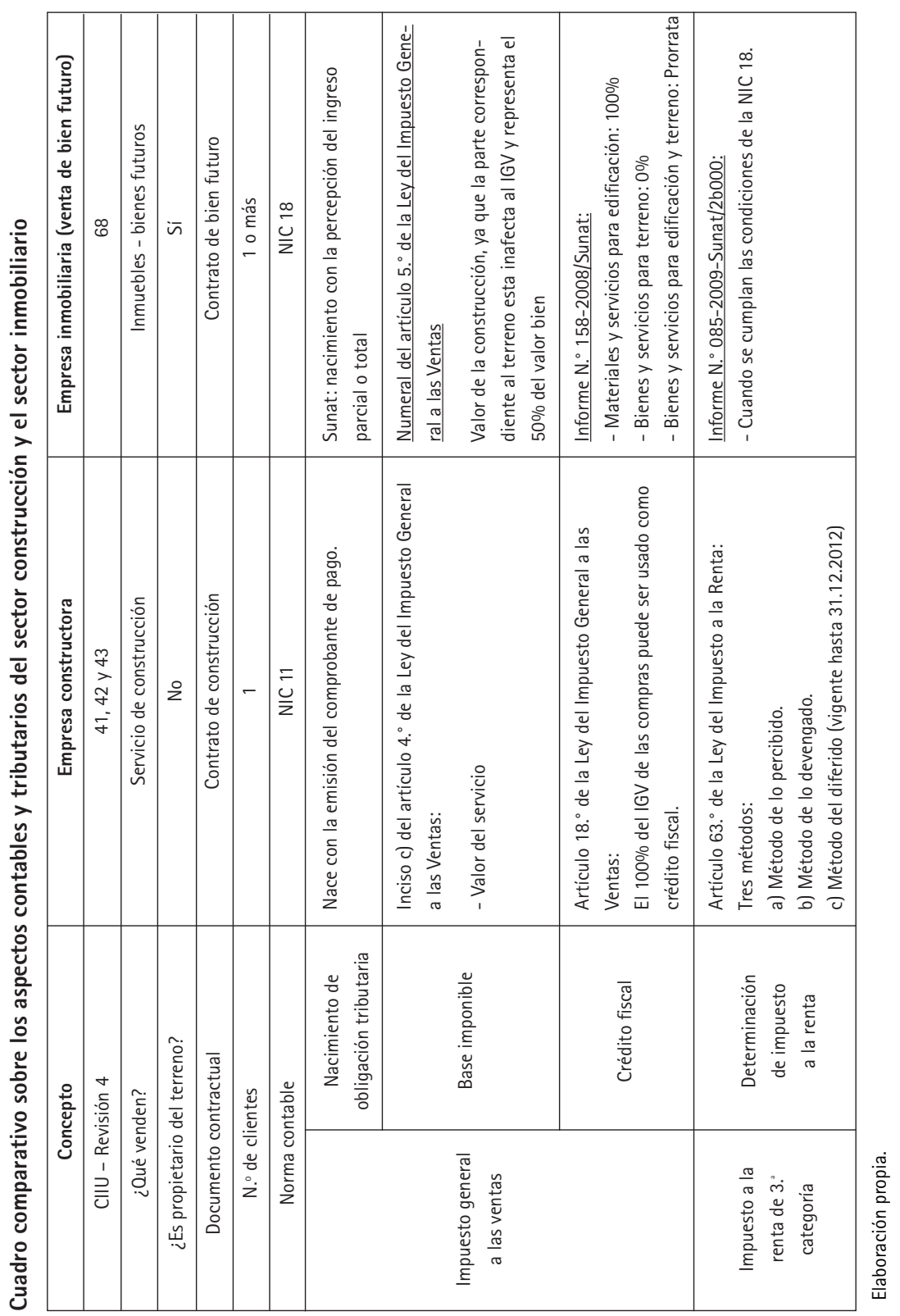




\section{Conclusiones}

- Luego de haber realizado una revisión de la literatura disponible sobre los temas tratados, de la información obtenida en las entrevistas realizadas, y de las experiencias que personas que llevan años trabajando en los sectores construcción e inmobiliario compartieron con nosotras, encontramos que no existe una buena definición de las actividades que desarrollan las empresas de cada sector, lo que da lugar a confusión sobre la metodología que deben aplicar las empresas constructoras e inmobiliarias para la determinación de sus impuestos. Muestra de ello es que las propias normas tributarias vigentes en el Perú cuentan con imprecisiones sobre el sector al cual están dirigidas algunas de las normas establecidas. Así, por ejemplo, encontramos que el artículo $10^{\circ}$ de la Ley del Impuesto General a las Ventas establece que "la primera venta por parte de las empresas constructoras [...]", haciendo referencia a una disposición que está dirigida a la venta de bienes que realizan las empresas inmobiliarias. La gran cantidad de seminarios que distintos estudios contables vienen dictando sobre los temas contables y tributarios relacionados tanto con el sector construcción como con el inmobiliario, nos permiten inferir que las normas contables y tributarias cuentan con algunos vacíos e imprecisiones que llevan a que los usuarios apliquen metodologías que no les corresponden de acuerdo a su giro de negocio.

De esta manera, concluimos que las normas contables y tributarias por sí solas no son suficientes para que las empresas de los sectores construcción e inmobiliario puedan determinar su impuesto general a las ventas e impuesto a la renta de manera adecuada.

- Si bien en lo que va del año la autoridad tributaria ha realizado modificaciones a las normas tributarias que afectan tanto al sector construcción como al inmobiliario, aún existen algunas discrepancias respecto a lo establecido por las normas y los principios contables.

En el caso del impuesto a la renta de las empresas constructoras, se ha eliminado la posibilidad de diferir los resultados hasta la finalización de la obra, dejando como posibles métodos los establecidos en los incisos a) y b) del artículo $63 .{ }^{\circ}$ de la Ley del Impuesto a la Renta, que suponen la realización de pagos a cuenta mensuales desde el inicio de las operaciones del proyecto de construcción. Si 
el objetivo hubiera sido el alineamiento entre la norma contable y la norma tributaria, dentro de los cambios hubiera estado incluida también la derogación del inciso a), en la medida en que no considera el principio de lo devengado.

En lo que se refiere a las empresas inmobiliarias, en nuestra opinión la obligación tributaria del impuesto general a las ventas debería nacer cuando el bien llegue a existir, tal como lo establece el Tribunal Fiscal. Hemos basado nuestra opinión en el criterio establecido en la NIC 18 acerca de la oportunidad en que un ingreso debe reconocerse como una venta. Consideramos que en la medida en que no se cumplan los requisitos para que una venta sea reconocida como tal y que las empresas no puedan transferir todos los riesgos a cliente, no debería existir a obligación del pago del IGV. Sin embargo, la modificación del artículo $3 .^{\circ}$ de la Ley del Impuesto General a las Ventas reafirma la posición de la Sunat, que establece que la obligación tributaria del impuesto general a las ventas nace con la percepción del ingreso, sea total o parcial. De esta manera, se observa la prioridad dada al factor temporal de recaudación más que al alineamiento entre la norma contable y la norma tributaria.

Así, concluimos que el objetivo de los cambios realizados a las normas tributarias, más que lograr un alineamiento hacia la norma contable, está orientado a lograr una mayor rapidez en el flujo de recaudación producto de las operaciones tanto de las empresas constructoras como de las inmobiliarias.

- Tanto las normas contables como las tributarias establecen metodologías para la determinación de la renta bruta para determinar el impuesto a la renta de cada período gravable. Cada una de ellas establece lo que se debe reconocer como ingresos y los relaciona con sus costos. En ese sentido, el área de ingeniería de obra es la principal fuente de información para que el área contable pueda reconocer los ingresos y costos de cada contrato de construcción que deben ser considerados dentro de un determinado período. Esta información permite la correcta y oportuna determinación del impuesto a la renta en las empresas constructoras.

En ese sentido, concluimos que la interacción entre el área contable y el área de ingeniería de obra es de vital importancia para la determinación del impuesto a la renta de las empresas constructoras. Para ello, consideramos importante que los ingenieros de obra cuenten con algunas nociones contables para poder entregar al área contable la información adecuada en el momento oportuno. Por 
otro lado, es importante que los contadores visiten y conozcan las obras para que puedan tener una mejor visión de las operaciones de la empresa y puedan ser capaces de identificar cualquier elemento que escape de las condiciones pactadas en cada contrato.

- Para la ejecución de los proyectos inmobiliarios, las empresas constructoras $\mathrm{y}$ las inmobiliarias tiene que recurrir a las entidades financieras en busca de financiamiento, cuyo costo está dado por la tasa de interés.

Las modificaciones que se han dado en las normas tributarias están obligando a las empresas a cambiar el momento en que deben hacer los pagos de sus impuestos. Así, las empresas constructoras, en las obras que inicien a partir del 1 de enero de 2013, deberán hacer los pagos a cuenta del impuesto a la renta desde el primer mes, y las empresas inmobiliarias ya no cuentan con la posibilidad de acogerse a lo establecido por el Tribunal Fiscal respecto del nacimiento de la obligación tributaria del impuesto general a las ventas cuando llegue a existir.

En ese sentido, las empresas de los sectores construcción e inmobiliario van a tener que considerar dentro del monto del capital de trabajo aquel que corresponde al pago de sus impuestos, generándose de esta manera un costo adicional de financiamiento.

De esta manera, podemos concluir que en sectores en los cuales los montos de inversión son considerables, una adecuada planificación tributaria resulta fundamental en la medida en que los costos financieros adicionales pueden afectar la utilidad generada por cada uno de los proyectos desarrollados. 



\section{Principales diferencias en el tratamiento contable en el sector minero}

Camila Bellido

Alonso Ulloa

Arturo Yamagoshi

\section{Resumen}

El presente trabajo de investigación tiene como objetivo proponer un tratamiento contable homogéneo de aquellas operaciones específicas del sector minero que aún presentan vacíos normativos contables para su respectivo registro.

Para llevar a cabo esta investigación, se realizaron diversas entrevistas con expertos del sector, firmas auditoras y contadores de empresas mineras, mediante las cuales se determinó el alcance de este trabajo. Las operaciones consideradas para el estudio son los costos de exportación y evaluación, la provisión por cierre de minas y los métodos de depreciación.

A continuación, se procedió a comparar las políticas y métodos contables de cuatro empresas mineras reconocidas en el sector. La información se obtuvo tanto de las notas a los estados financieros como de entrevistas con contadores de las mismas empresas. Estas empresas fueron seleccionadas sobre la base de la oportunidad y disponibilidad de brindar información para el desarrollo de este trabajo.

La comparación de la información recopilada y la revisión del marco normativo, legal y tributario aplicable a cada una de las operaciones analizadas, dieron las bases para la elaboración de propuestas de homogeneización de estas cuentas.

Los resultados del análisis muestran que existen tres métodos permitidos por la NIIF 6 para la contabilización de los costos de exportación y evaluación. La diferencia en la estimación de la provisión por cierre de minas radica en la determinación de la tasa de descuento y la actualización anual de la estimación. 
No se han encontrado diferencias en los métodos utilizados; sin embargo, no existe normativa que regule la aplicación de los métodos permitidos por la NIIF6.

\section{Introducción}

El sector minero cuenta con diversas operaciones y transacciones contables que difieren de las operaciones corrientes de otros sectores. Esto en cuanto a cuentas de activos fijos, pasivos, provisiones y gastos, las cuales merecen un registro y tratamiento contable específico, frente a lo que usualmente se hace. Por ello, determinar las diferencias y proponer un correcto tratamiento homogéneo es necesario para facilitar la comparación de información financiera de empresas dentro de este sector en crecimiento.

Este sector ha sido uno de los pilares centrales en la bonanza económica que ha vivido el Perú durante la última década. Esto ha generado que cada vez más empresas seleccionen al Perú como un punto principal para la inversión minera. Además, es el sector principal en la Bolsa de Valores de Lima. Por estas razones, surge la necesidad de que la información contable y financiera sea lo más transparente y uniforme posible.

Actualmente, en el Perú se ha comenzado un proceso para que el sector empresarial adapte totalmente las Normas Internacionales de Información Financiera (NIIF). Sin embargo, la complejidad de algunas de las operaciones del sector, que distan de parecerse a las de otros sectores, hace difícil que se pueda uniformar el lenguaje contable minero entre las empresas. La única norma especifica que existe es la NIIF 6, que se centra en la etapa de exploración y evaluación, la cual regula solamente aspectos relacionados con el tratamiento contable de los costos de exploración y evaluación de recursos minerales, entre otros, pero no toma en cuenta las demás etapas del proceso minero.

Por otro lado, herramientas como el plan contable general empresarial (PCGE) establecen pocas cuentas específicas para el sector; las principales son las relacionadas con el canon, con las reservas y con algunas provisiones que se manejan en las mineras. Pero, al haber operaciones específicas, existe poca uniformidad de la información, debido a que las empresas suelen basarse en sus principales politicas contables, las cuales difieren entre empresas.

Eso demuestra una gran carencia de normas específicas para el sector, que permitan que la información que se muestra, tanto a los usuarios internos como 
a los externos, sea entendida y permita realizar comparaciones de acuerdo a la realidad del sector.

\section{Principales diferencias en el tratamiento contable del sector minero}

Actualmente, la única norma contable que regula el tratamiento de las operaciones del sector minero es la NIFF 6 Exploración y evaluación de recursos minerales, lo cual deja un vacío normativo en el tratamiento contable de las demás etapas mineras. Adicionalmente, dicha norma deja abierta la posibilidad de determinar el registro contable sobre la base de políticas determinadas por diferentes empresas.

Esto significa que la contabilidad minera en el país se basa principalmente en las políticas contables determinadas por cada empresa, lo cual implica discrepancias entre empresas sobre el registro de las mismas operaciones.

Por otro lado, estas discrepancias generadas por la carencia de normas específicas que regulen el tratamiento contable afectan la comparación de información financiera entre empresas del mismo sector, así como las decisiones tomadas por los usuarios externos.

En los últimos años, se observa una tendencia hacia la homogeneización de la información contable y financiera; sin embargo, esto no se ha visto reflejado en industrias específicas como la minería. Por este motivo, se plantea un tratamiento uniforme de dichas cuentas críticas que difieren entre la minería y los sectores empresariales.

\section{Metodología}

En los siguientes párrafos, se describe la metodología empleada en el presente trabajo de investigación con el propósito de alcanzar los objetivos planteados. Esta incluye los objetivos, el alcance, las hipótesis, las herramientas previamente analizadas y un cronograma de trabajo.

\section{Objetivos}

\section{Objetivo general}

Proponer la estandarización de las cuentas evaluadas, que atienda las principales necesidades contables y financieras, para crear un tratamiento único que facilite 
tanto el flujo de información contable/financiera, como la comparabilidad de esta información entre distintas empresas.

\section{Objetivos específicos}

a. Analizar e identificar los principales procesos de la actividad minera.

b. Determinar la clasificación de las empresas mineras en el Perú.

c. Identificar qué tipo de cuentas específicas corresponden al sector minero.

d. Identificar los distintos registros de las operaciones en el sector minero.

e. Analizar el marco normativo aplicable a las cuentas analizadas.

f. Proponer casuística sobre las principales diferencias en el tratamiento contable de las cuentas.

\section{Hipótesis}

\section{Hipótesis general}

El tratamiento contable de las principales cuentas en el sector minero peruano difiere dentro de las empresas del mismo sector, lo cual impacta en la uniformidad y comparabilidad de la información financiera.

\section{Hipótesis específicas}

a. El sector minero se beneficiará positivamente al comparar métodos y criterios contables homogéneos cuya principal herramienta es el PCGE.

b. Se mejorarán los controles de los procesos de registro contable en el sector minero, independientemente del tipo de minera involucrado.

c. El impacto de la aplicación del tratamiento contable estandarizado propuesto será positivo sobre la comparabilidad.

d. Se facilitará el ingreso de nuevas inversiones mineras al sector al tener un marco contable homogéneo. 


\section{Alcance}

Los resultados de la investigación permitirán establecer el inicio para la homogeneización de los registros contables dentro de las empresas mineras en el país. Se analizarán las principales cuentas que difieren en el sector minero de acuerdo con las entrevistas que se realicen en el proyecto.

\section{Herramientas}

Se realizará la recopilación a través de dos tipos de fuentes: primarias y secundarias.

\section{Fuentes de información}

\section{Fuentes primarias}

La información de fuentes primarias será adquirida mediante entrevistas en profundidad a contadores de las principales empresas mineras en el sector, con la finalidad de conocer el tratamiento contable de las principales cuentas de las empresas y la adaptación del PCGE a la realidad de las mineras, así como lograr el mejor entendimiento de los procesos mineros.

Asimismo, se contactará con expertos en temas mineros, con la intención de ampliar los conocimientos sobre la situación real contable y financiera de las empresas del sector, así como conocer experiencias en el extranjero. Finalmente, habrá entrevistas con expertos en temas relacionados con el PCGE, con la intención de considerar cualquier contraposición u omisión de conceptos contables dentro de la propuesta y resultados de la investigación realizada ${ }^{1}$.

\section{Fuentes secundarias}

En cuanto a la información de fuentes secundarias, se realizará un análisis minucioso sobre el marco legal minero que existe en el país, con el propósito de conocer el marco legal por el cual se rigen las empresas mineras para su normal funcionamiento.

\section{Véase el anexo 1.}


Asimismo, se analizarán publicaciones especializadas sobre contabilidad minera y el nuevo tratamiento del PCGE, así como el marco normativo contable internacional (Normas Internacionales de Contabilidad, Normas Internacionales de Información Financiera, etc.).

\section{Descripción del sector minero}

El Perú, por naturaleza, es un país minero debido a la tradición que mantiene, ya que cuenta con un enorme potencial geológico, respaldado por la presencia de la cordillera de los Andes a lo largo de su territorio. Esta constituye la fuente principal de recursos minerales en el país, que son aprovechados por empresas reconocidas mundialmente en el sector.

A nivel mundial y latinoamericano, el país se ubica entre los primeros productores de diversos metales tales como oro, plata, cobre, zinc, hierro, estaño, molibdeno, teluro, entre otros, lo cual refleja la vasta diversidad de recursos y la capacidad de producción ${ }^{2}$ de la minería peruana, que representa la principal actividad económica del país.

El accionar de este sector representa más del 60\% de las exportaciones totales del país y aproximadamente 35\% de la recaudación por parte del Estado del impuesto a la renta de tercera categoría ${ }^{3}$. Las inversiones en minería para los años 2011-2012 alcanzan los US\$ 10.000 millones. La minería aporta con varias obras de inversión social, las cuales apoyan la lucha contra la pobreza en sus zonas de influencia. Asimismo, a través del Aporte Voluntario (Programa Minero de Solidaridad con el Pueblo), destinará S/. 2.500 millones en 5 años, que beneficiarán a 16 regiones, 57 provincias y 234 distritos. Además, ha evitado que al menos 2 millones de personas se encuentren en situación de pobreza.

La importancia del sector se muestra en su crecimiento. Muestra de ello es que desde el año 1994 hasta 2011 el peso de la minería en términos porcentuales se ha triplicado ${ }^{4}$.

2. Véase el anexo 2.

3. Perú: pais minero. Sociedad Nacional de Minería, Petróleo y Energía, marzo de 2011.

4. Diario Perú 21 (7 de diciembre de 2011). Recuperado el 23 de septiembre de 2012, de Perú21.pe: <http:// peru21.pe/2011/12/07/economia/afirman-que-peso-mineria-pbi-cada-vez-mayor-2002187>. 
Asimismo, el Banco de Crédito del Perú, en un informe sobre el sector, señala que el 58\% de los proyectos de inversión para el período 2011-2013 corresponden al sector minero y al de hidrocarburos ${ }^{5}$.

\section{Clasificación del sector minero}

Dentro del marco normativo vigente en el sector, se señalan los distintos tipos de concesiones mineras, tomándose como referencia la clasificación desarrollada por el abogado Guillermo García Montúfar, en su libro Derecho de minería $(1965)^{6}$.

La clasificación de las concesiones puede hacerse mediante distintos tipos de criterios, como el tipo de actividad, es decir, si son solamente empresas que funcionan dentro de una de las etapas del ciclo de vida de la mina. La naturaleza del tipo de mineral extraído es otro de los criterios aplicados. Asimismo, el método de exploración que aplique la empresa es una forma de determinar el tipo de concesión por utilizar. También existen las concesiones, que son vistas por el tamaño de la empresa minera que realiza las actividades en los yacimientos. Así como los mencionados, existen otros criterios que determinan el tipo de minería que existe en el Perú7.

\section{Etapas en la minería ${ }^{8}$}

Algunos expertos señalan que las etapas por las que tiene que pasar una empresa minera que se dedique a realizar toda la actividad, desde la exploración hasta el cierre de la mina, son siete.

Las etapas se pueden agrupar en tres fases: las previas a la operación, las que se realizan durante la operación y las posteriores a la operación.

Las etapas previas a las operaciones son aquellas que determinan la rentabilidad del proyecto por realizar, incluyendo actividades de cateo y prospección

\footnotetext{
5. Ibid.

6. García Montúfar, G. (1965). Derecho de mineria. Lima: Universidad Nacional Mayor de San Marcos.

7. Véase el anexo 3.

8. La información recolectada para esta sección fue tomada de las siguientes fuentes:

- Sociedad Nacional de Minería, Petróleo y Energía. (2011). Manual de aplicación práctica de las NIIF en el sector minero. Lima: Grambs Corporación Gráfica.

- Estudios Mineros del Perú S. A. C. (2011). Manual de minería. Lima: Estudios Mineros del Perú S. A. C.

- Ley General de Minería.
} 
de terrenos con el propósito de encontrar yacimientos donde comenzar con la exploración. Luego de obtener los permisos del caso, se procede a realizar una exploración más a fondo, hasta llegar a tener las pruebas técnicas y económicas sobre el yacimiento estudiado, para proceder luego con la inversión en infraestructura para el desarrollo de la mina, siempre con un plan determinado sobre los puntos por tratar.

Luego de tener la certeza técnica y económica sobre la viabilidad del proyecto en marcha, se procede con la explotación, que no es otra cosa que el inicio de las actividades de extracción del mineral, el procesamiento del mismo y su posterior comercialización. Es en este punto cuando las empresas recién comienzan a tener ingresos constantes.

Finalmente, se procede con las actividades de cierre de minas. Las fases del proceso de cierre incluyen: diseño inicial, aprobación gubernamental del plan de recuperación y financiamiento, recuperación progresiva durante la operación, fin de la producción con costos asociados al despido del personal, desmantelamiento de construcciones y reacondicionamiento de las áreas explotadas.

El abandono se da cuando se logra alcanzar el equilibrio de la extracción minera. En este caso, la empresa entrega la concesión de vuelta al Estado, dejando de lado cualquier tipo de responsabilidad de monitoreo o cualquier otra responsabilidad ${ }^{9}$.

Cabe recalcar que no todas las empresas del sector necesariamente tienen que pasar por todas las etapas de la minería; la mayoría se ubican en ciertas etapas, como aquellas que solo explotan y comercializan los minerales, así como las que se dedican a explorar yacimientos y a partir de esto venden proyectos mineros, entre otras.

\section{Análisis y evaluación de información}

\section{Cuentas analizadas}

Para el análisis y evaluación de la información, se han considerado las siguientes cuentas cuyo tratamiento contable difiere dentro de las empresas del sector minero:

9. Véase el anexo 4. 


\section{Costos de exploración y evaluación}

La exploración y evaluación de recursos minerales consiste en el examen detallado de un área geográfica de interés que tiene potencial para producir mineral y que merece una mayor exploración ${ }^{10}$. Dichos costos de exploración incluyen: salarios; gastos de personal; gastos del trabajo geológico, del trabajo geofísico y otros; depreciación; mantenimiento y costos de reparación de equipos; costos de exploración llevada a cabo por contratistas, entre otros.

El tratamiento contable en las empresas mineras del sector varía de acuerdo con la política que cada compañía mantenga en cuanto al registro de los costos de exploración. Existen tres posibilidades en el tratamiento contable de los costos de exploración ${ }^{11}$ :

- Cargar a resultados todos los costos de exploración y evaluación de recursos minerales en el período en que se incurren.

- Cargar a resultados todos los costos de exploración incurridos hasta que existan con certeza recursos minerales; a partir de esta etapa, se activan (capitalizan) todos los costos.

- Se activan todos los costos de exploración y evaluación.

\section{Provisiones por cierre de minas}

Las provisiones por cierre de minas están destinadas a cubrir el costo del plan de cierre de minas y deberán registrarse a partir del ejercicio contable en que el titular minero deba constituir garantía, según el cronograma aprobado por la autoridad competente ${ }^{12}$.

Dichos pasivos ambientales, de acuerdo con la NIC 37, deben registrarse a valor presente puesto que implican períodos largos de tiempo (descuento de flujos estimados). Además, deben actualizarse cada año para ajustar dicha provisión; es aquí donde se generan las principales diferencias: por un lado, la tasa de descuento, cuyo monto depende de las políticas de las empresas, y, por otro, la

10. Manual de aplicación práctica de las Normas Internacionales de Información Financiera en el sector minero, capítulo 3: "Costos de exploración y evaluación de recursos minerales".

11. NIIF 6 - Exploración y evaluación de recursos minerales.

12. Ley que Regula el Cierre de Minas (Ley 28090), artículo 12. 
actualización que cada empresa da a sus provisiones (variaciones en cuanto al tiempo que se registran: 1 año, 2 años o 3 años).

\section{Métodos de depreciación}

Los métodos de depreciación que se usan en minería varían de acuerdo con el tipo de activo fijo que se use.

Por un lado, se tiene la depreciación por línea recta, método que es como función del tiempo y no de la utilización de los activos. Se estima una vida útil al activo fijo y de esta forma se calcula la depreciación, cuyo gasto se distribuye de manera equitativa. Por otro lado está la depreciación por unidades de producción, que se basa en la función del rendimiento y del número de unidades que la empresa produce.

En el sector minero se cuenta con los siguientes activos fijos que usan el método lineal: muebles, maquinaria, enseres, etc. Para el método de unidades producidas, los activos son: edificios, construcciones, activos del plan de cierre de minas, etc. De dichos activos hay que distinguir los que tienen relación con la minería en sí, y los que no tienen relación. Aquellos que están relacionados con la minería son: la infraestructura dentro de la mina, temas de ventilación, equipos de perforación, soporte (maderas), luces, zonas de emergencia, rampas, etc.

\section{Marco teórico}

En este capítulo, se tratará de las principales implicancias contables y financieras que presentan las cuentas e información financiera evaluadas. Asimismo, las normas, leyes e interpretaciones internacionales que se deben tomar en cuenta en su tratamiento, con el propósito de mostrar la información contable de manera clara y fiable de acuerdo a la realidad de la empresa minera.

\section{Costos de exploración}

Existe doctrina contable internacional que puede ser tomada en cuenta en el análisis de los costos de exploración en el sector minero. En este punto, se mencionarán las Normas Internacionales de Información Financiera (NIIF), así como las Normas Financieras Contables (FAS, por sus siglas en inglés) cuyo tratamiento se asemeja al del sector, además de normas tributarias. Estas normas atienden distintos puntos dentro del tratamiento contable de los costos de exploración. 
Dentro de las normas analizadas, se encuentran las siguientes:

- NIIF 6 Exploración y evaluación de recursos minerales.

- $\quad$ NIC 8 Políticas contables, cambios en las estimaciones contables y errores.

- $\quad$ NIC 36 Deterioro del valor de los activos.

- NIC 38 Activos intangibles.

- FAS 19 Financial Accounting and Reporting by Oil and Gas Producing Companies.

- Texto Único Ordenado del Impuesto a la Renta - Decreto Supremo 1792004-EF.

La NIIF 6 es la norma contable que sirve de lineamiento a la actividad minera de exploración y extracción. Esta norma establece un marco normativo para el tratamiento de los desembolsos incurridos en las etapas de exploración y evaluación de recursos minerales. Aplica solo para gastos incurridos luego de un estudio de factibilidad de extracción, pero luego de obtener el derecho de explorar en dicha área.

Esta norma se refiere a la aplicación del párrafo 10 de la NIC 8, en el cual se determina cómo deben ser las políticas contables definidas por las compañías.

"En la ausencia de una NIF que sea aplicable específicamente a una transacción o a otros hechos o condiciones, la gerencia deberá usar su juicio en el desarrollo y aplicación de una política contable, a fin de suministrar información que sea:

(a) Relevante para las necesidades de toma de decisiones económicas de los usuarios; y

(b) fiable, en el sentido que los estados financieros:

(i) presenten de forma fidedigna la situación financiera, el rendimiento financiero y los flujos de efectivo de la entidad;

(ii) reflejen la esencia económica de las transacciones, otros eventos y condiciones, y no simplemente su forma legal;

(iii) sean neutrales, es decir, libres de prejuicios o sesgos;

(iv) sean prudentes; $y$

(v) estén completos en todos sus extremos significativos»" ${ }^{13}$.

13. NIC 8 Políticas contables, cambios en estimaciones contables y errores (párrafo 10). 
Los desembolsos se reconocerán como activos según política de la empresa, siempre y cuando se aplique el mismo criterio uniformemente. De realizarse un cambio en la política contable, deberá hacerse de acuerdo a la NIC 8, si es más fiable.

También distingue activos intangibles de materiales. En aquellos activos materiales que se consuman en el desarrollo de uno intangible, el importe de consumo será parte del activo intangible.

Cuando se tenga factibilidad del recurso mineral, los activos deberán ser reclasificados con una evaluación por deterioro previa, registrando la pérdida correspondiente de acuerdo a la NIC 36.

De acuerdo con dicha norma, las empresas son libres de llevar a cabo el registro de dichos desembolsos sobre la base de políticas contables. Existe la NIC 8 Políticas contables, cambios en estimaciones contables y errores, que regula el tratamiento de las políticas contables dentro de cualquier empresa.

De acuerdo a la NIC 8, las políticas contables son: «aquellos principios bases, acuerdos, reglas y procedimientos específicos que las organizaciones realizan para la elaboración de estados financieros»" ${ }^{14}$.

Asimismo, la gerencia, cuando elabore las políticas contables debe considerar los contenidos de la NIIF e incluir las definiciones, los criterios de reconocimiento y la medición establecida de las cuentas involucradas. Además, la gerencia debe tomar en cuenta los pronunciamientos de otras instituciones que empleen un marco conceptual similar al de emitir normas contables.

En el caso de los cambios que pueden surgir en las políticas contables, la empresa lo hará en el proceso de utilización de juicios basados en información fiable disponible más reciente. Según el párrafo 11, se realizará bajo dos situaciones:

(i) «Si es requerido por una NIIF;

(ii) permita tener estados financieros que suministren información más fiable y relevante sobre los efectos de las transacciones» ${ }^{15}$.

14. NIC 8 Políticas contables, cambios en estimaciones contables y errores (párrafo 5).

15. Ibíd. (párrafo 11). 
La NIC 38 (Intangibles) brinda apoyo en la determinación de políticas contables sobre el tratamiento contable de los costos de exportación y evaluación. Esta norma fija los requisitos para que un activo fijo sea tratado como tal.

Los requisitos que se deben cumplir para el reconocimiento de un activo intangible como tal son la identificabilidad, el control sobre el recurso en cuestión, la existencia de beneficios económicos futuros que fluyan hacia la entidad y la fiabilidad en la valoración del costo. Esto incluye los costos soportados inicialmente y aquellos incurridos posteriormente.

Este reconocimiento de los costos al importe en libros del activo intangible finalizará cuando los activos estén listos para operar, momento en el cual deberán empezar a ser amortizados, tanto por amortización lineal como por porcentaje constante sobre valor en libros o por unidades producidas.

Estos desembolsos sobre una partida de intangibles serán reconocidos como gastos en la medida en que se incurran hasta el momento en que cumplan con los requisitos para que sean reconocidos como activos tangibles.

Si la empresa reconoce el desembolso como un activo, la NIIF 6 establece para ciertos casos, ya mencionados, el uso de la NIC 36 Deterioro del valor de los activos. La empresa minera se encuentra en la obligación de reconocer cualquier tipo de deterioro en el valor de los activos que forman parte de exploración y evaluación. La norma da la posibilidad de realizar los cálculos del deterioro mediante la comparación del importe en libros con su importe recuperable, con independencia de la existencia de cualquier indicio de deterioro del valor, siempre y cuando se cumplan los siguientes requisitos:

(a) «En el caso de que el activo intangible no generase entradas de efectivo que sean en buena medida independientes de aquellos flujos que provienen de otros activos o grupos de activos y, en consecuencia, se compruebe su deterioro del valor como parte de la unidad generadora de efectivo a la cual pertenece, que los activos y pasivos que componen esa unidad no hayan cambiado significativamente desde que se realizó el cálculo más reciente del importe recuperable.

(b) El cálculo del importe recuperable más reciente diese lugar a una cantidad que exceda, por un margen significativo, el importe en libros del activo» ${ }^{16}$.

16. NIC 36 Derecho del valor de los activos (párrafo 24). 
A partir de un análisis de los eventos y circunstancias que han ocurrido y aquellas circunstancias que han cambiado desde que se efectuó el cálculo más reciente del importe recuperable, la probabilidad de que el importe recuperable corriente sea inferior al importe en libros puede ser remota.

Dentro de lo mencionado por la Ley del Impuesto a la Renta, específicamente en el artículo 37..$^{\circ}$ se menciona, en el inciso o), que los gastos de exploración, preparación y desarrollo incurridos por los titulares de la actividad minera, pueden llegar a ser deducidos en el período en que se producen o ser reducidos de acuerdo a la Ley General de Minas. Pero la norma no considera que los gastos sean deducibles en caso el proyecto no se lleve a cabo, y en muchos casos la Sunat no permite que sean deducidos ${ }^{17}$.

\section{Provisiones por cierre de minas}

Las provisiones por cierre de minas son un tema que ha generado mucha discusión en el sector. Por lo tanto, para el tratamiento de la provisión se debe mantener el marco normativo correspondiente para la estandarización de la estimación de los montos. El marco contable que apoyará el tratamiento de la cuenta es el siguiente:

- NIIF 13 Medición del valor razonable.

- NIC 16 Propiedades, planta y equipo.

- NIC 37 Provisiones, pasivos contingentes y activos contingentes.

- FAS 143 Accounting for Asset Retirement Obligations (AR0).

- CINIIF 1 Cambios en pasivos existentes por retiro de servicio, restauración y similares.

- CINIIF 5 Derechos por la participación en fondos para el retiro del servicio, la restauración y la rehabilitación medioambiental.

- $\quad$ Ley de Cierre - Ley 28090

- Texto Único Ordenado de la Ley General de Minería - Decreto Supremo 01492EM.

La obligación de las empresas para hacerse cargo del impacto ambiental que tienen sus operaciones se rige por la Ley de Cierre de Minas. 
Dentro de la norma, se establece que todo titular que se encuentre involucrado en la actividad minera tiene la obligación de realizar el cierre de las áreas, labores e instalaciones de la unidad minera de acuerdo a lo establecido en el plan de cierre de minas, el cual, según lo establecido, debe contar con garantías que aseguren el bienestar ambiental y comunitario.

Cabe señalar que el plan de cierre de minas es un instrumento de gestión ambiental conformado por acciones técnicas y legales que deben ser efectuadas por el titular de la actividad minera con el único fin de rehabilitar las áreas perturbadas por la actividad minera. Esta sirve como un complemento para el estudio de impacto ambiental y el programa de adecuación y manejo ambiental.

Los planes deben incluir no solamente las medidas que se aplicarán, sino también los presupuestos necesarios para llevar a cabo el plan. Además, debe incluir el estimado del presupuesto, el cronograma anualizado y las garantías. Toda esta información debe ser presentada al Ministerio de Energía y Minas, el cual realizará la verificación, la evaluación técnica y observaciones, y llegará a una resolución final sobre el material entregado.

En el artículo $20 .^{\circ}$, se menciona que el plan de cierre debe ser actualizado tres años después de su aprobación y, luego, cinco años después de su última actualización. Se debe tener en cuenta la opinión de la Dirección General de Minería si esta informa que existe algún desfase que pueda haber surgido luego de su actualización.

De acuerdo a la ley, el cierre de minas puede presentarse en tres distintos escenarios:

- Cierre temporal: de acuerdo a la circunstancias económicas u operacionales, puede existir el caso en el que se decida que sean temporalmente suspendidas, pero siempre teniendo un plan de reinicio de las operaciones.

- $\quad$ Cierre progresivo: es el que se va llevando a cabo en paralelo a la etapa de operación de la empresa, cuando un componente deja de ser útil para esta, el cual pasa por los procesos de cierre.

- Cierre final: sucede debido al agotamiento de los recursos minerales y cuando el costo/beneficio de continuar es negativo y se decide finalizar la operación de minado y de procesamiento, para dar inicio a las actividades establecidas en el plan de cierre. 
- Postcierre: son todas las actividades realizadas luego del cierre minero con el propósito de demostrar la estabilidad física de los daños efectuados por la actividad minera.

De acuerdo a lo establecido en el artículo $42 .^{\circ}$, el presupuesto se calcula sobre el monto estimado del valor presente neto actualizado del plan de cierre de mina, considerando como base la fecha de ejecución de las medidas consideradas en el plan, así como también montos de rehabilitación ya ejecutados, importes en garantía por constituirse, entre otros.

En el artículo subsiguiente, se indica que solo es admisible una diferencia del $30 \%$ por debajo del monto estimado durante la ejecución del plan; en caso se exceda dicho porcentaje, habría sanciones contra el titular de la actividad minera.

La garantía que la empresa debe establecer en su plan debe ser lo suficientemente líquida, debe contar con la documentación legal, y su valor debe ser permanentemente actualizado (como el plan), entre otras características. La valuación de la garantías ambientales se basa en el valor neto de realización, con lo cual, lo que se busca es reflejar el valor de venta menos los gastos adicionales en que se incurra.

Las empresas del sector tienen la obligación de reconocer una provisión por el cierre de minas, tal como se indica en la norma. Para el reconocimiento y posterior cálculo de la provisión de cierre, se debe actuar de acuerdo a lo establecido en la NIC 37 Provisiones, pasivos contingentes y activos contingentes.

De acuerdo a lo mencionado en la NIC 37, toda provisión debe ser reconocida solo si cumple con tres principales condiciones planteadas en el párrafo:

(i) «Una entidad que tiene una obligación presente (sea legal o implícita) como resultado de un hecho pasado.

(ii) Exista la posibilidad de salida de recursos, que incorporan beneficios económicos para cancelar tal obligación

(iii) Se pueden hacer estimaciones fieles del importe» ${ }^{18}$.

La provisión de cierre de mina cumple con estas tres condiciones si se toma en cuenta lo señalado en la norma (párrafo 19), que las provisiones serán re- 
conocidas con obligaciones cuya existencia sea independiente de las acciones futuras de las empresas. En este párrafo, se muestra un ejemplo de empresas extractivas que dañan el medio ambiente y que luego de sus operaciones deben restaurar los daños cometidos.

Por lo tanto, el importe estimado en dichas provisiones debe ser actualizado al final de cada período de información, con el objetivo de mantener un mejor control (párrafo 59). La tasa a la cual se debe descontar el monto debe ser considerada antes de impuestos y con los ajustes de cualquier riesgo inminente detectado (párrafos 47-50). La medición de la estimación debe ser revelada en cada período.

Al ser las mineras entidades con obligación de retirar, desmantelar y restaurar elementos de su propiedad, planta y equipo, deben aplicar la CINIIF 1. De acuerdo con la NIC 16, estos costos deben ser capitalizados al costo inicial del activo. Esta interpretación de la norma indica la forma de contabilización cuando hay un cambio en dichos pasivos generado por el retiro, desmantelamiento o restauración de los elementos del activo fijo.

«Los cambios en el pasivo se pueden dar por tres motivos:

1. Modificación estimada de la salida de recursos

2. Cambio en la tasa de descuento

3. Reversión del descuento (incremento que refleje paso del tiempo)».

Si el método de medición del activo es costo, se disminuirá o incrementará el valor del activo según el cambio del pasivo, siempre y cuando no exceda el valor en libros del activo y se haga la evaluación por desvalorización.

De utilizarse el método de revaluación, estos cambios afectarán directamente el excedente de revaluación por dichos activos. Las variaciones se reconocerán como otros resultados integrales (según la NIC 1, se deben revelar estos componentes).

Fuera de las normas internacionales de la IASB, existen ciertas normas importantes, como las planteadas por el FASB de los Estados Unidos de América. Ellos no toman en cuenta una norma específica para la minería, pero se pueden adaptar las normas generales a los sectores extractivos como petroleras o gas. 
La FAS 143 Accounting for Asset Retirement Obligations (AR0) señala que la estimación del valor razonable del retiro del activo sea reconocido como un pasivo en el período en el que ocurre la actividad. Además, señala que toda metodología de estimación debe ser sustentada en las notas a los estados financieros.

El valor razonable de la obligación por el retiro del activo equivale al monto por el cual el activo puede ser negociado entre las distintas partes interesadas durante el período evaluado. Por lo tanto, la técnica de evaluación utilizada es la del valor presente, la cual se realiza sobre los flujos de caja que generará la obligación por el retiro del activo. Se puede calcular el valor presente del activo mediante dos métodos. El primero es el método tradicional, el cual es el conjunto de flujos de caja estimados a una tasa simple con el propósito de alcanzar el valor razonable; el otro método utiliza una serie de distintos escenarios de flujos de caja que reflejen el rango de posibles resultados. La tasa de descuento apropiada para el descuento de los flujos que se debe utilizar es la aplicada a un caso que tenga los flujos de caja similares a los del activo analizado.

En la norma se establece que la tasa libre de riesgo es la tasa que se debe utilizar para descontar los flujos futuros del activo que se dará de baja en el futuro, pero la misma tiene que tomar en cuenta los riesgos que puedan presentarse.

La norma también establece las obligaciones que se les presentan a las empresas que pueden generar un pasivo ambiental, o por algún otro concepto. La empresa genera el pasivo desde el momento en que sus operaciones pueden afectar el bienestar del medio ambiente, ya que luego del cierre deberá realizar obras que subsanen lo afectado.

El ARO puede definirse como las obligaciones legales relacionadas con el cierre, la descontaminación y el retiro de activos de larga vida en todos los sectores, incluido el minero. Actualmente, muchas empresas presentan provisiones por AR0 para efectuar el cierre de minas. La norma también establece que la mejor forma de determinar el valor de la estimación es a través de la cotización de un tercero que pueda evaluar el monto calculado.

\section{Métodos de depreciación}

Los métodos de depreciación siguen los mismos lineamientos establecidos en las siguientes normas: 
- $\quad$ NIC 16 Propiedad, planta y equipo

- $\quad$ NIC 8 Políticas contables, cambios en estimaciones contables y errores.

La NIC 16 aplica a aquellos activos usador para la exploración y evaluación, pues se encuentran normados por la NIIF 6. Un elemento del activo deberá ser considerado como planta, maquinaria y equipo si y solo si se cumplen los siguientes requisitos:

a) «Sea probable que se obtengan beneficios económicos futuros derivados del mismo.

b) El costo pueda medirse con fiabilidad» ${ }^{19}$.

Los activos deben ser medidos al costo en el momento del reconocimiento. Es decir, el precio de dicho activo, los costos atribuibles a la ubicación del activo en su lugar y una estimación inicial de los costos de desmantelamiento y retiro del elemento, tal como la rehabilitación del lugar. Estos costos son abordados en la NIC 2.

Luego del reconocimiento inicial, hay dos formas de reconocimiento: modelo del costo o revaluación. La revaluación es el valor razonable del activo en el momento del análisis de su valor. Estos análisis deben hacerse con periodicidad o cuando se tenga indicio de la pérdida de valor de este.

La depreciación de los elementos de propiedad, planta y equipo se tratará por separado. El valor residual y la vida útil y el método de depreciación de los activos se revisarán como mínimo una vez al año, y cualquier cambio en estos deberá ser tratado de acuerdo con la NIC 8.

\section{Comparación de registros y tratamiento contable}

El tratamiento contable de las cuentas analizadas requiere un marco de registro contable apropiado. Dicho registro varía de acuerdo con la política contable que cada empresa aplique en su contabilidad. En el anexo 5, se puede apreciar el cuadro comparativo de los registros contables de empresas analizadas por intermedio de las notas a los estados financieros publicadas por la Superintendencia del Mercado de Valores (SMV) o por las entrevistas realizadas.

19. NIC 16 Propiedad, planta y equipo (párrafo 7). 
En el primer punto analizado, se tratan los gastos o costos de exportación. Su tratamiento difiere entre distintas empresas. En el caso de mineras grandes y medianas, se decide capitalizar los desembolsos, en forma de activo fijo. Se amortizan de acuerdo con el tiempo de vida de la mina. En este caso, la minera C lo realiza sobre la base de la evaluación de la probabilidad de que ingresen beneficios económicos producto de exploraciones futuras; esto lleva a que capitalice los desembolsos. En el caso de la minera B, la política mantenida por la compañía ha sido de reconocer como activos los gastos incurridos en actividades de exploración y evaluación.

Por otro lado, la minera A determina que la propiedad minera es económicamente viable (existencia de reservas probadas y probables) y los costos de exportación son capitalizados. Antes de dicho momento, los costos son cargados como gastos, según se incurre en ellos. La minera D posee una política similar en cuanto a los costos de exportación.

La comparación anterior muestra las diferencias en tratamiento que admite la NIFF 6, ya que, como señala la norma, queda como potestad de la empresa aplicar una política contable, siempre y cuando la mantenga de manera consistente durante los años siguientes.

\section{Costo de exploración y evaluación}

\section{Caso 1: Cargar a resultados}

El primer análisis corresponde al registro contable de los costos de exploración y evaluación. En el sector minero, el tratamiento contable va de acuerdo con la NIFF 6 previamente explicada. Bajo este marco teórico, existen tres tipos de registros contables que son aceptados por las normas internacionales.

Por un lado, algunas empresas pueden registrar los costos de exportación y evaluación como gastos, es decir, se cargan a los resultados del ejercicio. Estas empresas se caracterizan por ser muy conservadoras en el momento de registrar, porque estarían con la incertidumbre de encontrar o no minerales. Por tal motivo, se decide cargar todo a resultados, de acuerdo con el siguiente asiento:

Costo de exploración y evaluación (Gasto - DEBE) Cuentas por pagar diversas / Caja - bancos (HABER) 
Caso 2: Cargar a resultados hasta que exista certeza de recursos minerales, luego se activa

Por otro lado, existen empresas conservadoras que en primera instancia registran estos costos como gastos para luego, cuando exista certeza técnica y comercial de encontrar recursos minerales, activarlos, es decir, capitalizar dichos costos. Por lo tanto, existen dos registros, como se detalla en los siguientes asientos:

Costo de exploración y evaluación (Gasto - DEBE)

Cuentas por pagar diversas / Caja - bancos (HABER)

Intangibles (Activo - DEBE)

Costo de Ex. y Ev. / Resultados acumulados (HABER)

\section{Caso 3: Activar todos los costos de exploración y evaluación}

Finalmente, existen empresas con mayor propensión al riesgo, que desde el inicio de sus operaciones de exploración y evaluación deciden capitalizar (activar) estos costos, como en el siguiente asiento:

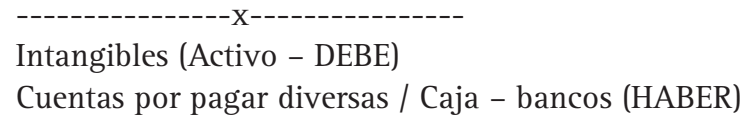

Provisión por cierre de minas

El segundo análisis corresponde al plan de cierre de minas, a través del cual, de acuerdo con la Ley 28090 explicada anteriormente, las empresas mineras deben cumplir con la rehabilitación del área utilizada. Contablemente, es necesario el registro de los pasivos ambientales (provisión), la actualización del valor presente, y el registro de los gastos derivados del plan de cierre de minas.

Las diferencias en el registro se generan con la actualización del valor presente de los flujos descontados, en donde la tasa de descuento y el período de actualización varían de acuerdo con cada empresa del sector. 
El primer registro corresponde al registro inicial de cierre de minas:

Cargas diferidas (Activo - DEBE)

Pasivo ambiental - Provisión (HABER)

Dicho activo, al ser considerado como un activo de larga duración, debe ser depreciado período a período de acuerdo con el siguiente asiento:

Servicios prestados por terceros (Gasto - DEBE)

Finalmente, conforme van pasando los años de vida de la mina sujeta al cierre de minas, el valor presente de los flujos descontados que sirven de base para el registro inicial de la provisión realizada se tiene que actualizar sobre la base de una tasa de descuento y una periodicidad determinada, de acuerdo con el siguiente asiento:

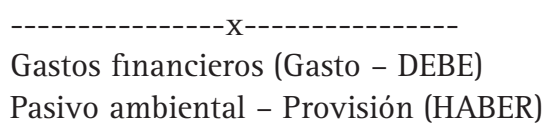

\section{Métodos de depreciación}

El tercer análisis corresponde al tratamiento contable de las depreciaciones. En las empresas del sector minero se usan dos métodos de depreciación y se registran de la misma forma:

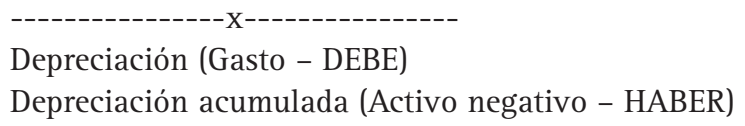

Sin embargo, el tratamiento contable en el sector minero varía de acuerdo con el tipo de activo fijo que sea. Aquellos activos como edificaciones y construcciones, y el activo por plan de cierre de minas, se deprecian usando unidades de producción. El resto de activos fijos, como muebles, maquinarias, enseres y unidades de transporte, se deprecian según el método de línea recta. En general, los activos que estén relacionados con la mina se deprecian con unidades de 
producción, mientras que los no relacionados con la mina, tales como los de oficina, se deprecian por el método de línea recta.

\section{Propuesta}

Sobre la base de lo planteado hasta el momento en cuanto a las diferencias en el tratamiento contable de los costos de exploración y evaluación, de las provisiones de cierre de minas y de los métodos de depreciación, proponemos la homogeneización del tratamiento contable dentro del sector minero.

\section{Propuesta planteada}

De acuerdo con el análisis realizado, la posición conservadora es la forma de registro y tratamiento contable que las empresas del sector minero deben adoptar. Dicho registro corresponde a los siguientes asientos:

$$
\begin{aligned}
& \text { Costo de exportación y evaluación (Debe - Gasto) } \\
& \text { Cuentas por pagar / Caja - bancos (Haber - Pasivo/activo) } \\
& \text {-----------1--------- } \\
& \text { Intangibles (Debe - Activo) } \\
& \text { Costos por Ex. y Ev. / U. retenida (Haber - Gasto/Patrimonio) }
\end{aligned}
$$

Esta posición corresponde a registrar en primera instancia los costos de exploración y evaluación como gastos, para luego, cuando exista certeza técnica y comercial de encontrar recursos minerales, capitalizarlos. Se propone esta opción ya que, según la NIC 38, «los desembolsos sobre una partida intangible deberán reconocerse como un gasto cuando se incurra en ellos» ${ }^{20}$. Sobre la base de esta NIC, se determina que inicialmente todos los costos de exploración y evaluación deben registrarse como gastos en el momento en que se incurra en ellos en una primera instancia. Posteriormente, se deben capitalizar (activar) cuando "Es probable que los beneficios económicos futuros que se han atribuido al mismo fluyan a la entidad y que el costo del activo puede ser medido de forma fiable» ${ }^{21}$. 
Además, de acuerdo con las entrevistas realizadas a empresas auditoras, existe la FAS 19, que recomienda que los costos de exploración destinados a determinar la existencia, o no, de reservas naturales, sean reconocidos en el período, asumiendo que no hay probabilidad de su contribución en los ingresos. Si bien esta norma aplica para el sector del petróleo, consideramos que el tratamiento contable se asemeja al sector minero en cuanto a la exploración de recursos y su registro como gastos cuando se incurra en ellos.

Se concluye que dicho registro es el más apropiado para los costos de exploración y evaluación, pues está permitido por la NIFF 6 y cumple con las consideraciones de la NIC 38. Por ende, las empresas del sector minero deberian considerar dichos costos en primera instancia como gastos, para luego capitalizarlos cuando haya certeza.

De esta forma, la empresa podrá realizar la reducción inicial. Esto beneficiará a la empresa puesto que podrá reducir los desembolsos, de acuerdo con lo establecido en el artículo $37 .^{\circ}$, inciso o), que indica que los gastos de exploración, preparación y desarrollo incurridos por los titulares de la actividad minera pueden llegar a ser deducidos en el período que se producen o se pueden reducir de acuerdo a la Ley General de Minas.

\section{Provisión de cierre de minas}

La provisión, que se tiene que realizar de acuerdo a la ley, ha creado cierta discrepancia en el sector acerca de la estimación del valor presente de la provisión de cierre, la que incluirá todos los futuros desembolsos en que la empresa incurrirá para efectuarlo. Asimismo, la actualización del valor de la provisión no se encuentra estandarizada en la industria, en un marco normativo que complemente.

Para el tema relacionado con la actualización del monto de la provisión, la propuesta recaería en que las empresas, con el fin de mostrar información clara y transparente a sus usuarios internos y externos, tendrán que realizar la actualización del monto de la provisión al final de cada período. Al tratarse de una industria en la que la incertidumbre crece constantemente por distintos motivos, el riesgo (conflictos sociales, escasez de recursos, entre otros), que puede llegar a generar salida de dinero, puede cambiar al final de cada período. 
El párrafo 59 de la NIC 37 menciona lo siguiente: "Las provisiones deben ser objeto de revisión de cada período sobre el que se informa, y ajustadas consiguientemente para reflejar en cada momento la mejor estimación disponible. En el caso de que no sea ya probable la salida de recursos, que incorporen beneficios económicos, para cancelar la obligación correspondiente, se procederá a liquidar o revertir la provisión".

Asimismo, la norma establece la obligación de las empresas extractivas cuyas operaciones pueden generar pasivos ambientales que, conforme pasa el tiempo, pueden modificar los desembolsos futuros. El valor razonable de la obligación del retiro del activo es equivalente al monto por el cual el activo puede ser negociado entre distintas partes interesadas durante el período evaluado. Por lo tanto, la técnica de evaluación utilizada es la del valor presente, la cual se realiza sobre flujos de caja que generará la obligación del retiro. Esto es lo que menciona la FAS 143.

En el caso de la tasa de descuento por aplicar para la estimación del monto de la provisión, se considerará la posición que respalda $\mathrm{PwC}$, la cual indica que en el caso de empresas que mantienen una contabilidad en dólares estadounidenses, la tasa de descuento que se utilizará es la del Tesoro estadounidense; y en el caso de las empresas que tienen una contabilidad en nuevos soles, se debe utilizar la tasa de los bonos soberanos que emite el Estado peruano.

Por lo tanto, se concluye que el tratamiento adecuado para la provisión minera es que la actualización del activo se debe dar al final de cada ejercicio contable, con el propósito de proveer a los usuarios de la empresa una mejor herramienta de análisis. Por otro lado, se debe tomar en cuenta la propuesta planteada para el descuento del monto provisionado.

\section{Conclusiones}

- El Perú, según lo investigado, es uno de los países de la región que se encuentran a la vanguardia en temas de tratamiento contable y adaptación de las normas internacionales. Por ejemplo, algunas empresas, antes de la promulgación de la Ley 28090, ley que regula el cierre de minas, ya aplicaban algunos de los principios establecidos en la FAS $19^{22}$. Por otro

22. Quispe, B. (29 de Octubre de 2012). Gerente Senior - Deloitte 
lado, se puede concluir que las diferencias que existieron en el sector han disminuido debido al incremento de normativa contable y legal, que ha permitido la homogeneización de ciertos registros. Sin embargo, aún existen tratamientos que no se encuentran estandarizados, como los mostrados en el presente trabajo, ya que muchos de ellos aún se realizan por intermedio del juicio técnico del contador. Por lo tanto, la hipótesis general planteada para el inicio de la investigación se cumple hasta cierto punto, ya que aún existen diferencias que se resuelven por intermedio de las políticas contables de cada empresa, y no por la normativa correspondiente.

- Existe una tendencia a adaptar las normas de contabilidad de información financiera, las cuales tienen como fin la estandarización de la información de manera global. Luego de realizar la investigación, en el sector minero aún existen diferencias que afectan el análisis que se puede hacer entre las distintas empresas de la industria, que al final repercute en la decisión de los inversionistas. Por ejemplo, el tratamiento contable de los costos de exploración, tal como se explicó en el presente trabajo, cuenta con tres distintos tratamientos, los cuales tienen un impacto en los distintos estados financieros. Si bien las mineras analizadas pueden llegar a ser del mismo tipo, el tratamiento puede diferir y la comparabilidad en ese aspecto se limita. Por temas de homogeneización de tratamiento contable, aún existen diferencias que se deben modificar.

- La estandarización de la información entre las empresas permitirá que el Perú logre ubicarse al mismo nivel de países mineros como Australia o Sudáfrica. Si bien se estima que la inversión no se verá afectada por estas diferencias contables, ya que existen mecanismos para superarlas, estas generan costos adicionales a las nuevas empresas, que podrían evitarse ${ }^{23}$.

- Los costos de exploración y evaluación se regulan mediante la NIIF 6, donde se indican los tres métodos diferentes de registro. Se puede apreciar que dentro del sector minero las empresas optan por uno de estos métodos y de acuerdo con la política que la empresa establezca, se procede a registrarlos. La gran mayoría utiliza el registro conservador, es decir, primero registran el gasto para luego activarlo. Sin embargo, las empresas más arriesgadas 
activan desde un inicio todos sus costos. Se considera que la mejor forma de registro, que tiene una posición conservadora, es registrar los costos como gastos cuando se incurre en ellos, para luego, cuando exista certeza técnica y comercial, activarlos. Esta forma de registro se sustenta también en la FAS 19, de aplicación para el sector petróleo en cuando a explotación de recursos. Se usa dicha norma por tener implicancias en el registro y la contabilización de recursos minerales; esta indica que también se deben considerar como gastos dentro del período incurrido.

- En cuanto a la provisión por cierre de minas, existe una ley en donde se homogeneizan ciertos aspectos de registro y tratamiento contable. Sin embargo, en cuando a las tasas de descuento para la estimación del monto de la provisión, existen variaciones que deben homogeneizarse. Si la contabilidad está en dólares, se descuenta usando la tasa de los bonos del Tesoro estadounidense; si la contabilidad está en soles, se usa la tasa de los bonos soberanos que emite el Estado peruano. Las empresas deben mostrar información a los usuarios externos e internos para que de esta forma la actualización de la provisión se estandarice de manera anual.

- No existen discrepancias en cuanto a la determinación del método de depreciación de los activos mineros ya que, por práctica común en el sector, estos son depreciados bajo el método de unidades producidas. Sin embargo, no hay normativa vigente que determine este tratamiento común, ni que tenga como objetivo uniformar los métodos de depreciación utilizados para los activos mineros. 



\section{Investigación sobre los métodos de costeo de huevos comerciales y la valorización del activo biológico}

Kerlyn Ávalos

Jaime Yépez

\section{Resumen}

El presente trabajo tiene como objetivos: (1) proponer un modelo de costeo para huevos comestibles aplicable a las empresas avícolas en el Perú bajo el marco de las normas internacionales de contabilidad y (2) la valorización del activo biológico. Para llevar a cabo la investigación, se realizaron entrevistas con expertos de la industria avícola, ejecutivos de empresas auditoras y expertos en la crianza de aves. Ellos brindaron su conocimiento y experiencia para el desarrollo de este documento, y se complementó con la propia investigación.

El presente trabajo se divide en dos capitulos: la primera parte consiste en una investigación sobre los métodos de costeo de huevos comerciales, mientras que la segunda parte trata de la valorización del activo biológico, particularmente la gallina o ave ponedora. En la primera parte de este trabajo, se exponen las principales características del sector, el ciclo de vida de la gallina y los métodos de costeo que existen en la industria. Una vez entendida la industria, se realiza una simulación de los costos basada en los métodos observados y se escoge el método que mejor refleje la realidad del sector. Con todo ello, se crea una herramienta de información gerencial para evaluar los costos dentro de las empresas avícolas, tomando como base las normas internacionales de contabilidad.

Por otra parte, el segundo capítulo del presente trabajo consiste en: (1) el entendimiento del marco teórico de la NIC 41 para la valorización del ave; (2) las ventajas y desventajas de la aplicación del valor razonable para el cálculo del activo biológico; (3) un comparativo de la valorización entre el valor razonable y el costo; y, finalmente, (4) se propone una metodología de valorización para 
este activo biológico. La importancia del estudio de valorización de un activo biológico se sustenta en la necesidad de presentar sólidos estados financieros basados en principios contables generalmente aceptados que permitan obtener una real situación de la empresa sin la necesidad de incurrir en costos adicionales.

\section{Introducción}

Por sus propiedades nutritivas y su arraigo en los hábitos de consumo de la población, los huevos de gallina tienen una alta participación en la canasta básica del hogar. En los últimos años, el consumo per cápita ha aumentado significativamente, pasando de 117 unidades en 2003 a 167 unidades en 2013, lo que significa un crecimiento de $43 \%{ }^{1}$ en los últimos diez años. No obstante, a pesar del fuerte crecimiento observado en los últimos años, todavía estamos debajo de otros países de la región. Por ejemplo, en México los habitantes consumen cerca de 474 huevos por año ${ }^{2}$.

El sector avícola constituye el sector agropecuario más importante del país, porque representa el 55\% del PBI pecuario, el 24\% del PBI agropecuario y el 1,8\% del PBI nacional ${ }^{3}$. La industria del huevo movió unos US\$ 500 millones en $2011^{4}$, lo cual representa un 10\% más que en 2010.

La oferta nacional de huevo comestible se encuentra concentrada en las regiones Lima y La Libertad, con 60\% y 16\% respectivamente ${ }^{5}$. Por otro lado, la demanda nacional está centralizada en Lima, con el 34\% del total, seguida por las regiones Piura, La Libertad, Cajamarca, Arequipa y Cusco, que en total representan el 35\% del total demandado.

Las empresas que participan en este sector se pueden dividir en tres tipos: (1) grandes empresas integradas verticalmente que poseen tecnología de punta, poseen economías de escala, venden sus productos a grandes cadenas de supermercados a través de mayoristas y exportan parte de su producción;

1. <http://elcomercio.pe/gastronomia/1643222/noticia-dia-mundial-huevo-conoce-todas-sus-bondades>.

2. <http://elcomercio.pe/gastronomia/1316720/noticia-desayunar-dos-huevos-diarios-te-ayuda-mantenertu-peso>.

3. Informe Caser (Club de Análisis y Riesgos). "Riesgos de mercado sector avícola, julio de 2012”.

4. <http://elcomercio.pe/gastronomia/1317745/noticia-mercado-huevo-mueve-us500-millones_1>.

5. Direcciones Regionales Agrarias - Dirección de Información Agraria, INEl, Apeim. 
(2) empresas medianas y pequeñas que venden sus productos a mercados y tiendas de abarrotes a través de intermediarios; y, por último, (3) los miles de pequeños comerciantes, la mayoría informales, parte de cuya producción es consumida dentro del hogar y el resto, vendido en el mercado de forma directa, sin intermediarios.

\section{Propuesta de investigación}

\section{Área de la investigación}

Este trabajo de investigación se enfoca en la contabilidad financiera. Se exponen las particularidades del sector avícola del Perú sobre las metodologías de costeo de los huevos comerciales y de las gallinas de postura conforme a la NIC 41 .

\section{Objeto de la investigación}

El objeto de esta investigación se centra en el tratamiento contable de los huevos comerciales y los activos biológicos dentro del sector avícola del Perú. Es decir, la gestión de la gallina de postura como generadora de la producción de huevos comerciales.

\section{Problema}

Dentro de la industria avícola peruana existen diferentes métodos de costeo para la producción de huevos comestibles, lo cual dificulta la medición de los costos de los huevos en las empresas de forma homogénea. Ello como consecuencia de la valoración de las gallinas de postura y la depreciación del activo, que tienen impacto dentro de los costos de los huevos comerciales. En ese sentido, el problema se define como la falta de una metodología estándar para el costeo de los huevos comestibles.

\section{Objetivos}

Plantear un modelo de costeo para la producción de huevos comerciales en relación con la gestión de los activos biológicos para las empresas avícolas del Perú, que permita identificar beneficios o pérdidas y realizar comparaciones entre empresas en términos económicos y financieros. 


\section{Objetivos específicos}

- Analizar los métodos de costeo de huevos dentro de la industria.

- Identificar las diferencias entre los métodos de costeo y su impacto dentro de los estados financieros.

- Plantear un modelo de costeo sobre la base de las Normas Internacionales de Contabilidad, que refleje mejor la realidad.

- Valorizar el activo biológico mediante el valor razonable.

- Analizar el impacto tributario y contable del valor razonable.

\section{Alcance de la investigación}

Esta investigación se enfoca en establecer un modelo de costeo para la producción de huevos comerciales y una valorización de la gallina de postura de acuerdo con las Normas Internacionales de Contabilidad.

\section{Hipótesis}

No existe una metodología de costeo estándar en la industria avícola para el costeo de los huevos comerciales, lo cual impide dar un lineamiento específico para las empresas y que estas puedan plantear diferentes criterios para el costeo.

\section{Hipótesis secundaria}

- Las pequeñas empresas del sector avícola no poseen un método de costeo que diferencie el costeo del huevo del costeo de la gallina ponedora.

- Las pequeñas empresas peruanas del sector avícola no tienen un método de costos que les permita mediar los activos biológicos al valor razonable mediante las Normas Internacionales de Contabilidad.

\section{Fuentes de información}

La presente investigación recoge fuentes de información primarias y secundarias.

\section{Fuentes primarias}

- Expertos de la industria.

- Auditores de la industria.

- Expertos en la aplicación de las Normas Internacionales de Contabilidad. 


\section{Fuentes secundarias}

- Teoría contable.

- Normas Internacionales de Contabilidad.

- Investigaciones de referencia.

- Revistas de investigación.

\section{Metodología}

La metodología de costeo de la presente investigación se centra en evaluar los modelos de costeo de huevos comerciales existentes en la industria; para lo cual, se evalúa de forma complementaria el costeo de las gallinas de postura en relación con las Normas Internacionales de Contabilidad. Todo ello para tener un panorama completo del costeo de huevos como consecuencia del costeo de las gallinas.

Con estos dos análisis, se pretende plantear un modelo de costeo con fundamentos contables sólidos que permita integrar ambos conceptos para la industria avícola del Perú. Y, de esta forma, presentar un modelo estándar que posibilite la comparación de la información entre empresas.

A continuación, se describe el método que se utilizó para el desarrollo de la presente investigación, con el propósito de cumplir con los objetivos planteados y poder validar las hipótesis planteadas.

I. Propuesta de la investigación

a. Identificar el problema.

b. Objetivos.

c. Hipótesis.

d. Fuentes primarias y secundarias.

II. Trabajo de campo

a. Análisis del marco teórico.

b. Entrevistas con diferentes expertos de la industria.

c. Entrevistas con expertos de las Normas Internacionales de Contabilidad.

d. Análisis de la industria.

e. Análisis de los métodos de costeo de huevos.

f. Planteamiento de la propuesta de costeo de huevos.

g. Valorización de activo biológico al valor razonable.

h. Conclusiones y recomendaciones. 


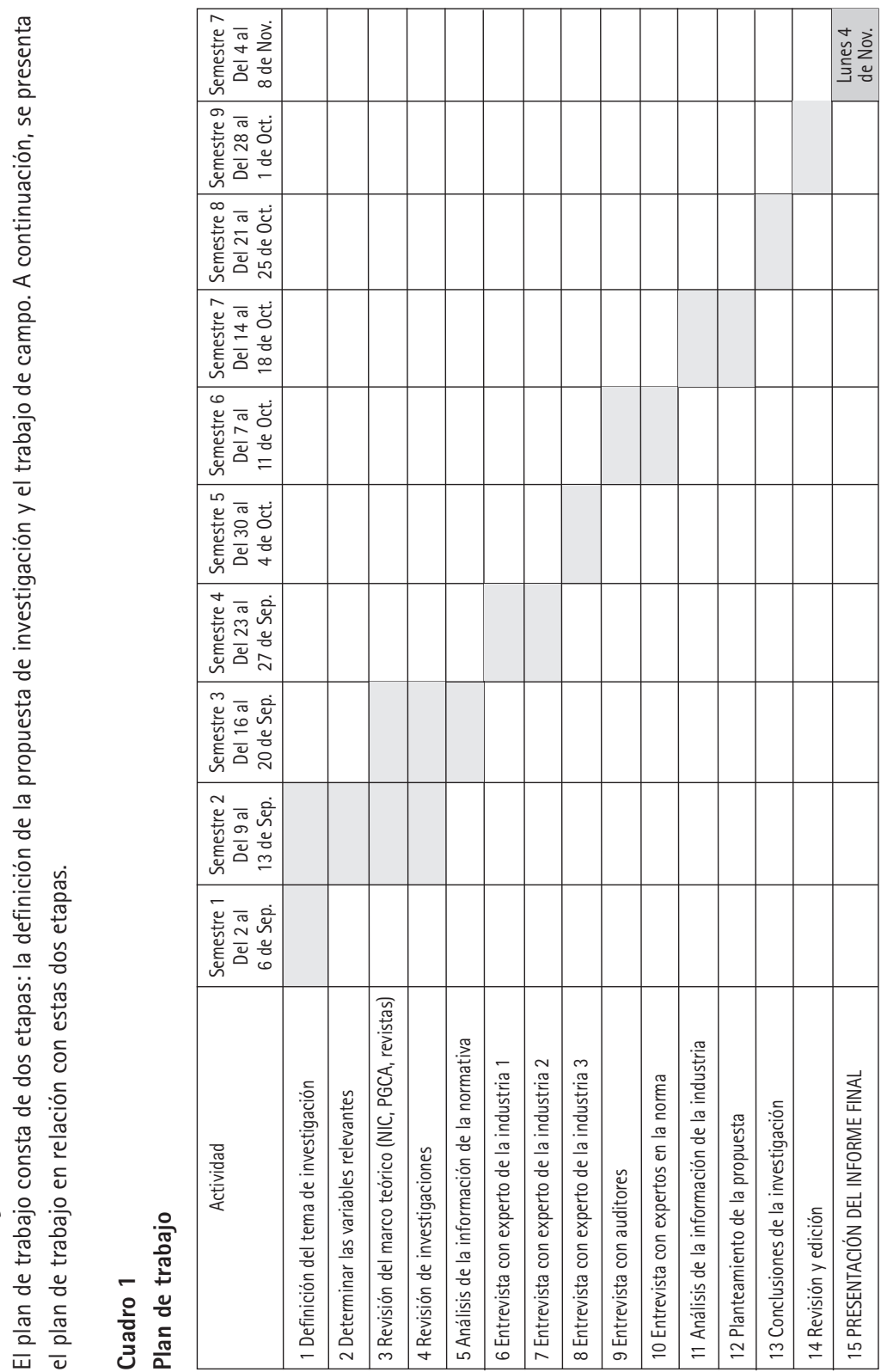




\section{Descripción del sector}

El sector agropecuario comprende los subsectores agrícola y pecuario, donde este último es el más relevante. El sector agropecuario es uno de los sectores más fuertes y dinámicos del PBI, pues ha mantenido una tasa de creciente de 4\% en promedio en los últimos 5 años (2008-2012), impulsado por el crecimiento continuo de ambos subsectores. La producción del sector agropecuario registró en 2012 un crecimiento de 5,1\% en relación con el año anterior (véase el anexo 5).

El subsector pecuario comprende la producción de aves, animales vacunos y porcinos, leche fresca, huevos y demás relacionados con animales. Este subsector ha venido creciendo a una tasa promedio de 5\% en los últimos 5 años (20082012). En el último período de 2011-2012, se registró un crecimiento de 4,86\%.

La producción nacional de huevos fue de alrededor de 314.000 TM durante 2012, y tuvo un crecimiento de 22\% durante el período 2007-2012, dando como resultado una tendencia creciente de la industria, que mantuvo una tasa de crecimiento promedio anual de $4 \%{ }^{6}$.

\section{Cuadro 2}

Producción nacional de huevos comerciales (expresado en miles de TM)

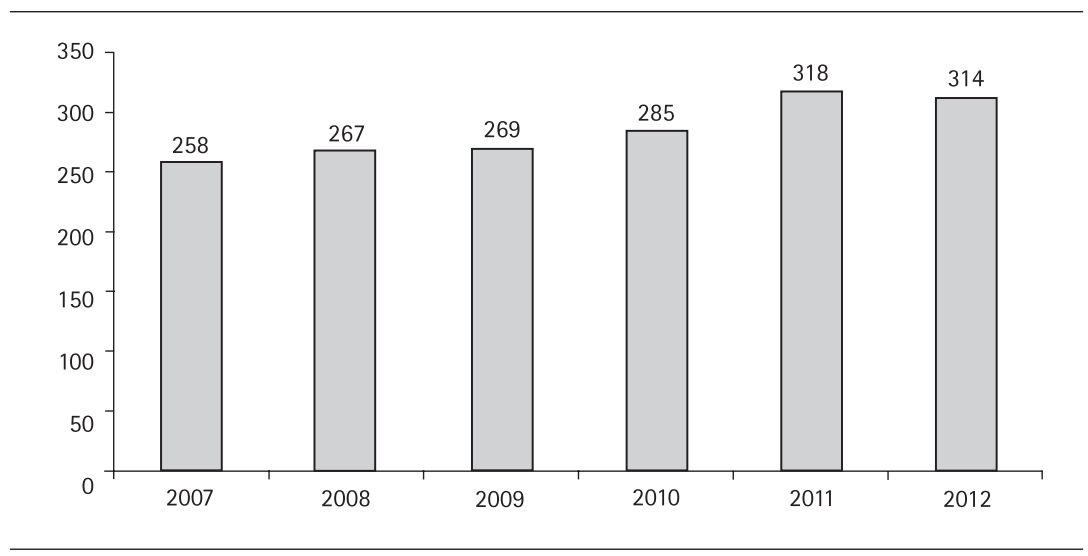

Fuente: INEI.

Elaboración propia.

6. Instituto Nacional de Estadistica e informática (INEI). 
Por otro lado, el consumo per cápita del Perú presenta niveles bajos en comparación con otros países como Argentina, Colombia y México. En el Perú, el consumo de huevos está aumentando, pero lo hace lentamente. En 2008, el consumo de huevos por persona al año fue de 140. Sin embargo, en 2011 el consumo se incrementó a unos 150 huevos al año por peruano ${ }^{7}$. El consumo de huevos en la última década ha crecido, a pesar de lo cual el Perú aún se ubica en la mitad de la tabla de América Latina. A nivel de América Latina, México es el país que consume más huevos per cápita, registrando en 2008 un consumo de 354 huevos al año por persona. Le siguen El Salvador con 207, Argentina con 205 y Colombia con 176 huevos por año.

\section{Cuadro 3}

Consumo per cápita de huevos, 2008 (huevos/hab/año)

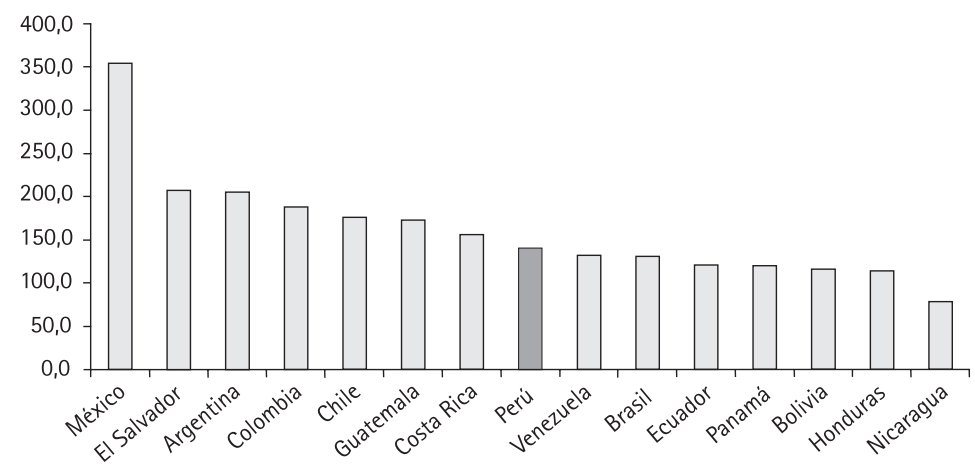

Fuente: Asociación Latinoamericana de Avicultura.

Por último, cabe señalar que el sector agrario goza de la Ley 27360, Ley que Aprueba las Normas de Promoción del Sector Agrario, la cual permite beneficios para el pago del impuesto a la renta. En el artículo $4 .^{\circ}$ de esta ley, se indica que la tasa aplicable para el impuesto a la renta es de 15\%, correspondiente a rentas de tercera categoría.

7. El Comercio. «El mercado del huevo mueve US\$ 500 millones». <http://elcomercio.pe/gastronomia/ 1317745/ noticia-mercado-huevo-mueve-us500-millones_1>. 


\section{Características de la industria}

A continuación, se describen algunas características del sector pecuario, particularmente de la producción de huevos comerciales.

\section{Atomización del sector}

Si bien existen dos empresas que controlan el 35\% del mercado, la gran mayoría de las empresas que existen son muy pequeñas, con un porcentaje de participación inferior al 1\%, o se encuentran dentro de la categoría de informales. De acuerdo con el Censo Nacional Agropecuario, existen alrededor de 532 unidades agropecuarias, las cuales se concentran en la crianza de gallinas $\mathrm{y}$, en consecuencia, en la producción de huevos.

En ese sentido, la producción de huevos es directamente proporcional a la cantidad de aves. La población de gallinas en 2012 fue de 14,5 millones de unidades, siendo este tipo de ave la segunda con mayor población en el Perú después del pollo (véase el cuadro 4). Cabe destacar que el pollo es el principal alimento en la comida nacional.

La crianza de aves ponedoras o gallinas tiene como principal objetivo la producción de huevos comerciales, así como la venta de carne del ave al final de su período de producción de huevos.

\section{Cuadro 4}

Población avícola en el Perú

\begin{tabular}{|l|c|c|c|c|c|c|}
\hline \multicolumn{1}{|c|}{ Descripción } & Total & $\begin{array}{c}\text { Pollos y pollas } \\
\text { de engorde }\end{array}$ & Gallinas & Gallos & Pavos & Patos \\
\hline $\begin{array}{l}\text { Número de unidades } \\
\text { agropecuarias } \\
\text { Población de aves }\end{array}$ & 2.066 & 1.257 & 532 & 65 & 78 & 134 \\
\hline
\end{tabular}

Fuente: Censo Nacional Agropecuario.

Elaboración propia.

\section{Alta dependencia de insumos importados}

Para la producción de huevos comerciales, es necesario utilizar distintas materias primas de consumo. Una de ellas es el alimento balanceado. El alimento 
balanceado está compuesto, en su mayoría, por maíz amarillo duro (MAD) y soya, los cuales son productos commodities importados de los mercados internacionales, comercializados en las principales bolsas del mundo.

Para explicar mejor este punto, se tomará como referencia la información de San Fernando, donde las materias primas importadas representan cerca del $80 \%$ del costo de la producción del alimento balanceado ${ }^{8}$. Ello implica que los resultados de las empresas avícolas dependen directamente de los precios internacionales. A continuación, se presenta la estructura de costos de ventas por segmento general y la fluctuación de los precios internacionales de estos dos insumos (MAD y soya).

\section{Gráfico 1}

\section{Principales insumos}

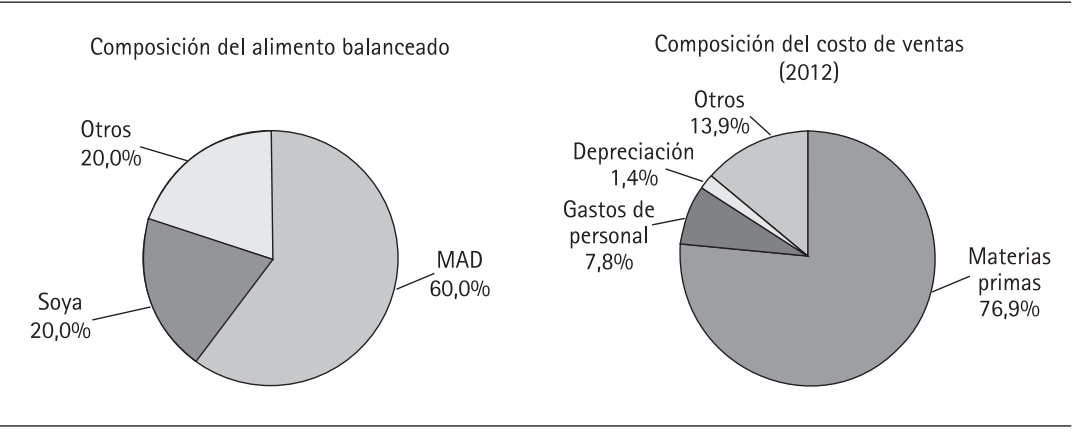

Fuente: Censo Nacional Agropecuario.

Elaboración propia.

\section{Márgenes netos bajos}

La industria avícola es una industria sensible a los cambios en el precio de las principales materias primas (MAD y soya) debido a que representan una gran proporción del costo de producción del alimento balanceado. Adicionalmente, esta industria es sensible a los precios de mercado: en períodos de exceso de oferta, los precios de los productos tienden a caer; y, por el contrario, en pe-

8. Apoyo \& Asociados. Asociados a Fitch Ratings. Reporte de clasificación de San Fernando 2013. 
ríodos de escasez de oferta, los precios tienden a subir. Ello ocurre porque los productos tienen períodos de vencimiento cortos y no se pueden almacenar por período largos, lo cual impide regular la oferta dentro del mercado y evitar las caídas o subidas de los precios.

Por todo ello, los resultados en términos de utilidad de dos de las más grandes empresas del sector avícola son de alrededor de 5,6\% (véase el cuadro 5). Ello permite tomar como referencia que esta industria mantiene niveles de rentabilidad bajos alrededor de lo mencionado.

\section{Cuadro 5}

Márgenes netos

\begin{tabular}{|l|c|c|c|}
\hline \multicolumn{1}{|c|}{ Empresa } & $\begin{array}{c}\text { Ingresos netos } \\
2011 \text { (miles de S/.) }\end{array}$ & $\begin{array}{c}\text { Utilidad neta } \\
2011 \text { (miles de S/.) }\end{array}$ & Margen neto \% \\
\hline San Fernando & 1.647 .365 & 90.779 & $5,51 \%$ \\
Redondos S. A. & 562.459 & 34.245 & $6,09 \%$ \\
\hline Total & 2.209 .824 & 125.024 & $5,66 \%$ \\
\hline
\end{tabular}

Fuente: Peru: The Top 10,000 Companies 2013.

\section{Competidores}

En la industria de producción de huevos comerciales, existen una gran cantidad de productores. De acuerdo con el Censo Nacional Agropecuario de 2012, existen 532 unidades agropecuarias que gestionan 14,6 millones de gallinas. Es decir, se tiene una gran cantidad de productores, que solo es superada por la cantidad de productores de pollo de engorde.

Dentro de los productores existen tres grandes empresas: La Calera, Río Bravo y San Fernando. La Calera es el líder, con una participación dentro de la oferta nacional de 25\%, seguida por Río Bravo con un 10\% y, finalmente, por San Fernando con un 4\%. En general, las empresas formales que declaran su producción al Ministerio de Agricultura representan la mayor porción; sin embargo, existe una considerable cantidad de productores informales: alrededor del 25\% de la producción ${ }^{9}$.

9. Entrevista con Vasco Masías, gerente comercial de La Calera. 


\section{Cuadro 6}

Participación de productores

\begin{tabular}{|l|c|}
\hline \multicolumn{1}{|c|}{ Empresa } & Participación \\
\hline La Calera & $25 \%$ \\
Rio Bravo & $10 \%$ \\
San Fernando & $4 \%$ \\
Santa Elena & $3 \%$ \\
\hline
\end{tabular}

Fuentes: Minag, entrevista con expertos, SMV.

\section{Descripción del ciclo de vida de la gallina}

El ciclo de vida de las gallinas de postura desde la incubación hasta el beneficio ${ }^{10}$ es de 2,2 años ${ }^{11}$ aproximadamente. Sin embargo, este tiempo puede fluctuar, dependiendo de las condiciones en las que se encuentre la crianza y de los niveles productivos que el ave presente. Por ejemplo, un factor relevante para beneficiar a una gallina es el nivel de producción de huevos por día.

El ciclo de vida comprende los procesos de crecimiento, de producción y de liquidación. El proceso de crecimiento comprende la incubación del huevo y el crecimiento de la gallina. En el proceso de producción, la gallina se encuentra produciendo huevos. Por último, el proceso de liquidación comprende el retiro de la gallina de los galpones para su posterior beneficio y comercialización (véase el cuadro 7).

\section{Cuadro 7}

Ciclo de vida de la gallina de postura

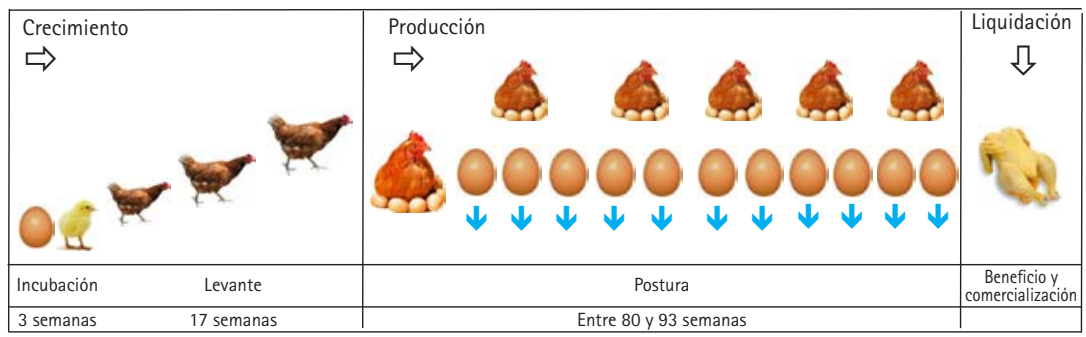

10. "Beneficio" es un término que significa dar muerte al ave.

11. Manual de estándares de rendimiento. Hy-Line Brown ponedoras comerciales. 2. ${ }^{a}$ edición. 


\section{Etapas del ciclo de vida de la gallina}

La gallina de postura pasa por las etapas de incubación, levante, postura y beneficio. Este ciclo no necesariamente se realiza en el mismo lugar geográfico dados los tratamientos especiales. Para demostrarlo, tomaremos como referencia a San Fernando; por ejemplo, la planta de incubación de ponedoras bebé (BB) se encuentra en Chorrillos, las granjas de ponedoras se encuentran al sur de Lima y las plantas de beneficio se encuentran en Huaral y Chincha ${ }^{12}$.

\section{Incubación}

En esta etapa, la gallina está en forma de huevo y experimenta el proceso de incubación en máquinas que simulan la incubación natural. Este proceso comprende 3 semanas o 21 días.

\section{Levante}

En esta etapa, la gallina se encuentra en un estado de gallina bebé y es trasladada a galpones de crecimiento donde se desarrollan todas las condiciones fisiológicas para producir. Las gallinas bebé son alimentadas con una dieta especial y empiezan su crecimiento. Esta etapa comprende 17 semanas aproximadamente.

\section{Postura}

En esta etapa, la gallina es trasladada de los galpones a las jaulas de postura, donde se encuentra lista para producir huevos comestibles. En esta etapa, el animal pone alrededor de 0,81 huevos de 62 gramos por día ${ }^{13}$. De acuerdo con los estándares productivos, el ave puede producir huevos durante entre 80 y 93 semanas. Sin embargo, los rendimientos y la calidad de los huevos se reducen a mayor tiempo de vida de la gallina. Por ello, cuando el animal llega a cierta edad adulta es beneficiado.

12. Página web visitada el 21.10.13 a las 8:22 a. m. <http://www.san-fernando.com.pe/institucional.html>.

13. Entrevista con Vasco Masías, gerente comercial de La Calera. 


\section{Beneficio}

En esta etapa, la gallina se encuentra en una etapa adulta y los rendimientos productivos de huevos son bajos a pesar del mismo nivel de consumo de alimento. Por tanto, el ave es retirada de los galpones de producción para luego ser beneficiada y comercializada.

\section{Indicadores productivos de la crianza de gallinas}

A continuación, se presentan los indicadores de producción que se emplearán para la elaboración de las simulaciones de costeo de huevos comerciales y valorización de la gallina (véase el cuadro 21). Estos indicadores comprenden las etapas de levante y postura. Para ello, se tomaron como referencia los estándares de crianza emitidos y se contrastaron con la información proporcionada por los expertos de la industria. Es importante detallar este punto porque es necesario tener un completo análisis la producción de huevos y gallinas para poder aplicar la Norma Internacional de Contabilidad 41.

\section{- Mortalidad}

Dada la condición biológica de las gallinas, estas sufren un proceso de transformación, degradación y muerte durante su ciclo de vida. Este indicador muestra el porcentaje de aves que mueren durante la crianza. De acuerdo con los estándares de crianza, este indicador se encuentra entre 3\% y $6 \%$ para un lote de producción.

\section{- Consumo de alimento}

Este indicador muestra la cantidad de alimento en gramos consumida por una gallina al día. Este indicador tiene gran impacto dentro del costeo puesto que los costos del alimento balanceado representan una gran porción.

\section{- Nivel de producción}

El nivel de producción muestra la cantidad de huevos producidos por gallina por día. Es decir, un nivel de producción de $89 \%$ explica que una gallina pone 0,89 huevos por día. Este indicador permite ver la productividad de huevos por 
gallina durante su ciclo de vida. Además, es determinante para tomar la decisión del momento de retirar a una gallina de la etapa de postura.

\section{- Peso del huevo}

El peso de huevo depende de la etapa en que se encuentre la gallina. Este presenta una curva creciente a medida que va creciendo el animal. El huevo tiende a ser cada vez más grande y frágil, especialmente al final del ciclo productivo estándar. El peso del huevo puede variar de 50 a 70 gramos.

\section{- Conversión de alimento}

La conversión de alimento es un indicador que mide la cantidad consumida de alimento por gallina y los kilogramos rendidos en huevos. Es decir, mide la cantidad en kilogramos de alimentos consumida para producir $1 \mathrm{~kg}$ de huevos.

Todos estos indicadores permiten calcular la cantidad consumida de alimento, medicamento, empaque para huevos y la producción de huevos en unidades y kilogramos. Todo lo cual da como resultado los requerimientos necesarios para la producción y comercialización de huevos.

A continuación, se presenta el cuadro de indicadores productivos de una gallina de postura, los cuales comprenden las dos etapas principales: levante y postura. Se considera, de acuerdo a los estándares de la industria, un ciclo de 1,5 años (18 meses) para la etapa de producción. 


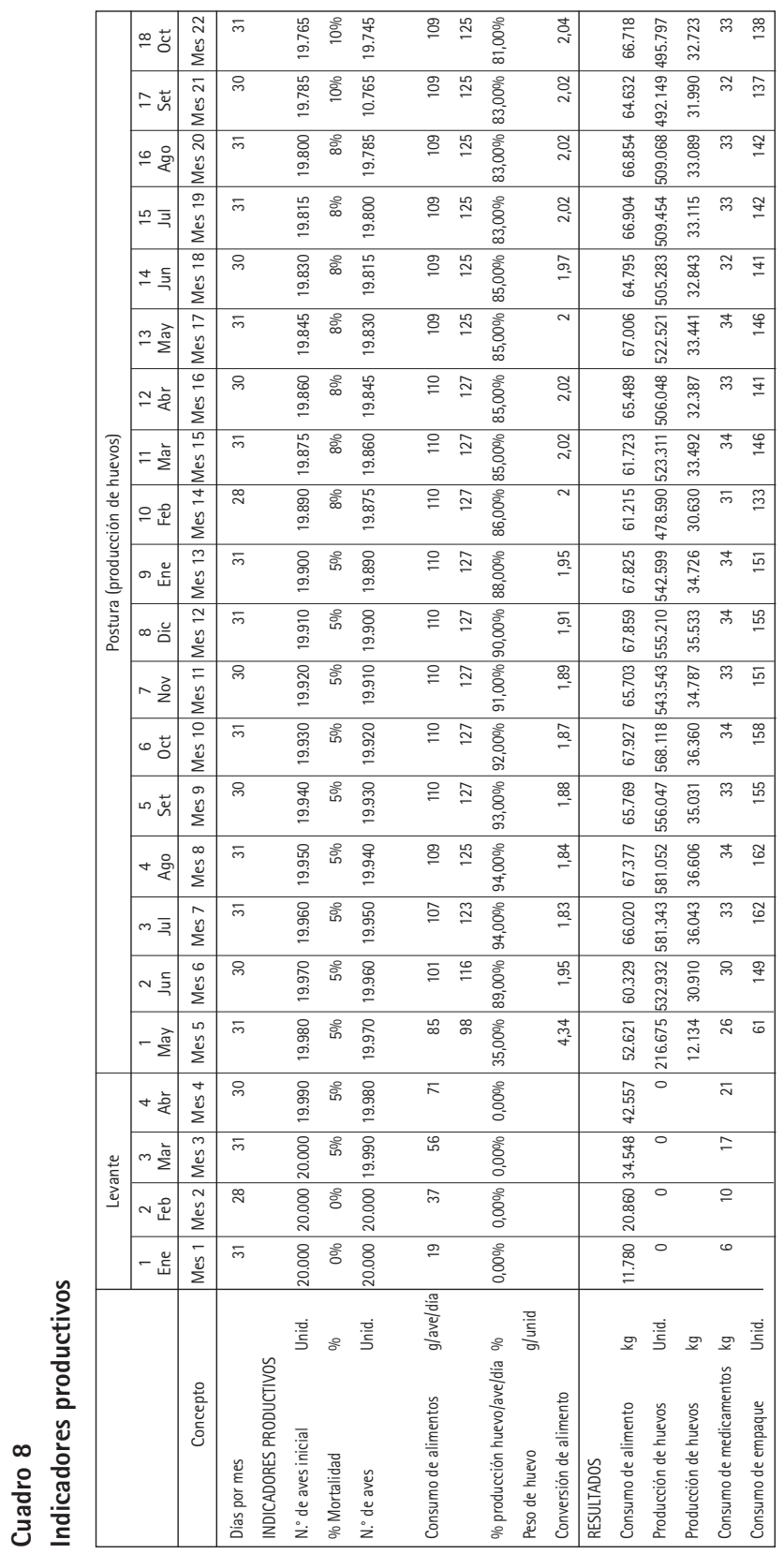




\section{Métodos de costeo de la industria}

Dentro de la industria avícola existen diferentes tipos de métodos de costeo de huevos comerciales. Cabe resaltar que el método consiste en emplear las variables del costo en el momento adecuado para que reflejen la realidad de una empresa. En ese sentido, se inicia la evaluación con el costeo de huevos comerciales, y luego se pasa al costeo de la gallina de postura. En esta parte del trabajo, se analizarán los métodos de costeo usados por tres empresas del sector: San Fernando S. A., La Calera S. A. C. y Perú Avick S. A., que en adelante serán denominados método de costeo $\mathrm{A}$, método de costeo $\mathrm{B}$ y método de costeo $\mathrm{C}$, respectivamente.

Cabe resaltar que cada empresa tiene estructuras de costos, rendimientos productivos, costos de materias primas y costos laborales diferentes; sin embargo, el presente trabajo no trata de simular las particularidades de cada empresa, sino de simular los costos de producción bajo un mismo parámetro. De esta forma, se busca analizar los resultados obtenidos a partir de la aplicación de los métodos de costeo. A continuación, se describen los tres métodos empleados.

\section{Método de costeo $\mathrm{A}$}

Este método comprende las dos etapas del activo biológico: el proceso de levante y la postura o producción de huevos. Este período comprende desde la gallina bebé hasta antes del beneficio del ave.

En este método, los costos de crianza durante la etapa de levante del ave, como las medicinas, el alimento balanceado, el empaque de huevos, la mano de obra, los gastos generales y la depreciación de los activos fijos, son registrados como activos biológicos. Es decir, todos esos gastos son activados.

A partir del proceso de postura, todos los costos incurridos en la etapa de postura del ave son asignados directamente a la producción de huevos. Es decir, el activo biológico deja de ser un activo biológico de desarrollo y pasa a ser un activo biológico en producción. Adicionalmente a ello, el activo biológico genera depreciación durante la producción, por tanto, ese monto es asignado al costo de huevo. De acuerdo con la norma ${ }^{14}$, el monto máximo para depreciar la gallina es de $75 \%$ por año. 
Adicionalmente, todos los costos incurridos en la etapa de postura del ave son asignados directamente a la producción de huevos. El activo biológico deja de ser un activo biológico de desarrollo y pasa a ser un activo biológico en producción.

Por último, los huevos, una vez extraídos, son asignados a la partida inventarios al costo. Mientras tanto, el ave, al final de su etapa de postura, es beneficiada.

\section{Cuadro 9}

\section{Método de costeo $\mathrm{A}$}

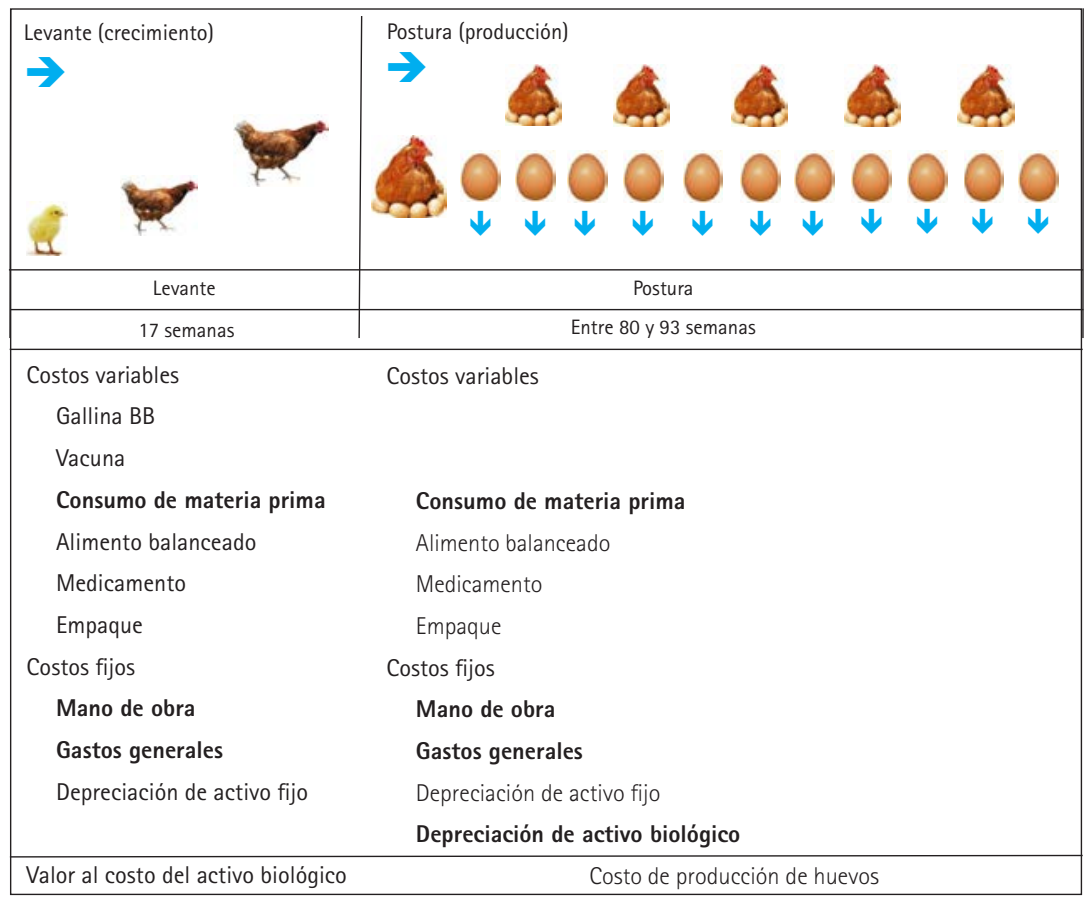

\section{Método de costeo $B$}

Este método comprende los procesos de levante, postura y beneficio del ave: desde la gallina bebé hasta el beneficio y comercialización del ave.

$\mathrm{Al}$ igual que en el método anterior, los costos de crianza durante la etapa de levante del ave, como las medicinas, el alimento balanceado, el empaque de huevos, 
la mano de obra, los gastos generales y la depreciación de los activos fijos, son registrados como activos biológicos. Es decir, todos esos gastos son activados.

A partir del proceso de postura, los costos en que incurra el animal son asignados directamente a los huevos comerciales. Es decir, el activo biológico deja de ser un activo biológico de desarrollo y pasa a ser un activo biológico en producción. Sin embargo, este método no considera la depreciación del activo biológico como parte del costo de producción de huevos.

En el proceso de beneficio, el ave es retirada de la producción y comercializada. El precio de mercado del ave es de $S / .6,00^{15}$. En esta etapa, se realiza el cálculo de la ganancia o pérdida por la venta del ave y el monto resultante se registra en los resultados del ejercicio.

\section{Cuadro 10}

\section{Método de costeo $B$}

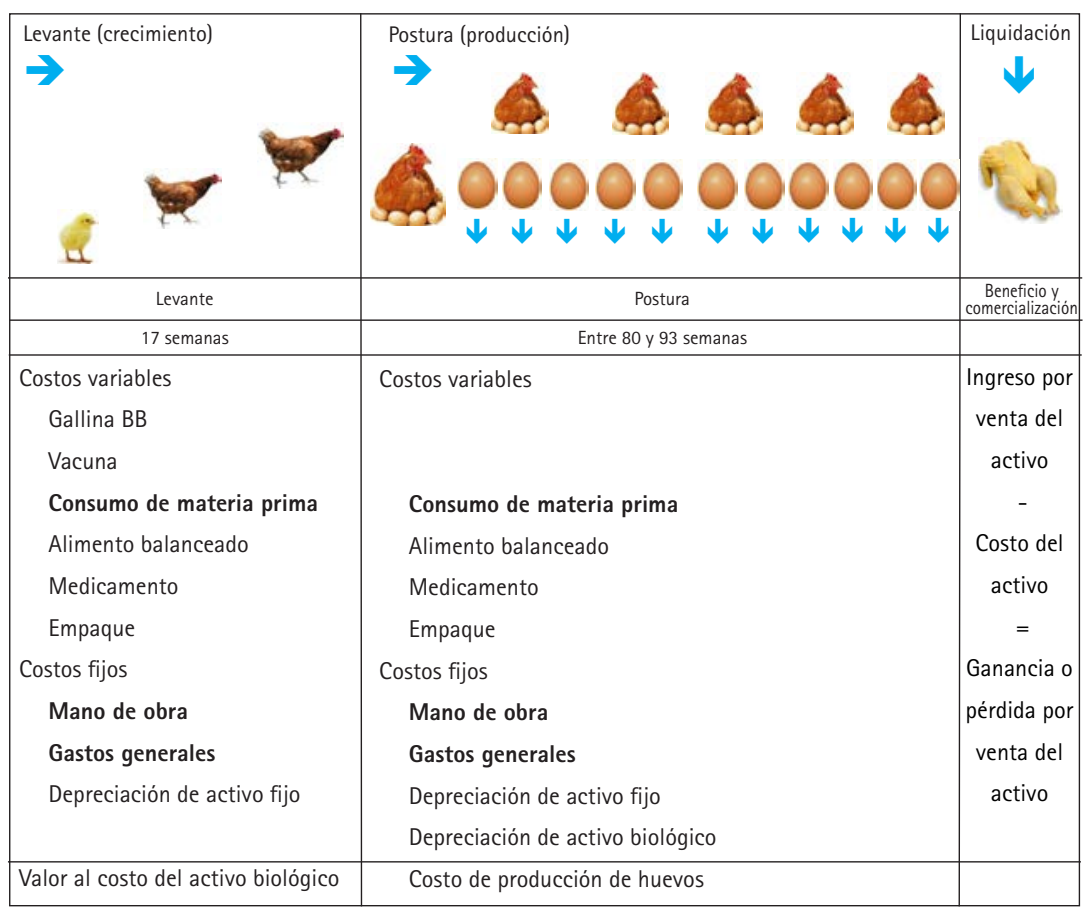

15. Entrevista con Vasco Masías, gerente comercial de La Calera 


\section{Método de costeo $\mathrm{C}$}

Este método no distingue las etapas de levante y postura. En él, no se registra ningún tipo de costo como parte del activo biológico. Es decir, no se hace diferencia entre los costos de poner en operación el activo biológico y los costos de producción de huevos. En ese sentido, todos los costos incurridos desde el crecimiento hasta la producción son asignados directamente al costo del huevo comercial. Una vez extraídos, los huevos son asignados a la partida inventario. Al final del proceso de postura, el ave es beneficiada.

Cabe destacar que en este método, cuando existen varios lotes de producción, el costo de levante de un lote se carga al costo de producción de postura de otro lote.

\section{Cuadro 11}

\section{Método de costeo $\mathrm{C}$}

\begin{tabular}{|l|l|}
\hline \multicolumn{1}{|c|}{ Levante (crecimiento) } \\
\hline 17 semanas \\
Costos variables \\
Gallina BB \\
Cacuna \\
Alimento balanceado \\
Medicamento \\
Empaque \\
Costos fijos \\
Mano de obra \\
Gastos generales \\
Depreciación de activo fijo
\end{tabular}




\section{Planteamiento de la propuesta de costeo}

Para la aplicación del modelo de costeo, se tomaron los datos proporcionados por la empresa Perú Avick en cuestiones de inversión, manejo productivo, indicadores productivos, costos, gastos e ingresos. Toda la información es referente a un nivel de producción de 20.000 aves.

A continuación, se detalla la inversión inicial del acondicionamiento necesario para la crianza de un lote de 20.000 gallinas (véase el cuadro 12). Es decir, la crianza de las aves en un mismo período determinado. Cabe resaltar que en la industria se manejan diferentes lotes de producción en distintos períodos de acuerdo a la demanda estimada.

- El galpón ${ }^{16}$ es el espacio de crianza, con una dimensión de 100 m x 10 m, donde se albergará a las aves en la etapa de producción.

- Cuartos de drywall son usados para albergar a las gallinas bebé durante su crecimiento o etapa de levante, hasta llegar a la etapa de producción de huevos.

- Jaulas para las gallinas: jaulas de metal para 4 gallinas, donde permanecerán durante toda la etapa de producción hasta el beneficio de las aves.

- Almacén de los huevos o inventarios.

- Carretillas para el recojo de huevos.

- Herramientas de granja.

Por otro lado, ese nivel de inversión generará un gasto por depreciación de los activos como consecuencia de las operaciones productivas. Para fines prácticos del presente trabajo, se tomará la tasa de depreciación tributaria (véase el cuadro 12). Sin embargo, lo adecuado es utilizar la tasa de depreciación financiera.

16. Lugar de crianza de las aves. 


\section{Cuadro 12}

Inversión

\begin{tabular}{|l|l|r|r|r|r|r|r|}
\hline \multicolumn{1}{|c|}{ Activos } & \multicolumn{1}{|c|}{ Descripción } & Unidades & $\begin{array}{c}\text { Valor de } \\
\text { venta }\end{array}$ & $\begin{array}{c}\text { Valor de } \\
\text { venta total }\end{array}$ & $\begin{array}{c}\text { Depreciación } \\
\text { tasa anual }\end{array}$ & $\begin{array}{c}\text { Depreciación } \\
\text { anual }\end{array}$ & $\begin{array}{c}\text { Depreciación } \\
\text { mensual }\end{array}$ \\
\hline Edificaciones & Almacén - edificio & 1 & 16.949 & 16.949 & $5 \%$ & 847 & 71 \\
Edificaciones & Galpón & 1 & 16.949 & 16.949 & $5 \%$ & 847 & 71 \\
Edificaciones & Cuartos de drywall & 1 & 12.712 & 12.712 & $5 \%$ & 636 & 53 \\
Equipos diversos & Carretillas & 4 & 254 & 1.017 & $10 \%$ & 102 & 8 \\
Equipos diversos & Herramientas & 4 & 169 & 678 & $10 \%$ & 68 & 6 \\
Equipos diversos & Jaulas de gallina & 5.000 & 18 & 91.525 & $10 \%$ & 9.153 & 763 \\
Equipos diversos & Equipos de cómputo & 1 & 1.695 & 1.695 & $25 \%$ & 424 & 35 \\
\hline \multicolumn{2}{|r|}{ Total } \\
\hline
\end{tabular}

Por otro lado, para la crianza de gallinas es necesario el requerimiento de colaboradores que se encarguen de actividades de alimentación y recojo de huevos. Para el manejo de 20.000 gallinas es necesario mantener a 3 operarios, 1 veterinario y al administrador de la granja (véase el cuadro 13).

\section{Cuadro 13}

Mano de obra

\begin{tabular}{|l|c|c|c|c|c|c|c|c|}
\hline \multicolumn{4}{|c|}{ Detalle del personal } & \multicolumn{3}{c|}{ Cálculo de la base tributaria } & Cálculo \\
\hline \multicolumn{1}{|c|}{ Puesto } & $\begin{array}{c}\text { N. }{ }^{\circ} \text { de } \\
\text { trabajadores }\end{array}$ & $\begin{array}{c}\text { Sueldo } \\
\text { bruto }\end{array}$ & $\begin{array}{c}\text { Sueldo } \\
\text { bruto anual }\end{array}$ & Gratificaciones & $\begin{array}{c}\text { Base } \\
\text { imponible }\end{array}$ & Deducciones & $\begin{array}{c}\text { Base } \\
\text { tributaria }\end{array}$ & $\begin{array}{c}\text { IR } \\
\text { anual }\end{array}$ \\
\hline Administrador & 1 & 1.800 & 21.600 & 3.600 & 21.600 & 25.900 & 0 & 0 \\
Veterinario & 1 & 1.500 & 18.000 & 3.000 & 18.000 & 25.900 & 0 & 0 \\
Operarios & 3 & 900 & 10.800 & 1.800 & 10.800 & 25.900 & 0 & 0 \\
\hline Total & 5 & 4.200 & 50.400 & 8.400 & & & & 0 \\
\hline
\end{tabular}

Asimismo, los costos variables comprenden el ave bebé, el alimento balanceado, las vacunas, los medicamentos contra las larvas y el empaque de los huevos. Cabe mencionar que este empaque tiene una presentación de paquete por 120 planchas con capacidad para 30 huevos cada una, las cuales son usadas para apilar la mercadería para su posterior venta en granja. 


\section{Cuadro 14}

\section{Costos variables}

\begin{tabular}{|l|c|c|r|r|}
\hline \multicolumn{1}{|c|}{ Descripción } & UDM & Valor unitario & IGV & Precio unitario \\
\hline Costos variables & & & & \\
Gallina BB & Unid. & 2,54 & 0,46 & 3 \\
Vacuna & Unid. & 0,04 & 0,01 & 0,05 \\
Alimento balanceado & $\mathrm{kg}$ & 1,02 & 0,18 & 1,2 \\
Medicamento & $\mathrm{kg}$ & 5,08 & 0,92 & 6 \\
Empaque & Paq. & 101,69 & 18,31 & 120 \\
\hline
\end{tabular}

Asimismo, se tienen los gastos generales en granja, como consumo de luz, consumo de agua, alquiler de la granja, telecomunicaciones y transporte de materia prima. Cabe resaltar que si el terreno es propio, entonces se debe generar un gasto por alquiler presunto.

\section{Cuadro 15}

\section{Gastos generales}

\begin{tabular}{|l|r|r|r|r|r|r|r|r|r|r|r|r|r|r|}
\hline \multicolumn{1}{|c}{ Concepto } & Mes 1 & Mes 2 & Mes 3 & Mes 4 & Mes 5 & Mes 6 & Mes 7 & Mes 8 & Mes 9 & Mes 10 & Mes 11 & Mes 12 & Año 1 & Año 2 \\
\hline Luz & 254 & 254 & 254 & 254 & 254 & 254 & 254 & 254 & 254 & 254 & 254 & 254 & 3.051 & 3.051 \\
Agua & 68 & 68 & 68 & 68 & 68 & 68 & 68 & 68 & 68 & 68 & 68 & 68 & 814 & 814 \\
Celulares & 64 & 64 & 64 & 64 & 64 & 64 & 64 & 64 & 64 & 64 & 64 & 64 & 814 & 814 \\
Teléfono, Internet & 127 & 127 & 127 & 127 & 127 & 127 & 127 & 127 & 127 & 127 & 127 & 127 & 1.525 & 1.525 \\
Transporte & 763 & 763 & 763 & 763 & 763 & 763 & 763 & 763 & 763 & 763 & 763 & 763 & 9.153 & 9.153 \\
Alquiler & 1.271 & 1.271 & 1.271 & 1.271 & 1.271 & 1.271 & 1.271 & 1.271 & 1.271 & 1.271 & 1.271 & 1.271 & 15.254 & 15.254 \\
Valor total & 2.547 & 2.547 & 2.547 & 2.547 & 2.547 & 2.547 & 2.547 & 2.547 & 2.547 & 2.547 & 2.547 & 2.547 & 30.599 & 30.599 \\
\hline
\end{tabular}

Con esta información proporcionada, se construyó un modelo de costeo que permite separar los costos incurridos en los procesos de levante y postura. El modelo esta soportado por los rendimientos estándares del ave mencionados anteriormente y por el aporte de los expertos del sector.

\section{Simulación de costos}

Con la información presentada, se procede a simular los costos durante las etapas de levante y postura. 


\section{- Etapa de levante}

En esta etapa, se incurre en costos variables y costos fijos. Los costos variables están conformados por el costo de la gallina bebé (polla bebé), las vacunas, el alimento balanceado, los medicamentos y el empaque de huevos. Dentro de estos costos, el costo más representativo es el del alimento balanceado.

Por otro lado, los costos fijos están conformados por el sueldo bruto, las gratificaciones, la compensación por tiempo de servicio y Essalud. Adicionalmente, están los gastos generales, los cuales son luz, agua, línea de celular, teléfono e Internet, transporte y alquiler de la granja. Cabe mencionar que estas cifras están relacionadas con el lugar de producción de Perú Avick (ciudad de Chilca).

\section{- Etapa de postura}

De igual manera, en esta etapa se incurre en costos variables y fijos. Sin embargo, en esta etapa se incorporan los costos generados por la depreciación del activo biológico. Cabe mencionar que el valor de los activos biológicos se calculó por un monto de S/. 210.658, y que la cantidad de aves es de 20.000 unidades. El resultado es un costo unitario por ave de S/. 10,53.

A continuación, se presenta el modelo de costeo de huevos comerciales, con base en los cuadros de rendimientos, costos variables y fijos presentados anteriormente. Como se puede observar en el cuadro 17, el costo del huevo fluctúa, en promedio, entre S/. 3,1 y S/. 3,3 por kilogramo. 


\section{Cuadro 16}

Valoración al costo del activo biológico

\begin{tabular}{|c|c|c|c|c|c|c|}
\hline & & \multicolumn{4}{|c|}{ Levante } & \\
\hline & & $\begin{array}{c}1 \\
\text { Ene }\end{array}$ & $\begin{array}{c}2 \\
\text { Feb }\end{array}$ & $\begin{array}{c}3 \\
\text { Mar }\end{array}$ & $\begin{array}{c}4 \\
\mathrm{Abr}\end{array}$ & \\
\hline Costo & & Mes 1 & Mes 2 & Mes 3 & Mes 4 & 4 meses \\
\hline Costo total & S/. & 75.423 & 33.033 & 47.005 & 55.197 & 210.658 \\
\hline Costos variables & & 63.657 & 21.267 & 35.239 & 43.430 & 163.593 \\
\hline Gallina BB & S/. & 50847 & & & & 50.847 \\
\hline Vacuna & S/. & 800 & & & & 800 \\
\hline Consumo de materia prima & & 12.010 & 21.267 & 35.239 & 43.430 & 111.945 \\
\hline Alimento balanceado & S/. & 11980 & 21.214 & 35.151 & 43322 & 111.666 \\
\hline Medicamento & S/. & 30 & 53 & 88 & 108 & 279 \\
\hline Empaque & S/. & 0 & 0 & 0 & 0 & 0 \\
\hline Costos fijos & & 11.766 & 11.766 & 11.766 & 11.766 & 47.065 \\
\hline Mano de obra & S/. & 8.213 & 8.213 & 8.213 & 8.213 & 32.853 \\
\hline Sueldo bruto & S/. & 6.000 & 6.000 & 6.000 & 6.000 & 24.000 \\
\hline Gratificaciones & S/. & 1.000 & 1.000 & 1.000 & 1000 & 4.000 \\
\hline CTS & S/. & 583 & 583 & 583 & 583 & 2.333 \\
\hline Essalud & S/. & 630 & 630 & 630 & 630 & 2.520 \\
\hline Gastos generales & & 2.547 & 2.547 & 2.547 & 2.547 & 10.186 \\
\hline Luz & S/. & 254 & 254 & 254 & 254 & 1.017 \\
\hline Agua & S/. & 68 & 68 & 68 & 68 & 271 \\
\hline Celulares & S/. & 64 & 64 & 64 & 64 & 254 \\
\hline Teléfono, Internet & S/. & 127 & 127 & 127 & 127 & 508 \\
\hline Transporte & S/. & 763 & 763 & 763 & 763 & 3.051 \\
\hline Alquiler & S/. & 1271 & 1.271 & 1.271 & 1271 & 5.085 \\
\hline Depreciación de activo fijo & S/. & 1.006 & 1006 & 1.006 & 1006 & 4.025 \\
\hline Depreciación de activo biológico & S/. & & & & & 0 \\
\hline $\mathrm{N} .^{\circ}$ de gallinas & Unid. & 20.000 & 20.000 & 20.000 & 20.000 & 20.000 \\
\hline Costo unitario gallina & S/. $x$ unidad & & & & & 10,53 \\
\hline
\end{tabular}




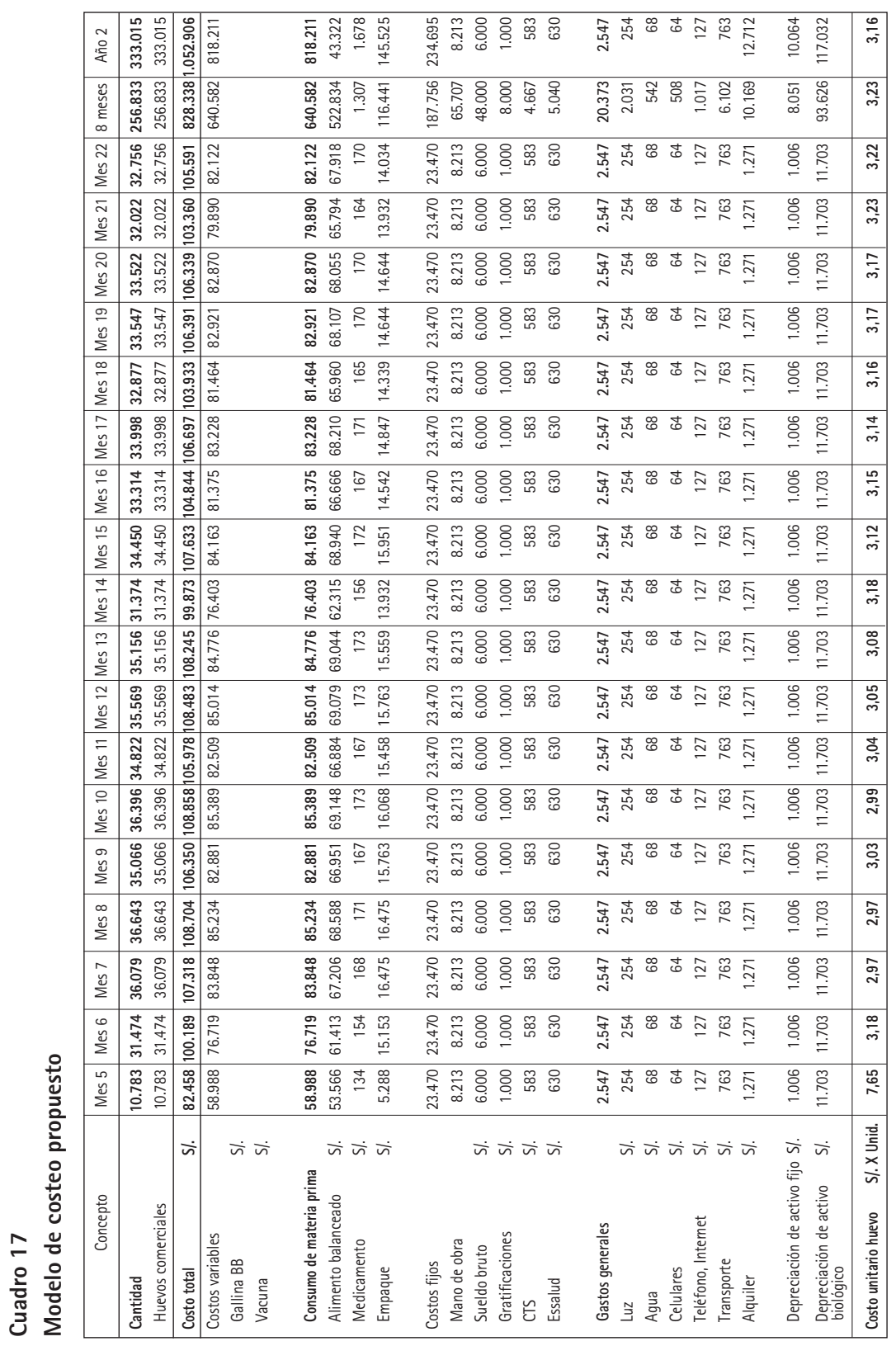


Cabe señalar que en el mes 5, el costo unitario del huevo es de S/. 7,6 por kilogramo. Ello se debe al bajo nivel de producción de huevos/dia/ave de 35\%, mientras que los costos fijos se mantienen constantes. Para ese caso, la NIC 2 menciona que el inventario se medirá al costo o al valor neto realizable, según cual sea menor. Es decir, se tiene un costo de S/. 7,6 para ese mes, pero el valor neto realizable fluctúa entre S/. 3,1 y S/. 3,2 anualmente. En ese sentido, el inventario se tendrá que medir al valor neto realizable y la diferencia será reconocida como un gasto.

- Simulación e impacto de los métodos de costeo A, B y C

A continuación, se presenta la simulación de costeo de los métodos descritos anteriormente. Para este análisis, se separaron los resultados en los dos períodos que comprende la producción de huevos.

Como se puede notar, el método de costeo A presenta costos estables de un año al otro. Esto debido a que el costo de depreciación se distribuye entre los 18 meses de producción, lo cual no genera incrementos o reducciones en los costos.

Por otro lado, el método de costeo B tampoco genera variaciones de un período a otro, puesto que la depreciación no se registra como parte del costo de producción. Sin embargo, se registra la diferencia entre los ingresos y los egresos por la venta del activo biológico.

Por último, el método de costeo $\mathrm{C}$ es el que presenta las mayores variaciones de costos unitarios. Ello porque no registra el activo biológico, sino que carga todos los costos de levante al costo de producción. 


\section{Cuadro 18}

Simulación de costeo, primer año

\begin{tabular}{|c|c|c|c|c|c|c|c|}
\hline \multicolumn{2}{|l|}{ Costo primer año (12 meses) } & \multicolumn{2}{|c|}{ Método A } & \multicolumn{2}{|c|}{ Método B } & \multicolumn{2}{|c|}{ Método C } \\
\hline Huevos producidos & $\mathrm{kg}$ & 256.833 & & 256.833 & & 256.833 & \\
\hline Costo total & S/. & 828.338 & & 734.712 & & 945.370 & \\
\hline Costos variables & & 640.582 & $77 \%$ & 640.582 & $87 \%$ & 804.175 & $85 \%$ \\
\hline Gallina BB & S/. & 0 & $0 \%$ & 0 & $0 \%$ & 50.847 & $5 \%$ \\
\hline Vacuna & S/. & 0 & $0 \%$ & 0 & $0 \%$ & 800 & $0 \%$ \\
\hline Consumo de materia prima & & 640.582 & $77 \%$ & 640.582 & $87 \%$ & 752.527 & $80 \%$ \\
\hline Alimento balanceado & S/. & 522.834 & $63 \%$ & 522.834 & $71 \%$ & 634.500 & $67 \%$ \\
\hline Medicamento & S/. & 1.307 & $0 \%$ & 1.307 & $0 \%$ & 1.586 & $0 \%$ \\
\hline Empaque & S/. & 116.441 & $14 \%$ & 116.441 & $16 \%$ & 116.441 & $12 \%$ \\
\hline Costos fijos & & 187.756 & $23 \%$ & 94.130 & $13 \%$ & 141.196 & $15 \%$ \\
\hline Mano de obra & & 65.707 & $8 \%$ & 65.707 & $8 \%$ & 98.560 & $10 \%$ \\
\hline Sueldo bruto & S/. & 48.000 & $6 \%$ & 48.000 & $6 \%$ & 72.000 & $8 \%$ \\
\hline Gratificaciones & S/. & 8.000 & $1 \%$ & 8.000 & $1 \%$ & 12.000 & $1 \%$ \\
\hline CTS & S/. & 4.667 & $1 \%$ & 4.667 & $1 \%$ & 7.000 & $1 \%$ \\
\hline Essalud & S/. & 5.040 & $1 \%$ & 5.040 & $1 \%$ & 7.560 & $1 \%$ \\
\hline Gastos generales & & 20.373 & $2 \%$ & 20.373 & $3 \%$ & 30.559 & $3 \%$ \\
\hline Luz & S/. & 2.034 & $0 \%$ & 2.034 & $0 \%$ & 3.051 & $0 \%$ \\
\hline Agua & S/. & 542 & $0 \%$ & 542 & $0 \%$ & 814 & $0 \%$ \\
\hline Celulares & S/. & 508 & $0 \%$ & 508 & $0 \%$ & 763 & $0 \%$ \\
\hline Teléfono, Internet & S/. & 1.017 & $0 \%$ & 1.017 & $0 \%$ & 1.525 & $0 \%$ \\
\hline Transporte & S/. & 6.102 & $1 \%$ & 6.102 & $1 \%$ & 9.153 & $1 \%$ \\
\hline Alquiler & S/. & 10.169 & $1 \%$ & 10.169 & $1 \%$ & 15.254 & $2 \%$ \\
\hline Depreciación de activo fijo & S/. & 8.051 & $1 \%$ & 8.051 & $1 \%$ & 12.076 & $1 \%$ \\
\hline Depreciación de activo biológico & S/. & 93.626 & $11 \%$ & & $0 \%$ & & $0 \%$ \\
\hline Costo unitario & $\mathrm{S} / . \mathrm{X} \mathrm{kg}$ & 3,23 & & 2,86 & & 3,68 & \\
\hline
\end{tabular}




\begin{tabular}{|c|c|c|c|c|c|c|c|}
\hline \multicolumn{2}{|l|}{ Costo segundo año (10 meses) } & \multicolumn{2}{|c|}{ Método A } & \multicolumn{2}{|c|}{ Método B } & \multicolumn{2}{|c|}{ Método C } \\
\hline Huevos producidos & $\mathrm{kg}$ & 333.015 & & 333.015 & & 256.833 & \\
\hline Costo total & S/. & 1.052 .906 & & 935.874 & & 935.874 & \\
\hline Costos variables & & 818.211 & $78 \%$ & 818.211 & $87 \%$ & 818.211 & $87 \%$ \\
\hline Gallina BB & S/. & 0 & $0 \%$ & 0 & $0 \%$ & 0 & $0 \%$ \\
\hline Vacuna & S/. & 0 & $0 \%$ & 0 & $0 \%$ & 0 & $0 \%$ \\
\hline Consumo de materia prima & & 818.211 & $78 \%$ & 818.211 & $87 \%$ & 818.211 & $87 \%$ \\
\hline Alimento balanceado & S/. & 671.008 & $64 \%$ & 671.008 & $72 \%$ & 671.008 & $72 \%$ \\
\hline Medicamento & S/. & 1.678 & $0 \%$ & 1.678 & $0 \%$ & 1.678 & $0 \%$ \\
\hline Empaque & S/. & 145.525 & $14 \%$ & 145.525 & $16 \%$ & 145.525 & $16 \%$ \\
\hline Costos fijos & & 234.695 & $22 \%$ & 117.663 & $13 \%$ & 117.663 & $13 \%$ \\
\hline Mano de obra & & 82.133 & $8 \%$ & 82.133 & $8 \%$ & 82.133 & $8 \%$ \\
\hline Sueldo bruto & S/. & 60.000 & $6 \%$ & 60.000 & $6 \%$ & 60.000 & $6 \%$ \\
\hline Gratificaciones & S/. & 10.000 & $1 \%$ & 10.000 & $1 \%$ & 10.000 & $1 \%$ \\
\hline CTS & S/. & 5.833 & $1 \%$ & 5.833 & $1 \%$ & 5.833 & $1 \%$ \\
\hline Essalud & S/. & 6.300 & $1 \%$ & 6.300 & $1 \%$ & 6.300 & $1 \%$ \\
\hline Gastos generales & & 25.466 & $2 \%$ & 25.466 & $3 \%$ & 25.466 & $3 \%$ \\
\hline Luz & S/. & 2.542 & $0 \%$ & 2.542 & $0 \%$ & 2.542 & $0 \%$ \\
\hline Agua & S/. & 678 & $0 \%$ & 678 & $0 \%$ & 678 & $0 \%$ \\
\hline Celulares & S/. & 636 & $0 \%$ & 636 & $0 \%$ & 636 & $0 \%$ \\
\hline Teléfono, Internet & S/. & 1.271 & $0 \%$ & 1.271 & $0 \%$ & 1.271 & $0 \%$ \\
\hline Transporte & S/. & 7.627 & $1 \%$ & 7.627 & $1 \%$ & 7.627 & $1 \%$ \\
\hline Alquiler & S/. & 12.712 & $1 \%$ & 12.712 & $1 \%$ & 12.712 & $1 \%$ \\
\hline Depreciación de activo fijo & S/. & 10.064 & $1 \%$ & 10.064 & $1 \%$ & 10.064 & $1 \%$ \\
\hline Depreciación de activo biológico & S/. & 117.032 & $11 \%$ & & $0 \%$ & & $0 \%$ \\
\hline Costo unitario & $\mathrm{S} / . \mathrm{X} \mathrm{kg}$ & 3,16 & & 2,81 & & 2,81 & \\
\hline
\end{tabular}




\section{- Impacto de los métodos de costeo}

El impacto de los métodos de costeo se centra en dos aspectos: tributario y contable. El primero se explica porque en un período se tendrá un mayor costo que reducirá la base tributaria, pero en el segundo período los costos serán menores, generando una mayor base tributaria.

Por otro lado, el impacto contable se tendrá en los costos unitarios, puesto que en los métodos B y C no se genera depreciación del activo biológico, lo cual puede dar la sensación de que los costos son mejores.

\section{Cuadro 19}

Costos unitarios de los métodos de costeo

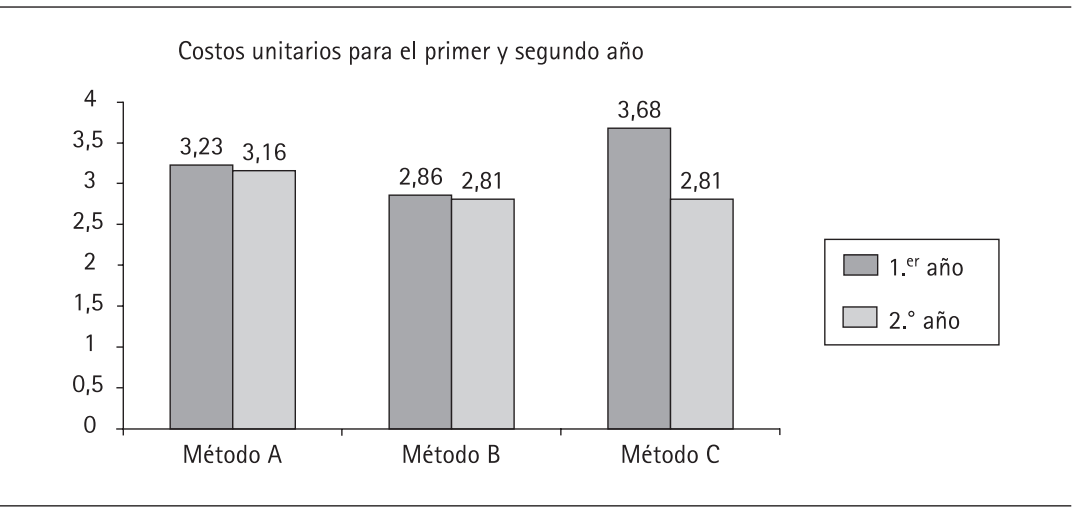

\section{Propuesta de costeo}

El método de costeo que mejor refleja la realidad es el "método de costeo A", donde se valoriza al activo durante su etapa de levante, para luego generar depreciación durante la etapa de postura. Las razones de ello se explican a continuación:

- Este método reconoce al activo biológico siguiendo la NIC 41.

- El modelo refleja adecuadamente el costo de la depreciación del activo biológico dentro del costeo de los huevos comerciales.

- Este método hace distinción de las principales etapas de producción del activo biológico: etapa de levante y etapa de postura. 
- Por último, la valorización de los huevos comerciales se realiza al costo en referencia a la NIC 2, la cual indica que todo producto cosechado o extraído debe valorizarse al costo.

\section{Valoración del activo biológico}

En esta parte del trabajo, se procede a realizar la valorización del activo biológico mediante la aplicación de la NIC 41 Agricultura. Para realizar la simulación, se tomarán los supuestos considerados en el modelo de costeo planteado.

\section{Marco teórico para la aplicación de la NIC 41}

\section{- La necesidad de una NIC sobre agricultura}

La mayoría de empresas agrícolas son pequeñas e independientes, preocupadas por el efectivo y pago de impuestos. Son entidades familiares a las que a menudo se aconseja elaborar estados financieros con el propósito de información general, aunque no siempre se les exige, por lo que algunos creen que una Norma Internacional de Contabilidad sobre agricultura no tendría una aplicación amplia. Sin embargo, las pequeñas entidades agrícolas buscan capital de bancos o gobiernos, los cuales solicitan estados financieros basados en sólidos principios contables generalmente $\operatorname{aceptados}^{17}$.

Un problema para una norma era la diversidad de actividades agrícolas y que cada una de ellas tendría principios particulares según los ciclos de producción cortos o largos.

Por otro lado, se resalta la importancia de la agricultura en la economía de países en desarrollo.

- Alcance de la norma

- No se aplica la norma cuando el activo biológico deja su ciclo productivo o cosecha.

- $\quad$ No se aplica cuando se extiende el proceso (ejemplo: la producción de vino).

17. International Accounting Standards Committee Foundation. Normas Internacionales de Información Financiera: emitidas al 1 de enero de 2012. 
- Existe la posibilidad de aplicar la norma cuando existe un proceso largo de curación o maduración tras la cosecha de producto (ejemplo: uva a vino y leche a queso).

\section{- Activo biológico}

La norma define a un activo biológico como un animal vivo o planta que se ve afectado por una transformación biológica. Este proceso comprende las etapas de crecimiento, degradación, producción y procreación. La NIC 41 menciona que los activos biológicos se midan a su reconocimiento inicial y al final se midan a su valor razonable menos los costos de venta, salvo cuando el valor razonable pueda ser medido fiablemente.

La entidad reconocerá un activo biológico solo cuando: (a) tenga el control del activo como resultado de sucesos pasados; (b) sea probable que fluyan a la entidad beneficios económicos futuros asociados al activo; y (c) el valor razonable o costo del activo pueda ser medido de forma fiable.

- Valor razonable

Según la NIC 41, el valor razonable es el importe por el cual un activo puede ser intercambiado, o un pasivo puede ser cancelado, entre un comprador y vendedor interesado y debidamente informado que realizan una transacción bajo términos de libre competencia.

\section{- Jerarquía de valorización}

- $\quad$ El precio del activo en un mercado activo.

- El precio de transacción reciente del activo si no existe un mercado activo.

- Los precios del mercado para activos similares, ajustados por los puntos de diferencia.

- Estándares de la industria dentro del sector en el que opera la compañía.

- El valor presente de los flujos de efectivo futuros que generará el activo.

Las ganancias o pérdidas surgidas por causa del reconocimiento inicial de un activo biológico según su valor razonable menos sus costos estimados en el 
punto de venta, así como las surgidas en todos los cambios sucesivos en el valor razonable menos los costos estimados en el punto de venta, deben ser incluidas en el resultado neto del ejercicio contable en que aparezcan.

En el caso de las gallinas, según el experto consultado de $\mathrm{PwC}$, estas no cuentan con un mercado activo. Para que exista un mercado activo, debe existir un mercado donde se transe el activo biológico desde el momento en que nazca. Actualmente, existen empresas que venden pollas bebé, pero son pocas en el mercado, por lo que no se podría decir que existe un mercado activo para las pollas bebé. Para que exista un mercado activo, deben existir muchas empresas que ofrezcan y compren el producto libremente.

En el caso de que no exista un mercado activo, una entidad debe utilizar por lo menos uno de los datos de la siguiente información para determinar el valor razonable, siempre que estuviesen disponibles: el precio de la transacción más reciente en el mercado, suponiendo que no haya habido un cambio significativo en las circunstancias económicas entre la fecha de tasación y el período sobre el cual se informa; los precios de mercado de activos similares, ajustados para reflejar las diferentes existentes.

En algunas circunstancias, el valor razonable puede ser fácilmente determinable, sin un costo o esfuerzo desproporcionado, aun cuando no haya disponibles precios o valores determinados por el mercado para un activo biológico en su condición actual. Para esto se evalúa si el valor presente de los flujos de efectivo netos esperados procedentes del activo descontados a una tasa de mercado da lugar a una medición fiable del valor razonable.

En el cálculo del valor presente de los flujos de efectivo esperados, la entidad incluirá los flujos de efectivo netos que los partícipes del mercado esperarían que el activo generase en su mercado más relevante. La entidad no incluirá flujos de efectivo destinados a la financiación de los activos, ni flujos por impuestos o para restablecer los activos biológicos tras la cosecha o recolección (por ejemplo: los costos de replantar los árboles, en una plantación forestal, después de la tala de los mismos).

Asimismo, la entidad debe incorporar las expectativas de posibles variaciones en los flujos de efectivo sobre los propios flujos esperados, sobre la tasa de descuento o sobre una combinación de ambos. 
Por último, una entidad medirá los activos biológicos cuyo valor razonable no sea fácilmente determinable sin costo o esfuerzo desproporcionado, al costo menos cualquier depreciación acumulada y cualquier pérdida por deterioro del valor acumulada.

Información por revelar

- La empresa debe revelar la ganancia o pérdida surgida durante el ejercicio corriente por el reconocimiento inicial de los activos biológicos y los productos agrícolas, así como por los cambios de valor razonable menos los costes estimados en el punto de venta de los activos biológicos.

- La empresa debe describir:

(a) la naturaleza de sus actividades relativas a cada grupo de activos biológicos; $\mathrm{y}$

(b) las valoraciones no financieras, o las estimaciones de las mismas, relativas a las cantidades físicas de:

(i) cada grupo de activos biológicos al final del ejercicio; y

(ii) la producción agrícola del ejercicio.

- La empresa debe revelar los métodos y las hipótesis significativas aplicadas en la determinación del valor razonable de cada grupo de productos agrícolas en el punto de cosecha o recolección, así como de cada grupo de activos biológicos.

- La empresa debe revelar el valor razonable, menos los costes estimados en el punto de venta, de los productos agrícolas cosechados o recolectados durante el ejercicio, determinando el mismo en el punto de recolección.

- Una conciliación de los cambios en el importe entre el comienzo y el final del período corriente. La conciliación incluirá:

- La ganancia o pérdida surgida de cambios en el valor razonable menos los costos de venta.

- Los incrementos procedentes de compras.

- Los decrementos procedentes de cosechas o recolección.

- Los incrementos procedentes de combinaciones de negocios.

- Las diferencias en cambio que surgen de la conversión de los estados financieros de un negocio en el extranjero a la moneda de presentación de la entidad que informa. 
Para una entidad que presenta sus activos biológicos al costo, una empresa debe revelar:

a) Una descripción de los activos biológicos.

b) Una explicación de la razón por la cual no puede medirse con fiabilidad el valor razonable.

c) Si es posible, el rango de estimaciones entre las cuales es altamente probable que se encuentre el valor razonable.

d) El método de depreciación utilizado.

e) Las vidas útiles o las tasas de depreciación acumuladas.

f) El importe en libros bruto y la depreciación acumulada, al principio y al final del período.

Costos de ventas

El costo de ventas son los costos incrementales incurridos a la hora de vender un activo. Un activo biológico debe ser medido a su valor razonable menos los costos estimados en punto de venta. Los costos en el punto de venta incluyen:

- Comisiones de intermediarios y comerciantes. Por ejemplo, comisiones pagadas a brokers $y$ dealers ${ }^{18}$, impuestos y comisiones pagadas a las agencias reguladoras.

- Cargos correspondientes a agencias reguladoras.

- Cargos correspondientes a las bolsas o mercados organizados de productos.

- Impuestos y gravámenes que recaigan sobre las transferencias o costos financieros.

Los costos en el punto de venta excluyen:

- Costos de transporte u otros para llevar el activo al mercado, los cuales son deducidos en la determinación del valor razonable.

18. PwC. A Practical Guide to Accounting for Agricultural Assets, p. 8. 


\section{Ventas bajo la NIC 41}

La venta de activos biológicos produce un ingreso que es definido bajo la NIC 18 Ingresos. Los ingresos comprenden el valor razonable del pago por recibir o por cobrar solo para la venta de productos agrícolas y/o activos biológicos. Se registra neto de impuestos a las ventas, rebajas o descuentos ${ }^{19}$.

Los ingresos según la NIC 41 pueden clasificarse de la siguiente manera ${ }^{20}$ :

- Ganancia o pérdida inicial proveniente de los activos biológicos.

- Cambios en el valor razonable menos los costos de venta de los activos biológicos.

- Ganancia o pérdida inicial sobre los productos agrícolas.

Las pérdidas iniciales surgen cuando el activo biológico es comprado. El costo de este activo biológico es por lo general mayor que su valor razonable menos el costo de venta, ya que este último representa el precio de salida; por lo tanto, los costos de transacción presentan una pérdida. Las ganancias iniciales surgen cuando se generan nuevos activos biológicos, por ejemplo, cuando nace una gallina.

Cambios en el valor razonable menos los costos de venta de un activo biológico representan la diferencia en el valor de un período, normalmente en el acumulado. A veces, resulta difícil separar la ganancia inicial debido a la procreación. El valor aumenta debido al crecimiento del activo biológico, su procreación y el alza en los precios, pero baja como consecuencia de degeneración, enfermedad y precios más bajos.

Por último, las ganancias o pérdidas iniciales sobre los productos agrícolas representan la diferencia entre el cambio en valor en libros de los activos biológicos debido a la cosecha de los productos agrícolas. Estos productos luego se transfieren a existencias.

Cabe destacar que no se considera como ingreso el valor residual del activo fijo, debido que estos productos se considera como inventario disponible, por lo que se regirían por la NIC.

19. Ibídem, p. 9.

20. Ídem. 
A continuación, las diferentes etapas en la vida contable de los activos biológicos ${ }^{21}$ :

\section{Cuadro 20}

Etapas en la vida contable de los activos biológicos

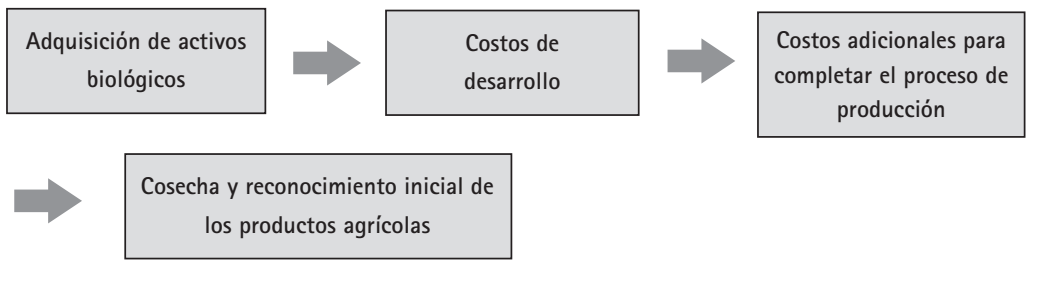

Diferencias en la aplicación del valor razonable según la NIC 41

Los estados financieros deben reflejar la situación real de la empresa y para ello deben seguir los lineamientos de las normas contables. En ese sentido, la NIC 41 avala el valor razonable para contabilizar los activos biológicos (gallina ponedora), que difiere del costo histórico. Se emplea el enfoque de valor razonable en la medición del activo biológico excepto en casos en que ese valor no se pueda calcular de forma fiable en el reconocimiento inicial o su cálculo sea muy costoso.

La medición al valor razonable es más fiable porque se basa en los beneficios futuros de los activos biológicos. Esto es aplicado por los mercados activos, en los cuales el precio está en función de los beneficios futuros. En el siguiente cuadro, se pueden observar las diferencias en la aplicación del valor razonable según la NIC 41.

21. Ídem. 


\section{Cuadro 21}

\section{Diferencias en el cálculo del valor razonable en activos biológicos}

\begin{tabular}{|l|l|}
\hline \multicolumn{2}{|c|}{ Seguimiento del valor razonable en los activo biológicos y productos agrarios (NIC 41) } \\
\hline \multicolumn{1}{|c|}{ Positivo } & \multicolumn{1}{c|}{ Negativo } \\
\hline $\begin{array}{l}\text { Permite reflejar las variaciones de valor en ciclos largos } \\
\text { de producción. }\end{array}$ & $\begin{array}{l}\text { Gran volatilidad en los precios o resultados } \\
\text { agrarios. }\end{array}$ \\
\hline $\begin{array}{l}\text { Ofrece información más adecuada para evaluar el riesgo. } \\
\text { dan mejor reflejados tomando como referencia los cambios } \\
\text { en el valor razonable de los activos biológicos. }\end{array}$ & $\begin{array}{l}\text { Pueden existir activos biológicos que no sean } \\
\text { fiables de medir a valor razonable. }\end{array}$ \\
\hline $\begin{array}{l}\text { Muchos activos biológicos son negociados con precios de } \\
\text { mercado observables. Esto permite ver las expectativas } \\
\text { de mercado relativas largos. }\end{array}$ & $\begin{array}{l}\text { Está basado en suposiciones subjetivas que no } \\
\text { se pueden verificar. }\end{array}$ \\
\hline
\end{tabular}

\section{Aplicación de la NIC 41}

Para la aplicación de la norma, se tomarán en consideración los datos obtenidos a través de las entrevistas con los expertos y trabajo de campo. Todo ello con el propósito de ilustrar la aplicación de la norma mediante el modelo propuesto.

De acuerdo con la NIC 41, para el cálculo del valor razonable se procede a proyectar los flujos económicos de la empresa, y serán descontados a una tasa de descuento del costo del capital promedio ponderado (WACC).

\section{Supuestos de evaluación:}

- Los rendimientos del activo biológico serán los mencionados anteriormente.

- El lote de gallinas será de 20.000 aves desde la etapa de levante; sin embargo, esta se verá afectada por la mortalidad.

- El crecimiento en número de gallinas es de 5\% anual. 
- La etapa de postura del ave será de 1,5 años.

- La depreciación anual del ave será la mencionada por la norma, de 75\% al año.

- $\quad$ El tipo de cambio es S/. 2,75 por dólar.

- Los huevos se clasifican según su tamaño y calidad, y los precios estarán en función de ello.

- La venta de los huevos será en granja y al contado.

- Las compras de materias primas se realizan de forma semanal. Por tanto, no se tiene stock de materias primas.

- $\quad$ El costo de la deuda es de $15 \%$.

- La estructura de deuda / capital + deuda es de 30\%.

La tasa de descuento se calculó de la siguiente manera: 


\section{Cuadro 22}

\section{Cálculo de la tasa de descuento}

(a) Costo del patrimonio (CAPM):

CAPM: TD $=R_{\text {fus }}+b^{*}\left(R_{\text {mUS }}-R_{\text {fUS }}+C R P\right)$

Fuente: CFA Institute

Componente Instrumento utilizado y fuente Sustento

\begin{tabular}{|c|c|c|c|}
\hline Tasa libre de riesgo $\left(\mathrm{R}_{\text {fus }}\right)$ & $\begin{array}{l}\text { US Bono de Tesoro (10 años) } \\
5 \text { años promedio simple } \\
\text { Fuente: Federal Reserve (FDR) }\end{array}$ & $\begin{array}{l}\text { Instrumento mas representativo para } \\
\text { una inversión sin riesgo. }\end{array}$ & $6,73 \%$ \\
\hline 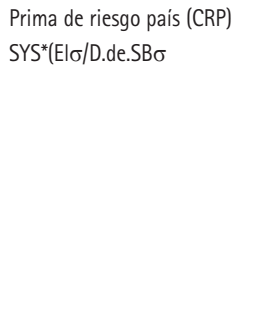 & $\begin{array}{l}\text { Spread de retorno a bonos soberanos } \\
\text { (EMBI+ Perú) multiplicado por la } \\
\text { desviación estándar anualizada del } \\
\text { indice de la bolsa peruana sobre } \\
\text { desviación estándar anualizada de } \\
\text { bonos Brady soberanos del Perú. } \\
\text { Fuente: BCRP } \\
\sigma_{p}: 14 \text { años } \\
\sigma_{\text {PUB }}: 35 \text { años }\end{array}$ & $\begin{array}{l}\text { Debido a que la empresa se encuentra } \\
\text { fisicamente en el Perú, hay que ajustar la } \\
\text { tasa libre de riesgo de los Estados Unidos } \\
\text { a la tasa libre de riesgo peruana. El factor } \\
\text { de ajuste es el spread EMBI+ Perú }\end{array}$ & $1,97 \%$ \\
\hline Beta apalancada $(\beta)$ & $\begin{array}{l}\text { Estos se determinan por medio de la } \\
\text { covarianza entre los rendimientos } \\
\text { de un sector y los del mercado. } \\
\text { Muestran el riesgo de una Industria } \\
\text { o sector en relación con el mercado. } \\
\text { Fuente: Damodaran }\end{array}$ & $\begin{array}{l}\text { Los betas utilizados corresponden a } \\
\text { empresas comparables en mercados } \\
\text { emergentes por ser más represen- } \\
\text { tativos. Los mismos se encuentran } \\
\text { apalancados según la estructura } \\
\text { deuda / patrimonio promedio de las } \\
\text { empresas comparables. }\end{array}$ & 1,00 \\
\hline $\begin{array}{l}\text { Prima de riesgo de mercado } \\
\left(\mathrm{R}_{\text {mus }}-\mathrm{R}_{\mathrm{fus}}\right)\end{array}$ & $\begin{array}{l}\text { Diferencia entre el retorno del mer- } \\
\text { cado de los Estados Unidos (S\&P 500) } \\
\text { y la tasa libre de riesgo (US Bono de } \\
\text { Tesoro de } 10 \text { años). } \\
\text { Fuentes: Yahoo Finance, BCRP } \\
\text { Sample size: } \\
\left(R_{\text {mus }}\right): 15 y e a r s\end{array}$ & $\begin{array}{l}\text { Diferentes países tienen diferentes } \\
\text { niveles de riesgo (medido como la } \\
\text { variablllidad de la rentabilidad de } \\
\text { un activo). Es por eso que la prima } \\
\text { de mercado se tiene que ajustar a la } \\
\text { volatilidad peruana. }\end{array}$ & $\begin{array}{r}\text { CAPM } \\
\text { nominal } \\
15,39 \%\end{array}$ \\
\hline
\end{tabular}




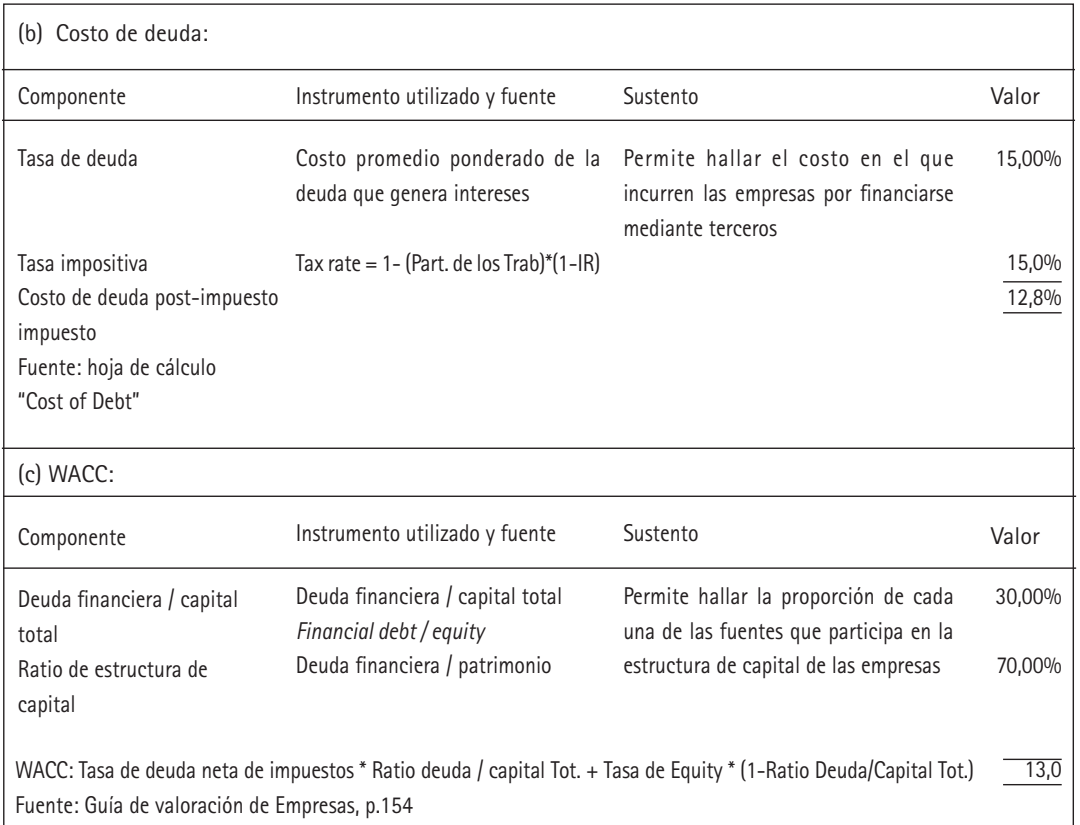

A continuación, se presentan los flujos económicos proyectados para la aplicación de la NIC 41 en la valorización del activo biológico. Como se puede observar, los ingresos empiezan a partir del mes 5, dado que los meses anteriores comprenden la etapa de levante. Asimismo, para la aplicación de la NIC 41, los ingresos por la venta del ave no forman parte del cálculo, puesto que se convierte en un producto cosecha dentro de la NIC 2. 


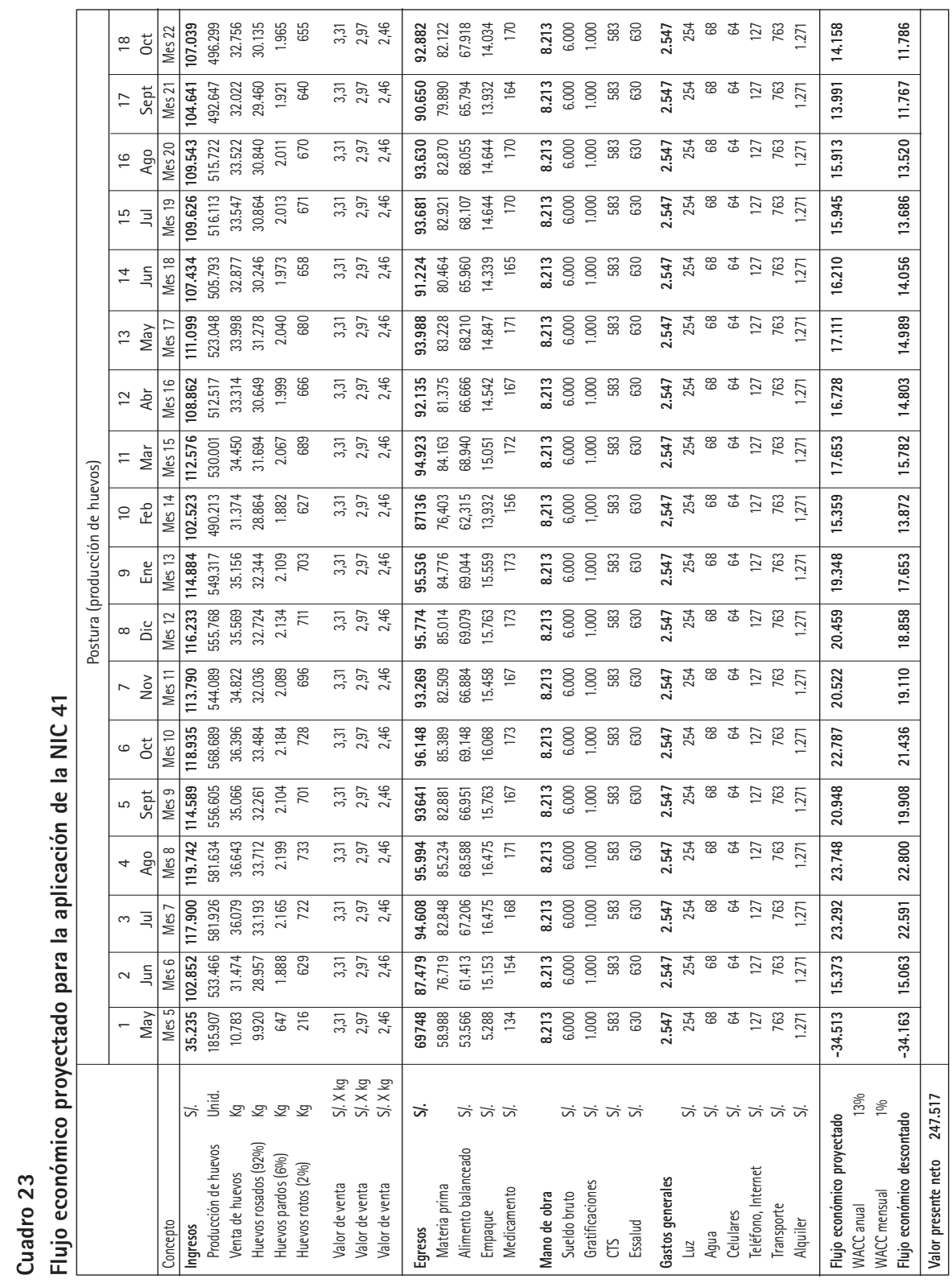


Como resultado de la aplicación de la valorización del activo biológico al costo y la valorización del activo mediante el valor razonable, se tendrá una diferencia de ganancia o pérdida que refleja el efecto de la NIC 41. Como se puede notar en el cuadro 16, el valor de los activos biológicos medidos al costo es de S/. 209.258. Cabe señalar que el costo de estos activos biológicos es calculado con base en todos los gastos incurridos en la etapa de levante (las medicinas, el alimento balanceado, el empaque de huevos, la mano de obra, los gastos generales y la depreciación de los activos fijos son registrados como activos biológicos), los cuales son activados durante esta etapa. El valor razonable de los activos biológicos es S/. 258.115. Este monto se obtuvo de utilizar el flujo de caja económico y traerlo a valor presente, como se puede apreciar en el cuadro 23. En este caso, se puede observar que el valor razonable de los activos biológicos es mayor que el costo de estos, por lo que se obtiene una ganancia por efecto NIC 41 de S/. 48.857.

\section{Cuadro 24}

\section{Efecto de la NIC 41}

\begin{tabular}{|lr|}
\hline Activos biológicos valorizados al costo & 210.658 \\
\hline Efecto NIC 41 & 36.859 \\
\hline Activos biológicos al valor razonable & 247.517 \\
\hline
\end{tabular}

Una vez calculado el valor razonable del activo biológico, se debe incorporar al activo de la empresa mediante un asiento de ajuste. Como se explicó anteriormente, en vista de que el valor razonable es mayor que el costo del mismo, se produce una ganancia por medición de activos al valor razonable. A continuación, se detallará el asiento contable que se debe realizar.

\section{Cuadro 25}

Ajuste de cuenta contable

\begin{tabular}{|ll|c|c|}
\hline & & Debe & Haber \\
\hline 35 & ACTIVOS BIOLÓGICOS EN PRODUCCIÓN & 48.857 & \\
351 & Activos biológicos en producción & & \\
3511 & De origen animal & & \\
76 & GANANCIA POR MEDICIÓN DE ACTIVOS NO FINANCIEROS AL VALOR RAZONABLE & & 48.857 \\
762 & Activos biológicos & & \\
\hline
\end{tabular}


La partida de activos biológicos se presenta en los EE. FF. de la siguiente manera, bajo los resultados de la NIC 41 .

\section{Cuadro 26}

Presentación de EE. FF.

\begin{tabular}{|ccc|}
\hline & Aves & Total \\
& S/. & S/. \\
Activo biológico en postura & 258.115 & 258.115 \\
\hline Total & 258.115 & 258.115 \\
\hline
\end{tabular}

En caso una empresa posea más de un tipo de activo biológico, estos deberán presentarse de forma separada. Asimismo, si la empresa cuenta con varios lotes de producción, agrupados por edad, se debe indicar el valor razonable por etapas, diferenciando los activos biológicos que están en proceso de levante y los activos biológicos que están en proceso de postura. En el siguiente cuadro, se muestra cómo se debe presentar en los EE. FF.

\section{Cuadro 27}

Presentación de EE. FF. con supuestos

\begin{tabular}{|lccc|}
\hline & Gallina & Pollo & Total \\
& $\mathrm{S} /$. & $\mathrm{S} /$. & $\mathrm{S} /$. \\
Activo biológico en levante & $\mathrm{XXX}$ & $\mathrm{XXX}$ & $\mathrm{XXX}$ \\
Activo biológico en postura & $\mathrm{XXX}$ & $\mathrm{XXX}$ & $\mathrm{XXX}$ \\
\hline Total & $\mathrm{XXX}$ & $\mathrm{XXX}$ & $\mathrm{XXX}$ \\
\hline
\end{tabular}

Impacto tributario

De acuerdo con la norma tributaria peruana, ámbito tributario, se sigue llevando el modelo del costo, por lo que la NIC 41 no tiene efecto alguno en el pago del impuesto a la renta. La NIC 41 se debe observar para la elaboración de información financiera.

Para el ente fiscalizador, solo podrán ser deducibles los gastos que no hayan sido resultado de cálculos del valor razonable, sino que provengan de las operaciones. 


\section{Conclusiones}

- La industria avícola es una de las más importantes del sector pecuario, el cual ha mantenido crecimientos promedios de 5\% en los últimos 5 años.

- La producción de huevos mantiene una tasa de crecimiento constante de $4 \%$ en promedio, impulsada por una mayor difusión de los beneficios asociados al huevo.

- La gran mayoría de empresas del sector son pequeñas, con bajo poder de negociación.

- Existe un alto grado de informalidad en el sector avícola.

- Las grandes empresas están integrándose verticalmente hacia adelante.

- No existe un modelo de costeo uniforme en las empresas que operan en la producción de huevos.

- Muchas empresas no diferencian los costos incurridos en la etapa de levante de los de la etapa de postura, sobre todo empresas pequeñas.

- El método de costeo de huevos comerciales que mejor refleja la realidad es aquel donde se valoriza al activo durante la etapa de levante, para luego generar depreciación durante la etapa de postura o producción de huevos.

- El modelo planteado de valorización de activo biológico no tendría ningún impacto tributario para las empresas, pero es importante desde el punto de vista financiero.

- El modelo planteado es fácil de desarrollar para cualquier empresa que participe en este sector, y no es costosa su implementación. 



\title{
5. Método de costeo de ganado vacuno para las empresas ganaderas peruanas
}

\author{
David Carranza \\ Alejandro Gonzales \\ Marlene Ke Jun
}

\section{Resumen}

El presente trabajo de investigación tiene como objetivo proponer un modelo de costeo homogéneo aplicable a empresas y asociaciones ganaderas del Perú bajo el marco de las Normas Internacionales de Contabilidad (NIC 41).

Para llevar a cabo esta investigación, se realizaron diversas entrevistas con expertos de diferentes ámbitos, tales como: contabilidad financiera, auditoría financiera y ganadería, mediante las cuales se determinó el alcance de este trabajo.

Se analizaron y compararon los modelos de costeo Carlos Llenque (Universidad del Callao) y el del Fondo Nacional de Ganadería Lechera «Fongal». Dentro de los principales hallazgos, se puede observar que ambos modelos no cumplen con los alcances propuestos por la NIC 41 y que el modelo Carlos Llenque se basa en el costeo tradicional, mientras que el modelo "Fongal» utiliza un método de costeo directo.

La comparación y análisis de los modelos, junto con la información obtenida del sector lácteo y entrevistas, sentaron las bases para la elaboración de un modelo de costeo. Dicho modelo toma en cuenta los procesos biológicos del animal, la situación del sector a nivel nacional y los alcances de la NIC 41 . 


\section{Introducción}

En los últimos años, de acuerdo con estadísticas y datos macroeconómicos sobre el crecimiento del Perú 1 , se puede apreciar que los productos extraídos del ganado vacuno han cobrado gran importancia en la canasta básica alimentaria de la población nacional. Las ganaderías extensiva e intensiva ${ }^{2}$ han constituido herramientas importantes para el desarrollo económico y social del país, beneficiando a productores y consumidores. Dicho rubro ha alcanzado su crecimiento más notable en las provincias de Cajamarca, Arequipa y Lima, y ha atravesado por varias etapas hasta llegar a la estructura atomizada que tiene hoy. Luego de las políticas impuestas con la reforma agraria, se terminó por eliminar los centros productivos más importantes del país y el período inflacionario consolidó un gran debilitamiento del sector. Finalmente, las nuevas políticas impuestas en la década de 1990 abrieron el mercado y eliminaron los subsidios, lo cual permitió un sano desarrollo de la economía peruana, pero a su vez perjudicó al sector ganadero, pues abrió las puertas a la importación de leche en polvo del extranjero con precios menores que la producida localmente ${ }^{3}$.

En el Perú, actualmente existen dos grupos involucrados en este rubro: por un lado están los ganaderos individuales, gremios, asociaciones y cooperativas, que se dedican a la crianza de ganado vacuno y extracción de leche; y, por otro lado, las grandes empresas procesadora de lácteos, que usan la leche de los ganaderos como materia prima para fabricar sus productos. Dado que las agroindustriales son pocas y los ganaderos se encuentran dispersos geográficamente unos de otros, los agroindustriales cuentan con un poder de negociación mayor que los ganaderos.

En el presente trabajo, se propone un modelo de costeo del ganado vacuno a partir de los modelos de Llenque (Universidad del Callao) y Fongal (Fondo Nacional de Ganadería Lechera). Este modelo de costeo tiene la finalidad de ser aplicado por aquellos ganaderos que hayan optado por asociarse con otros

1. "Hoja de balance de alimentos, 1997-2008». Ministerio de Agricultura.

2. Ganadería extensiva: es la ganadería perdurable en el tiempo y que mantiene un nivel de producción sin perjudicar al medio ambiente o al ecosistema. Ganadería intensiva: el ganado se encuentra estabulado, generalmente bajo condiciones de temperatura, luz y humedad que han sido creadas en forma artificial, con el objetivo de incrementar la producción en el menor lapso de tiempo.

3. Infolactia. 
y que no solo busquen considerar aspectos tributarios, sino también aspectos financieros bajo el marco propuesto por la NIC 41.

\section{Área}

El presente trabajo de investigación se centra en el ámbito de la contabilidad financiera, y específicamente en la contabilidad del sector ganadero. Además, se delimitan los alcances de la investigación dentro del marco presentado por la NIC 41. En ese sentido, la presente investigación tiene impacto en los ámbitos contable y administrativo de la empresa, puesto que el costeo adecuado para los activos biológicos no solo muestra cifras informativas, sino que sirve como herramienta para la toma de decisiones.

\section{Objetivos}

El objetivo de esta investigación son los activos biológicos (AB) de las empresas ganaderas peruanas dedicadas a la crianza de vacunos para la extracción de leche. Para ello, se utilizan como guía las normas internacionales, con énfasis en la NIC 41, la cual prescribe el tratamiento contable, la presentación en los estados financieros y la información por revelar en relación con la actividad agrícola 4 . Dentro de la definición de $\mathrm{AB}$ en dicha norma, se encuentran dos ramas principales: animales y plantas. Para efectos de esta investigación, solo se presta atención a la rama de animales, y específicamente al ganado vacuno, entendiéndose a este como el grupo de $\mathrm{AB}$ conformado por vacas y becerros. Además, se incluye el concepto de producto cosecha o de recolección, definido como "la separación del producto del $\mathrm{AB}$ del que procede o el cese de los procesos vitales de un $\mathrm{AB}$ » (numeral 5 de la NIC 41). Para fines de la presente investigación, se considera a la leche producida por el ganado vacuno como el producto cosecha o de recolección.

\section{Objetivo general}

Proponer un modelo de costeo de los activos biológicos para las empresas ganaderas peruanas, de modo que pueda ser utilizado con la finalidad de identificar el beneficio o pérdida generado al ganadero por la producción y comercialización de su producto cosecha.

4. NIC 41 Agricultura. 


\section{Objetivos específicos}

A continuación, se detallan los objetivos específicos planteados para la presente investigación:

- Identificar métodos de costeo para el sector ganadero peruano, haciendo énfasis en el ganado vacuno.

- Comparar los métodos de costeo utilizados por las empresas peruanas que cuentan con ganado vacuno, e identificar las diferencias existentes entre ellos, así como contrastar los resultados obtenidos con la aplicación del modelo propuesto.

- Identificar los recursos utilizados por las empresas ganaderas para el desarrollo del ganado vacuno y la obtención del producto cosecha.

- Catalogar los recursos definidos anteriormente como partidas de gasto y costo asociadas al ganado vacuno.

\section{Alcance}

En la presente investigación, se busca establecer una metodología dentro de los estándares y alcances de la norma internacional y generar comparabilidad entre empresas del mismo sector, de modo que dichas empresas cuenten con una herramienta para el análisis financiero de sus resultados y que les permita formular estrategias a futuro.

\section{Metodología}

El presente trabajo se basó en el método inductivo de investigación, dado que se partió de observaciones específicas del sector ganadero, y a través de ellas se obtuvo una generalización: "un modelo de costeo para ganado vacuno" que las empresas ganaderas del Perú puedan utilizar, y que esté acorde con las normas internacionales y los principios de contabilidad generalmente aceptados.

La metodología del proceso de investigación se planteó de la siguiente manera: 


\section{Diseño de la investigación}

\section{- Recolección de la información}

De manera inicial para esta investigación, se planteó la obtención de información a través de la consulta de fuentes primarias: entrevistas a expertos de diferentes ámbitos, tales como la contabilidad financiera, la auditoría financiera y la ganadería. Dicha información brindó herramientas para comparar los escenarios teóricos y reales, y a la vez permitió buscar y analizar las diferencias existentes entre ellos.

Por otro lado, también se extendió la investigación hacia fuentes secundarias. Para ello, se realizó la revisión de documentos, informes, libros, normas y datos estadísticos. El detalle de la bibliografía se muestra de manera específica más adelante, en la sección «Herramientas».

\section{- Análisis y evaluación de la información obtenida}

Una vez concluida la fase de recopilación de datos, se procedió a analizar la información obtenida y plantear un modelo de costeo de los $\mathrm{AB}$, el cual permite a las empresas ganaderas peruanas que cuenten con activos biológicos vacunos contar con información confiable sobre el valor real de los mismos, y poder tomar decisiones más seguras. Para apoyar el correcto desarrollo del modelo, se plantearon casos prácticos que engloben los diferentes escenarios posibles.

Para el análisis y evaluación de la información, se procedió de la siguiente manera:

A. Determinar las herramientas disponibles para costeo de los activos biológicos (ganado vacuno).

B. Hacer un diagnóstico del tipo de costeo que emplean las empresas ganaderas locales y determinar si su modelo de costeo de activos biológicos atiende necesidades financieras y tributarias.

C. Evaluar la relevancia de los diferentes modelos de costeo de los activos biológicos en la determinación del retorno esperado de las empresas ganaderas en la venta del producto cosecha (leche). 


\section{- Evaluación de los modelos}

Luego de transcurrido el trabajo de campo, se analizaron las fuentes obtenidas y se corroboró cuáles son los principales problemas de los modelos existentes. Una vez hallados estos problemas, se propuso una metodología basada en las normas internacionales, y según esta base se elaboró un modelo propio de la investigación.

\section{- Presentación del modelo}

Se buscó realizar un modelo que recoja los mejores atributos que existen actualmente, para así lograr un proceso de asignación de costos más uniforme dentro de las empresas ganaderas del Perú.

\section{Hipótesis}

\section{Hipótesis general}

Actualmente, existen métodos de costeo para el producto cosecha de ganado vacuno, es decir, la leche, los cuales recogen información acerca de los recursos utilizados para su desarrollo, pero estos no atienden todas las necesidades de las empresas, ya que no permiten llevar un control del valor de los activos biológicos y no necesariamente cumplen con los estándares y alcances propuestos por las normas internacionales.

\section{Hipótesis específicas}

A continuación, se detallan las hipótesis específicas:

- La determinación del costo de producto cosecha es inexacta debido a que las empresas peruanas no incorporan efectos financieros en sus cálculos.

- El desconocimiento del valor real de los activos biológico podría generar resultados distorsionados al ganadero, pudiendo ser ganancias o pérdidas no reflejadas en sus reportes financieros.

- No existe comparabilidad entre empresas del sector ganadero debido a que cada una cuenta con un método de costeo diferente. 
- En el sector vacuno no existen modelos bajo los alcances de la NIC 41, sino que todas las investigaciones se concentran en el rubro de agroexportación.

\section{Fuentes de información}

Se realizó la recopilación a través de dos tipos de fuentes.

Fuentes primarias

Se buscó respaldar la presente investigación con información obtenida a través de las siguientes fuentes primarias:

Expertos profesionales:

- $\quad$ Christian de la Torre 0., experto en NIC 41, senior manager, $\mathrm{PwC}^{5}$.

- $\quad$ Edgar Alva, experto en normas contables, profesor, Universidad del Pacífico.

- Rolando Castro Molina, experto en ganadería.

- Héctor Guevara Rivera, gerente de Fongal.

Fuentes secundarias

- $\quad$ Norma Internacional de Contabilidad (NIC 41).

- Texto Único Ordenado de la Ley del Impuesto General a las Ventas e Impuesto Selectivo al Consumo. Decreto Supremo 055-99-EF.

- $\quad$ CPC. Carlos Guillermo Llenque Curo, Diseño de un sistema contable de costos para un microempresario de ganadería lechera (Caso Cercado del Callao. Región Callao). Universidad Nacional del Callao, Facultad de Ciencias Económicas.

- Lorenzo Helguera, Bruno Lanfranco y Ernesto Majó, Ajustes a los resultados económicos, valorización de activos biológicos y productos agrícolas.

5. Anexos: entrevista con expertos. 


\section{Antecedentes}

\section{Evolución histórica del sector ganadero}

De acuerdo información obtenida del Ministerio de Agricultura del Perú ${ }^{6}$ (Minag), la actividad ganadera en el Perú mantuvo una época de auge desde inicios del siglo XX, sostenida en el manejo de las empresas privadas y el apoyo del Estado, principalmente en la sierra peruana y también con una destacable presencia en la costa. El período de auge duró hasta la década de 1970, en la que se inició una época de declive a causa de las políticas de Estado, a raíz de la reforma agraria. El resultado fue la desaparición de los centros ganaderos más importantes (atomización de las instituciones ganaderas) y la pérdida de los mejores reproductores del país. Esta situación se mantuvo y empeoró a lo largo de la década de 1980 debido a las políticas populistas, que introdujeron subsidios al mercado y fomentaron la importación de insumos y productos de origen animal que competían en condiciones más favorables que las de los productos nacionales.

Recién en la década de 1990, a raíz de las medidas adoptadas para terminar con la hiperinflación, se terminó con la política de subsidios, se abrió el mercado interno y se liberaron la oferta y la demanda. Así, con la reducción de los aranceles y la estabilización del tipo de cambio, se pasó a un período de libre comercio. A pesar de que la razón de esto haya sido positiva para la producción nacional, se terminó por perjudicarla, debido a una invasión de productos importados a bajo precio. Con todo esto, el sector ganadero viene tratando de recuperarse y modernizarse, pero el ritmo se mantiene lento, debido al gran número de productores pequeños y a la dificultad que implica esta estructura productiva.

\section{Sector ganadero vacuno en el Perú}

En el último Censo Nacional Agrario del año 2012, publicado en la web perulactea. $\mathrm{com}^{7}$, la población de ganado vacuno creció en 12\% (comparada con la cifra obtenida en el censo del año 1994): pasó de 4.495 .263 a 5.037 .499 cabezas. La distribución por zonas geográficas es mayoritaria en la parte altoandina: 74\% en la sierra, $15 \%$ en la selva y $11 \%$ en la costa. También se indica que el $42 \%$

\footnotetext{
6. <http://www.minag.gob.pe/portal/sector-agrario/pecuaria/sector-pecuario-en-el-perú?start=1>.

7. <http://www.perulactea.com/2013/02/14/mas-productores-y-mas-ganado-avances-del-censo- agropecuario-peruano/>.
} 
de las cabezas de ganado vacuno existentes en el país están divididas entre los departamentos de Cajamarca, Puno, Ayacucho y Cusco.

La crianza del ganado vacuno tiene como objetivo la producción de carne y la producción de leche, además de los derivados de esta. En la zona costera, la producción se ha basado en animales procedentes de la sierra llevados a establos (engorde intensivo). Para ello, es necesario asegurarse de que los animales cumplan con una serie de requisitos en cuanto a su conformación, edad, talla, peso, estado sanitario y grado de mejoramiento genético. Por otro lado, en la sierra, la crianza de ganado vacuno está orientada también al trabajo (yunta), adicionalmente a la carne y leche. La producción está dirigida principalmente al mercado local y al autoconsumo; adicionalmente, la mayoría del ganado responde a razas criollas. Su alimentación se sostiene principalmente en pastos naturales existentes en la zona, y en pastos cultivados de corte y pastoreo. El desarrollo de la actividad es poco tecnificado, presenta dificultades para el acceso a una adecuada asistencia técnica y, además, existen problemas sanitarios que merman el aumento de la población y la producción. Finalmente, en la Amazonía, la producción se caracteriza por el empleo de ganado cruzado con diferente grado de mestizaje entre el criollo, cebú y europeo. La alimentación está basada en el uso de forraje al pastoreo (denominado sistema extensivo), para lo cual se talan y queman extensiones de árboles.

Junto con el detalle de las razas existentes en el Perú, es necesario definir con más detenimiento los propósitos para los cuales se puede criar ganado vacuno, puesto que para cada una de las funciones se requieren una serie de características que permiten los mejores resultados en cada caso.

Por un lado, está el ganado criado para la producción de carne; este ha sido criado para la producción de carne para el consumo. Cabe resaltar que se enfatiza la producción de carcasas de alto rendimiento, que produzcan cortes de óptima calidad. Las principales razas son Hereford, Shorthorn, Aberdeen Angus, Charolaise, Limousin, Chianina, Nellore, Brahman, Charbray, Brangus, Braford, Beef Master y Santa Gertrudis.

Por otro lado, también existe ganado con doble propósito: producción de leche y carne, sin especialización exclusiva en una u otra. Entre las principales razas figuran Brown Swiss, Simmental, Normando, Shorthorn Lechero, Abondance, Gir, Guzerá, Gyrolando, Siboney, Huallaga y Amazonas. 
Finalmente, también se utiliza ganado como herramienta de arado. Las razas más representativas son Brown Swiss y Criollo.

\section{Análisis del sector lácteo}

Se realiza un análisis del sector lácteo con énfasis en los ganaderos que cuentan con las vacas para producir leche. La finalidad del análisis es conocer la realidad de la cadena productiva del sector para definir los principales problemas de este; por otro lado, el modelo de costeo que propone la investigación tiene que ajustarse a los escenarios que presenta la ganadería peruana.

A continuación, se definen algunas características del sector lácteo:

\section{Estructura de clientes de los ganaderos}

Los principales clientes de los ganaderos están conformados, en primer lugar, por los grandes agroindustriales, básicamente empresas como Gloria, Nestlé y Laive. Por otro lado, está también la agroindustria rural, pequeñas plantas que realizan producción de queso artesanal. Asimismo, el Estado también interviene en la compra de leche para los programas sociales (Pronaa y Programa del Vaso de Leche). Por último, existen familias que compran la leche directamente de los ganaderos bajo la modalidad del "porongueo».

\section{Mayor poder de negociación de los grandes agroindustriales}

Los agroindustriales recolectan la leche a través de todo el territorio nacional. Las grandes empresas, como Gloria, diseñan una red de distribución y de acopio para llegar desde la costa a la selva. Esto con el propósito de satisfacer la demanda creciente del mercado por la leche, y ya que la oferta no llega a cumplir con las expectativas del mercado. Por otro lado, cuando hay déficit de leche fresca, el mercado se abastece importando leche en polvo.

\section{Alta atomización de la ganadería láctea}

Los ganaderos se encuentran dispersos en parcelas de tierra, lo cual impide una producción eficiente de la leche y dificulta el uso de la tecnología en la extracción de dicho producto. 


\section{Bajos márgenes de utilidad}

La particularidad de la producción de leche en el Perú y la falta de regulación fomentan la comercialización de leche de baja calidad. Además, es sabido que muchas veces los ganaderos operan por debajo del punto de equilibrio. Finalmente, los ganaderos deben aceptar el precio que les ofrecen las empresas agroindustriales.

\section{Asimetría de mercado}

Existe una alta atomización de ganaderos en parcelas y una alta concentración de poder en la agroindustria. Estas producen un efecto de oligopolio por parte de la agroindustria, lo que le permite imponer su estrategia y planificar la cadena láctea a su beneficio.

\section{Débil práctica de asociación en los ganaderos}

Solo 23\% de los ganaderos lecheros en el Perú están asociados, lo cual impide la organización eficiente de los recursos para una producción de ganadería moderna y competitividad acordes a los estándares mundiales.

\section{Marco teórico}

Una vez definida la metodología por utilizar en el presente trabajo de investigación y presentada una reseña de la realidad y situación actual del mercado ganadero vacuno en el Perú, se procedió a establecer el marco teórico sobre el cual se basa el método de costeo. Para ello, se definieron cuáles son los procesos biológicos del animal, de modo que se puedan definir los gastos relacionados con dichos activos en sus diferentes etapas de vida. Adicionalmente, se determinó cuáles son los alcances de la NIC 41 para el costeo de estos activos biológicos. Y, finalmente, se realizó un análisis de los aspectos tributarios relacionados con este tema.

\section{Procesos biológicos de la vaca (etapas biológicas)}

Para efectos de la investigación, es necesario distinguir los procesos biológicos de los bovinos, ya que de dichos ciclos depende la recolección de la leche, así como los gastos operativos. 


\section{Cuadro 1}

Ciclo de reproducción de la vaca promedio

\begin{tabular}{|c|c|c|c|c|c|c|c|c|c|c|c|c|c|c|c|c|c|c|c|c|c|}
\hline & \multicolumn{21}{|c|}{ Meses } \\
\hline Ciclo & 18 & 19 & 20 & 21 & 22 & 23 & 24 & 25 & 26 & 27 & 28 & 29 & 30 & 31 & 32 & 33 & 34 & 35 & 36 & 37 & 38 \\
\hline Primera preñez & & & & & & & & & & & & & & & & & & & & & \\
\hline Gestación & & & & & & & & & & & & & & & & & & & & & \\
\hline Ordeñado $\left({ }^{*}\right)$ & & & & & & & & & & & & & & & & & & & & & \\
\hline Segunda preñez $\left.{ }^{(*}\right)$ & & & & & & & & & & & & & & & & & & & & & \\
\hline
\end{tabular}

$\left(^{*}\right)$ A los tres dias de haber parido, la vaca puede ser ordeñada.

$\left({ }^{*}\right)$ A los dos meses de haber parido, la vaca puede volver a ser inseminada. En total, una vaca puede parir una vez al año, durante 14 años como máximo. Cada mes se deben inseminar vacas con el propósito de asegurar la producción de leche todo el año.

Fuente: Proyecto Empresarial «De la Vaca» 2011-II, Universidad del Pacifico.

De esta manera, podemos observar que el proceso de recolección de la leche no solo toma en consideración tener las vacas bien cuidadas, sino que representa esfuerzos logísticos adicionales para mantener la producción durante el año. Por un lado, las etapas en que estos animales no están en producción también forman parte del proceso biológico. Uno de estos casos es el período de "recría", el cual comprende el tiempo desde el nacimiento hasta la primera preñez, en el que el animal está desarrollándose y todavía consume leche materna. Este período debe considerar que el animal no tiene capacidad de generar algún flujo económico, sino más bien consume el producto cosecha para su crecimiento.

\section{Cuadro 2}

\section{Período de recría}

\begin{tabular}{|ll|}
\hline Recría & Edad de recría \\
\hline En cunas & hasta 2 meses \\
En destete & de 2 a 4 meses \\
Terneras chicas & de 4 a 6 meses \\
Terneras medianas & de 6 a 9 meses \\
Terneras grandes & de 9 a 11 meses \\
Vaquillas & de 11 a 14 meses \\
\hline
\end{tabular}

Fuente: Modelo de costeo de Carlos Llenque (Universidad del Callao, 2011). 
Por otro lado, existen etapas en que el animal deja de producir leche como resultado de fenómenos naturales, tales como períodos de frío extremo o sequías. A esta etapa se le conoce como "vacas secas», y más adelante se ejemplifica el tratamiento que se le da a este animal durante esta fase. Finalmente, encontramos el estado de "preparto», en que la vaca se prepara para parir y corta la producción de la leche.

NIC 41 para el costeo de los activos biológicos vacunos

\section{- Conceptos básicos de la norma}

Para entender el ámbito de acción de esta norma, es necesario definir de forma previa conceptos básicos, de modo que se pueda entender la dinámica de estos activos biológicos dentro del marco de la norma internacional.

En primer lugar, es necesario entender el concepto de transformación biológica. Este se refiere al cambio natural que experimenta un activo biológico a lo largo de su vida. Incluye el crecimiento de animales vivos o plantas, la reducción en su producción debido al envejecimiento o enfermedad, y la producción de nuevos activos biológicos a través de un programa reproductivo administrado.

Los activos biológicos incluyen:

- Ovejas, chanchos, ganado, aves y peces.

- Vacas lecheras.

- Árboles de un bosque.

- $\quad$ Plantas para cosechar (por ejemplo: trigo y vegetales).

- Árboles, plantas y arbustos de los que se cosecharán productos agrícolas (por ejemplo: árboles fruteros, vides y arbustos de té).

El producto cosecha de un activo biológico (por ejemplo: leche, hojas de té y madera) no es considerado como otro activo biológico más, sino que se asume como existencias. Los productos cosechados se transfieren a esta cuenta a valor razonable menos los costos de venta, y luego son contabilizados de acuerdo a la NIC 2 Existencias. Sin embargo, mientras que los productos sigan creciendo o sigan unidos al activo biológico, su valor forma parte del valor de aquel. 
Según la NIC 41, el terreno relacionado con la actividad agrícola no debe ser considerado como un activo biológico. Dicho terreno está sujeto a los principios de reconocimiento y medición de la NIC 16 Inmueble, maquinaria, planta y equipo. El terreno que es propiedad de un tercero y que le alquila a una entidad para realizar actividades agrícolas, probablemente será la propiedad de inversión del tercero y se contabiliza de acuerdo a la NIC 40 Propiedad de inversión.

\section{- Medición de los activos biológicos en la NIC 41}

La NIC 41 requiere que los activos biológicos se midan a su reconocimiento inicial y que en cada fecha del balance general se actualicen a su valor razonable menos los costos de venta, salvo en algunos casos. Existen dos circunstancias en las que la norma permite dejar de utilizar el valor razonable actual. Primero, en la fase inicial del ciclo de vida de un activo, y, segundo, cuando el valor razonable no se puede medir confiablemente en su reconocimiento inicial.

La primera excepción permite que los costos se aproximen al valor razonable cuando hay poca transformación biológica. Por ejemplo, para la planta o semilla de los árboles de frutas plantadas en una fecha inmediatamente anterior a la fecha del balance general. Se aplica la misma regla cuando el impacto de la transformación biológica sobre el precio no se espera que sea significativo (por ejemplo: para el crecimiento inicial de un pino cuyo ciclo de vida es de 30 años) (párrafo 24 de la NIC 41).

La segunda excepción a la norma en la que el valor razonable no puede ser medido confiablemente contribuye con el trabajo, ya que conforma uno de los supuestos de la investigación. La norma, por lo general, incluye el caso hipotético en el que el valor razonable puede ser medido confiablemente por un activo biológico. Dicha presunción puede ser refutada solamente si en la fecha del reconocimiento inicial de un activo biológico no existe o no se encuentran disponibles precios de mercado y además no hay estimaciones alternativas del valor razonable que demuestren calidad de confiables.

Si la estimación del valor razonable se considera claramente poco confiable, dicho activo biológico se mide al costo menos cualquier depreciación acumulada o cualquier pérdida por deterioro (párrafo 30 de la NIC 41). Se debe tomar en cuenta que al determinar si un activo está deteriorado, se hace necesario establecer una estimación de su valor real. 
Debido a que la excepción a la norma solo se puede aplicar al reconocimiento inicial, para refutar la presunción, la entidad que reporta tener un activo que no puede ser valorizado debe poder demostrar que el precio pagado por dicho activo no era el precio de mercado. Una compañía que adopta las normas por primera vez solo puede utilizar esta excepción hasta que el activo tenga un precio de mercado o pueda ser valorizado utilizando una técnica de valorización. Una vez que se haya determinado el valor razonable de un activo biológico, el modelo de costo ya no se aplica.

\section{- Definición de valor razonable}

La definición actual del valor razonable en la NIC 41 es el importe por el cual un activo puede ser intercambiado o un pasivo puede ser cancelado, entre un comprador y un vendedor interesados y debidamente informados, que realizan una transacción bajo términos de libre competencia. El valor razonable representa el precio de mercado de un activo con base en las expectativas actuales.

La NIC 41 incluye una jerarquía no oficial de mediciones de valorización similares a las incluidas en la NIC 36 Deterioro de activos y la NIC 39 Instrumentos financieros: medición y reconocimiento.

Jerarquía del valor razonable en la NIC 41

Esta jerarquía se puede resumir en los ítems detallados a continuación:

- $\quad$ El precio del activo en un mercado activo.

- $\quad$ El precio de transacción reciente del activo si no existe un mercado activo.

- Los precios del mercado para activos similares, ajustados por los puntos de diferencia.

- Estándares de la industria dentro del sector en el que opera la compañía.

- $\quad$ El valor presente de los flujos de efectivo futuros que generará el activo.

Muchos activos biológicos tienen precios de mercado importantes o valores disponibles, como es el caso de productos biológicos que generalmente son "commodities» básicos que deben ser comercializados activamente. Por ejemplo, por lo general existen precios del mercado para los terneros y lechones, puesto que existe un mercado activo para estos activos. 
Cuando no se dispone de los precios o valores de mercado para un activo biológico, se presenta el valor de los flujos de efectivo esperados de dicho activo. De forma consistente con el objetivo de estimar el valor razonable, los flujos de efectivo deben estar basados en data del mercado. Por ejemplo, aunque hay un mercado para el salmón que haya llegado al término de su crecimiento, no hay un mercado para el salmón que no haya llegado al término de su crecimiento. El valor razonable de un salmón que no haya llegado al término de su crecimiento se mide al proyectar los ingresos de efectivo de la venta del salmón que haya llegado al término de su crecimiento, menos las salidas de efectivo necesarias para que el salmón crezca al peso necesario para que ingrese en el mercado, y descontando dichas salidas de efectivo al valor presente actual.

\section{Tipos de entradas y salidas de efectivo por incluir en el modelo de flujo de efectivo}

El modelo de flujo de efectivo debe incluir todos los ingresos y salidas de efectivo atribuibles directamente, y solo debe tomar en consideración esos flujos de efectivo. Los ingresos de efectivo serán el precio en el mercado de cada cosecha en la vida del activo; las salidas serán las incurridas al criar o para que el activo crezca y llevarlo al mercado (por ejemplo: la mano de obra directa, el alimento, el fertilizante y el transporte hasta el mercado).

Si otros activos significativos se utilizan para complementar el activo biológico, el modelo de flujo de efectivo puede reflejar los fundamentos económicos de esto; de lo contrario, el valor razonable estaría sobreestimado. Por ejemplo, si una entidad es dueña de un terreno, los flujos de efectivo deben incluir una cantidad nominativa de salida de efectivo en la que se incurrirá en el "alquiler" del terreno, que sea comparable con el activo de una entidad que alquila terreno de un tercero. El valor razonable del activo biológico es independiente del valor del terreno en el que se cultiva o crece tal activo.

\section{Importancia del precio de un contrato}

Los precios de contratos no son necesariamente relevantes para determinar el valor razonable porque dicho valor refleja el mercado actual en el que un comprador y vendedor realizan una transacción bajo los términos de libre competencia.

A la fecha de la firma del contrato entre las partes, el precio del contrato debe ser el mejor estimado del futuro precio de mercado y, por lo tanto, debe ser un precio relevante que se pueda usar en el modelo de flujos de efectivo. Posteriormente, los precios históricos de los contratos quizá no representen mayor relevancia 
para el valor razonable actual del activo biológico en sí. Por lo tanto, el valor razonable de un activo biológico o de productos agrícolas no es influenciado por la existencia de un contrato salvo que los precios del contrato representen precios del mercado actual.

En algunos casos, un contrato por la venta de un activo biológico o de productos agrícolas puede ser un contrato oneroso según la NIC 37 Provisiones, pasivos contingentes y activos contingentes, y debe ser medido de acuerdo a esa norma. La existencia de un contrato oneroso no debe afectar el valor razonable de un activo biológico.

\section{Partida "costos de venta"}

Los costos de venta ("costs of sales") son costos crecientes en los que se incurre durante el proceso de venta de un activo. Dentro de este costo se incluyen las comisiones que se pagan a los corredores y vendedores, impuestos por transferencia y otros impuestos, y tarifas que se pagan en las agencias de regulación o intercambios de "commodities». Los costos de venta no incluyen el costo de transportar el activo al mercado (que se incluye en el valor razonable) ni los impuestos a la renta y costos de financiamiento.

Con respecto a los ingresos (o renta) bajo las normas contables, se considera la venta de productos agrícolas como ingreso según la NIC 18 Ingresos. Los ingresos comprenden el valor razonable del pago por recibir o por cobrar solo para la venta de productos agrícolas y/o activos biológicos. Se registra neto de impuestos a las ventas, rebajas o descuentos.

Dentro del alcance de la NIC 18 están los ingresos que surgen de los cambios en el valor razonable y en las ganancias y pérdidas iniciales de los activos y productos agrícolas. Las ganancias del valor razonable son los ingresos de acuerdo con el marco. Las ganancias de valor razonable se pueden mostrar como parte del ingreso total pero separadas de los ingresos.

Los ingresos, según la NIC 41, se pueden clasificar de la siguiente manera:

- Ganancia o pérdida inicial proveniente de los activos biológicos.

- Cambios en el valor razonable menos los costos de venta de los activos biológicos.

- Ganancia o pérdida inicial sobre los productos agrícolas. 


\section{Consideraciones sobre las partidas de ingresos y pérdidas}

Las pérdidas iniciales sobre los activos biológicos generalmente surgen cuando se compra un activo biológico. El costo del activo biológico por lo general es mayor que su valor razonable menos los costos de venta, ya que este último representa el precio de salida; por lo tanto, los costos de transacción crean una pérdida. Las ganancias iniciales sobre un activo biológico surgen cuando se generan nuevos activos biológicos; por ejemplo, cuando nace un becerro o un lechón.

Los cambios en el valor razonable menos los costos de venta de activos biológicos representan la diferencia en el valor de período a período, normalmente en el acumulado. Por lo tanto, a veces resulta difícil distinguir de la ganancia inicial debido a la procreación. El valor por lo general aumenta debido al crecimiento, la procreación y el alza de precios, pero puede bajar debido a la degeneración, la enfermedad y los precios más bajos.

Finalmente, las ganancias o pérdidas iniciales sobre los productos agrícolas representan la diferencia entre el cambio en valor en libros de los activos biológicos debido a la cosecha de los productos agrícolas. Se refleja en la última fase de la creación de valor del proceso biológico y los productos cosechados se transfieren a existencias. Es posible que surjan costos futuros en la preparación de las existencias para el mercado.

Según la NIC 41, se requiere que las ganancias y pérdidas que surgen bajo la norma sean reveladas en forma agregada, tal como lo señala el párrafo 40 de la NIC 41. También se debe considerar que la norma no requiere ni recomienda separar la ganancia o pérdida. Separar las ganancias y pérdidas que surgen del reconocimiento inicial y los cambios durante el año puede resultar poco práctico.

En cuanto a la revelación de las distintas categorias de ingresos, esta se puede hacer en el estado de ganancias y pérdidas o en las notas a los estados financieros, ya que no hay un requisito específico en la NIC 41 sobre dónde se deben revelar dichas categorías. En la práctica, muchas entidades revelan estas categorías en una línea separada en el estado de ganancias y pérdidas. La NIC 1 Presentación de estados financieros, requiere que los ingresos se muestren en el estado de ganancias y pérdidas; una revelación solo en las notas no es aceptable. 
En el caso de que una empresa haya elegido mostrar las ganancias y pérdidas que surgen bajo la NIC 41, la presentación del cambio en el valor razonable debe estar en la parte superior del estado de ganancias y pérdidas. Ello debido a que el cambio en el valor razonable puede resultar en montos positivos y negativos, y es mejor presentar dicho cambio después de los ingresos y otros ingresos, pero antes de los gastos.

La forma en la que se deberán presentar los gastos subsecuentes en relación con la actividad agrícola dependerá de algunos factores. Dichos costos pueden incluir alimentación, servicios de veterinario, cosecha, desmalezado, irrigación, fertilizante y costos de cosecha y matanza. La NIC 41 no prescribe el tratamiento de dichos costos. Antes de la adopción de la NIC 41, muchos negocios agrícolas tenían la política de capitalizar algunos de estos costos, sobre todo aquellos relacionados con el desarrollo de planta o ganado por madurar hasta que sean productivos. Puesto que la NIC 41 no prescribe el tratamiento de gastos subsecuentes, dicho tratamiento aún se permitiría bajo la NIC 41. Sin embargo, pueden surgir problemas para definir qué debe ser capitalizado y qué debe ser contabilizado. Muchas entidades ahora adoptan una política de tratamiento para todos los gastos como "costos de producción». Esto también está permitido. Sin embargo, la medición de la ganancia o pérdida agregada que surge durante el período actual a la fecha del reconocimiento inicial de los activos biológicos y los productos agrícolas y del cambio en valor razonable menos los costos de venta de los activos biológicos que deben ser revelados de acuerdo al párrafo 40 de la NIC 41, será afectada directamente si alguna parte de los costos han sido capitalizados. Entonces se deberá revelar la política contable usada para el tratamiento de dichos costos.

Tanto la NIC 2 como la NIC 16 excluyen a los activos biológicos de sus alcances, pero estos pueden ser usados por analogía si la entidad adopta la política de capitalizar dichos costos. Por lo tanto, los costos en relación con el desarrollo de activos biológicos se capitalizan al utilizar el criterio de dichas normas y ajustando periódicamente al volver a medir los activos biológicos a su valor razonable. La gerencia debe utilizar su juicio para determinar qué costos son elegibles para capitalización (es decir, se pueden capitalizar los costos de trabajo de los empleados que están directamente involucrados con la administración de los activos biológicos, pero los costos en relación con el personal de venta no se pueden capitalizar). 


\section{- Ejemplo práctico}

A continuación, se utilizará un caso práctico para comprender cuál sería la forma de costear bajo los alcances de la NIC 41. Primero, debemos categorizar al ganado según variables relevantes y hallar cuál es el valor en libros que se tendrá en la cuenta contable:

Cuenta contable
\begin{tabular}{|l|c|c|c|}
\hline \multicolumn{1}{|c}{$\mathbf{3 5 2 1 2}$} & Activo biológico \\
\hline Vacas & Edades & Raza & Valor en libros \\
\hline Vaca 1 & 7 & 1 & $1.460,67$ \\
Vaca 2 & 5 & 2 & 624,00 \\
Vaca 3 & 10 & 3 & 894,00 \\
Vaca 4 & 10 & 2 & $1.066,67$ \\
Vaca 5 & 4 & 3 & $1.263,67$ \\
Vaca 6 & 1 & 2 & 500,00 \\
Vaca 7 & 4 & 1 & $1.657,67$ \\
Vaca 8 & 4 & 2 & $1.854,67$ \\
Vaca 9 & 8 & 3 & $2.051,67$ \\
Vaca 10 & 3 & 3 & $2.248,67$ \\
\hline \multicolumn{3}{|c|}{ Saldo inicial } \\
\hline
\end{tabular}

Elaboración propia.

De esta manera, se procede a proyectar y calcular el valor razonable de los activos biológicos:

\section{Cuadro 3}

Cálculo del valor razonable

\begin{tabular}{|c|c|c|c|c|c|c|c|}
\hline PERIOODOS & 1 & 2 & 3 & 4 & 5 & 6 & 7 \\
\hline INGRESO & 25.036 & 26.405 & 19.304 & 27.127 & 23.796 & 18.343 & 20.213 \\
\hline GASTOS & (12.570) & (13.394) & (13.092) & (15.525) & (12.712) & (16.140) & (16.255) \\
\hline UTILIDAD & 12.466 & 13.011 & 6.212 & 11.602 & 11.084 & 2.203 & 3.958 \\
\hline WACC & $11 \%$ & & & & & & \\
\hline VAN & S/. 43.637,44 & & & & & & \\
\hline
\end{tabular}

Elaboración propia. 
Y de esta manera se realiza el ajuste de la cuenta contable. Cabe resaltar que el resultado obtenido, S/. 43.637,44, constituye cuál debería ser el saldo presentado en el balance general, mas no el ingreso o gasto que se muestra en el estado de resultado.

\begin{tabular}{|lr|}
\hline Saldo inicial & S/. $13.621,67$ \\
Costo de alimentación & S/. 5.000,00 \\
Mano de obra & S/. 7.500,00 \\
Costos indirectos & S/. $6.000,00$ \\
Efecto NIC 41 & S/. $11.515,77$ \\
Saldo final & S/. $43.637,44$ \\
\hline
\end{tabular}

A través de este cuadro, podemos apreciar que los gastos operativos se pueden activar siempre y cuando estos no excedan el saldo hallado a través del cálculo del valor razonable. Más adelante, veremos cuál es el efecto impositivo que estas adiciones tienen. Los gastos por alimentación, planilla y costos indirectos suman S/. 18.500,00; sumándoles el saldo inicial, obtenemos S/. 32.121,67, siendo este valor inferior al hallado por el cálculo del valor razonable. Es por esta razón que a la diferencia que falta para alcanzar los S/. 43.637,44 se le denomina "Efecto NIC 41" (en este caso considerado un ingreso, este efecto puede ser negativo también, ya que se utilizará como última herramienta para alcanzar el valor determinado como saldo de la cuenta de activos biológicos).

\section{Normas tributarias}

Dentro de la normativa pertinente para la investigación, encontramos la Ley 27360, Ley que Aprueba las Normas de Promoción del Sector Agrario, cuyo alcance y efecto se resumen en el siguiente cuadro ${ }^{8}$ : 


\begin{tabular}{|c|c|c|c|}
\hline Beneficios & $\begin{array}{l}\text { Actividad } \\
\text { agraria }\end{array}$ & $\begin{array}{c}\text { Actividad } \\
\text { agroindustrial }\end{array}$ & $\begin{array}{l}\text { Actividad } \\
\text { acuícola }\end{array}$ \\
\hline $\begin{array}{l}\text { Tasa de } 15 \% \text { sobre la renta de tercera categoria del impuesto } \\
\text { a la renta. }\end{array}$ & Sí & Sí & Sí \\
\hline $\begin{array}{l}\text { Exoneración del IES aplicable a las remuneraciones de los tra- } \\
\text { bajadores que laboren para empleadores de la actividad agraria, } \\
\text { bajo relación de dependencia. }\end{array}$ & Sí & Sí & Si \\
\hline $\begin{array}{l}\text { Seguro de Salud Agrario (reciben todas las prestaciones del Seguro } \\
\text { Social de Salud y el aporte es del } 4 \% \text { de la remuneración). }\end{array}$ & Sí & Si & Sí \\
\hline $\begin{array}{l}\text { La aplicación de una tasa especial de depreciación de } 20 \% \text { anual } \\
\text { a las inversiones en obras de infraestructura hidráulica y obras de } \\
\text { riego que realicen los beneficiarios durante la vigencia de la ley. }\end{array}$ & Sí & Sí & No \\
\hline $\begin{array}{l}\text { Los beneficiarios que se encuentren en la etapa preproductiva de } \\
\text { sus inversiones, podrán recuperar el IGV y el IPM pagados por las } \\
\text { operaciones de importación y/o adquisición local de bienes de ca- } \\
\text { pital, insumos, prestación de servicios y contratos de construcción, } \\
\text { siempre que se utilicen directamente en la etapa preproductiva, } \\
\text { la cual no podrá exceder de } 5 \text { años. }\end{array}$ & Sí & Sí & No \\
\hline
\end{tabular}

Base Legal: Ley 27360 y Reglamento aprobado mediante Decreto Supremo 049-2002-AG.

IES derogado a partir del 1/12/2001 por Artículo Único de la Ley 28378, publicada el 10/11/2004.

\section{Modelos existentes de costeo}

A lo largo de la segunda parte de la investigación, se presentó información relevante sobre el ciclo de vida del bovino, y también se mencionó el impacto financiero que estas etapas pueden ocasionar. Adicionalmente, se determinó cuáles son los alcances de la NIC 41 para el costeo de estos activos biológicos y se realizó un análisis de los aspectos tributarios relacionados con este tema.

En este acápite, se analizarán dos modelos hallados con el propósito de identificar sus esquemas, objeto de costo, estructura de costos y sistema de costeo; luego, compararlos a nivel de resultados reales; y, finalmente, aplicar los alcances de la NIC 41. 
- Modelo de costeo de Carlos Llenque (Universidad del Callao, 2011)

En primera instancia, analizaremos el modelo propuesto por el CPC Carlos Llenque para la Universidad del Callao.

A continuación, se explica el esquema de asignación de costos utilizado por el autor:

El modelo de costeo de la Universidad del Callao utiliza el sistema de costo tradicional, ya que diferencia entre costos directos e indirectos. Los costos directos contemplan dos conceptos principales: materiales directos y mano de obra directa. En el caso de la crianza del ganado vacuno, los materiales directos se refieren a insumos alimenticios para el desarrollo del animal. Por otro lado, la mano de obra directa hace referencia a la planilla de los empleados involucrados de forma directa en el cuidado del ganado. Para el caso de los costos indirectos, el modelo considera tres conceptos: materia prima directa, mano de obra indirecta y gastos generales de fabricación. Para el caso de la materia prima indirecta, el modelo considera insumos como medicamentos, vacunas, detergentes y semen, los cuales se utilizan para una óptima gestión del cambio en el activo biológico. Luego, se considera para el concepto de mano de obra indirecta la planilla asociada al personal administrativo de la empresa, veterinario, guardián y asesor técnico, quienes no necesariamente tienen un contacto directo con el ganado pero buscan su bienestar. Finalmente, para el concepto de gastos generales de fabricación se consideran los servicios públicos como agua, luz y teléfono, entre otros insumos.

Todo este proceso se detalla de manera gráfica a continuación: 


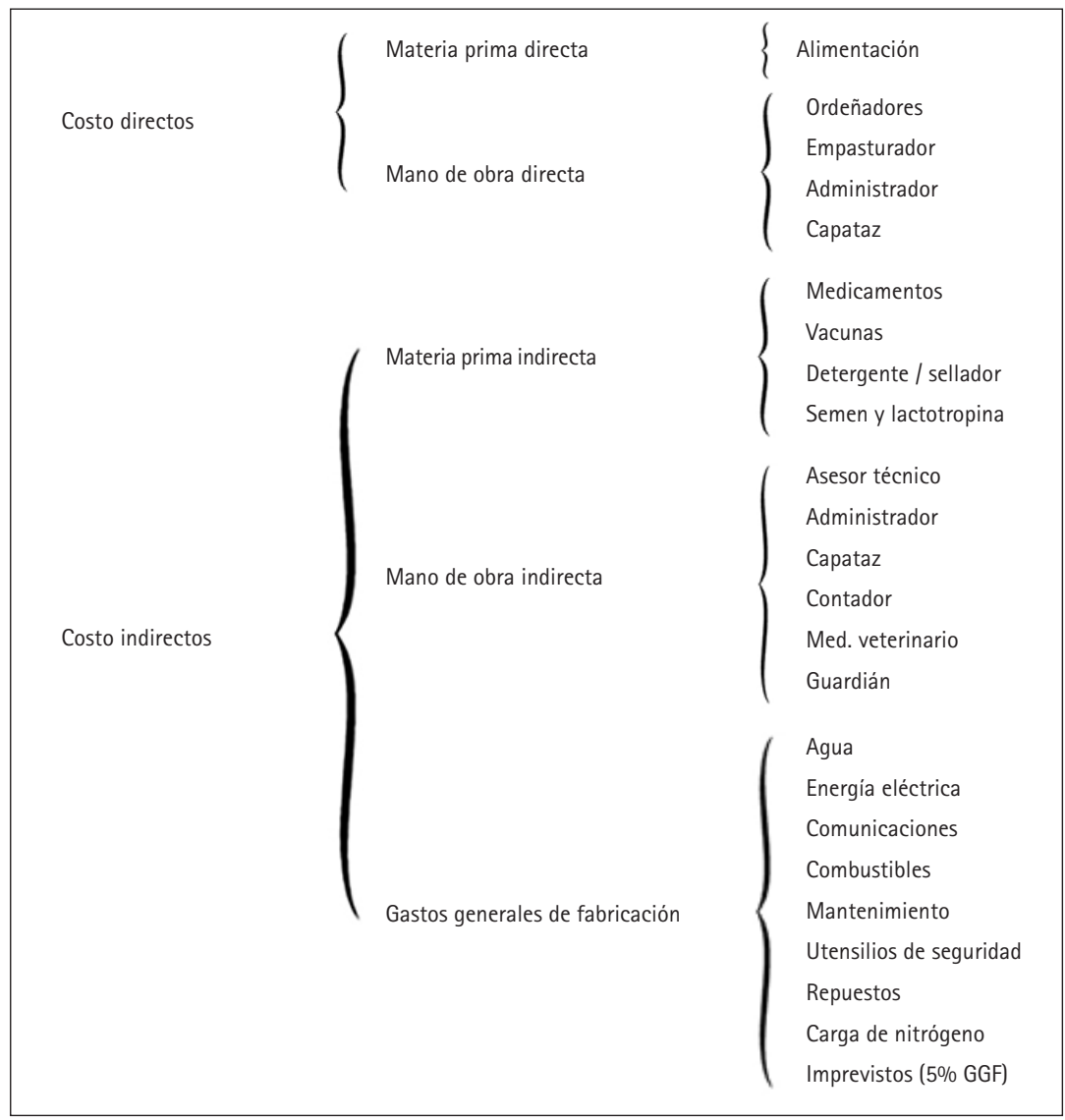

Elaboración propia.

De esta manera, podemos observar cómo este modelo agrupa los costos relacionados; se puede identificar la forma de un costeo tradicional o absorbente. Por otro lado, es importante mencionar que el objeto de costo de este modelo no es el activo biológico sino el producto cosecha, en este caso la leche.

Siguiendo con la descripción del modelo, es importante tener en cuenta cuál es la aplicación de esta estructura en la realidad y cuál es la relevancia de cada concepto. Por ello, se utiliza la información real de un hato de 138 vacunos para simular cuál sería el costo de producir un litro de leche. 


\section{Cuadro 4}

Mano de obra directa e indirecta

\begin{tabular}{|c|c|c|c|c|}
\hline & C. unit. mensual & Cto. total mensual & Cto. total anual & $\%$ \\
\hline \multicolumn{5}{|l|}{ Mano de obra directa } \\
\hline Ordeñadores & 520 & S/. $3.640,00$ & S/. $43.680,00$ & $7 \%$ \\
\hline Empasturador & 650 & S/. 650,00 & S/. $7.800,00$ & $1,16 \%$ \\
\hline Administrador & 480 & S/. 480,00 & S/. 5.760,00 & $0,86 \%$ \\
\hline \multirow[t]{2}{*}{ Capataz } & 328,5 & S/. 328,50 & S/. $3.942,00$ & $0,59 \%$ \\
\hline & & S/. 5.098,50 & S/. $61.182,00$ & $9,13 \%$ \\
\hline \multicolumn{5}{|l|}{ Mano de obra indirecta } \\
\hline Asesor técnico & 700 & S/. 700,00 & S/. $8.400,00$ & $1,25 \%$ \\
\hline Administrador & 720 & S/. 720,00 & S/. $8.640,00$ & $1,29 \%$ \\
\hline Capataz & 401,5 & S/. 401,50 & S/. $4.818,00$ & $0,72 \%$ \\
\hline Contador & 300 & S/. 300,00 & S/. $3.600,00$ & $0,54 \%$ \\
\hline Med. veterinario & 700 & S/. 700,00 & S/. $8.400,00$ & $1,25 \%$ \\
\hline \multirow[t]{3}{*}{ Guardián } & 550 & S/. 550,00 & S/. $6.600,00$ & $0,98 \%$ \\
\hline & & S/. $3.371,50$ & S/. 40.458,00 & $6,03 \%$ \\
\hline & Subtotal MO & S/. $8.470,00$ & S/. $101.640,00$ & $15,16 \%$ \\
\hline
\end{tabular}

Fuente: Modelo de costeo de Carlos Llenque (Universidad del Callao, 2011).

Se puede apreciar, en la segunda y tercera columnas, cuáles serían los costos mensuales y anuales para la mano de obra directa e indirecta. Se puede apreciar que el peso de estos componentes dentro del total de costos operativos asciende a $15,16 \%$.

Para el caso de las materias primas, concepto que corresponde a los insumos utilizados para alimentar al vacuno, se observa un peso de 75,80\%, siendo este el más importante sobre el total de costos operativos. También se cuenta con el dato correspondiente a materiales indirectos, los cuales contemplan medicamentos, vacunas, entre otros insumos. Estos tienen un peso de 1,85\%, el cual, sumado con el 75,80\% de los materiales directos, nos da 77,65\%.

En última instancia, se cuenta con los gastos generales de fabricación, los cuales constituyen el $7,19 \%$ y comprenden servicios públicos y gastos por mantenimiento. 


\begin{tabular}{|c|c|c|c|}
\hline & Cto. total mensual & Cto. total anual & $\%$ \\
\hline \multicolumn{4}{|l|}{ Materia prima directa } \\
\hline Alimentación & S/. 42.347,13 & S/. 508.165,56 & $75,80 \%$ \\
\hline \multicolumn{4}{|l|}{ Materia prima indirecta } \\
\hline Medicamentos & S/. 215,97 & S/. 2,591.64 & $0,39 \%$ \\
\hline Vacunas & S/. 31,76 & S/. 381,12 & $0,06 \%$ \\
\hline Detergente / sellador & S/. 359,95 & S/. 4.319,40 & $0,64 \%$ \\
\hline \multirow[t]{2}{*}{ Semen y lactotropina } & S/. 423,47 & S/. 5.081,64 & $0,76 \%$ \\
\hline & S/. $1.031,15$ & S/. $12.373,80$ & $1,85 \%$ \\
\hline Subtotal MP & S/. 43.378,28 & S/. 520.539,36 & $77,65 \%$ \\
\hline \multicolumn{4}{|c|}{ Gastos generales de fabricación } \\
\hline Agua & $S / .220,00$ & S/. $2.640,00$ & $0,39 \%$ \\
\hline Energía eléctrica & S/. $1.600,00$ & S/. $19.200,00$ & $2,86 \%$ \\
\hline Comunicaciones & S/. 150,00 & $S / .1 .800,00$ & $0,27 \%$ \\
\hline Combustibles & $S / .750,00$ & $S / .9 .000,00$ & $1,34 \%$ \\
\hline Mantenimiento & S/. 200,00 & S/. $2.400,00$ & $0,36 \%$ \\
\hline Utensilios de seguridad & $S / .430,00$ & $S / .5 .160,00$ & $0,77 \%$ \\
\hline Repuestos & S/. 200,00 & S/. $2.400,00$ & $0,36 \%$ \\
\hline Carga de nitrógeno & S/. 280,00 & S/. $3.360,00$ & $0,50 \%$ \\
\hline Imprevistos (5\% GGF) & S/. 191,50 & S/. $2.298,00$ & $0,34 \%$ \\
\hline Subtotal GGF & S/. 4.021,50 & S/. 48.258,00 & $7,19 \%$ \\
\hline Total MD + MP + GGF & S/. 55.869,78 & S/. 670.437,36 & $100,00 \%$ \\
\hline
\end{tabular}

Fuente: Modelo de costeo de Carlos Llenque (Universidad del Callao, 2011).

De esta manera, se obtiene la siguiente estructura de costo.

\section{Estructura de costos real:}

- Mano de obra: $15,16 \%$

- Materia prima: $77,64 \%$

- Gastos generales de fabricación: $7,20 \%$

Costo de producción de un litro de leche:

S/. 0,899

Precio del mercado por litro de leche:

S/. 1,000

Margen:

S/. 0,101 
- Modelo del Fondo Nacional de Ganadería Lechera «Fongal», 2012

Siguiendo con los modelos analizados, encontramos el modelo utilizado por el Fondo Nacional de Ganadería Lechera, proveído por su gerente Héctor Guevara Rivera. Cabe resaltar que Fongal es el organismo que busca la asociación de los ganaderos lecheros y su bienestar en el país, y como organización busca también el mejor desarrollo para el ganado, así como su mejora genética y buen trato.

De la misma manera que en el modelo anterior, se procede a esquematizar el modelo según su estructura de costos y asignación de los mismos:

El modelo de Fongal diferencia entre costos variables y costos fijos, pero también considera una disminución del costo por la venta de los vacunos que no sirvan para la producción, y sus desechos como materia prima para otras empresas. Dentro de los costos variables, encontramos principalmente alimentación del ganado, sanidad y costos por reproducción.

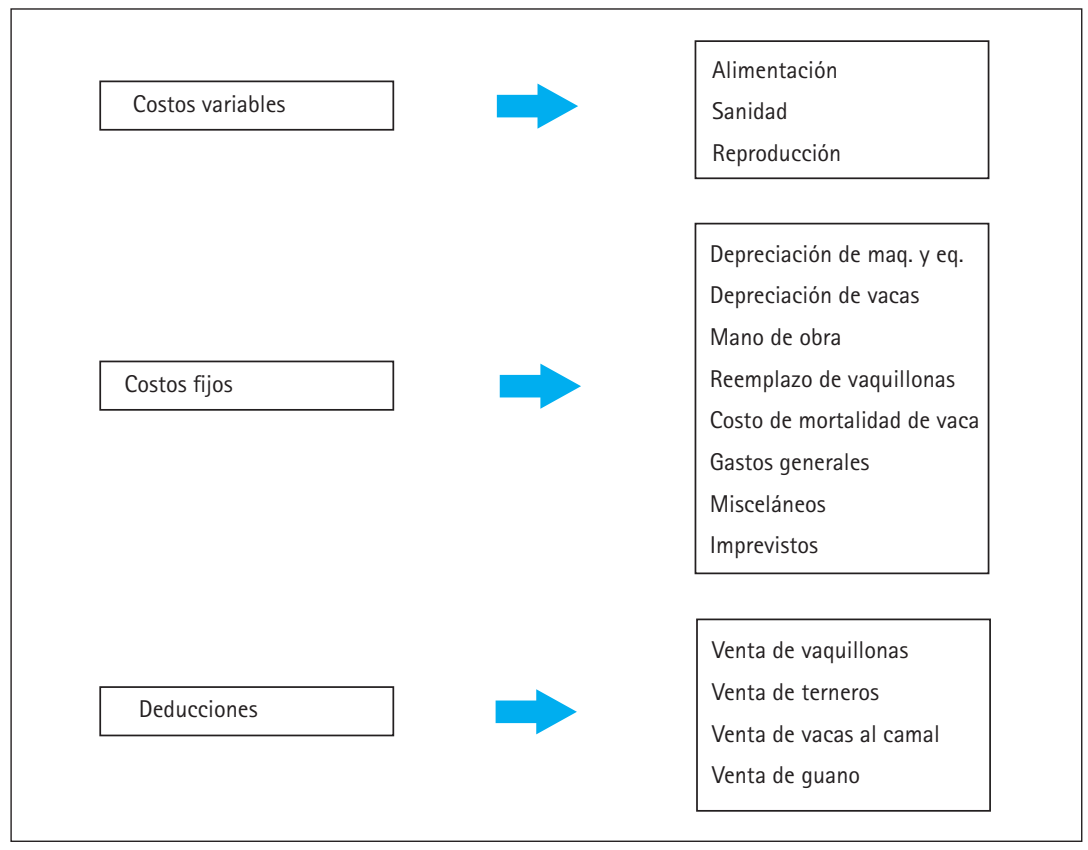

Elaboración propia. 
En el caso de los costos fijos costos por depreciación de maquinaria y equipos, depreciación de vaca, concepto que corresponde al paso de la vida útil del animal, se toman 4 años como tiempo de uso. Siguiendo con los costos fijos, encontramos conceptos como reemplazo de vaquillonas; costo por mortandad; gastos generales, los cuales engloban servicios públicos y otros conceptos; misceláneos; e imprevistos. Finalmente, el modelo considera deducciones correspondientes a la realización y venta de vacunos que no contribuyen a la producción de leche. Inicialmente, estos se consideraron entre los costos variables y fijos, así que se agregan nuevamente con la finalidad de tener un efecto neto de 0 mientras se genera contribución marginal para la empresa.

Analizando el modelo, podemos observar un modelo de costeo directo o variable, ya que se dividen los costos y se agrupan según la definición de costos variables y fijos.

\section{Cuadro 5}

\section{Costos variables}

\begin{tabular}{|c|c|c|}
\hline A. COSTOS VARIABLES & $\begin{array}{c}\text { Soles } \\
\text { por vaca/año }\end{array}$ & \\
\hline A.1 Alimentación & S/. $7.833,18$ & $60 \%$ \\
\hline A.2 Sanidad & 196,06 & $2 \%$ \\
\hline A.3 Reproducción & 165,43 & $1 \%$ \\
\hline Total costo variable - $\mathrm{A}$ & S/. 8.194,67 & $63 \%$ \\
\hline
\end{tabular}

Fuente: Modelo de costeo Fongal.

De esta manera, podemos observar que los costos variables representan el 63\% de los costos operativos, siendo el concepto más importante la alimentación del ganado, con $60 \%$. 


\section{Cuadro 6}

\section{Costo fijos}

\begin{tabular}{|c|c|c|c|c|}
\hline B. & COSTOS FIJOS & & & \\
\hline B.1 & Depreciación de maq. y eq. & & S/. 348,07 & $3 \%$ \\
\hline B.2 & Depreciación de vacas & & S/. 936,89 & $7 \%$ \\
\hline B.3 & Mano de obra & & S/. $1.216,48$ & $9 \%$ \\
\hline B.4 & Reemplazo de vaquillonas & & S/. $1.499,02$ & $11 \%$ \\
\hline B.5 & Costo de mortalidad/vaca & & S/. 187,38 & $1 \%$ \\
\hline \multirow[t]{6}{*}{ B.6 } & Gastos generales & & S/. 295,70 & $2 \%$ \\
\hline & B.6.1 - Luz & & S/. 97,88 & $0,75 \%$ \\
\hline & B.6.2 - Combustible & & S/. 113,47 & $0,87 \%$ \\
\hline & B.6.3 - Teléfono & & S/. 14,34 & \\
\hline & B.6.4 - Mant. de maq. y equipos & & S/. 50,07 & \\
\hline & B.6.5 - Mant. de corrales & & S/. 19,95 & \\
\hline B.7 & Misceláneos & $1 \%$ & S/. 126,78 & $1 \%$ \\
\hline \multirow[t]{2}{*}{ B.8 } & Imprevistos & $2 \%$ & S/. 253,56 & $2 \%$ \\
\hline & Total costo fijo - B & & S/. 4.863,89 & \\
\hline
\end{tabular}

Fuente: Modelo de costeo Fongal.

Por el lado de los costos fijos, podemos encontrar conceptos tales como depreciaciones de los activos fijos, como el activo biológico, la mano de obra, gastos generales y estimación de siniestros. Todo estos conceptos suman 39\%. De esa manera, podemos sumar los costos variables y fijos, obteniendo un resultado de $102 \%$. Esto se ajustaría deduciendo los gastos relacionados con la venta del activo biológico presentado a continuación:

TOTAL $(A+B)$

S/. $13.058,56$
C. DEDUCCIONES
C.1 Venta de vaquillonas
S/. 240,00
C.2 Venta de terneros
S/. 18,00
C.3 Venta de vacas al camal
S/. 227,50
C.4 Venta de guano
$\mathrm{S} / .17,52$
S/. 503,02

Fuente: Modelo de costeo Fongal.

TOTAL COSTO (A+B-C) S/. 12.555,54


De esta manera, obtenemos un costo anual relacionado con el mantenimiento y desarrollo de la vaca. Ahora, se calcula cuál es la producción anual del animal, con la finalidad de costear un litro de leche.

\section{Cuadro 7}

Costo del litro de leche

\begin{tabular}{|c|c|c|c|}
\hline \multirow[t]{5}{*}{ D. } & PRODUCCIÓN LECHE & $8.700,00$ & $\mathrm{~kg} / \mathrm{vaca} / \mathrm{año}$ \\
\hline & Prom. establo/dia & 23,84 & $\mathrm{~kg} / \mathrm{vaca} / \mathrm{dia}$ \\
\hline & Costo kg de leche & S/. 1,44 & \\
\hline & $10 \%$ margen & S/. 0,14 & \\
\hline & Precio venta & S/. 1,59 & \\
\hline
\end{tabular}

Fuente: Modelo de costeo Fongal.

\section{Comparación entre los modelos}

Luego de haber presentado los dos modelos de costeo, es necesario hacer hincapié en sus semejanzas y diferencias con el propósito de determinar cuál puede ser la metodología actual del sector ganadero.

A continuación, se presenta un cuadro comparativo entre el modelo de la Universidad del Callao y el de la Asociación de Ganaderos de Lima.

\section{Cuadro 8}

\section{Comparación entre modelos de costeo}

\begin{tabular}{|c|c|c|}
\hline & $\begin{array}{c}\text { Modelo de costeo de Carlos Llenque } \\
\text { (Universidad del Callao, 2011) }\end{array}$ & $\begin{array}{c}\text { Modelo de Fondo Nacional de } \\
\text { Ganaderia Lechera «Fongal», 2012 }\end{array}$ \\
\hline Cantidad de vacas & 138 & 150 \\
Método de costeo & Costeo absorbente o tradicional & Costeo directo \\
Costos variables & $77,65 \%$ & $61 \%$ \\
Costos fijos & $22,35 \%$ & $39 \%$ \\
Costos totales & $100 \%$ & $100 \%$ \\
Producción promedio de leche por dia & 15,01 litros por vaca & 23,84 litros por vaca \\
Costo unitario por litro de leche & S/. 0,90 $/ .1,44$ \\
Contribución marginal & S/. 0,10 & S/. 0,14 \\
\hline Valor de venta & S/. 1,00 & S/. 1,58 \\
\hline
\end{tabular}

Elaboración propia. 
Dentro de los principales hallazgos, se observa que ambos modelos utilizan el producto cosecha como objeto de costo en vez del activo biológico, como manda la norma internacional. Es por eso que desde el inicio se infiere que estos modelos no cumplen con los alcances propuestos por la NIC 41. También es válido mencionar que la cantidad del ganado es parecida en ambos casos; luego, se determinó que cada modelo se toma con base en un método de costeo diferente. En el caso del modelo de la Universidad del Callao, este se basa en un costeo tradicional o absorbente, ya que considera la estructura de MD, MOD y CIF como base para obtener un producto terminado. Por otro lado, el modelo de Fongal utiliza un método de costeo directo, ya que agrupa sus costos entre variables y fijos.

Para poder comparar estos modelos de manera más efectiva, se tuvo que utilizar el mismo modelo de costeo. Para el caso de la Universidad del Callao, se convirtió el método de costeo tradicional a uno directo agrupando los materiales directos e indirectos como costos variables, y la diferencia, la mano de obra directa e indirecta y los gastos generales de fabricación, como fijos. Una vez realizado el cambio, se obtienen los siguientes resultados: a nivel porcentual, los costos variables del modelo de Carlos Llenque representan un 77,65\%, mientras que para Fongal representan 61\%. Para el caso de los costos fijos, estos resultaron ser 22,35\% para Carlos Llenque y 39\% para Fongal, pudiéndose concluir que para el caso de la Universidad del Callao, del total de sus costos operativos se invirtieron mayores recursos en conceptos de alimentación, medicamentos, sanidad, etc. Por otro lado, el Fondo Nacional de Ganaderos presenta un menor costo variable, pero esto se compensa con una mayor inversión en infraestructura, siendo esta traducida a través de la depreciación del activo biológico y fijo; por otro lado, fueron consideradas mayores provisiones por el cese de vida de los animales y reemplazo de estos.

\section{Propuesta planteada}

De este modo, y tomando en consideración los datos obtenidos a través de las entrevistas a expertos y el trabajo de campo, pasamos a ver el modelo que propone la investigación.

\section{Modelo planteado}

Para la elaboración de este modelo, se utilizaron los datos del costeo de la asociación de ganaderos de Lima "Fongal». Con ellos, se pudo completar del costeo de cálculo del valor razonable de los activos biológicos: 


\begin{tabular}{|c|c|}
\hline TOTAL COSTO (A+B-C) & S/. $12.555,54$ \\
\hline PRODUCCIÓN DE LECHE & $\mathrm{kg} /$ vaca/año \\
\hline Promedio establo/dia & $\mathrm{kg} / \mathrm{vaca} / \mathrm{dia}$ \\
\hline Costo I de leche & S/. 1,44 \\
\hline $10 \%$ de margen de contribución & S/. 0,14 \\
\hline Valor de venta & S/. 1,59 \\
\hline IGV & S/. 0,29 \\
\hline Precio de venta & S/. 1,87 \\
\hline
\end{tabular}

Para la proyección de los flujos, se utilizaron supuestos de crecimiento para los conceptos que afectan a los ingresos y gastos proyectados.

\section{SUPUESTOS DE CRECIMIENTO}

$\begin{array}{lcl}\text { Cantidad de vacas } & 5 \% & \text { Anual } \\ \text { Vacas en producción } & 90 \% & \text { Número de vacas } \\ \text { Litros de leche anuales } & 10 \% & \text { Anual } \\ \text { Valor de venta } & 1 \% & \text { Anual }\end{array}$

Utilizando estos supuestos, se proyectaron flujos de ingresos y gastos, los cuales eran resultados de la interacción de algunos conceptos como:

Cantidad de vacas: representa el número total de animales en el hato. Vale recalcar que alrededor del 90\% se encuentran en producción, del total. Al inicio de la proyección, se cuenta con 150 vacunos.

Alquiler del terreno: representa el costo que se debe asumir por el uso del terreno. Es válido resaltar que es un costo que se tiene que reconocer aunque se cuente con un terreno propio.

Producción de litros anuales: es la cantidad ordeñada de una vaca al año; esta aumenta debido a una mejor alimentación y desarrollo del animal.

Valor de venta de la leche: se propone un crecimiento del valor de venta debido a que se espera que cada vaca mejore genéticamente y la leche sea de mejor calidad. También es importante mencionar que se encuentra dentro de los objetivos negociar mejores precios de manera continua. 
Para el caso de los costos relacionados con el animal, se tomó como base el costo hallado en los modelos anteriores, ya que este considera todos los desembolsos y flujos relacionados con el desarrollo del vacuno.

Este esquema se puede apreciar a continuación de manera gráfica:

\section{Cuadro 9}

\section{Esquema de proyección}

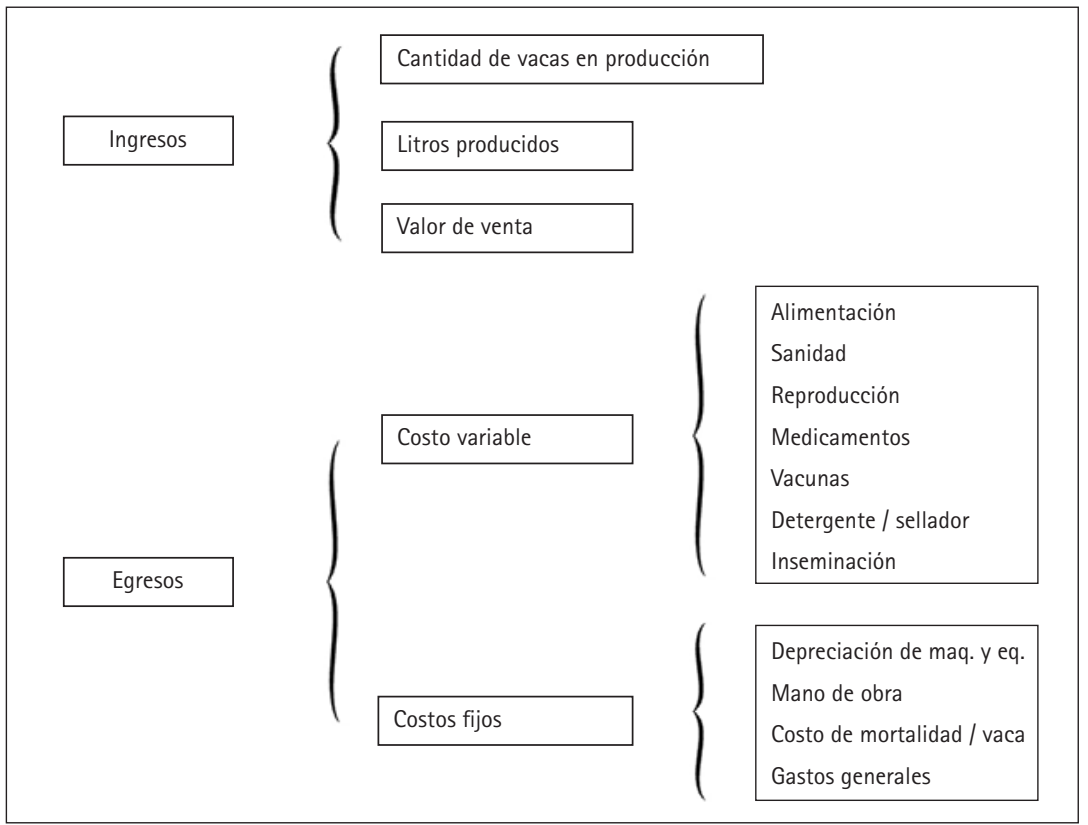

Siguiendo este esquema, se proyectaron 10 años tomando en consideración los supuestos de crecimiento y el esquema planteado. De esta manera, se obtuvo una utilidad para cada período, la cual fue descontada a una tasa de $25 \%$, asumiendo un nivel de riesgo moderadamente alto, debido a que este rubro se encuentra sujeto a factores externos como los precios de los alimentos, los cuales en su mayoría son "commodities»; también, dada la existencia de tanta oferta por parte de las cuencas lecheras; $y$, finalmente, por variables climáticas que pueden afectar la producción. El resultado final es un valor actual neto, el cual representaría el saldo de la cuenta contable 35212 Activos biológicos - Costo. 


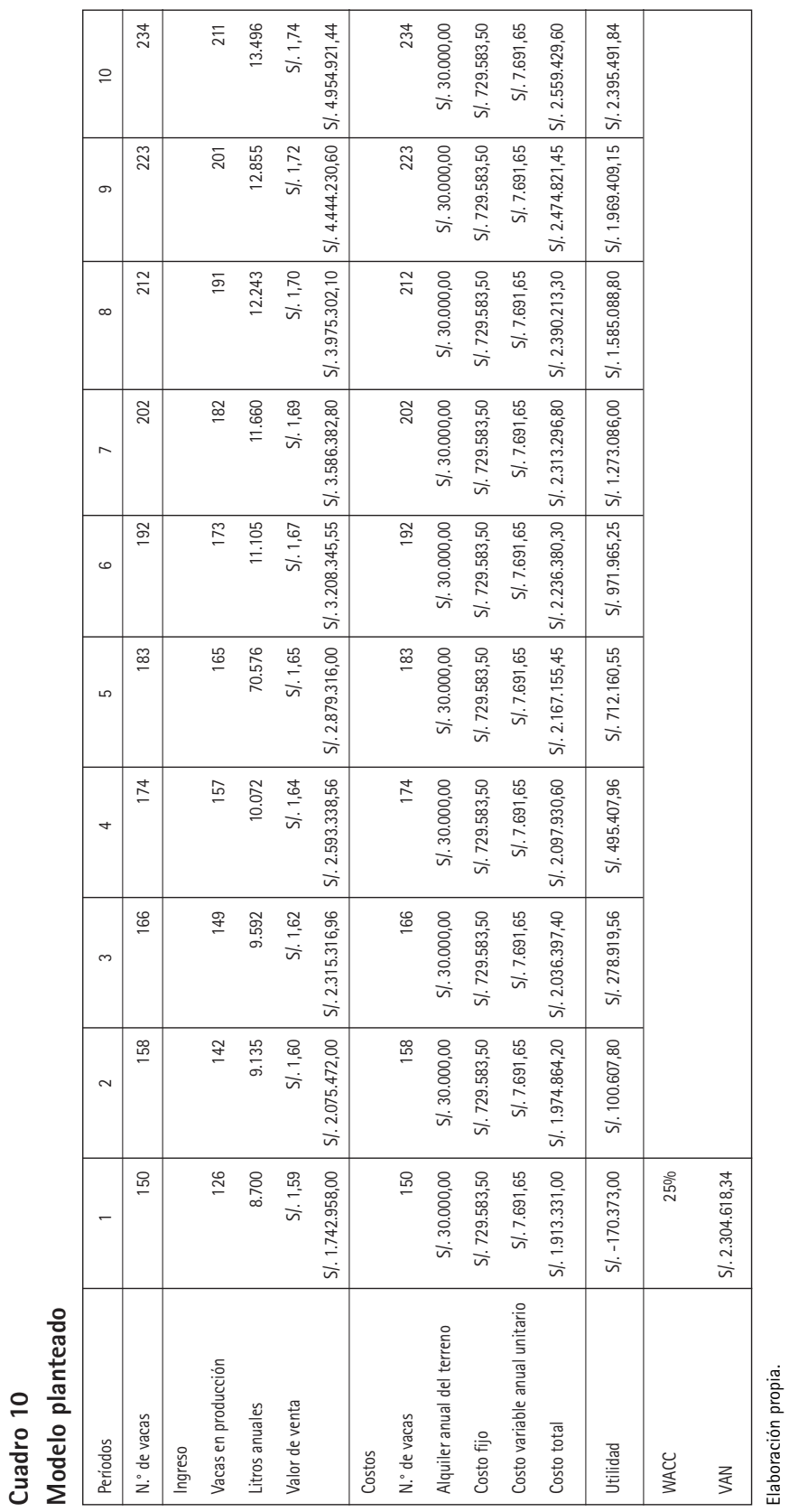


De modo que se obtiene el saldo de la cuenta a la fecha y se realizan los ajustes para la elaboración de reportes financieros.

\begin{tabular}{|c|c|c|c|c|}
\hline \multicolumn{2}{|l|}{ CUENTA CONTABLE } & \multicolumn{3}{|c|}{35212 ACTIVO BIOLÓGICO } \\
\hline Cantidad de vacas & Categoria & Precio de venta & Valor de venta & Costo de adquisición \\
\hline 46 & Vacas de alta producción & $S / .2 .000,00$ & S/. $4.576,27$ & S/. $210.508,47$ \\
\hline 50 & Vacas de media producción & S/. $1.500,00$ & S/. $3.432,20$ & S/. $171.610,17$ \\
\hline 30 & Vacas de baja producción & $S / .900,00$ & S/. 2.059,32 & S/. $61.779,66$ \\
\hline 24 & Vacas en seca & S/. 700,00 & S/. $1.601,69$ & S/. $38.440,68$ \\
\hline \multirow[t]{3}{*}{150} & & & Saldo inicial & S/. $482.338,98$ \\
\hline & & & Costos deducibles & S/. 1.822.279,36 \\
\hline & & & Saldo final & S/. 2.304.618,34 \\
\hline
\end{tabular}

Elaboración propia.

Una vez calculado el saldo final, se debe incorporar al activo no corriente mediante un asiento de ajuste. Por un lado, se debe observar cuál es el valor actual de la cuenta de activos biológicos y se activan los costos operativos siempre y cuando no excedan el valor razonable calculado. En este caso específico, había suficientes costos para activar y alcanzar el monto hallado mediante el cálculo del valor razonable. Dado un caso opuesto, se debe incorporar el «efecto NIC 41", como se presentó en el acápite del marco teórico.

\section{Impactos tributarios}

Debido a que el modelo planteado no presenta un caso donde se puedan aplicar los ajustes tributarios correspondientes al modelo de costeo, se utilizó el caso planteado en el marco teórico, con el propósito de analizar cuáles son los efectos de la NIC 41 desde el punto de vista tributario, ya que el valor razonable tiende a generar impacto en los resultados del ejercicio. 


\section{Cuadro 11}

\section{Impactos tributarios}

\begin{tabular}{|c|c|c|}
\hline ESTADO DE RESULTADOS & Financiero & Tributario \\
\hline Ingresos & S/. $\quad 30.015,77$ & $X X X X X$ \\
\hline Costo de ventas & S/. $-18.500,00$ & S/. $\quad-18.500,00$ \\
\hline Utilidad bruta & $11.515,77$ & S/. $-18.500,00$ \\
\hline Gastos administrativos & $X X X X X$ & $X X X X X$ \\
\hline Gasto de ventas & $X X X X X$ & $X X X X X$ \\
\hline Utilidad operativa & $X X X X X$ & $X X X X X$ \\
\hline Partidas financieras & $X X X X X$ & $X X X X X$ \\
\hline Utilidad antes de IR & $11.515,77$ & S/. $-18.500,00$ \\
\hline IR & $-3.454,73$ & $X X X X X$ \\
\hline Utilidad neta & $8.061,04$ & S/. $\quad-18.500,00$ \\
\hline
\end{tabular}

Elaboración propia.

De esta manera, se puede observar que la NIC 41 no genera ningún efecto tributario. Esto se debe a que el valor razonable representa un valor estimado y no constituye un hecho en el presente. Es por ello que desde el punto de vista de la administración tributaria, solo serán deducibles aquellos gastos que no sean resultado de los cálculos del valor razonable sino que provengan de las operaciones. Por otro lado, desde el punto de vista financiero se pueden tener ingresos y gastos asociados con el desarrollo y mantenimiento de los activos biológicos.

\section{Conclusiones}

A continuación, se presentan las principales conclusiones de la investigación:

- Actualmente el sector agrario se encuentra en crecimiento constante. Este crecimiento se atribuye a un auge económico del país, mas no a una iniciativa o mejora del mismo sector. 
- En el sector ganadero, especialmente en el vacuno, existe una alta atomización de las unidades agropecuarias a través de todo el territorio. También se identificó una débil asociatividad de los mismos ganaderos, apoyando la existencia de un bajo poder de negociación con las principales empresas acopiadoras de leche y reducidos márgenes de utilidad.

- Existen modelos de costeo de los activos biológicos, la gran mayoría de los cuales se utilizan para plantas y no animales. Esto se debe a que no existe un incentivo para este sector, siendo la leche un producto muy importante para la canasta básica. Esta realidad se apoya en la anterior conclusión, demostrando que el sector vacuno se encuentra estancado en la actualidad.

- Existen beneficios tributarios por parte del Estado para la promoción y mejora del sector ganadero, pero estos no son aprovechados por empresas que se dediquen a la crianza de animales, sino más por agricultores que exportan los productos al exterior. Los plazos de estas leyes se siguen ampliando actualmente.

- El modelo planteado se puede aplicar a cooperativas y ganaderos que decidan por voluntad propia desarrollar esta actividad como un negocio, más que como un método de subsistencia y un mercado artesanal.

- Se debe tomar en consideración que el modelo se basa en la norma internacional, la cual tiene como objetivo gerenciar y observar cuál es el desarrollo de los activos biológicos de la empresa. 



\section{Anexos}

\section{Capítulo I}

\section{Anexo 1}

\section{Características de la industria}

El sector hidrocarburos tiene como características la complejidad de los procesos, la intensiva regulación presente y los altos riesgos del sector.

La búsqueda de petróleo es un proceso complejo y multidisciplinario que involucra ciencia y el desarrollo y uso de tecnología sofisticada, la cual incluye diversos tipos de capital humano, ya que se requieren diversos conocimientos específicos.

Cabe resaltar que la producción de petróleo y gas es una de las actividades más altamente reguladas. Para el caso del Perú, los principales entes reguladores son Perupetro y Osinerg ${ }^{1}$. Estos reguladores controlan la capacidad, la oportunidad y los métodos mediante los cuales los pozos son perforados; el ratio de producción; y la salud y seguridad de los trabajadores, como el aspecto ambiental donde se desarrolla el proyecto de hidrocarburos.

Por otra parte, una de las características más importantes en esta industria son los altos riesgos presentes en el sector. Entre los riesgos más relevantes está la etapa de exploración de pozos, ya que de cada 5 pozos explorados, aproximadamente 2 están $\operatorname{secos}^{2}$. Estas actividades son altamente riesgosas puesto que los inversionistas deben realizar una inversión significativa sin tener la certeza de que tendrán rentabilidades seguras en el futuro.

1. <http://www2.osinerg.gob.pe/MarcoLegal/pdf/LEYOH-\%2026221.pdf>.

2. Curso de petróleo y gas. Ernst \& Young (agosto de 2006). 
Otros riesgos presentes en el sector son cambios constantes en precios, liquidez, riesgos políticos y gubernamentales, y problemas con la comunidad.

\section{Anexo 2}

\section{Etapas de la actividad petrolera}

El proceso de toda la actividad petrolera se divide en dos etapas: upstream $^{3} \mathrm{y}$ downstream ${ }^{4}$.

Para el caso de la etapa de upstream, se subdivide en cinco etapas ${ }^{5}$ : adquisición de propiedades, exploración, desarrollo, producción y abandono. Asimismo, en la etapa de downstream se subdivide en cuatro etapas ${ }^{6}$ : transporte, distribución, refinación y comercialización.

\section{a. Etapa de adquisición de propiedades}

En el sector de hidrocarburos, las actividades de perforación de pozos y producción de petróleo son generalmente adquiridas por arrendatarios. Para el caso peruano, el dueño de la propiedad minera es el Estado peruano, el cual, por medio de la empresa Perupetro, otorga dos tipos de contrato a los arrendatarios: contrato de licencia y contrato de servicio.

Los contratos de licencia otorgan al inversionista el derecho a extraer y explotar hidrocarburos en el área del contrato. Para este tipo de contrato, la propiedad de los hidrocarburos extraídos es del contratista. Asimismo, el contratista está obligado a pagar una regalía en efectivo al Estado peruano.

Para el caso de los contratos de servicios, se otorgan derechos de extracción y explotación de hidrocarburos al contratista; sin embargo, la propiedad de estos hidrocarburos extraídos y medidos es del Estado peruano. Asimismo, el Estado peruano paga al contratista una retribución en función de la producción.

Por otra parte, los costos asociados a esta primera etapa pueden ser honorarios de intermediarios, honorarios de registro de la propiedad, costos legales, entre otros. Estos costos serán capitalizados cuando se incurra en ellos. Asimismo,

\footnotetext{
3. <http://www.repsol.com/es_es/corporacion/conocer-repsol/nuestra-actividad/upstream/>.

4. <http://www.repsol.com/es_es/corporacion/conocer-repsol/nuestra-actividad/downstream/>.

5. Curso de petróleo y gas. Ernst \& Young (agosto de 2006).

6. <http://www.repsol.com/es_es/corporacion/conocer-repsol/nuestra-actividad/downstream/>
} 
el costeo total se debe realizar al menos una vez al año, para determinar y asumir pérdidas de valor.

\section{b. Etapa de exploración}

En esta segunda etapa, se realizan estudios especializados para comprobar la existencia de reservas en los pozos.

El origen del petróleo se debe a la descomposición de sustancias orgánicas de restos animales o vegetales depositados en los fondos marinos y durante el proceso de sedimentación. Esta materia orgánica se puede ubicar bajo tierra aproximadamente a 20.000 o más pies de profundidad, y se convierte en petróleo crudo por acción del calor, luego de miles de años.

Los costos asociados a esta etapa son:

- Costos de exámenes y estudios que garanticen zonas que contienen reservas de petróleo.

- $\quad$ Costos de perforación de pozos exploratorios.

- Costos geológicos, los cuales se basan en la preparación de mapas topológicos, estudios magnéticos y estudios de gravedad.

- Costos geofísicos, los cuales se basan exámenes sísmicos que revelan la ubicación donde se debe realizar la perforación exploratoria.

- Derechos de acceso a las propiedades para conducir dichos estudios.

- Salarios y otros gastos de geólogos, geofísicos y otros que llevan a cabo estos estudios.

- $\quad$ Costos de mantener y retener propiedades no desarrolladas.

- Costos de perforación y equipamiento de pozos exploratorios; estos costos permiten la presencia de petróleo en un área no probada.

\section{c. Etapa de desarrollo}

En esta etapa del proceso de la actividad de extracción de hidrocarburos, se incurre en diversos costos luego de la confirmación de la existencia de las reservas petroleras en los pozos explorados. 
Entre los costos más importantes, tenemos:

- Construcción de las instalaciones adecuadas para la extracción, el tratamiento, la reunión y el almacenamiento del petróleo.

- Costos de protección y mantenimiento del medio ambiente.

- Costos de salud de los trabajadores.

d. Etapa de producción

En esta cuarta etapa del proceso del sector de hidrocarburos los principales costo del sector son:

- Costos incurridos para operar y mantener los pozos probados, los cuales contienen reservas petroleras; asimismo, se suma el mantenimiento de la maquinaria necesaria.

- Sueldos y salarios del personal que opera los pozos, así como los equipos e instalaciones relacionados.

- Reparaciones y mantenimiento.

- Consumo de materiales, suministros, combustibles y servicios utilizados en pozos y equipos e instalaciones relacionados.

- Depreciación de equipos e instalaciones de soporte de la producción.

- Costo de "workovers»; estos son costos ocasionales, necesarios en situaciones en que se desea mantener los ratios máximos de producción.

\section{e. Etapa de abandono}

Esta es la última fase del proceso del sector de hidrocarburos, la fase final de la vida de un campo de petróleo, e involucra actividades como el rescate de los equipos de pozo, el retiro de las plataformas terminales y otras instalaciones, y el taponamiento de pozos.

Cabe resaltar que se tiene que realizar un plan de abandono de pozos, el cual debe considerar los siguientes asuntos: informe de reservas, estudio sobre costos de abandono y restauración del medio ambiente en los que se incurrirá en el futuro (a precios de mercado), plan de contingencias futuras por incremento de precios o cambio de condiciones (por ejemplo, 5\%) y tasa de descuento para traer a valor presente los costos futuros de abandono y restauración del medio ambiente. 


\section{Anexo 3}

\section{Reservas}

Para la determinación de las reservas existentes en cada pozo petrolero, se requieren conocimientos especiales de profesionales que tengan experiencia y preparación académica adecuada.

Determinación de las características físicas de la formación ${ }^{7}$ :

- Área y espesura de la zona productiva.

- Porosidad de la roca reservorio.

- Permeabilidad de la roca reservorio.

- Saturación de petróleo, gas y agua.

- Profundidad de la formación productiva.

En cuanto a la clasificación de las reservas, tenemos los siguientes tipos ${ }^{8}$ :

\section{Reservas probadas}

Son cantidades estimadas de petróleo crudo y gas natural en las que la información geológica y de ingeniería demuestra, con razonable certeza, que serán recuperables bajo las condiciones económicas y operativas existentes. Existen reservas probadas desarrolladas y reservas probadas no desarrolladas.

Por otra parte, las reservas probadas no desarrolladas son reservas probadas que serán recuperadas de pozos nuevos o pozos exitosos, en los cuales se necesita efectuar un gasto importante para su culminación.

\section{Reservas probables}

En el caso de las reservas probables, se incluyen las reservas especulativas, donde el riesgo es relativamente alto. Asimismo, son aquellas que dependen de desarrollos favorables o eventos (por ejemplo, trabajos de remediación) que no se pueden predecir con suficiente exactitud.

7. Curso de petróleo y gas. Ernst \& Young (agosto de 2006).

8. <http://industria-petrolera.lacomunidadpetrolera.com/2008/12/clasificacin-de-las-reservas. $h$ tm/>. 


\section{Reservas posibles}

Las reservas posibles son aquellas que están soportadas por información de ingeniería y geología, pero que están sujetas a algún elemento de riesgo que no permite clasificarlas como reservas probadas.

\section{Capítulo II}

Guía de preguntas para entrevistas con gerentes de empresas constructoras

Preguntas introductorias:

- ¿Cuál es su opinión respecto a la evolución de los sectores construcción e inmobiliario en los últimos 10 años?

- ¿Cuál considera usted que es la razón principal de dicha evolución?

- ¿ ¿Considera usted que existe riesgo de que en el Perú se esté produciendo una especie de burbuja inmobiliaria similar a la ocurrida en los Estados Unidos?

Preguntas sobre la definición de una empresa constructora y una inmobiliaria:

- En su opinión, ¿cuál es la principal característica que diferencia a una empresa constructora de una inmobiliaria?

- En su opinión, si una empresa construye y vende por cuenta propia las unidades inmobiliarias, ¿es una empresa constructora o inmobiliaria?

Preguntas sobre las normas tributarias:

- ¿Considera usted que las normas tributarias relacionadas con los sectores construcción e inmobiliario son lo suficientemente claras para que las empresas puedan determinar el impuesto general a las ventas y el impuesto a la renta sin mayor confusión?

- ¿Cuál es su opinión respecto a los cambios que se han dado a las normas tributarias, principalmente en el impuesto general a las ventas y el impuesto a la renta?

- ¿De qué manera la empresa se ha visto afectada por estos cambios? 
- ¿Por cuál de los tres métodos establecidos en el artículo 63. de la Ley del Impuesto a la Renta ha optado en su empresa para la determinación de la renta bruta?

- $\quad$ Ahora que se ha derogado el inciso c) del artículo 63. de la Ley del Impuesto a la Renta, ¿por cuál método van a optar para la determinación de la renta bruta?

- ¿Considera usted que una planificación estratégica de los impuestos es importante para el sector? ¿Por qué?

- ¿Su empresa ha recibido algún tipo de multa por una incorrecta aplicación de las normas tributarias?

Preguntas sobre el rol del contador y el área de ingeniería para la determinación de impuestos:

- En su opinión, ¿cuál es el rol de contador en una empresa constructora o inmobiliaria?

- ¿Considera usted que el área contable y el área de ingeniería de obra deben tener comunicación permanente? ¿Deberían, tal vez, contar con un día específico a la semana agendado para reunirse?

Preguntas sobre los seminarios que dictan los estudios contables:

- ¿Ha acudido a algún seminario sobre el tratamiento contable y tributario para las empresas de los sectores construcción e inmobiliario? ¿Por qué?

- ¿Pudo aclarar las dudas que tenía sobre los temas tocados en el seminario?

Guía de preguntas para entrevistas con gerentes de empresas inmobiliarias

Preguntas introductorias:

- ¿Cuál es su opinión respecto a la evolución de los sectores construcción e inmobiliario en los últimos 10 años?

- ¿Cuál considera usted que es la razón principal de dicha evolución? 
- ¿Considera usted que existe riesgo de que en el Perú se esté produciendo una especie de burbuja inmobiliaria similar a la ocurrida en los Estados Unidos?

Preguntas sobre la definición de una empresa constructora y una inmobiliaria:

- En su opinión, ¿cuál es la principal característica que diferencia a una empresa constructora de una inmobiliaria?

- En su opinión, si una empresa construye y vende por cuenta propia las unidades inmobiliarias, ¿es una empresa constructora o inmobiliaria?

Preguntas sobre las normas tributarias:

- ¿Considera usted que las normas tributarias relacionadas con los sectores construcción e inmobiliario son lo suficientemente claras para que las empresas puedan determinar el impuesto general a las ventas y el impuesto a la renta sin mayor confusión?

- ¿Cuál es su opinión respecto a los cambios que se han dado en las normas tributarias, principalmente en el impuesto general a las ventas y el impuesto a la renta?

- ¿De qué manera la empresa se ha visto afectada por estos cambios?

- $\quad$ Si usted estuviera en una empresa constructora, ¿por cuál de los tres métodos establecidos en el artículo 63. ${ }^{\circ}$ de la Ley del Impuesto a la Renta optaría para la determinación de la renta bruta?

- Sobre el nacimiento de la obligación tributaria del IGV existen dos posiciones opuestas de la Sunat y del Tribunal Fiscal. En su opinión, ¿cuál debería ser la correcta? ¿Bajo qué posición determinan el IGV?

- ¿Considera usted que una planificación estratégica de los impuestos es importante para el sector? ¿Por qué?

- ¿Su empresa ha recibidoo algún tipo de multa por una incorrecta aplicación de las normas tributarias? 
Preguntas sobre el rol del contador y el área de ingeniería para la determinación de impuestos:

- En su opinión, ¿cuál es el rol del contador en una empresa constructora o inmobiliaria?

- ¿Considera usted que el área contable y el área de ingeniería de obra deben tener comunicación permanente? ¿Deberían, tal vez, contar con un día específico a la semana agendado para reunirse?

Preguntas sobre los seminarios que dictan los estudios contables:

- ¿Ha acudido a algún seminario sobre el tratamiento contable y tributario para las empresas de los sectores construcción e inmobiliario? ¿Por qué?

- ¿Pudo aclarar las dudas que tenía sobre los temas tocados en el seminario?

Guía de preguntas para entrevistas con un asesor de Capeco

Preguntas introductorias:

- ¿Cuál es su opinión respecto a la evolución de los sectores construcción e inmobiliario en los últimos 10 años?

- ¿Cuál considera usted que es la razón principal de dicha evolución?

- ¿Considera usted que existe riesgo de que en el Perú se esté produciendo una especie de burbuja inmobiliaria similar a la ocurrida en los Estados Unidos?

Preguntas sobre las normas tributarias:

- ¿Considera usted que las normas tributarias relacionadas con los sectores construcción e inmobiliario son lo suficientemente claras?

- ¿Cuál es su opinión respecto a los cambios que se han dado en las normas tributarias, principalmente en el impuesto general a las ventas y el impuesto a la renta? 
- ¿De qué manera las empresas se ha visto afectadas por estos cambios?

- En su opinión, ¿existen discrepancias entre la norma contable y las normas tributarias relacionadas con los sectores construcción e inmobiliario?

- ¿No ha pensado proponer a Capeco la elaboración de algún tipo de guía contable y tributario que permita a los interesados en los sectores construcción e inmobiliario contar con una base más solida para la determinación de sus impuestos?

- En su opinión, con la derogación del inciso c) del artículo 63 de la Ley del Impuesto a la Renta, ¿por cuál método deberían optar las empresas constructoras para la determinación de la renta bruta?

- ¿Qué opina sobre el cambio que se ha hecho en el artículo $3^{\circ}$ de la Ley del Impuesto General a las Ventas?

Preguntas sobre el rol del contador:

- En su opinión, ¿cuál es el rol del contador en una empresa constructora o inmobiliaria?

- ¿Considera usted que el área contable y el área de ingeniería de obra deben tener comunicación permanente? ¿Deberían, tal vez, contar con un día específico a la semana agendado para reunirse?

Preguntas sobre los seminarios que ha dictado:

- ¿Cuáles son las dudas más frecuentes que han tenido las personas que han asistido a los seminarios?

- ¿La mayoría de las personas que acuden a los seminarios son contadores?

Guía de preguntas para entrevistas con contadores de los sectores construcción e inmobiliario

Preguntas introductorias:

- ¿Cuál es su opinión respecto a la evolución de los sectores construcción e inmobiliario en los últimos 10 años? 
- ¿Cuál considera usted que es la razón principal de dicha evolución?

- ¿Considera usted que existe riesgo de que en el Perú se esté produciendo una especie de burbuja inmobiliaria similar a la ocurrida en los Estados Unidos?

Preguntas sobre las normas tributarias:

- ¿Considera usted que las normas tributarias relacionadas con los sectores construcción e inmobiliario son lo suficientemente claras para que las empresas puedan determinar el impuesto general a las ventas y el impuesto a la renta sin mayor confusión?

- Cuando ha tenido que consultar a expertos, como por ejemplo a la Sunat, por alguna duda relacionada con aspectos tributarios, ¿ha obtenido información clara y precisa?

- ¿Cuál es la mayor dificultad que encuentra en el manejo de la contabilidad del sector construcción y/o inmobiliario?

- ¿Sabe si existe una guía tributaria lo suficientemente clara y completa que sirva de base para los contadores para un buen manejo de la contabilidad de las empresas constructoras y/o inmobiliarias?

- ¿Considera usted que es vital una buena coordinación entre el área contable y los ingenieros de obra para una buena determinación de los impuestos?

- ¿Considera usted que una planificación estratégica de los impuestos es importante para el sector? ¿Por qué?

- ¿Cuál es su opinión respecto a los cambios que se han dado en las normas tributarias, principalmente en el impuesto general a las ventas y el impuesto a la renta?

- ¿De qué manera la empresa se ha visto afectada por estos cambios?

- Sobre el nacimiento de la obligación tributaria del IGV de las empresas inmobiliarias existen posiciones opuestas de la Sunat y del Tribunal Fiscal. En su opinión, ¿cuál debería ser la correcta? ¿Bajo qué posición determinan el IGV? 
- Considera que, si bien la NIC 18 marca las pautas para la determinación del impuesto a la renta considerando que el bien existe, ¿la posición del Tribunal Fiscal es la que se debería tomar en cuenta para la determinación del IGV?

- ¿Cree usted que una de las principales estrategias de las empresas de este rubro deba ser el uso eficiente del crédito fiscal?

Preguntas sobre los seminarios que dictan los estudios contables:

- ¿Ha acudido a algún seminario sobre el tratamiento contable y tributario para las empresas de los sectores construcción e inmobiliario? ¿Por qué?

- ¿Pudo aclarar las dudas que tenía sobre los temas tocados en el seminario?

\section{Capítulo III}

Anexo 1

Cuadro de entrevistados

\begin{tabular}{|l|c|c|}
\hline \multicolumn{1}{|c|}{ Nombre y/o cargo } & \multicolumn{1}{|c|}{ Empresa } & Fecha \\
\hline $\begin{array}{l}\text { Jannet Rivera } \\
\text { Directora }\end{array}$ & Consultora del Tercer Milenio S. A. C. & $1 / 9 / 12-13 / 10 / 12$ \\
Marta Chávez Passano & Universidad del Pacifico & \\
$\begin{array}{l}\text { Docente de la Facultad de Ciencias } \\
\text { Empresariales }\end{array}$ & Ernest \& Young & $8 / 9 / 2012$ \\
Katherine Villanueva & & $15 / 10 / 2012$ \\
Gerente & PricewaterhouseCoopers & \\
Juan Carlos Mejía & & $24 / 10 / 2012$ \\
Gerente & Deloitte & \\
Beatriz Quispe & & $29 / 10 / 2012$ \\
Gerente senior & Minera A & \\
Controller & Minera B & $5 / 10 / 2012$ \\
Jefe de Contabilidad & Minera D & $26 / 9 / 2012$ \\
Gerente de Contabilidad & & \\
\hline
\end{tabular}

Elaboración propia. 


\section{Anexo 2}

\section{Descripción de la minería}

Zinc

Miles de toneladas métricas

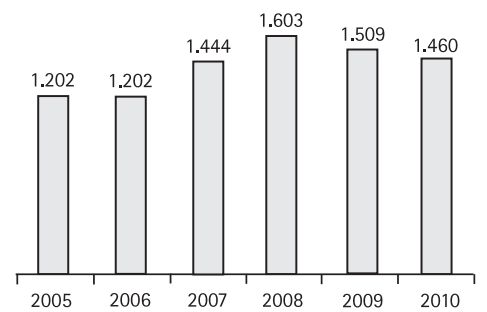

Estaño

Miles de toneladas métricas

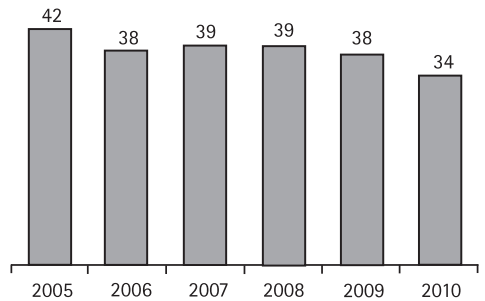

\section{Cobre}

Miles de toneladas métricas

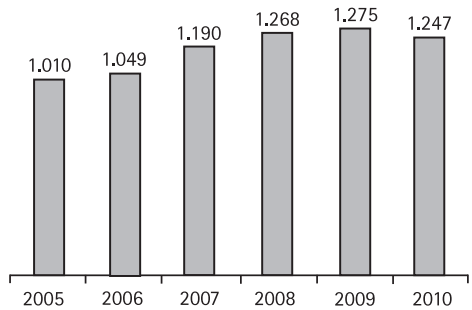

Plata

Toneladas

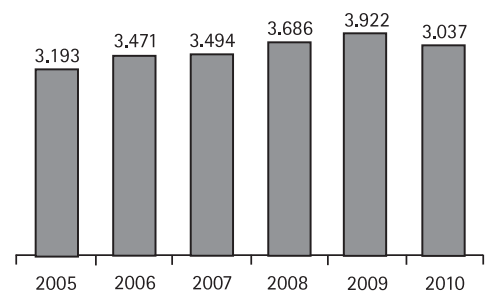

Oro

Toneladas

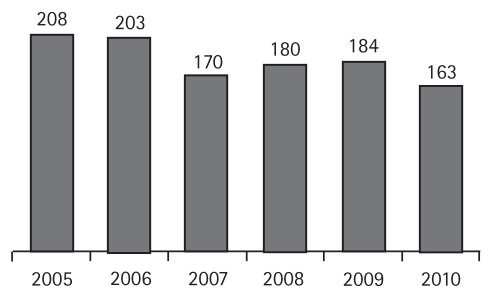

Fuente: Sociedad Nacional de Minería, Petróleo y Energía. 


\begin{tabular}{|c|c|c|c|c|c|c|c|c|c|c|c|c|c|c|c|}
\hline & | & 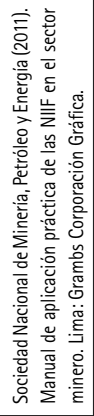 & (을 & 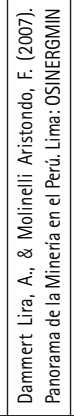 & 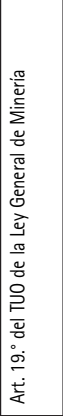 & 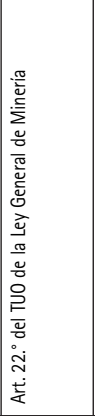 & 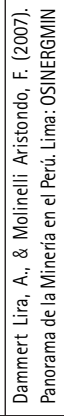 & 흠 & 哥 & 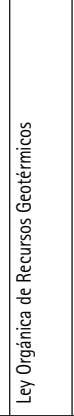 & 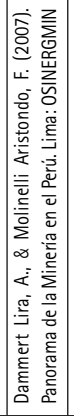 & 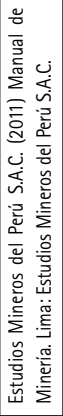 & 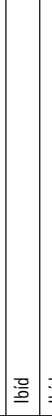 & 음 & 哥 \\
\hline & 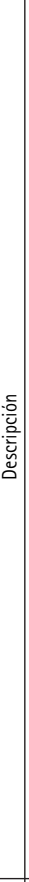 & 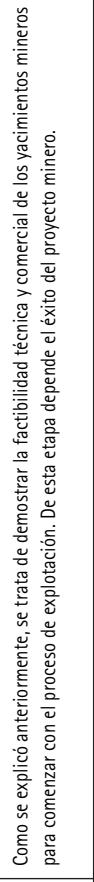 & 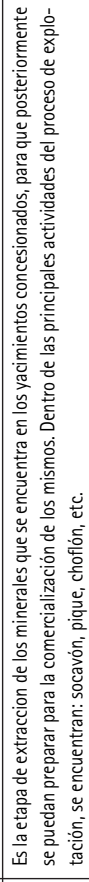 & 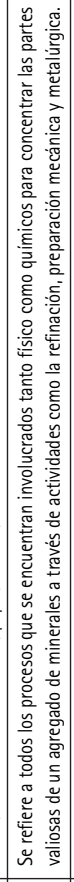 & 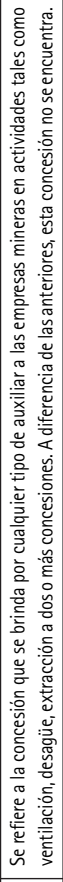 & 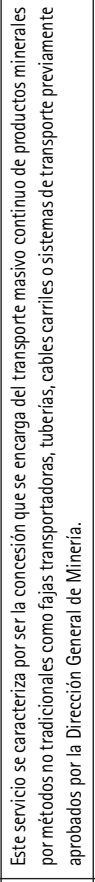 & 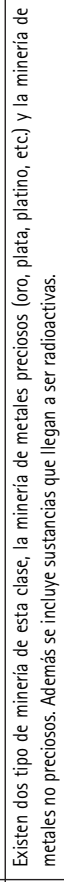 & 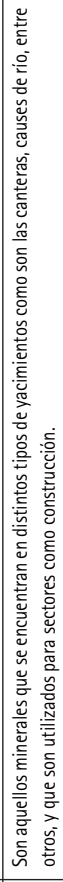 & 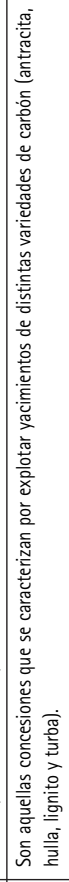 & 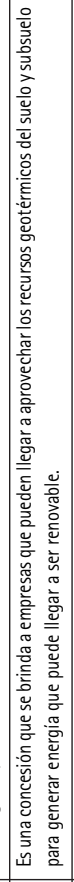 & 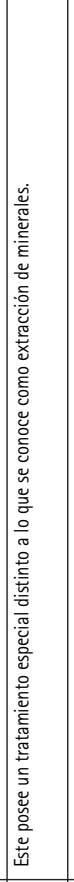 & 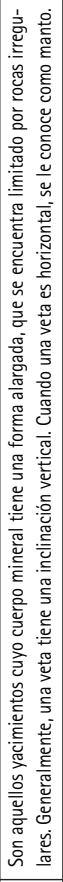 & 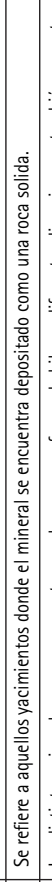 & 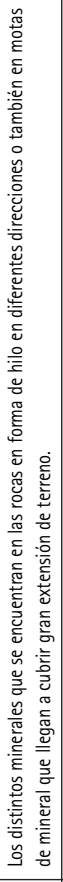 & 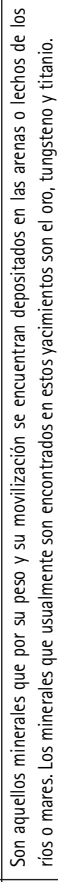 \\
\hline 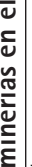 & 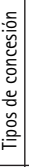 & 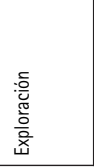 & 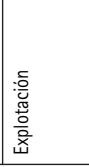 & 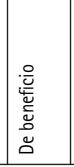 & 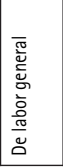 & 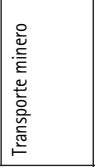 & 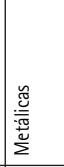 & 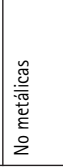 & 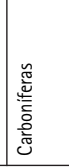 & 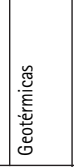 & 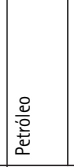 & 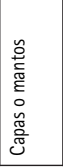 & 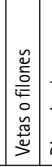 & 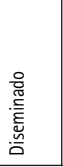 & $\mid \frac{\sqrt{5}}{\sum_{\bar{\alpha}}^{\frac{\pi}{4}}}$ \\
\hline & .气. & \multicolumn{5}{|c|}{ 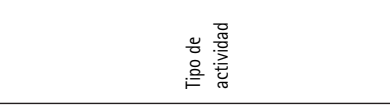 } & \multicolumn{4}{|c|}{ 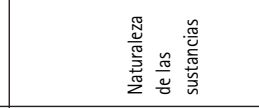 } & \multicolumn{5}{|c|}{ 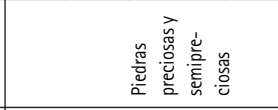 } \\
\hline
\end{tabular}




\begin{tabular}{|c|c|c|c|c|c|c|c|c|c|c|c|c|c|}
\hline 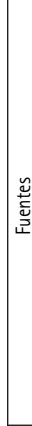 & 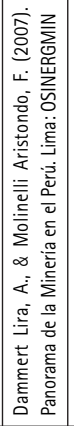 & \begin{tabular}{|l} 
\\
을
\end{tabular} & 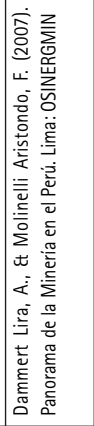 & 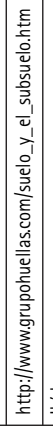 & & 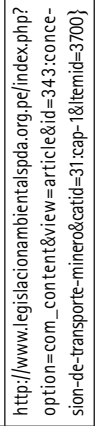 & |을 & 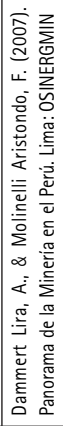 & 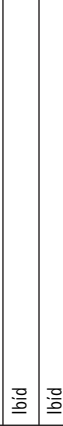 & 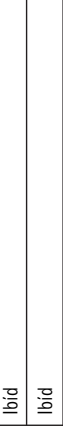 & 总 & 을 & 믕 \\
\hline : & 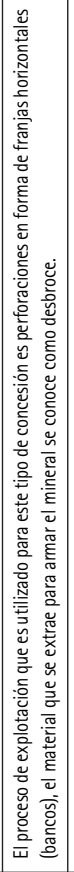 & 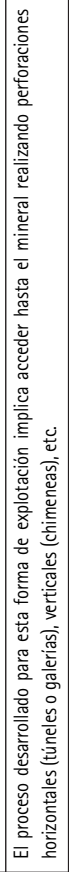 & 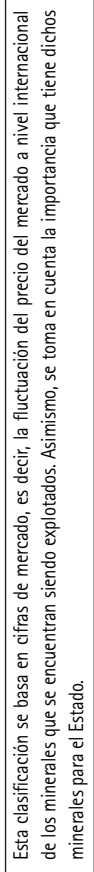 & 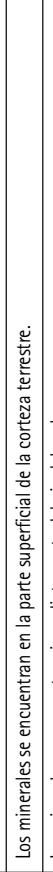 & 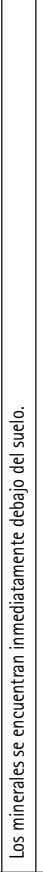 & 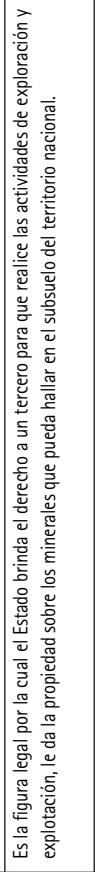 & 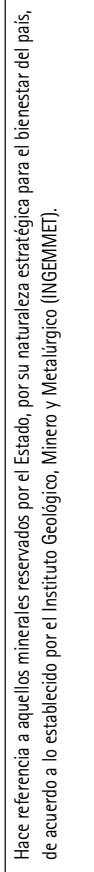 & 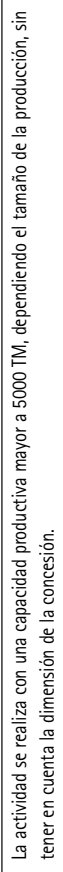 & 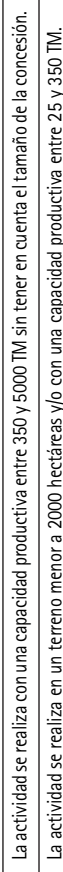 & 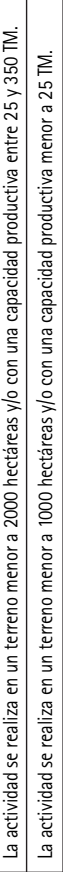 & 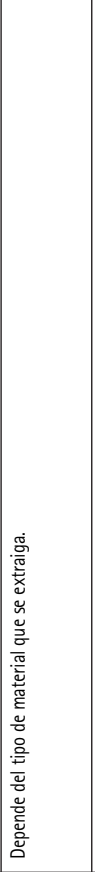 & 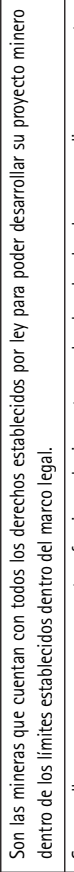 & 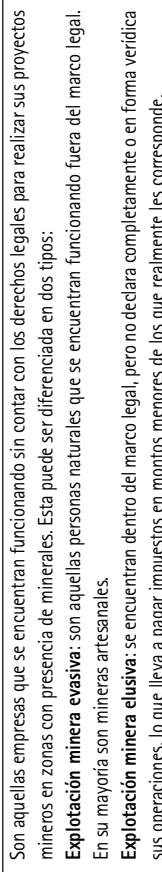 \\
\hline ذّ & 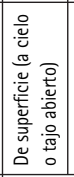 & 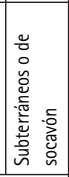 & 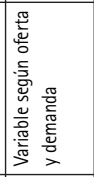 & 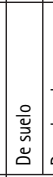 & 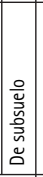 & 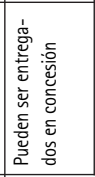 & 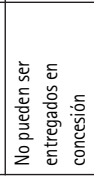 & 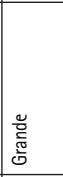 & 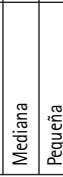 & 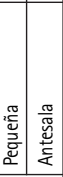 & 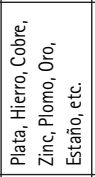 & 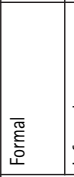 & 总 \\
\hline & & & 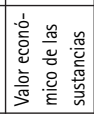 & 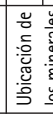 & $\frac{\mathscr{v}}{\tilde{w}}$ & & & & 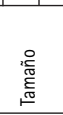 & & 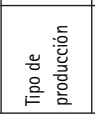 & & 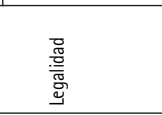 \\
\hline
\end{tabular}




\section{Anexo 4}

\section{Etapas en la minería}

\section{i. Cateo y prospección}

El objetivo de esta etapa es determinar futuros yacimientos mineros. La etapa se inicia con el proceso del cateo, el cual consiste en realizar búsquedas visuales de anomalías geológicas en la superficie, lo que puede dar indicios de presencia de minerales.

El siguiente proceso es el de la prospección, en el cual la observación se realiza con el apoyo de herramientas tecnológicas para poder alcanzar mejores resultados. Las herramientas utilizadas pueden ser: fotos aéreas, datos satelitales, y técnicas geofísicas (para observar las propiedades físicas de las rocas analizadas) o geoquímicas (para obtener resultados químicos de los materiales observados).

\section{ii. Solicitud de petitorio}

En esta etapa, la empresa tendrá que solicitar el petitorio de concesión para continuar con una exploración más exhaustiva, el cual no garantiza que la empresa obtendrá la propiedad del terreno superficial ni de los recursos del subsuelo, cuyo propietario será el Estado. La empresa será dueña solo de los recursos que extraiga de dicho yacimiento. Cabe señalar que para conservar este derecho las empresas abonan al estado anualmente el derecho de vigencia, que es de US\$ 2 por hectárea al año en el caso de medianas y grandes empresas.

\section{iii. Exploración}

En esta etapa, las empresas realizan estudios más profundos con el propósito de determinar la cantidad (reservas), calidad (ley promedio), características y valor del yacimiento mineral. Además, es importante si el material que será extraído tiene el potencial para recuperar económicamente su contenido metálico, por lo que se practican distintas pruebas en laboratorios.

Dentro de las actividades que se desarrollan en la etapa están las operaciones de perforación diamantina, que consisten en realizar perforaciones en el subsuelo con el propósito de analizar el contenido mineral, así como algunas labores subterráneas (galerías, cruceros y chimeneas de exploración). 
Hay dos tipos de exploraciones, la de ampliación de reservas, que se realiza en zonas interesantes desde el punto de vista minero y que no han sido exploradas antes o lo han sido muy superficialmente, y la de reposición de reserva.

\section{iv. Evaluación del proyecto (técnica y económica) e impacto ambiental}

\section{Estudio de factibilidad}

Este estudio deberá contener los puntos generales que sistematicen la información obtenida en la etapa de exploración con el propósito de poder comparar la producción y su valor con los costos necesarios para obtenerla, tanto respecto de la vida de la mina, como a lo largo de cada ejercicio: se estima también el flujo de caja esperado y la rentabilidad del proyecto.

\section{Estudio de impacto ambiental (EIA)}

Según lo establecido por ley, las empresas que decidan iniciar un nuevo proyecto minero deberán realizar un estudio de impacto ambiental sobre las actividades que se realizarán durante las operaciones o luego del cierre/abandono. Este estudio es uno de los requisitos para comenzar con las operaciones, demostrando que las futuras actividades por realizar no alterarán el entorno y que los desechos que se produzcan serán tratados de acuerdo a lo establecido por las normas internacionales y locales.

\section{v. Desarrollo y construcción}

Consiste en los trabajos previos que se realizan para poder tener acceso al mineral desde la superficie, es decir, establecer el plan de extracción y producción de los minerales. Dependiendo del tipo de proyecto de minería del que se trate (subterránea o a tajo abierto), se realizarán los trabajos para el desarrollo de los yacimientos; todo esto como resultado del plan de factibilidad.

Posteriormente, se culminará con la planificación y se comenzará con los trabajos de infraestructura para realizar la extracción. 


\section{vi. Producción o explotación}

\section{Extracción minera a tajo abierto}

Se suele utilizar cuando los yacimientos son de gran tamaño y tienen una forma regular, y los minerales se encuentran ubicados cerca de la superficie y existe un gran volumen de mineral por extraer, siempre y cuando el costo de extraer el material sea inferior al costo de comercialización; en caso las operaciones ya se encuentren avanzadas, muchas empresas se deciden por continuar con el método subterráneo. El proceso de explotación es a través de perforaciones en forma de franjas horizontales (bancos). El material que se extrae para armar el mineral se conoce como desbroce. Las actividades que se realizan en este método de explotación son las cuatro siguientes: exploración y desarrollo; perforación y disparos; carguí; y acarreo.

\section{Extracción minera subterránea}

Este tipo de explotación minera se suele utilizar cuando el yacimiento se encuentra ubicado en un terreno cuyo espesor tiene un costo que supera el de removerlo para realizar un tajo abierto. Asimismo, cuando la zona de mineralización es angosta y profunda. Para lograr generar el acceso hasta el mineral, se realizan perforaciones horizontales (túneles o galerías), verticales (chimeneas), etc. Los procesos comprendidos en la realización de este método son: explotación y extracción, transporte y manipuleo de minerales.

\section{Procesamiento metalúrgico}

Debido a que los minerales extraídos no se encuentran preparados para su distribución comercial, se necesita prepararlos para que posteriormente entren en el proceso de fundición y refinación.

\section{Concentración}

Es el proceso por el cuales el mineral es separado debido a los distintos procesos de reducción de tamaño por los que tiene que pasar, para separar el material que tiene valor de las impurezas (relave). El objetivo es reducir el tamaño del 
mineral para reducir los costos de tratamiento, transporte, etc. Los procesos que integran la concentración son: recepción de materiales, chancado, molienda, flotación y secado de concentrados.

\section{Fundición y refinanciación}

Se realiza este procedimiento con el objetivo de recuperar los metales de su estado luego del proceso de concentración. Mediante la fundición, se obtienen los metales en estado de pureza, listos para su posterior comercialización industrial.

\section{vii. Cierre y abandono}

Es un proceso que se debe proyectar desde la planificación de los estudios de factibilidad, debido a que las legislaciones de muchos países (incluyendo la del Perú) norman a través de decretos legislativos el adecuado cuidado del ecosistema en el momento de realizar cualquier actividad minera. Por lo tanto, la presentación de un plan de cierre es obligatoria para toda empresa minera que se encuentre en operación, que inicie operaciones o que las reinicie.

Las fases del proceso de cierre incluyen: diseño inicial, aprobación gubernamental del plan de recuperación y financiamiento, recuperación progresiva durante la operación, fin de la producción con costos asociados al despido del personal, desmantelamiento de construcciones, y reacondicionamiento de las áreas explotadas.

El abandono se da cuando se logra alcanzar el equilibrio de la extracción minera. En este caso, la empresa entrega la concesión de vuelta al Estado, dejando de lado cualquier tipo de responsabilidad de monitoreo o cualquier otra responsabilidad. 


\begin{tabular}{|c|c|c|c|}
\hline & & 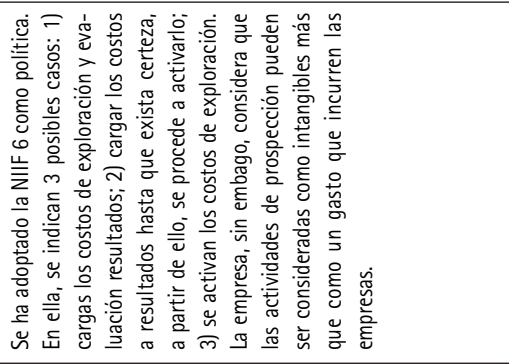 & 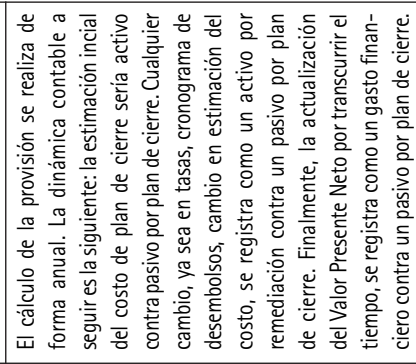 \\
\hline$\frac{d}{\sqrt{2}}$ & & 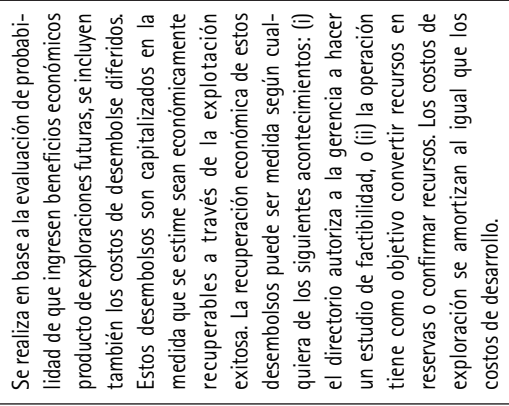 & 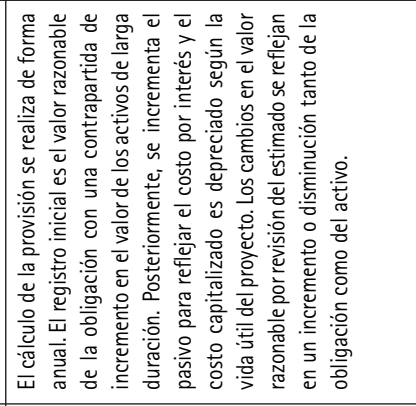 \\
\hline 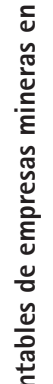 & & 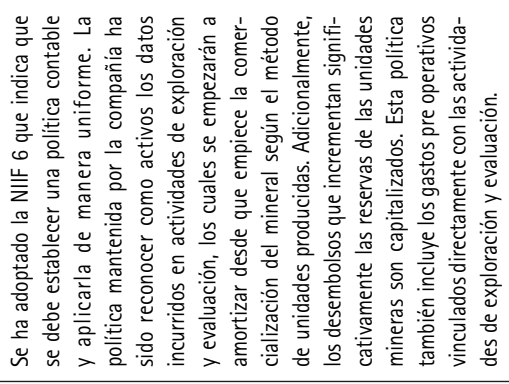 & 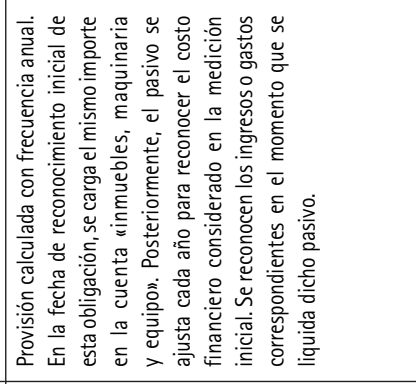 \\
\hline 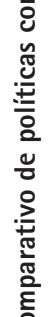 & & 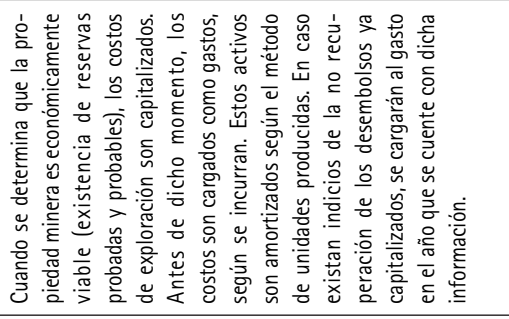 & 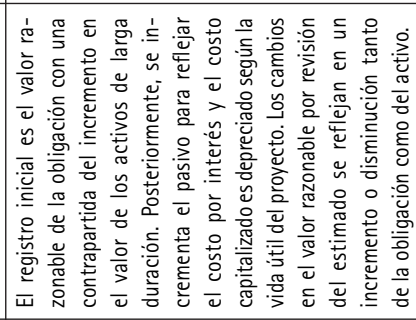 \\
\hline 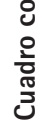 & & 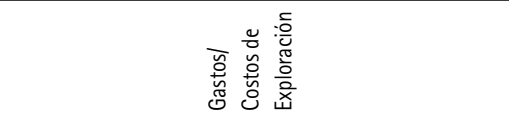 & 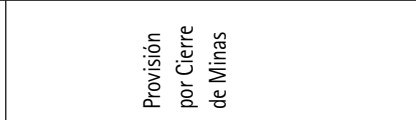 \\
\hline
\end{tabular}




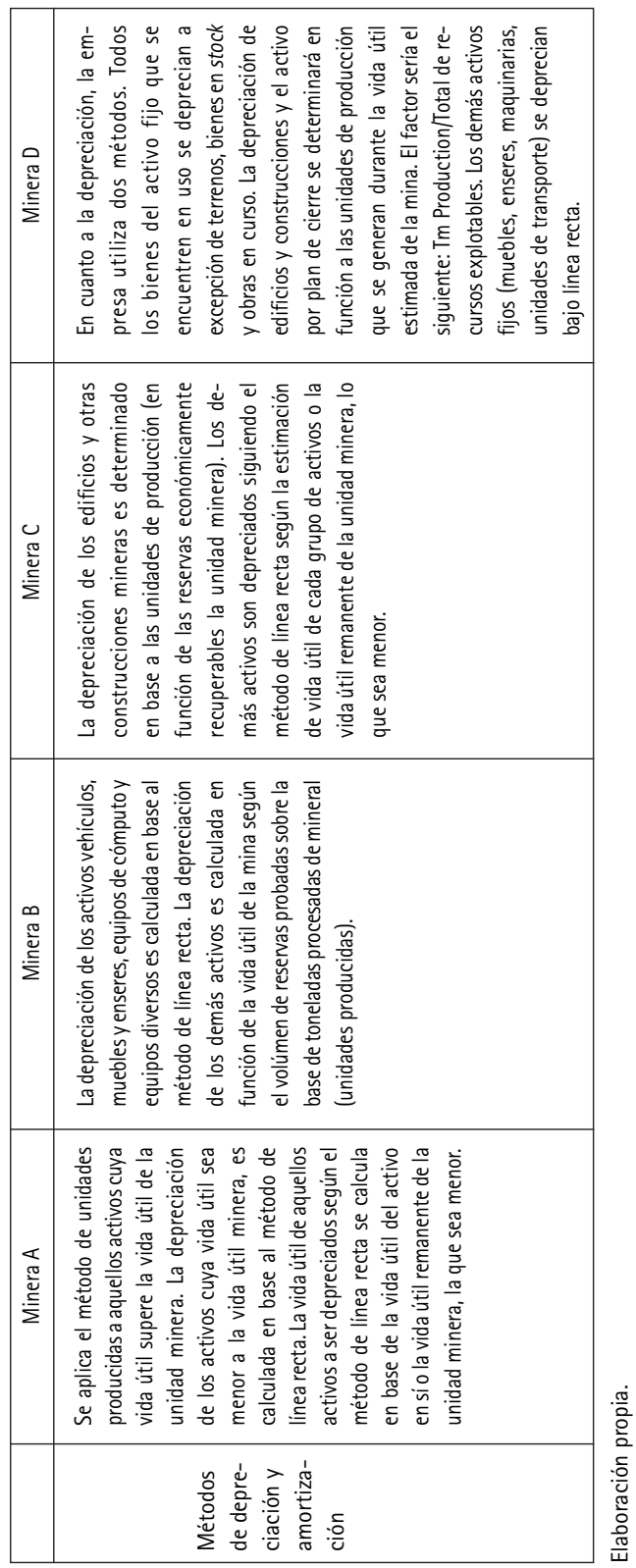




\section{Capítulo IV}

Anexo 1

Entrevista a expertos

\begin{tabular}{|ll|}
\hline Experto entrevistado & Vasco Masías \\
\hline Cargo & Gerente comercial \\
\hline Empresa & La Calera \\
\hline
\end{tabular}

Conclusiones

- La empresa La Calera no tiene un sistema de costeo fijo. Solo utiliza flujos de caja para poder medir su rentabilidad.

- Para la industria resultan de mucha importancia los indicadores productivos.

- El ave es considerada un activo biológico.

- Desde que nace hasta las 20 semanas, se considera levante. El ave pone huevos a partir de esa fecha en adelante. El costo incurrido en el ave es de aproximadamente US\$ 3.

- Desde semana 20 hasta la 75, el costo del ave es de aproximadamente otros US\$ 3.

- La normativa peruana pone mucho énfasis en la crianza del pollo y deja en un segundo nivel la producción de huevos.

- La Sunat, para revisar el pago del impuesto a la renta, mide la conversión como resultado del consumo de alimento para producir kilogramos de huevos.

- 100 gallinas ponen en promedio 82 huevos por día; 78 huevos por día si están mal manejadas; y 95 huevos por día si están bien manejadas.

- No conviene que se cambie el método de costeo de ninguna empresa, ya que la Sunat investiga cualquier cambio realizado: el costo de realizarlo no compensaría el beneficio del cambio. 


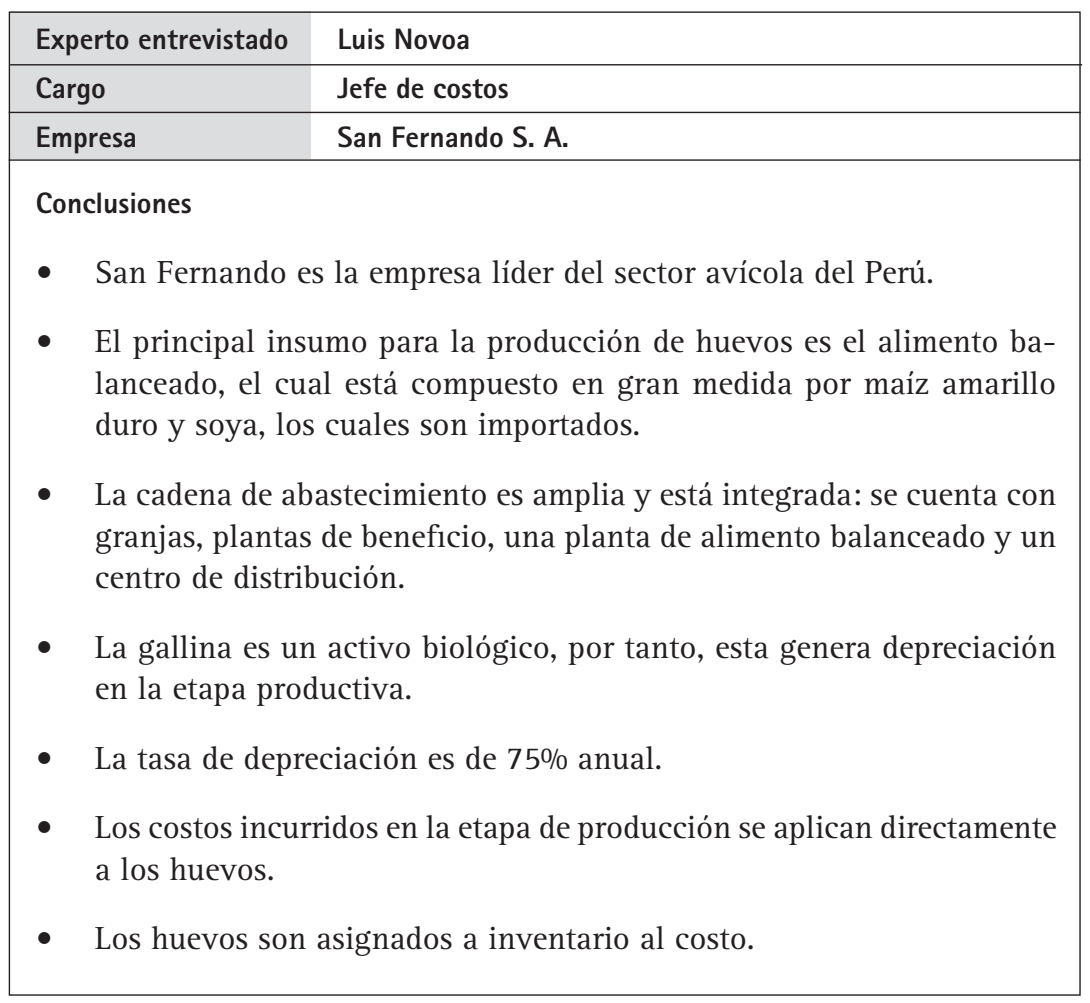




\begin{tabular}{|ll|}
\hline Experto entrevistado & Kenny Pucuhuayla \\
\hline Cargo & Gerente \\
\hline Empresa & Perú Avick S. A. C. \\
\hline
\end{tabular}

\section{Conclusiones}

- Perú Avick S. A. C es una empresa que produce y comercializa huevos.

- La empresa opera en la ciudad de Chilca.

- La empresa mantiene una población de 8.000 gallinas.

- La producción de huevos está alrededor de las $350 \mathrm{TM}$ al año.

- La industria es complicada porque existen períodos de abundancia de huevos en el mercado y los precios caen.

- Existen períodos del año en que los costos superan a los ingresos.

- Las empresas pequeñas no pueden comprar las gallinas en estado de huevo porque no cuentan con las instalaciones, por lo que compran las gallinas en estado bebé (recién incubadas), las cuales tienen un precio de $\mathrm{S} / .3,00$.

- La gallina bebé debe recibir un cuidado especial porque es muy sensible a enfermedades.

- La gallina está apta para producir en aproximadamente 4 meses.

- El ave tiene un ciclo de producción de entre 1,5 años y 2 años. Sin embargo, cuanta mayor edad tengan, menores serán los rendimientos de huevos por día y los huevos serán más defectuosos. Lo recomendable es un ciclo de 1,5 años.

- El alimento balanceado es la materia prima más importante. Su precio se encuentra entre S/. 1,00 y S/. 1,30, el cual depende de los precios del maíz.

- El precio del huevo fluctúa durante todo el año por la estacionalidad del consumo de proteína.

- Durante la producción de huevos, existen diferentes tipos: huevos rosados, huevos porosos y huevos rotos. 


\begin{tabular}{|ll|}
\hline Experto entrevistado & Christian de La Torre $\mathbf{0 .}$ \\
\hline Cargo & Gerente senior \\
\hline Empresa & PricewaterhouseCoopers \\
\hline Conclusiones & \\
\hline
\end{tabular}

- $\quad$ El ave ponedora se considera un activo biológico. Esta ave se valoriza bajo los estándares de la NIC 41.

- El huevo se considera un producto agrícola. Este huevo agrícola se valoriza bajo los estándares de la NIC 2 .

- Las empresas avícolas que pasen de las 3.000 UIT (S/. 10,8 millones) deben presentar estados financieros auditados bajo IFRS.

- Un activo biológico no se puede depreciar bajo IFRS.

- Muchos dueños de empresas avícolas no valorizan sus activos biológicos con el pretexto de que estos tienen poca vida útil (1,5 años); sin embargo, esto está mal.

- En el caso de la NIC 2, siempre se registra al costo o al valor razonable, el menor de los dos.

- El sector avícola goza de una ley que permite el pago de solo el $15 \%$ por concepto de impuesto a la renta.

- En el caso del ave ponedora, no existe un mercado activo; en el caso de otros productos, sí, como es el caso del azúcar que cotiza en el mercado de productos en la Chicago Exchange Board.

- La mejor manera de calcular el valor de un ave es proyectar sus flujos futuros y descontarlos a valor presente.

- Para calcular el costo del huevo, lo mejor es calcular sus costos incurridos y colocarlos como existencia. 


\section{Anexo 2}

Ley 27360

Ley 27360 - Ley que Aprueba las Normas de Promoción del Sector Agrario.

Los beneficios aplicados para el sector avícola, dentro del marco de la presente ley, se detallan en los siguientes artículos:

Artículo $4 .^{\circ}$ Impuesto a la Renta.- aplíquese la tasa de 15\% sobre la renta, para efecto del Impuesto a la Renta, correspondiente a rentas de tercera categoría.

Artículo 8. Impuesto Extraordinario de Solidaridad.- Impuesto Extraordinario de Solidaridad a las remuneraciones de los trabajadores que laboren para empleadores de las actividades agrarias, bajo relación de dependencia.

Este artículo fue derogado a partir del 1.12.2001 por el Artículo Único de la Ley N. ${ }^{\circ} 28378$, publicada el 10.11.2004․

Artículo 9. ${ }^{\circ}$ Seguro de Salud y Régimen Previsional.- el aporte mensual al Seguro de Salud para los trabajadores de la actividad agraria, a cargo del empleador, será del 4\% de la remuneración en el mes por cada trabajador.

De acuerdo al numeral 2.4 del artículo $2 .^{\circ}$ de la presente ley, se restringe de los beneficiarios a las actividades avícolas que no utilicen maíz amarillo duro importado en su proceso productivo. En consecuencia, las empresas avícolas, como San Fernando S. A., presentaron un Recurso de Agravio Constitucional con el objeto de que se ordene la inaplicación del numeral 2.4 del artículo 2. de la Ley 27360, que aprueba las normas de promoción al sector agrario, por considerar que la exclusión de los beneficios tributarios para los productores avícolas que utilicen en sus procesos productivos maíz amarillo duro importado, resulta lesivo a los derechos constitucionales a la igualdad en materia tributaria de la empresa recurrente, resultando asimismo contrario al principio de jerarquía de los tratados y reserva de la Administración para la regulación de aranceles.

9. Ley 28378, publicada el 10-11-2004. 


\section{Anexo 3}

Descripción del huevo comercial

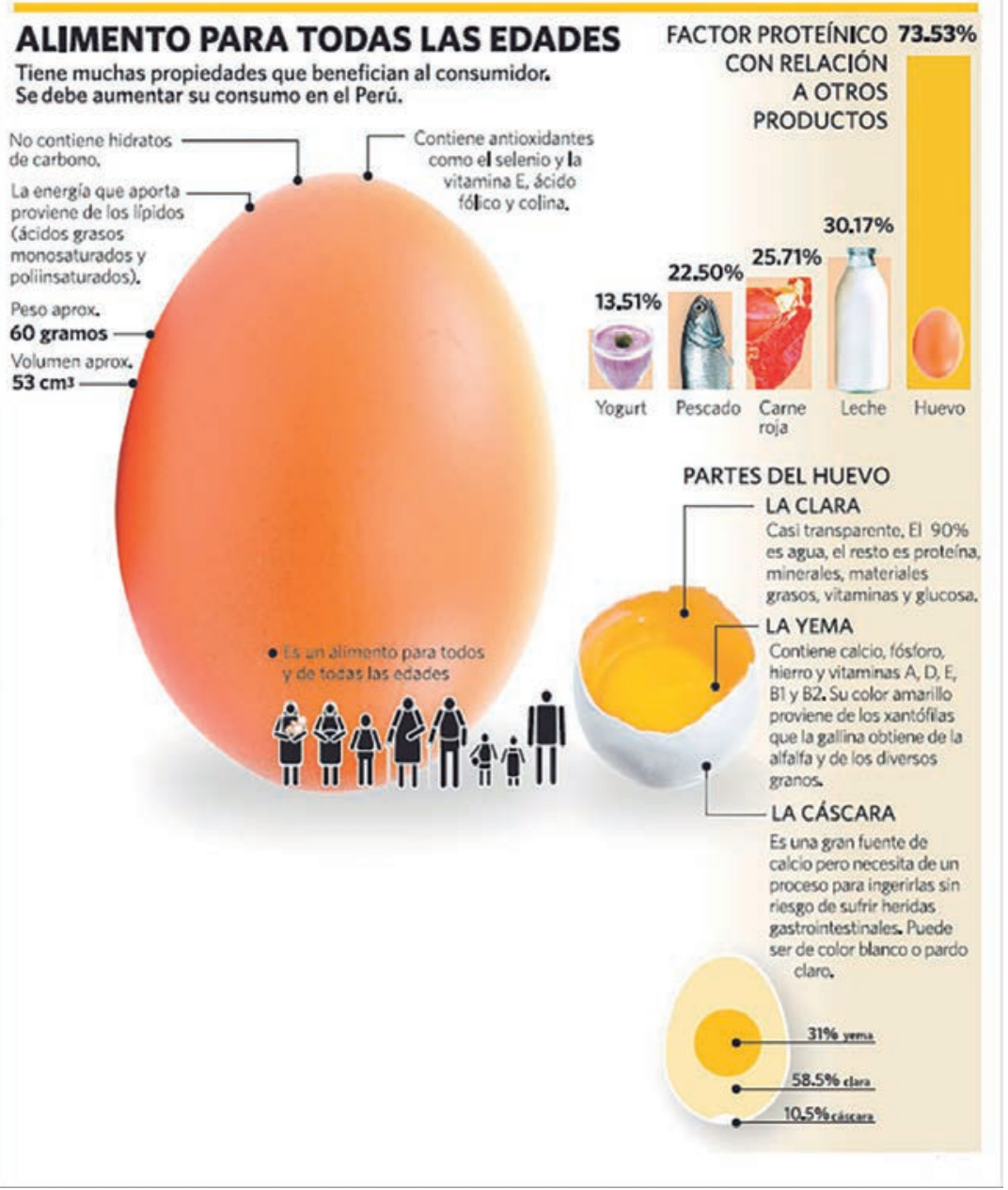

Fuente: La República. 


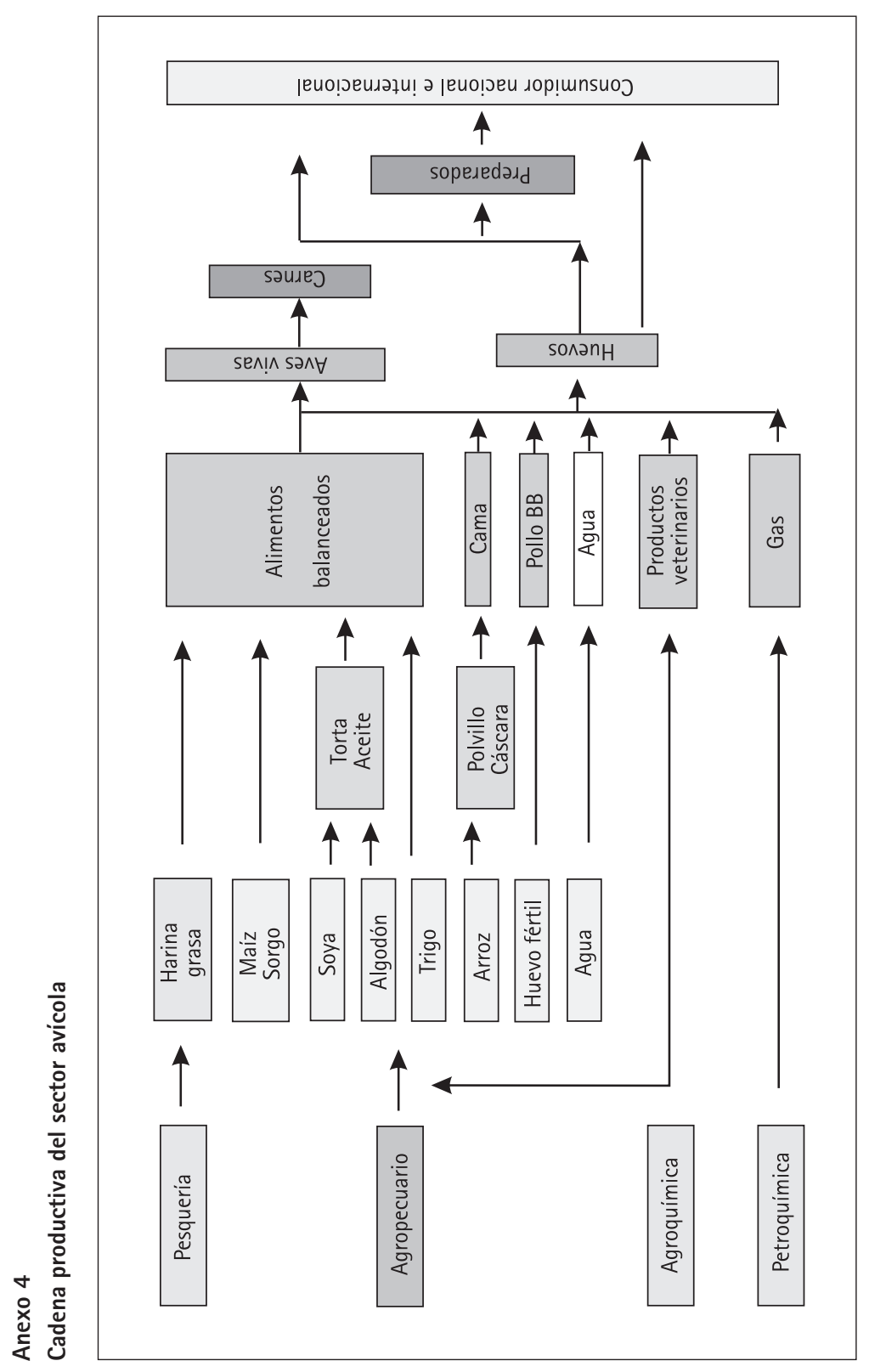

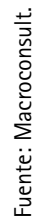




\section{Anexo 5}

\section{San Fernando S. A.}

San Fernando S. A. se fundó en el año 1948, como una empresa dedicada a la crianza de patos. Actualmente es una empresa dedicada a la producción y comercialización de alimentos de consumo masivo: pollo, pavo, cerdo, huevo y productos elaborados (embutidos), los cuales son ofrecidos y comercializados en todo el Perú ${ }^{10}$. Adicionalmente a ello, se mantiene el negocio genético, que está dirigido a productores de aves. La empresa es líder en los segmentos de pollo, pavo, productos elaborados y genética, los cuales, representan 70\%, 9\%, 8\% y 6\% de los ingresos de la compañía, respectivamente.

- Misión: contribuir al bienestar de la humanidad suministrando alimentos de consumo masivo en el mercado global.

- Visión: ser competitivos a nivel mundial suministrando productos de valor agregado para la alimentación.

Además, la organización ha desarrollado la calidad de sus productos, procesos e infraestructura, lo que ha permitido posicionarlos como una empresa destacada del sector de consumo masivo. Esto se demuestra en los premios y certificaciones obtenidos. De igual manera, es una de las pocas empresas que mantiene integrada toda la cadena de producción, la cual está conformada por plantas de alimento balanceado para la crianza, granjas reproductoras de animales, planta de incubación de aves, granjas de crianza, plantas de productos procesados, planta de beneficios de aves, centros de distribución y flota de transporte.

\section{Participación de mercado}

\begin{tabular}{|l|r|r|r|r|r|}
\hline \multicolumn{1}{|c|}{ Línea de negocio } & 2008 & 2009 & 2010 & 2011 & 2012 \\
\hline Pollos & $29 \%$ & $27 \%$ & $27 \%$ & $29 \%$ & $29 \%$ \\
Pavos & $64 \%$ & $67 \%$ & $67 \%$ & $74 \%$ & $70 \%$ \\
Cerdos & $3 \%$ & $3 \%$ & $3 \%$ & $3 \%$ & $4 \%$ \\
Huevos & $5 \%$ & $5 \%$ & $4 \%$ & $4 \%$ & $5 \%$ \\
Procesados & $32 \%$ & $32 \%$ & $34 \%$ & $34 \%$ & $31 \%$ \\
Genética & $35 \%$ & $40 \%$ & $40 \%$ & $34 \%$ & $42 \%$ \\
\hline
\end{tabular}

Fuente: Apoyo y Asociados - Fitch Ratings.

10. Página web visitada el 21.10 .13 a las 8:22 a. m. <http://www.san-fernando.com.pe/institucional.html>. 


\section{Anexo 6}

\section{La Calera}

La Calera es actualmente la mayor productora de huevos del país, abasteciendo al 98\% de las cadenas de supermercados en Lima Metropolitana, y mantiene una participación de mercado del $25 \%$ a nivel nacional ${ }^{11}$. La compañía emplea a 1.000 personas.

Después de 35 años en el negocio, la producción de huevos alcanza los 2 millones de unidades por día, y actualmente la compañía es la líder en producción y distribución de huevos en el país. Toda la producción está localizada en Chincha. Ello le permite controlar la integración vertical, lo cual ha sido parte de la clave de su éxito. Por eso, La Calera maneja toda la cadena de producción y suministros de huevos ${ }^{12}$.

11. Entrevista con Vasco Masias, gerente comercial de La Calera.

12. Página web visitada el día 21/10/2013. <http://loshuevosdelperu.com/nosotros/historia.htm/>. 


\section{Anexo 7}

Tablas de rendimiento de las gallinas

\begin{tabular}{|c|c|c|c|c|c|c|c|c|}
\hline \multirow[b]{2}{*}{$\begin{array}{l}\text { Edad en } \\
\text { semanas }\end{array}$} & \multicolumn{2}{|c|}{$\begin{array}{c}\text { \% de producción } \\
\text { ave-dia }\end{array}$} & \multirow{2}{*}{ 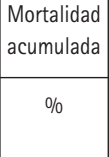 } & \multicolumn{2}{|c|}{$\begin{array}{c}\text { Huevos acumulados } \\
\text { ave-dia }\end{array}$} & \multirow{2}{*}{$\begin{array}{c}\text { Peso } \\
\text { corporal } \\
\mathrm{kg}\end{array}$} & \multirow{2}{*}{$\begin{array}{c}\text { Peso del huevo } \\
\text { promedio }\end{array}$} & \multirow{2}{*}{$\begin{array}{c}\begin{array}{c}\text { Consumo } \\
\text { de alimento }\end{array} \\
\text { g/día } \\
\text { por ave }\end{array}$} \\
\hline & $\begin{array}{c}\text { Condiciones } \\
\text { óptimas }\end{array}$ & $\begin{array}{l}\text { Condiciones } \\
\text { promedio }\end{array}$ & & $\begin{array}{l}\text { Condiciones } \\
\text { óptimas }\end{array}$ & $\begin{array}{l}\text { Condiciones } \\
\text { promedio }\end{array}$ & & & \\
\hline 18 & 9.00 & 3.00 & 0.00 & 0.60 & 0.20 & 1.48 & 50.00 & 78.00 \\
\hline 19 & 16.00 & 11.00 & 0.10 & 1.80 & 1.00 & 1.53 & 50.60 & 80.00 \\
\hline 20 & 49.00 & 32.00 & 0.10 & 5.20 & 3.20 & 1.65 & 51.20 & 89.00 \\
\hline 21 & 72.00 & 65.00 & 0.20 & 10.20 & 7.80 & 1.72 & 53.20 & 93.00 \\
\hline 22 & 89.00 & 78.00 & 0.30 & 16.50 & 13.20 & 1.78 & 54.40 & 96.00 \\
\hline 23 & 93.00 & 87.00 & 0.30 & 23.00 & 19.30 & 1.80 & 55.50 & 100.00 \\
\hline 24 & 96.00 & 93.00 & 0.40 & 29.70 & 25.80 & 1.84 & 56.60 & 103.00 \\
\hline 25 & 96.00 & 93.00 & 0.40 & 36.40 & 32.30 & 1.85 & 57.70 & 104.00 \\
\hline 26 & 96.00 & 93.00 & 0.50 & 43.10 & 38.90 & 1.86 & 58.50 & 105.00 \\
\hline 27 & 96.00 & 94.00 & 0.60 & 49.80 & 45.40 & 1.88 & 58.90 & 106.00 \\
\hline 28 & 96.00 & 94.00 & 0.60 & 56.60 & 52.00 & 1.89 & 59.80 & 108.00 \\
\hline 29 & 96.00 & 94.00 & 0.70 & 63.30 & 58.60 & 1.90 & 60.20 & 108.00 \\
\hline 30 & 95.00 & 94.00 & 0.70 & 69.90 & 65.20 & 1.90 & 61.20 & 108.00 \\
\hline 31 & 95.00 & 93.00 & 0.80 & 76.60 & 71.70 & 1.90 & 61.40 & 109.00 \\
\hline 32 & 95.00 & 93.00 & 0.90 & 83.20 & 78.20 & 1.91 & 61.60 & 109.00 \\
\hline 33 & 94.00 & 93.00 & 0.90 & 89.80 & 84.70 & 1.91 & 62.00 & 110.00 \\
\hline 34 & 94.00 & 93.00 & 1.00 & 96.40 & 91.20 & 1.91 & 62.20 & 110.00 \\
\hline 35 & 94.00 & 92.00 & 1.10 & 103.00 & 97.70 & 1.91 & 62.30 & 110.00 \\
\hline 36 & 93.00 & 92.00 & 1.10 & 109.50 & 104.10 & 1.92 & 62.40 & 110.00 \\
\hline 37 & 93.00 & 92.00 & 1.20 & 116.00 & 110.50 & 1.92 & 62.50 & 110.00 \\
\hline 38 & 93.00 & 91.00 & 1.30 & 122.50 & 116.90 & 1.92 & 62.60 & 110.00 \\
\hline 39 & 93.00 & 91.00 & 1.40 & 129.00 & 123.30 & 1.93 & 2.70 & 110.00 \\
\hline 40 & 92.00 & 91.00 & 1.50 & 135.50 & 129.60 & 1.93 & 62.80 & 110.00 \\
\hline 41 & 92.00 & 90.00 & 1.50 & 141.90 & 135.90 & 1.93 & 63.00 & 110.00 \\
\hline 42 & 91.00 & 90.00 & 1.60 & 148.30 & 142.20 & 1.94 & 63.10 & 110.00 \\
\hline 43 & 91.00 & 91.00 & 1.70 & 154.60 & 148.60 & 1.94 & 63.10 & 110.00 \\
\hline 44 & 91.00 & 90.00 & 1.80 & 161.00 & 154.90 & 1.94 & 63.10 & 110.00 \\
\hline 45 & 90.00 & 90.00 & 1.90 & 167.30 & 161.20 & 1.95 & 63.20 & 110.00 \\
\hline 46 & 90.00 & 90.00 & 2.00 & 173.60 & 167.50 & 1.95 & 63.20 & 110.00 \\
\hline 47 & 89.00 & 90.00 & 2.10 & 179.80 & 173.80 & 1.95 & 63.20 & 110.00 \\
\hline 48 & 89.00 & 89.00 & 2.20 & 186.10 & 180.00 & 1.95 & 63.30 & 110.00 \\
\hline 49 & 89.00 & 89.00 & 2.30 & 192.30 & 186.30 & 1.95 & 63.30 & 110.00 \\
\hline 50 & 88.00 & 88.00 & 2.40 & 198.50 & 192.40 & 1.95 & 63.30 & 110.00 \\
\hline 51 & 88.00 & 88.00 & 2.50 & 204.60 & 198.60 & 1.95 & 63.30 & 110.00 \\
\hline
\end{tabular}




\begin{tabular}{|c|c|c|c|c|c|c|c|c|}
\hline \multirow[b]{2}{*}{$\begin{array}{l}\text { Edad en } \\
\text { semanas }\end{array}$} & \multicolumn{2}{|c|}{$\begin{array}{c}\text { \% de producción } \\
\text { ave-dia }\end{array}$} & \multirow{2}{*}{\begin{tabular}{|c|}
$\begin{array}{c}\text { Mortalidad } \\
\text { acumulada }\end{array}$ \\
$\%$
\end{tabular}} & \multicolumn{2}{|c|}{$\begin{array}{c}\text { Huevos acumulados } \\
\text { ave-dia }\end{array}$} & \multirow{2}{*}{$\begin{array}{c}\begin{array}{c}\text { Peso } \\
\text { corporal }\end{array} \\
\mathrm{kg}\end{array}$} & \multirow{2}{*}{$\begin{array}{c}\text { Peso del huevo } \\
\text { promedio }\end{array}$} & \multirow{2}{*}{\begin{tabular}{|c}
$\begin{array}{c}\text { Consumo } \\
\text { de alimento }\end{array}$ \\
$\begin{array}{c}\text { g/dia } \\
\text { por ave }\end{array}$
\end{tabular}} \\
\hline & $\begin{array}{c}\text { Condiciones } \\
\text { óptimas }\end{array}$ & $\begin{array}{c}\text { Condiciones } \\
\text { promedio }\end{array}$ & & $\begin{array}{c}\text { Condiciones } \\
\text { óptimas }\end{array}$ & $\begin{array}{c}\text { Condiciones } \\
\text { promedio }\end{array}$ & & & \\
\hline 52 & 88.00 & 87.00 & 2.60 & 210.80 & 204.70 & 1.95 & 63.30 & 110.00 \\
\hline 53 & 87.00 & 87.00 & 2.70 & 216.90 & 210.80 & 1.95 & 63.40 & 110.00 \\
\hline 54 & 87.00 & 87.00 & 2.80 & 223.00 & 216.90 & 1.95 & 63.40 & 110.00 \\
\hline 55 & 87.00 & 86.00 & 2.90 & 229.00 & 222.90 & 1.96 & 63.40 & 110.00 \\
\hline 56 & 86.00 & 86.00 & 3.00 & 235.10 & 228.90 & 1.96 & 63.40 & 110.00 \\
\hline 57 & 86.00 & 85.00 & 3.10 & 241.10 & 234.90 & 1.96 & 63.50 & 110.00 \\
\hline 58 & 86.00 & 85.00 & 3.30 & 247.10 & 240.80 & 1.96 & 63.50 & 110.00 \\
\hline 59 & 86.00 & 85.00 & 3.40 & 253.10 & 246.80 & 1.96 & 63.50 & 110.00 \\
\hline 60 & 85.00 & 84.00 & 3.50 & 259.10 & 252.60 & 1.96 & 63.60 & 110.00 \\
\hline 61 & 85.00 & 84.00 & 3.60 & 265.00 & 258.50 & 1.96 & 63.60 & 110.00 \\
\hline 62 & 84.00 & 83.00 & 3.70 & 270.90 & 264.30 & 1.96 & 63.70 & 110.00 \\
\hline 63 & 84.00 & 83.00 & 3.90 & 276.80 & 270.10 & 1.96 & 63.70 & 110.00 \\
\hline 64 & 83.00 & 83.00 & 4.00 & 282.60 & 275.90 & 1.96 & 63.80 & 110.00 \\
\hline 65 & 83.00 & 82.00 & 4.10 & 288.40 & 281.70 & 1.96 & 63.80 & 110.00 \\
\hline 66 & 82.00 & 82.00 & 4.20 & 294.10 & 287.40 & 1.96 & 63.90 & 109.00 \\
\hline 67 & 82.00 & 81.00 & 4.30 & 299.90 & 293.10 & 1.96 & 63.90 & 109.00 \\
\hline 68 & 81.00 & 81.00 & 4.50 & 305.60 & 298.80 & 1.96 & 64.00 & 109.00 \\
\hline 69 & 81.00 & 81.00 & 4.60 & 311.20 & 304.40 & 1.96 & 64.00 & 109.00 \\
\hline 70 & 80.00 & 80.00 & 4.70 & 316.80 & 310.00 & 1.97 & 64.10 & 109.00 \\
\hline 71 & 80.00 & 79.00 & 4.80 & 322.40 & 315.60 & 1.97 & 64.10 & 109.00 \\
\hline 72 & 79.00 & 79.00 & 5.00 & 328.00 & 321.10 & 1.97 & 64.20 & 109.00 \\
\hline 73 & 78.00 & 78.00 & 5.10 & 333.40 & 326.60 & 1.97 & 64.20 & 109.00 \\
\hline 74 & 78.00 & 77.00 & 5.20 & 338.90 & 331.90 & 1.97 & 64.30 & 109.00 \\
\hline 75 & 77.00 & 76.00 & 5.40 & 344.30 & 337.30 & 1.97 & 64.30 & 109.00 \\
\hline 76 & 77.00 & 76.00 & 5.50 & 349.70 & 342.60 & 1.97 & 64.40 & 109.00 \\
\hline 77 & 76.00 & 75.00 & 5.70 & 355.00 & 347.80 & 1.97 & 64.40 & 109.00 \\
\hline 78 & 75.00 & 74.00 & 5.80 & 360.20 & 353.00 & 1.97 & 64.50 & 109.00 \\
\hline 79 & 75.00 & 74.00 & 6.00 & 365.50 & 358.20 & 1.97 & 64.50 & 109.00 \\
\hline 80 & 74.00 & 74.00 & 6.10 & 370.70 & 363.40 & 1.97 & 64.60 & 109.00 \\
\hline
\end{tabular}

Fuente: Manual de estándares de rendimiento Hy-Line Brown.

Elaboración propia. 


\section{Anexo 8}

\section{Producto bruto interno por sectores}

\begin{tabular}{|c|c|c|c|c|c|c|}
\hline $\begin{array}{l}\text { PRODUCTO BRUTO INTERNO POR SECTORES } \\
\text { (Variaciones porcentuales) }\end{array}$ & 2007 & 2008 & 2009 & 2010 & 2011 & 2012 \\
\hline Agropecuario 2/ & 3.25 & 7.25 & 2.29 & 4.86 & 4.19 & 5.11 \\
\hline Agricola & 1.98 & 7.36 & 0.91 & 5.28 & 3.25 & 5.25 \\
\hline Pecuario & 5.27 & 6.02 & 4.4 & 4.26 & 5.58 & 4.86 \\
\hline Pesca & 6.86 & 6.31 & -7.9 & -12.22 & 31.83 & -11.85 \\
\hline Minería 2/ & 3.45 & 7.63 & 0.6 & -0.15 & -0.2 & 2.16 \\
\hline Mineria metálica y no metálica & 1.7 & 7.28 & -1.14 & -4.79 & -3.17 & 2.14 \\
\hline Hidrocarburos & 17.26 & 10.28 & 16.13 & 29.46 & 18.1 & 2.28 \\
\hline Manufactura & 11.06 & 8.95 & -7.06 & 14.1 & 5.62 & 1.32 \\
\hline Procesadores de recursos primarios & -2.68 & 8.31 & 0.03 & -1.63 & 13.03 & -6.48 \\
\hline Manufactura no primaria & 14.01 & 8.86 & -8.52 & 17.29 & 4.35 & 2.76 \\
\hline Electricidad y agua & 8.39 & 7.85 & 1.19 & 7.69 & 7.44 & 5.21 \\
\hline Construcción & 16.62 & 16.46 & 6.15 & 17.43 & 3.05 & 15.15 \\
\hline Comercio & 9.67 & 13 & -0.4 & 9.69 & 8.83 & 6.71 \\
\hline Otros servicios & 9.5 & 8.62 & 4.18 & 7.47 & 8.5 & 7.44 \\
\hline $\begin{array}{l}\text { Impuesto a los productos y } \\
\text { derechos de importación }\end{array}$ & 6.4 & 11.06 & -1.14 & 8.71 & 6.69 & 6.57 \\
\hline PRODUCTO BRUTO INTERNO & 8.91 & 9.8 & 0.86 & 8.76 & 6.86 & 6.28 \\
\hline
\end{tabular}

Fuente: BCRP 


\section{Capítulo V}

\section{Entrevistas a expertos}

\begin{tabular}{|l|l|}
\hline Empresa & $\begin{array}{l}\text { Fondo Nacional de Ganadería Lechera "Fongal» / Asociación de } \\
\text { Ganaderos de Lima }\end{array}$ \\
\hline Entrevistado & Héctor Guevara Rivera, gerente \\
\hline
\end{tabular}

\section{Conclusiones}

- Fongal representa a las diferentes asociaciones de ganaderos en todas las regiones del país. Velan por los intereses del sector de ganaderos.

- No hay un dato confiable sobre el grado de asociatividad de los ganaderos a nivel nacional. Existen datos sobre las unidades agropecuarias.

- Hay muchas asociaciones, pero no están legalmente constituidas.

- En el sector lácteo no hay muchos proyectos, a pesar de que el Estado tiene una serie de herramientas que les permitirían desarrollarlos de manera efectiva.

- En el pasado, se implementó un fondo para desarrollar mejores proyectos tanto para las asociaciones como para las cooperativas, pero, debido a la desconfianza entre miembros de los mismas organizaciones, no se concretó.

- No conviene la creación de fondos si las cooperativas y asociaciones no se dedican a su gestión. Las organizaciones que existen tienen recursos muy limitados, ya que solo cuentan con los aportes de los socios.

- En Chile, existió la iniciativa de profesionales que se acercaban a estas asociaciones con el propósito de ver qué procesos se podían mejorar, luego elaboraban un plan y se presentaban al Ministerio de Agricultura, el cual se encargaba de financiar el proyecto. De esta manera, se promovió la ganadería de manera efectiva.

- Las zonas productoras son tres en el país: Arequipa, Lima y Cajamarca. El crecimiento que estas tienen cada año es muy bajo.

- La difusión es uno de los principales problemas, ya que esta recae en las mismas organizaciones de provincias y muchas veces estas no cumplen con el deber de informar a los ganaderos de manera oportuna sobre los beneficios o incentivos que ofrece el Estado. 
- $\quad$ El 60\% de la producción de leche se concentra en las tres cuencas lecheras antes mencionadas. El otro 40\% también es importante, ya que tiene un efecto social. Este $40 \%$ es generado por economías de subsistencia: ganaderos que ven en el acopio de leche una forma de hacer caja chica y dar sustento a sus familias.

- Las peores crisis ocurren cuando se incrementan los precios de los insumos (maiz, forraje, soya, etc.), ya que esto se traslada al costo de producción, disminuyendo el margen por litro de leche.

- En el Perú no existe comparabilidad entre unidades agropecuarias desde el punto de vista de costos e ingresos, ya que cada una tiene su propio modelo de alimentación y crianza del animal, y de la ubicación geográfica. Por otro lado, las grandes empresas agroindustriales pagan diferentes precios dependiendo de las características de la leche (grasas, sólidos, agua); esto también se aplica a la región y se considera un precio base donde se aplican premios y descuentos.

- En la Costa existen más condiciones para asociarse; esto se debe a diferencias en costo y un mejor acceso a insumos.

- $\quad$ Se considera que una empresa mediana tiene entre 80 y 300 vacas.

- También existe iniciativa por parte de las empresas agroindustriales, que ofrecen descuento en la compra de equipos o en algunos casos donan los activos con la finalidad de obtener un mejor producto.

- Una de las principales razones por las que estos negocios no prosperan es por el margen tan pequeño que hay por la venta de leche.

- Existen empresas extranjeras que tiene hatos de 40-50 vacas que son rentables.

- $\quad$ Perú depende en 25\% de la importación de leche en polvo.

- La productividad por vaca en el país es baja en comparación con estándares internacionales. $\mathrm{Al}$ año 2011, las vacas en promedio producen 2.400-2.500 litros por vaca al año, lo cual no es mucho (en los Estados Unidos, la productividad llega a 10.000 litros por vaca al año).

- Se deben plantear objetivos sobre la productividad y el consumo con la finalidad de empujar el mercado. 


\begin{tabular}{|l|l|}
\hline Empresa & PricewaterhouseCoopers \\
\hline Entrevistado & Christian de la Torre, experto en la NIC 41 (senior manager) \\
\hline
\end{tabular}

\section{Conclusiones}

- No existe un mercado activo donde se trancen la compra y venta de la mayoría de los $\mathrm{AB}$ que hay en el país, menos bovinos. Se toma en cuenta como herramienta final el valor razonable (VR), el cual es el más utilizado en el país.

- La norma sí tiene un método homogéneo, ya que esta dice cuáles son sus alcances. No existe homogeneidad en los cálculos, pero sí hay estándares internacionales. Tampoco hay estándares en la industria, y es por eso que se toma el VR. Es el más fácil de demostrar. Una de las grandes industrias de $\mathrm{AB}$ en América Latina se encuentra en Brasil.

- Se utiliza como tasa de descuento el WACC. Se considera el riesgo país para el cálculo del COK.

- $\quad$ Se puede estimar el VR del AB desde que este tiene capacidad de generar flujos futuros.

- Anteriormente, no era obligatorio utilizar la NIC 41, así que se utilizaba el modelo del costo de adquisición. Algunos aplicaban IFRS y otros, PCGA.

- $\quad$ En el caso de Usgap vs. IFRS, son bastante similares.

- $\quad$ El ganadero no tiene idea de cuánto le cuesta producir leche, solo vende.

- La NIC 41 se calcula hasta los ceses de los procesos vitales del AB o cuando se desprende del producto cosecha.

- $\quad$ El VR también se transfiere a cada existencia que se obtiene bajo la NIC 2 ; para esto, se utilizan métodos de cálculo de materialidad (valuación con inventario físico) en el caso de auditorías.

- $\quad$ Costo vs. VNR > el menor; con ese valor se registra.

- $\quad$ En el caso de la NIC 16, estos terrenos son tomados como AF y no se consideran sus flujos futuros. 
- Para el cálculo del AB, sí se debe tomar en cuenta la tenencia de los terrenos y se les disminuye un «alquiler ficticio o presunto». Esto permite comparar aquellas empresas que alquilan locales con aquellas que son propietarias.

- En el caso de la variación del costo que sufren los AB bajo los alcances de la NIC 41, este se debe mezclar con los gastos operativos con la finalidad de obtener el saldo descontado de los flujos futuros (VPN). Se deben revelar en las notas a los EE. FF.

- ¿Se reparten dividendos tomando en cuenta ingresos generados por la NIC 41? Es posible, pero no se debería, ya que son estimaciones y proyecciones que no necesariamente se van a cumplir.

- ¿Se pueden adecuar modelos que hayan sido creados para plantas a animales? Como modelo sí, ya que solo se estiman ingresos y gastos.

- En el caso de las vacas, se deben considerar el costo de alimentación, veterinario, inseminación, etc.

Impactos tributarios:

- En el caso del impuesto a la renta, todo ingreso que sea gravable genera carga tributaria.

- Hasta el 2021, el IR para este sector es de 15\% por ley, con el propósito de fomentar e incentivar la exportación y la producción.

- ¿La variación del costo de los AB genera IR? Ninguno de los efectos de la NIC 41 genera IR, ya que no tiene efecto impositivo.

- ¿Existe algún otro incentivo tributario para este sector? No, el principal es el IR. Falta revisar el caso del IGV.

\section{Agroindustria:}

- Los precios de la leche se calculan según la estructura de costo y según márgenes de las empresas agroindustriales.

- La competencia también influye en la imposición de precios.

- Algunas empresas optimizan el costo y juegan con los márgenes, ya que no todas tiene el mismo grado de inversión en investigación y desarrollo. 


\begin{tabular}{|l|l|}
\hline Empresa & Cooperativa San Antonio de Rancas \\
\hline Entrevistado & Rodolfo Rivera (gerente) \\
\hline
\end{tabular}

Conclusiones:

- Todo el año hay en promedio 45 o 50 vacas en ordeño. El 60\% son toros y el 40\% son vacas, a nivel de cooperativa. A nivel de comunidad, hay 150 cabezas en ordeño (dato dice que hay 1.552 vacunos en toda la comunidad). Cada comunera tiene como responsabilidad llevar contabilidad de su ganado con la finalidad de tener datos totales.

- Se trabaja con la inseminación artificial. Hay semen nacional (S/. 80) y semen importado (S/. 110; incluye mano de obra). La diferencia es el valor genético.

- En la cooperativa hay 360 socios y a nivel comunal, 750 comuneros.

- Cada año, la comunidad hace su campaña de dosificación para saber quiénes tienen cuánto ganado. Tienen todos los datos de los animales: padrón de stock de animales.

- Se tiene una producción diaria de 2,5 litros promedio por vaca en época de sequía, en época normal llega a 4,5 litros. La sequía dura aproximadamente 4 meses.

- Es eficiente tener 3 vacas por hectárea en pasto natural. En total hay un aproximado de 3.500 hectáreas (cooperativa).

- La comida balanceada es comprada mensualmente: 10 costales de 40 kilos. Por vaca, se estiman 30 o 40 kilogramos.

- Existen planes para construir cobertizos o galpones para estar a salvo del friaje.

- Hay una mínima tasa de mortandad de vacas: 2 vacas de 100 al año.

- La gestación de la vaca consta de 9 meses y luego debe descansar 6 meses para que se reconstruya el útero. El becerro debe esperar 2 años para poder ser destetado. Por otro lado, se puede inseminar a la vaca nuevamente, con la finalidad de que produzca leche en su período de gestación. 
- La mejora de pastos tiene un costo estimado: S/. 3.000 a S/. 4.000, aproximadamente.

- El terreno disponible: 1.000 hectáreas de propiedad de la cooperativa. Solo son necesarias 50 hectáreas. De preferencia, el terreno tiene que ser en ladera, para que el agua de las lluvias no se acumule y fluya bajo la pendiente.

- $\quad$ La falta de agua es un problema crítico de la zona.

- En noviembre es la mejor época para sembrar, ya que el pasto ya está húmedo. En septiembre y octubre, se debe preparar el suelo.

\begin{tabular}{|l|l|}
\hline Empresa & Universidad Agraria \\
\hline Entrevistado & Adrian Pumayala (zootecnista) \\
\hline
\end{tabular}

\section{Conclusiones:}

- Un Brown Swiss mejorado llega a producir entre 10 y 15 litros. El cruce absorbente consiste en poco a poco ir mejorando la calidad de los animales con la finalidad de obtener un ganado adaptado a la altura y con una producción constante.

- En el último tercio de la etapa de gestación es mejor que la vaca coma pasto cultivado y tenga una buena rotación de cancha. El problema en este tipo de comunidades es que se tiene una gran cantidad de ganado, por lo que no hay un buen manejo de pastoreo. Uno de los problemas principales es el sobrepastoreo, ya que los vacunos son erosionadores por naturaleza.

- Un pasteurizador de calidad normal cuesta entre S/. 4.000 y S/. 7.000. De la misma manera, un ordeñador se encuentra entre el rango de S/. 3.000-6.000.

- Estos tipos de maquinaria tienen como característica un mejor trato al animal. En el caso de la ordeñadora, relaja a la vaca, ya que el flujo es constante. El propósito de contar con este tipo de activos es estandarizar procesos. 
- El consumidor de ahora no busca el sabor ficticio que puede obtener en productos masivos; por ello, busca productos más naturales. Es por ello que optar por una presentación frutada puede tener mayor acogida, pero un menor tiempo de vida.

- El tiempo de vida de la leche fresca es de 2 semanas a una temperatura de $4{ }^{\circ} \mathrm{C}$, pero con respecto a la distribución este tiempo puede disminuir a 7 días.

- El litro de leche pasteurizada de La Molina tiene un precio de S/. 2,602,80 .

- El proceso de pasteurización puede evitar la aparición de enfermedades como brucelosis y fiebre malta.

\begin{tabular}{|l|l|}
\hline Empresa & Austracorp \\
\hline Entrevistados & Roberto Eidson (gerente general) \\
& $\begin{array}{l}\text { César Leiva Hernández (gerente corporativo de ventas) } \\
\text { Hugo Méndez Castro (gerente técnico y proyectos) }\end{array}$ \\
\hline
\end{tabular}

Conclusiones:

- Austracorp es una empresa importadora y comercializadora de insumos para la industria láctea y no láctea (alimenticio), como: leche fluida, leche en polvo, suero, concentrado proteico, grasa, glucosa, etc.

- Ellos importan porque no es suficiente la leche que pueden conseguir en el Perú para abastecer a las grandes empresas como Gloria, Laive y Alicorp, que son sus clientes.

- Barreras de entrada a los supermercados: se les tiene que ofrecer un producto diferenciado (como cepas probióticas, algún componente vitamínico, etc.).

- Debido a que la leche es un insumo perecible, la planta pasteurizadora debe estar cerca de la zona de abastecimiento. 
- Ventas: por ser una empresa importadora, sufre variaciones en el precio de su producto. Este tema puede afectar sus ventas, debido a que sus clientes preferirán comprarle a su competencia (si es que el precio sube). Sus clientes se fijan mucho en el precio de los insumos porque así compiten en el mercado, abaratando sus costos y obtienen un precio bajo y competitivo en el mercado (Gloria y Laive, que venden en mercados masivos).

- Estacionalidad: desde el mes de marzo, el consumo de derivados lácteos es creciente, hasta llegar a un pico en el julio-agosto. Luego, se mantiene constante hasta octubre, y a partir del mes de noviembre empieza a caer hasta febrero del siguiente año, cuando se restablece. 


\section{LA GANADERÍA LECHERA EN CRISIS EL ESTADO Y EL ABUSO DE POSICIÓN DE DOMINIO EN EL MERCADO DE LA LECHE}

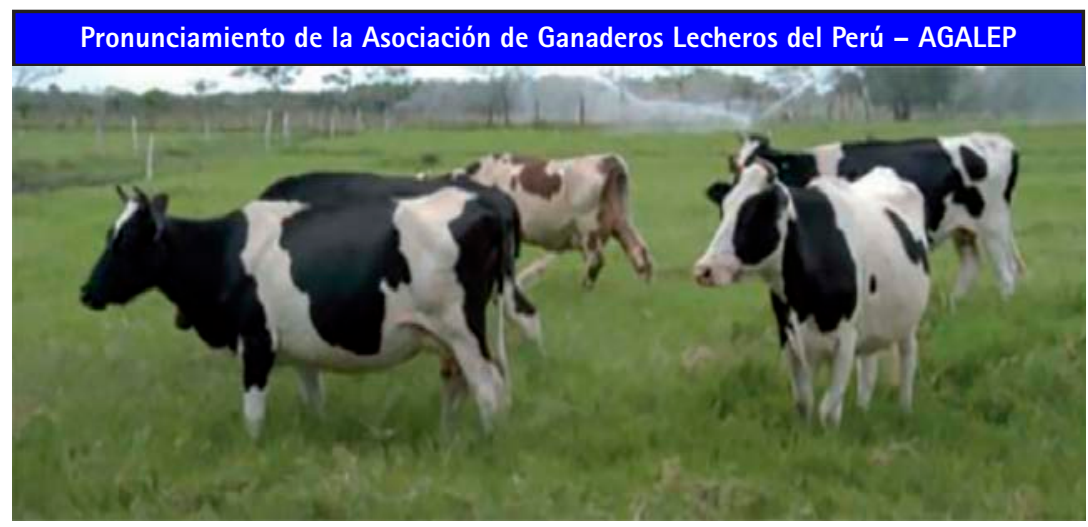

En nombre de los miles de productores de Leche del Perú queremos hacer de conocimiento público el grave problema estructural que hoy se manifiesta en 'una crisis de grandes proporciones y graves consecuencias para los productores de leche del Perú:

\section{EL PROBLEMA DE FONDO}

1. Somos un pais infraalimentado: consumimos $61 \mathrm{~kg}$ de leche por persona al año, en todas sus formas, cuando la FAO recomienda un mínimo de $120 \mathrm{~kg}$, cifra que alcanzan y superan la mayoría de los paises de Sudamérica; situación que nos pone a nivel de los paises más pobres del planeta.

2. Los productores de Leche en el Perú realizamos nuestras actividades en un mercado que registra graves distorsiones, al estar dominado por una industria con características cuasi monopólicas y evidente posición de dominio de una sola empresa, que por esa razón, se permite fijar unilateralmente los precios de compra de leche fresca a los ganaderos.
3. Hemos acudido al Ministerio de Agricultura; Indecopi y el Congreso planteando la necesidad de intervenir en el mercado regulándolo, tal como se hace en los principales paises productores para poder equilibrar la balanza y evitar de esta manera las repetidas manifestaciones de abuso de posición de dominio que se producen, tanto en lo referente a los precios pagados a los productores como en la evaluación unilateral de la calidad de la leche, con base en la cual se premia o castiga al productor. Ninguna de estas instituciones ha acogido nuestro pedido, $y$ todas se "han lavado las manos", manifestando su incapacidad para intervenir.

4. No obstante lo anterior, la Constitución Política del Perú en su artículo N. ${ }^{\circ} 61$ dice «El Estado facilita y vigila la libre competencia. Combate toda práctica que la limite y el abuso de posiciones dominantes o monopólicas». Siendo este un mercado donde evidentemente no funciona la libre competencia, esperariamos que el Estado cumpla su rol.

Miguel Caillaux Zazzali

Presidente de la Asociación de Ganaderos Lecheros del Perú Agalep 


\section{Referencias bibliográficas}

Cómo escribir y publicar trabajos científicos

2. ${ }^{\text {a edición }}$

Robert A. Day

The Oryx Press, Estados Unidos, 1996

Cómo se hace una tesis

6. edición

Umberto Eco

Gedisa, México, 1986

Cómo ser un consultor exitoso

2. ${ }^{\text {a edición }}$

William A. Cohen

Norma, Colombia, 2003

\section{Contabilidad}

8. ${ }^{\text {a edición }}$

Charles T. Horngren, Walter Harrison Jr. y M. Suzanne Oliver

Prentice Hall, México, 2010

\section{Contabilidad financiera}

11. edición

Carl S. Warren, James M. Reeve y Jonathan E. Duchac

Cengage Learning, México, 2010

Contabilidad financiera. Una introducción a conceptos, métodos y usos

1. ${ }^{\text {a }}$ edición

Clyde P. Stickney, Roman L. Weil, Katherine Schipper, Jennifer Francis y Beatrice Avolio Alecchi

Cengage Learning, Argentina, 2012

Diccionario de la Real Academia Española

22. edición

Real Academia Española

Espasa, España, 2001 